\title{
SPACE FOR PLACE
}

A method towards architectural place-making

By Annabel Childs

A 120-point thesis

submitted to the Victoria University of Wellington

in partial fulfilment of the requirements for the

degree of Master of Architecture (Professional).

Victoria University of Wellington

School of Architecture 


\section{ACKNOWLEDGMENTS}

Thank you to my friends and family for supporting me throughout my time at university.

Thank you to my supervisor, Adele Leah. I was privileged and so grateful to have had your guidance throughout this past year. 


\section{CONTENTS}

Chapters $1-4$ presents the physical and theoretical context of the research.

CHAPTER ONE

06

INTRODUCTION

CHAPTER TWO

16

THEORETICAL CONTEXT

CHAPTER THREE

37

SITE HISTORY (PAST)

SITE ANALYSIS (PRESENT) 


\section{CONTENTS}

Chapters 5 - 10 encompass the design work of this thesis. These design chapters outline the aim, methods and processes used to inform architecture that uses the character and identity

of Wellington's Civic Square (past and present) to reconstruct a future architectural identity.

CHAPTER FIVE

75

CONCEPTUAL DESIGN

DIRECTION

CHAPTER SIX

95

HUMAN SCALE DESIGN

INSTALLATION

CHAPTER SEVEN

121

FORMAL DESIGN

DIRECTION

CHAPTER EIGHT

138

PUBLIC SCALE DESIGN

PROCESS

CHAPTER NINE

202

PUBLIC SCALE

DESIGN OUTCOME

CHAPTER TEN

254

CONCLUSION 


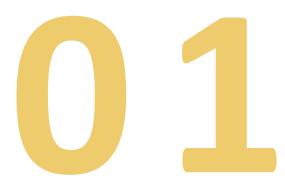

\section{CHAPTER ONE}

Establishes the overall scope, aims, objectives and methodology of the proposed research. 


\section{RESEARCH QUESTION}

To what extent can the construction of an architectural identity strengthen the relationship between people and place, when articulating notions of meaning and memory?

\section{ABSTRACT}

The consequence of homogenised place is becoming a growing concern across New Zealand's built environment (Najafi, 2011). In a time where placelessness, sameness and architectural standardization threaten the concept of spatial identity, there is an opportunity to research further into how we can design to maintain cultural and spatial differentiation within New Zealand's cities.

Wellington City is New Zealand's capital, it is an old city with copious layers of topographic and environmental depth. With the harbour water and undulating terrain greatly contributing to the city's identity, the somewhat disenfranchised population that occupy Wellingtons Streets are lacking this connection to place. This research is looking to defend the notion of a bounded place through reinterpreting our architectural identity. This research searches for continuity in the face of change, where takings from the environment's past and present will come together to create one unified future identity.

This thesis investigates design opportunities within Wellington's Civic square, design explorations and interventions seek to encourage and foster a rich sense of attachment to place. Architectural qualities are used as tools, with which to think through and create connections around which people actively create identities. The final design outcome aims to facilitate discussion of those qualities of public space that encourage and sustain concern for Wellington's social identity and its contribution to a sense of place. 


\section{RESEARCH AIM}

The aim of this thesis is to explore and develop a series of design techniques which can be utilised to contribute to a social identity in Wellington's Civic Square and foster a greater relationship between people and place.

\section{OBJECTIVES}

To consider and discuss the concepts of identity and sense of place with relevance to Wellington's Civic Square.

To carry out a thorough site analysis and research into the past, present and future use of Wellington's Civic Square.

To explore the ways in which the character and identity of Wellington's Civic Square (past and present), can be utilised to inform a future architectural identity.

The narrative of social identity will acknowledge the importance of past events and their impact on the present and future. Research into what constitutes the meaning of place and the importance of building upon a social identity will challenge how we design public architecture.

The design process will consider universal concepts of Civic design and sensorial qualities, to create a spatial experience that connects people with the past whilst also addressing the present and future setting. The final design intends to reconstruct space that is negatively affected by the static nature of architecture, investigating how architecture can be used to activate commonplace. Various approaches will be implemented working towards spatial attachment, inviting people to linger and gather in new and existing public space. 


\title{
PROPOSED SITE
}

\author{
Te Ngakau Civic Square \\ (Wellington Civic Square).
}

This thesis proposes an architectural intervention to revitalise the public life of Wellington's Civic Square, focusing on building a stronger connection between people and place at this site.

The proposition highlights the role of architecture in the urban landscape in fostering a communal identity and in turn a sense of place. It aims to uncover the rich history of the Wellington's natural environment and the city, while building upon civic design techniques and strategies, in an effort to celebrate the presence of architecture in the heart of Wellington City and empower communities through design. 

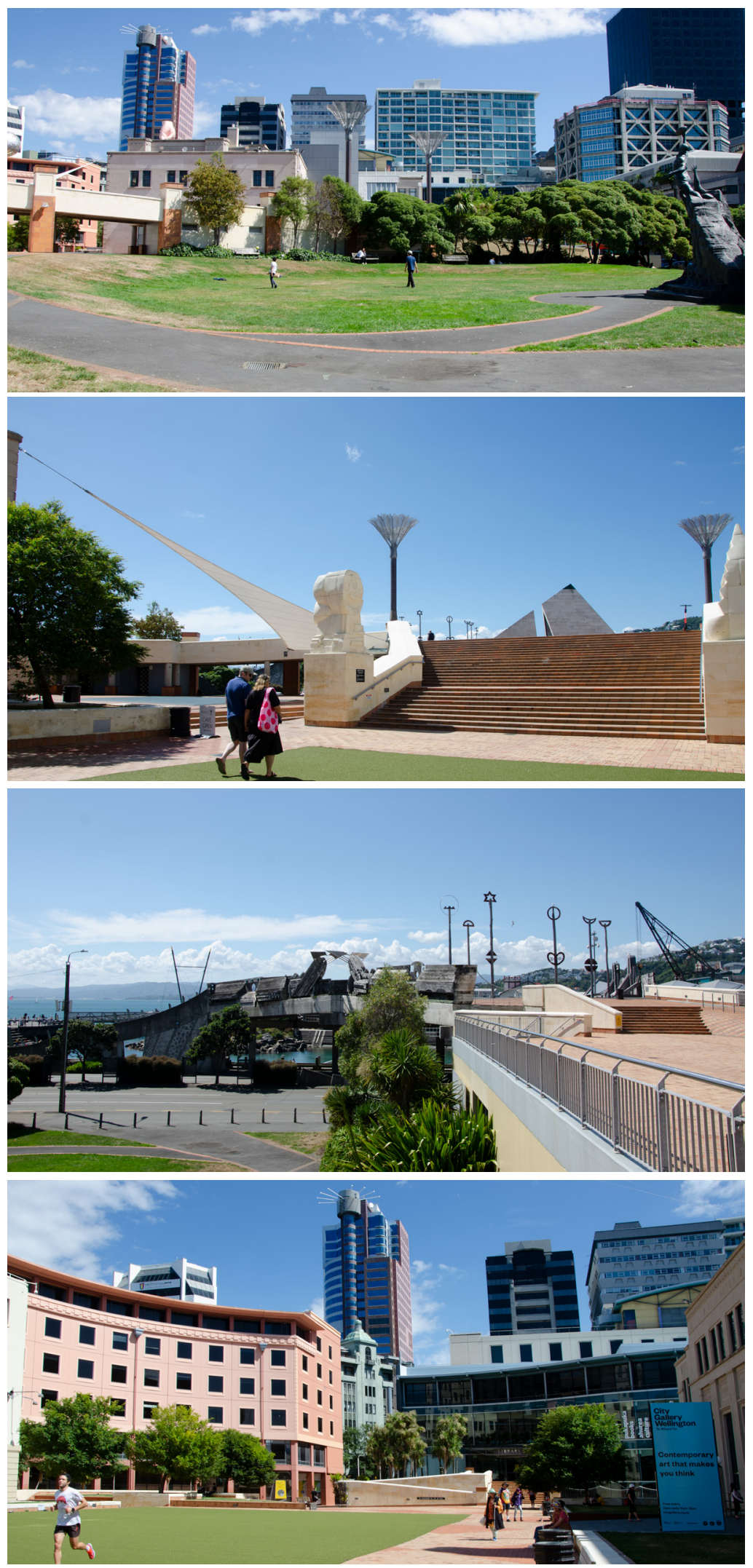
ROLE OF THE DESIGN

Wellington is leading towards a state of architecture that is engaging in a lack of identity, with public thresholds and third spaces emitting the essence of 'nonplace' (Page, 1996). Placelessness signifies loss of meaning. This loss of meaning reflects how people's perception of attachment to place has transformed over time. While arguably lost to Wellingtons emerging architecture at the present moment, there is a need for more intelligent and rigorous context in constructing buildings and structures that become unextractable from their urban context (Stephen, 1996).

The role of this design is to facilitate this essence of 'nonplace' through building upon the relationship between people and place, using key concepts of place attachment, social interaction, and social identity. This research aims to acknowledge the ability of design to connect to the past and present, thus in effect creating the future through architectural interventions. The topographic and environmental depth of the site will be explored, looking at history and time, with moving through time being the journey to identity.
With ever changing cities, the current design of Civic Square was once accurate to its environment however, it has not grown with time, nor the growth of the city. The objective of this design is to develop an evolving identity in Wellingtons Civic Square through suggesting the enduring needs and aspirations of humanity for public architecture that sustains, comforts, and becomes cubicles for memory, relationships, and joy. 
ENGAGEMENT WITH SUSTAINABILITY

The design outcome of this thesis engages with sustainability through designing with a strong consideration of the architectures future use. The architectural intervention creates a spatial experience that connect people with the past whilst also addressing the present and future setting. The future environment is considered through thorough site analysis of the past and present use of Wellington Civic square and successively the future prospect of the site's identity. This thesis approaches planning for the future through considering the current position of the site and designing in a responsive manner, flexible to the sites prospective future needs. 


\section{METHODOLOGY}

This research will engage with design - as - research as the primary research methodology. Through using this approach, the design progression can undertake an iterative and cyclic process, where design tests will be critically analysed with the intent of confirming the overall design outcome based on how it responds to the research proposition, methodology, and theoretical planning material. This research will test methods of exploring intangible qualities in design through using physical and digital modelling, physical and digital drawings, and architectural renders.

The approach of Jane Rendell will be followed in which she states "instead of posing research questions and then finding answers, in much design research the process operated through generative modes, producing works at the outset that may then be reflected upon later" (Rendell, 117). Digital and analogue drawing will also be used to support the development of intimate spatial qualities.

This thesis will be structured in a traditional and linear manner for the purpose of reading, but the way design will be carried out is through a non - linear movement between varied analogue and digital design methods. 

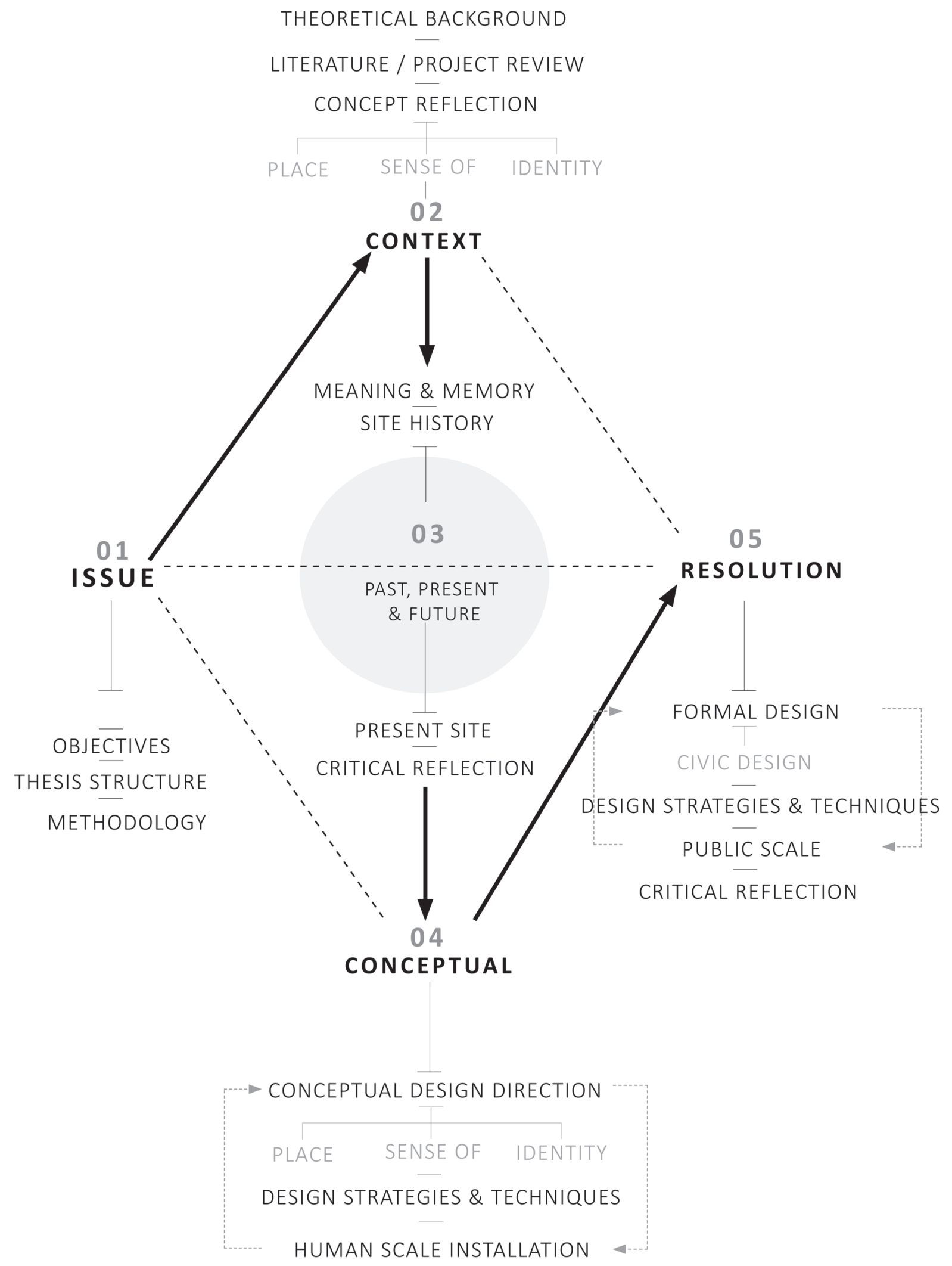

CRITICAL CONSIDERATION \& REFLECTION 


\section{METHODOLOGIES DIAGRAM}

The methodologies diagram (figure 2) looks at this research as having 5 key phases.

Phase one focuses' on the Issue at hand, looking at scope \& proposition, objectives, thesis structure and methodology.

Phase two is about the context of the research, with theoretical background into the understanding of key ideas surrounding the concern of constructing architectural identities. Key authors have been analysed in this phase according to how their work develops and questions the three concepts of 'place' 'sense of place' and 'identity'.

Phase three involves a thorough site analysis and research into the past, present and future use of Wellington's Civic Square. This theory in turn provides a background to measure designs against, giving context for the character and identity of Civic square.

Phase four establishes the conceptual design direction, building from the research in the theoretical context chapters. Strategies to construct an architectural identity using the researched theory of place, sense of place and identity have established a framework to measure the designs against literature.

The final phase on this diagram represents the formal design process. The design phase outlines the aim, method and processes used to create architecture that enforces the character and identity of Wellington's Civic Square.

Both the conceptual and formal design processes undertake an iterative and cyclic process through trialling, testing, thinking, and redoing. The purpose of having a human scale installation prior to the public scale design installation is to work in a reflective sequence in which the succeses' and failures of the human scale approach are reflected upon and enhanced in developing the final public scale outcome. 


\section{2}

\section{CONTEXT}

Provides a theoretical background into the comprehensive understanding of key ideas surrounding the concern of social identities and their place in public architectural discourse. This chapter addresses key authors within the realm of this research topic. The authors writing is analysed according to how it develops and questions the three concepts of: place, sense of place and identity. The research has been interpreted to form a common definition and scope for each of these three concepts thus, to be used and reflected upon throughout this thesis. 
PLACE IN THE URBAN REALM

\section{Understanding the notion of 'Place'}

The notion of 'Place' is a very broad and overarching concept. 'Place' is inherently phenomenological in nature, meaning it is about the personal connection individual people have with their environment, concentrating on the study of spatial consciousness and the direct experience of space (B. K. Haywood., 2014).

Frank Vanclay, Professor of rural and environmental sociology in the Tasmanian Institute of Agricultural Research, describes 'place' as being 'space' imbued with meaning (F. Vanclay, 2008). This means that the concept of 'place' is considered to be more about the meanings that are invested in an environment rather than the physicality and the locality of the site. Vanclay determines that the meanings invested in place are contributed to by the following:

1. Biophysical characteristics (climatic conditions, rainfall, etc.). It is the biophysical characteristics that are important in being a foundation for these personal meanings.

2. Landmarks and significant features in the landscape. These contribute to 'place' (or sense of place) though providing an icon to which symbolic meaning can be ascribed.

3. Spaces where people gather and meet. These interactive localities create invested social meanings at specific locations.

4. Designed characteristics of a space. Unique features develop meaningful qualities through subsequent spatial experiences.
These characteristics determined by Vanclay indicate that place is therefore, the coming together of biophysical, social, and psychological aspects of society. These personal meanings that turn 'space' into 'place' contribute toward the relationship between people and the environment. 'Place' prevails when 'house' becomes 'home' and is created through space that is committed to attaching meaning and value to its environment. For the purpose of this research, 'Place' therefore exists when someone is able to tell a story about a specific locality, thus, indicating a sense of personal meaning.

\footnotetext{
"To be human is to live in a world that is filled with significant places: to be human is to have and to know your place"
}

(Relph, 1986, p.61) 
SENSE OF PLACE IN THE URBAN REALM

\section{Understanding the notion of 'Sense of Place'}

The term 'Sense of Place' has been considerably analysed in the realm of environmental and architectural research. It has been defined, dissected, and measured in many ways. 'Sense of Place' is recognised as a holistic, integrated concept (F. Vanclay, 2008, p.7). This results in a struggle to definitively interpret its conceptual meaning, as there is not simply one universal definition to follow. Due to the macro nature of this concept, an appreciable amount of unpacking is needed.

This research has considered various key authors and their perspective on qualities of a 'sense of place.' From a review of this literature the fundamental components of this concept have been identified.

'Sense of place' is a complex concept of emotion and bond to the human environment, often used to describe the relationship between people and place (J.D. Adams, 2013). Many publications define 'Sense of Place' as the meaning people assign to a space, but such definitions are essentially no different to the notion of 'place' itself. Therefore, for the purpose of this research, 'sense of place' more specifically refers to the individual rather than the prescribed meaning of place, expressing an individual's connection and experience of place (Y.F. Tuan, 1979).

There are many terms used consistently throughout 'sense of place' literature which often lack a definition. These terms repeatedly contribute to the notion of a 'sense of place' and enable a stronger understanding of the concept's key components.

Four key components of a 'sense of place' and their subsequent definitions follow:

1. Place Attachment. Place Attachment is a concept that reflects the bonds between people and place. In theory, 'place attachment' is considered to be the closest component in the understanding of a 'sense of place.' Place attachment specifically acknowledges the extent to which an individual has positive feelings about the environment they are in.

2. Place Identity. Place Identity works closely with the notion of 'place attachment, however refers to the extent to which a person's identity is invested into the local place. Place identity can be seen as the self - perceived strength of association between an individual and a specific place.

3. Place Familiarity. Similarly, to the notion of 'place attachment,' place familiarity refers to an individual's perception of place. People who have a strong sense of place often bear an essence of place familiarity. Place familiarity relates to the extent of knowledge an individual has about a local environment or specific place. 


\section{SENSE OF PLACE IN THE URBAN REALM}

\section{Understanding the notion of 'Sense of Place'}

4. Belongingness or Rootedness. This term refers to community as place. It relates to the way people feel in a place and whether they feel that they belong there. The sentiment of belongingness/rootedness often corresponds with civic design strategies where community and social capital is a key focus.

(Tuan, 1975; Relph, 1986; Altman and Low, 1992; Manzo, 2003; Vanclay, et al., 2008).

When integrating ideas of place attachment, place identity, place familiarity and belonginess/rootedness, 'sense of place' becomes the lens through which people experience and make meaning of their experiences in and with place (J.D. Adams, 2013). Research observes that the perception of 'place' and 'sense of place' varies among people, as people may ascribe different meanings and experiences to the same place in relation to its social, economic, cultural, ecological, aesthetic or historical aspects (A. Russ et al, 2015).
The considered literature determines that 'sense of place' is defined by personal experience, identities, and social interaction. The concept of 'sense of place' therefore evolves through personal experiences, defining how people view, interpret, and interact with an environment. Theory concludes 'sense of place' to be an emotional connection between people and place. Thus, categorising 'sense of place' as a cognitive and perceptual structure, perceived through individual linkages and meaning to a space. The perceptual nature of 'sense of place' therefore echoes the intersections of culture, environment, history, politics, and economics, and is impacted by both the natural and built environment. 


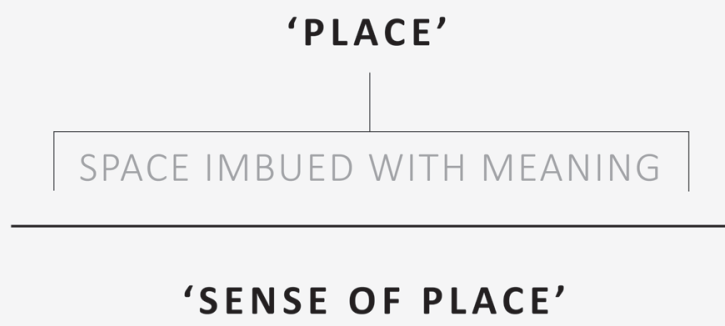

EMOTIONAL CONNECTION BETWEEN PEOPLE \& PLACE

PLACE ATTACHMENT PLACE IDENTITY

BELONGINGNESS PLACE FAMILIARITY 
SENSE OF PLACE CASE STUDY

Surry Hill Library \& Community Centre. Francis - Jones Morehen Thorp.

Located within the Surry Hill suburb of Sydney, the Surry Hill Library and Community Centre sought to serve a community known for its diverse cultural backgrounds. While working closely with the community it became apparent that there was a need for a building that could be accessible by all and serve multiple needs. As a result, this building combines multiple programmes of a library, community centre and childcare facility, creating a space where the whole community can come together.

The design of the Surry Hill Library and Community Centre is committed to the ways in which architecture can support and foster civic life. Civic buildings bring people together around shared interests and community purpose (LMN). This design offers a sense of belongingness as it refers to community as place. The feeling of belongingness achieved as through implemented civic design strategies where there has been a focus on community and social capital. 


\section{SENSE OF PLACE CASE STUDY}

\section{Christchurch Botanic Garden Visitor Centre.}

Patterson Associated.

The Christchurch Botanic Gardens Visitor Centre is a multi - functional building located beside the Avon River in Christchurch's Hagley Park. Hagley Park is one of the oldest public gardens in New Zealand. The Christchurch Botanic Gardens Visitor Centre is a strong contemporary building that connects with the typology of a traditional Victorian farm homestead once found on New Zealand's rural landscapes (J. Harvey, 2015).

Planned around a longitudinal circulation route, the visitor centre provides a café, exhibition space, a workspace, and a function room, arranged public to private from front to back. The structures long form creates an essence of an ethereal presence within the greenery of the gardens. The repeated angular bays and serrated roof profile achieve elegance and cultural meaning. Appropriately, botanic themes inform elements throughout the building such as the patterned precast concrete and its subsequent dappled leaf shadow, alongside the carpet pattern which comprises of blown - up plant microbes. The result of this meaningfully considered detail is a thoroughly integrated work of architecture that derives a positive experience between people and place.
Patterson's Associated approached the design of this building through looking at the cities civic trends and then designing to create a community for the future. They believed that through an emphasis on belonging, a sense of identity to place was logically created and correspondingly, a sense of belonging for the users and the inhabitants of that place. Through researching identity, utility, amenity, cultural impact and context, their design of the Visitor centre aligns both community and ecological impacts, ultimately creating an effective urban design that contributes to a strong sense of identity and attachment to place (J. Harvey, 2015).

This case study creates a unique expression of community in which the experience of the architecture is rooted in both the aspiration and substance of civic life. The architectural success of the building is defined by how people experience institutional values and collective aspirations, manifested through its physical appearance in the public realm. 


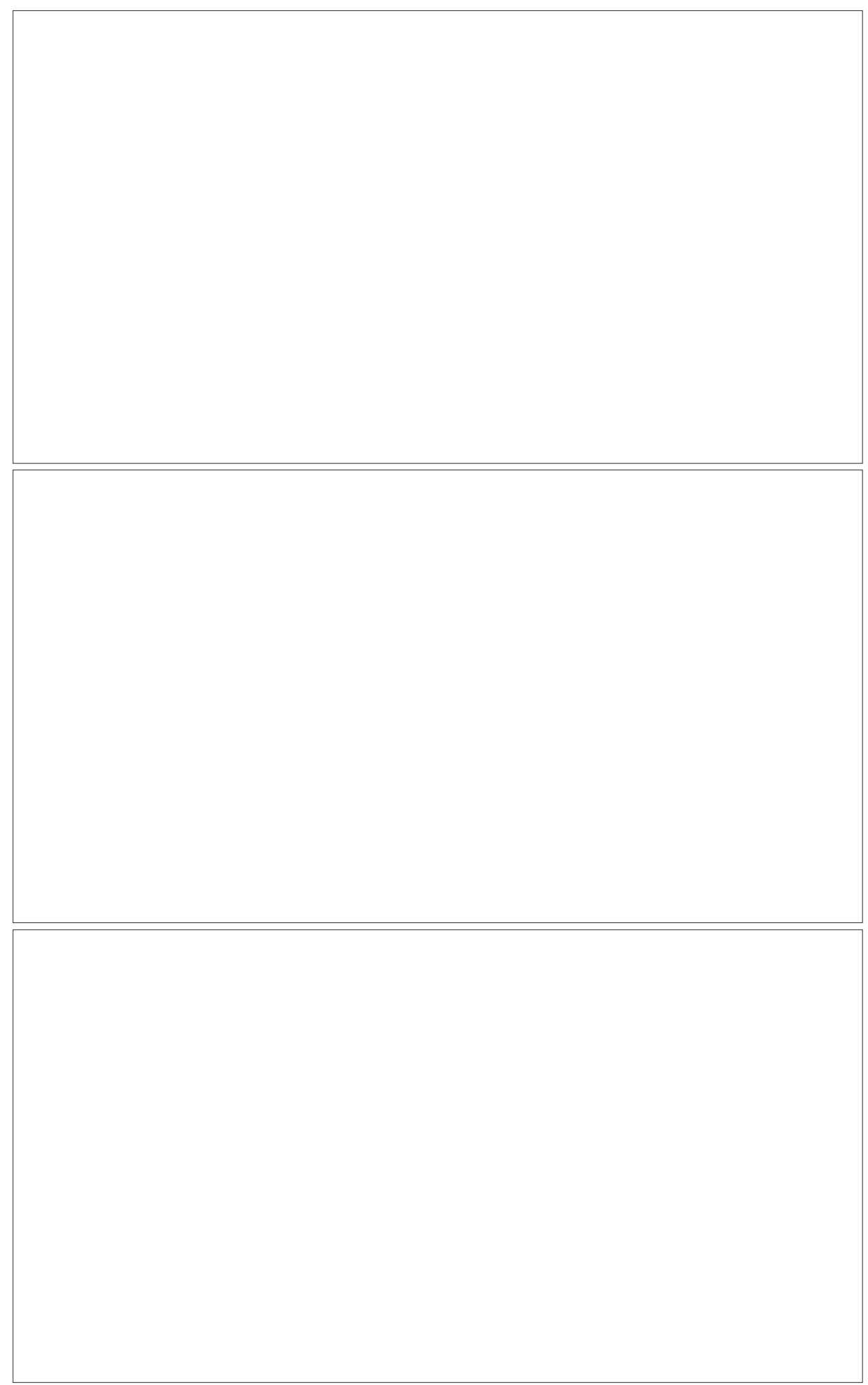

Fig.5. Christchurch Botanic Garden Visitor Centre. 


\section{IDENTITY IN ARCHITECTURE}

Understanding the notion of 'identity' in architecture.

\section{IDENTITY}

The word identity has different meanings and definitions according to discipline. In general, identity can be defined as a set of material, biological, psychological, and cultural features differentiating every individual, group, population, or culture from others (Z. Torabi, \& S. Brahman, 2013 P.107). Identity is essentially a source of meaning and differs from one society to the next. Identity is inherent, natural, gradual, and inevitable, creating our yesterday, today and our future (Z. Torabi, \& S. Brahman, 2013 P.112).

\section{IDENTITY \& ARCHITECTURE}

According to Rappaport, identity is the ability to distinguish and identify one element from another. Ideas, effects, and functions resulting from meaningfully designed architectural qualities define a building's architectural identity ( $\mathrm{Z}$. Torabi, \& S. Brahman, 2013 P.107). Factors such as architectural narratives, aesthetics and design originality are the results of dynamic thoughts that create genuine and meaningful architecture with identity.

The built environment plays an important role in the development of a city's identity. Successful architectural identities should embody a comprehensive whole, responding to the surrounding environment, community, and the individual (M. Hough, 1990: 179 -193). Identity in the built environment is important because it influences how people see themselves and how they interact with others. People need to be able to identify with an environment to build a relationship with it.

\section{MEANING \& MEMORY}

An architectural image imbued with identity, inherently involves notions of meaning and memory. Identity is intimately tied to meaning and memory, both individual and collective. Meaning is created through a biological response to the physical environment, while memory is endorsed through the history of an urban landscape (Norberg-Schulz, 1975: pp 426-434). Recognizing the cultural context of our history and memory is important, as understanding and remembering our history forms part of our identity.

Urban landscapes and the built environment have the power to nurture society's public memory and encompass shared meaning in the form of a perceptive architectural identity. The built environment needs to incorporate elements of social relevance in order to foster a relationship between people and place. Architecture is perceived as an expression of society (V. Miller, 2011). Therefore, through combining notions of meaning and memory, an architectural identity can be constructed, creating places that evoke a sense of pride and belonging for all. Architectural identities create environments that attribute greater personable and meaningful characteristics to the people. 


\section{IDENTITY CONSTRUCTION}

\section{Constructing an 'architectural identity'.}

\section{PAST \& PRESENT}

The narrative of identity in architecture acknowledges the importance of past events and their impact on the present and the future. Researcher Christopher Tilley's proposes the idea that in constructing identities, the past governs the present, rather than the present governing the past (C. Tilley, 2006). Such a view suggests an unchanging essence to identity beneath its different forms. Tilley argues that both societies and people may change according to the social circumstances in which they find themselves, but they are still the same society and the same person with a core of enduring key traits, of which it is the business of the architect as an analyst to try and trace (C. Tilley, 2006).

The natural and built environments are made out of a whole network of past experiences and future expectation, always carrying meanings and relationships extending beyond their means. Tilley confirms that the construction of identities is intimately connected to history, the past, and holds out the promise of a desired future. $\mathrm{He}$ proclaims that fostering a sense of place requires its deliberated re - presentation. Thus, the kinds of place we produce, and want, are inextricably bound up with the politics of identity.
Amongst his research, Tilley draws a distinction between 'modernist' and 'postmodernist' strategies of identity construction. The former works in fixing and grounding identities in the past. The latter adversely attempts to resist all means of fixation, looking for identity to remain an open concept, embracing perpetual change (C. Tilley, 2006). Taking from this perspective, this research looks to foster identity construction through combining these notions, ultimately creating architecture that is rooted in modern traditions while also tied to historic, geographic, and cultural context.

"identity is only an unfinished game... moved into the future through a symbolic detour through the past."

(Christopher Tilley) 
IDENTITY

IN ARCHITECTURE

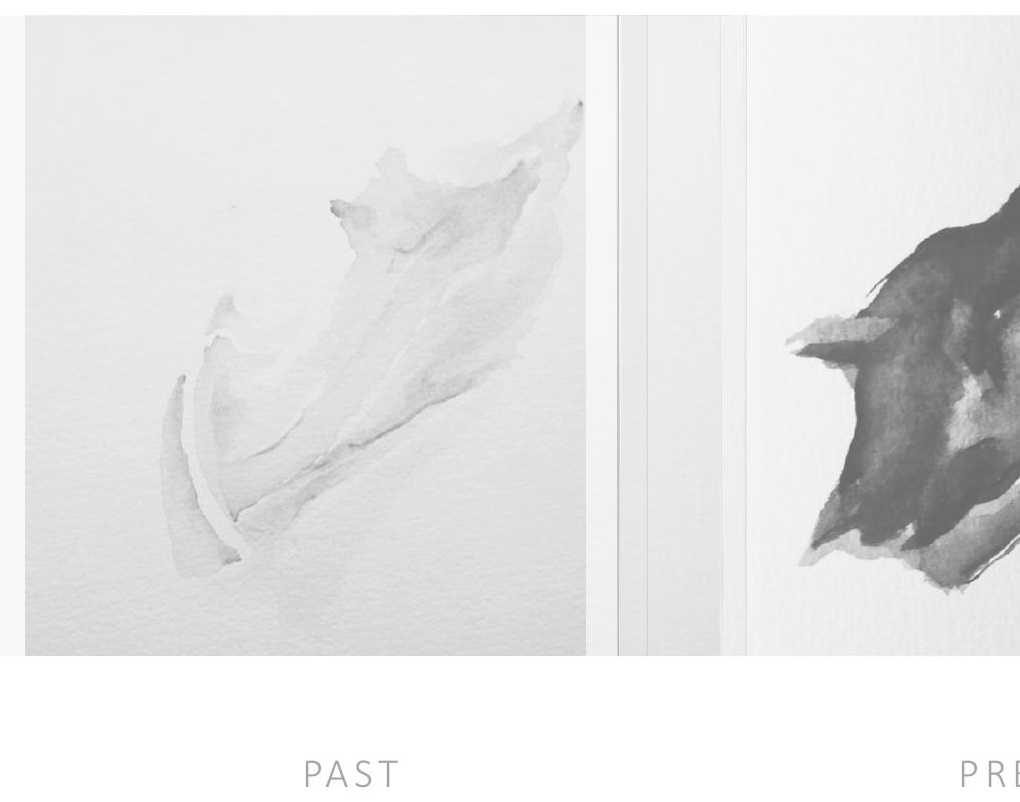




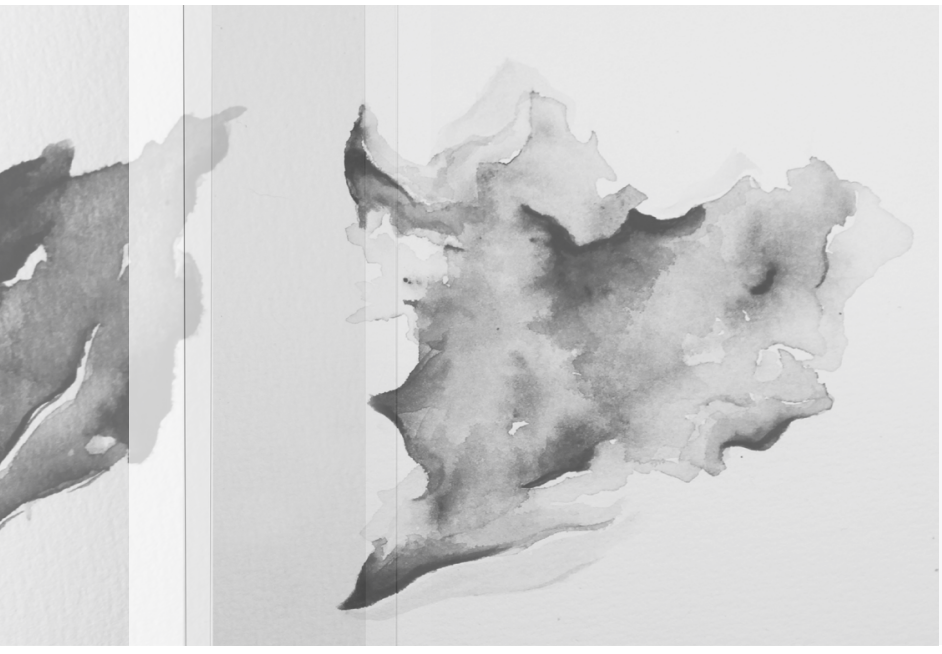

ESENT

FUTURE 


\title{
IDENTITY CONSTRUCTION
}

\author{
Constructing an 'architectural identity'.
}

\section{CRITICAL REGIONALISM THEORY}

When looking at translating this conceptual notion of identity into physical architectural form, the approach of critical regionalism provides a fundamental starting point. Critical Regionalism is a contemporary architectural theory, predominantly developed by architectural critic Kenneth Frampton (K. Frampton, 1983 pp. 149 - 151). Frampton created this theory in response to arising problems posed by contemporary global development, primarily criticising the movement of modernisation and the effect of universalizing architecture (K. Frampton, 1983). Thus, critical regionalism is an approach to architecture that strives to counter architectural placelessness and a lack of architectural identity.

Critical regionalism refers to the establishment of connections between new works and pre - existing local and regional characteristics, seeking to provide an architecture rooted in modern tradition while also tied to historic, geographical, and cultural context (K. Frampton, 1983). Critical regionalism is regionalist through drawing on the natural resources of a local context, taking design inspiration from climatic conditions, topographic landform, and cultural characteristics such as distinct lifeways, organisation and patterns of land use, distinct modes and materials used in construction and styles of architecture ( $\mathrm{T}$. Cresswell, 2014). It is critical because it draws away from a consistent belief in regional uniqueness, which can end up in traditional nostalgia through the endless repetition of vernacular architectural forms (T. Cresswell, 2014).
Under Kenneth Frampton, this theory is defined as "culture's unique identity, manner of place - making, architectonic strategies, qualities of the environment in dialogue with local means for coping with that environment, and possible tactile experiences that may enrich ones being there"(K. Frampton, 1983). His research firmly asserts that critical regionalism is not an embrace of vernacular stylistic elements, nor an opposition towards modern architecture, rather it is the "capacity to condense the artistic potential of the region while reinterpreting cultural influences coming from the outside" (K. Frampton, 1983 pp. 156). Therefore, the key principle in critical regionalism is a commitment to place rather the space, where architecture is designed to make a case for the topographic and climatic conditions of a site, the tectonics of architectural construction, and the tactile sensibility of architecture (H. Foster,1985).

Critical regionalism can be considered as a concept, tool, technique, attitude, ideology, or habit of thought. It is a theory that supports resistance to various forms of hegemonic, universal, or otherwise standardizing structures that in turn diminish local differentiation. This theory proposes alternatives in the form of methods and criteria for the respect, revitalization, and, if necessary, the reconstruction of an architectural identity (H. Foster,1985). Critical regionalism theory principally stands as an approach in which the tactile surpasses the visual, the tectonic dominates the scenography and the hybrid is favoured over the homogenous. Emphasis, as Frampton says, should be on topography, climate, light, and tectonic form, ultimately complementing our normative visual experience by readdressing the tactile range of human perceptions (K. Frampton, 1983). 


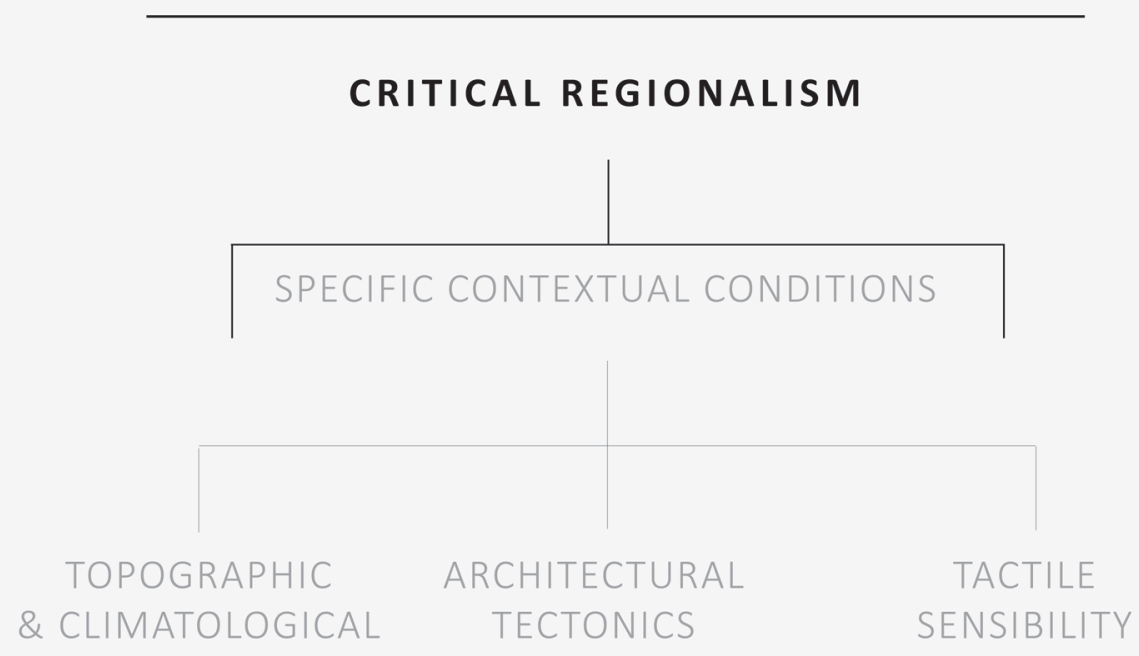




\section{IDENTITY CONSTRUCTION}

\section{Constructing an 'architectural identity'.}

\section{EMBODIMENT METHOD}

Kenneth Frampton asserts that the theory of critical regionalism involves a strong connection with the tactile sensibility of architecture. Thus, the phenomenological concept of embodiment is marked as a central method in leading towards the construction of an architectural identity.

Architectural professor Rochus Hinkel recognises the current contemporary manner of urban design. He discus' the crucial points that ground place as a space for creating connections and building relationships between people and place, through the construction of identities. His view on the nature of identity construction provides a background to this study of embodiment in architecture.

In his research, Hinkel forges the argument that it is the immediacy of our embodied experiences of the world that have a profound effect on the way in which we relate to both things and persons (R. Hinkel, 2011). In this regard, Identities are therefore made up of the multiple ways in which we perceive and receive the world through our senses (R. Hinkel, 2011). Embodiment is thus an existential condition in the construction of any sense of identity. This means that the manner of identity relates in a fundamental way to the manner in which agency is experienced. Only being in place and experiencing things and persons in place can build connections and thus create a direct sense of identity.
How we relate to others, and the environment, very much depends on modes of cognition and experiential abilities which are embodied (C. Tilley, 2006). This concept enforces the significance of material forms in strengthening the relationship between people and place. Material forms have the power to act as key metaphors of embodied identities, as they become tools with which to think through and create connections around which people actively build relationships with place (C. Tilley, 2006).

Rochus Hinkle's research throws light upon the power of architectural spaces and their means to articulate notions of personal identity with wider social notions of a character and soul. He acknowledges the ability for materiality to fix an individual in a particular desired image through experiential mediation. The body is an enabling condition for the construction of meaning and the architectural efficacy of material metaphors is inseparable from bodily, sensory engagement with particular places (C. Tilley, 2006).

"Identities must be felt, they can never be simply imagined"

(Christopher Tilley) 
IDENTITY CONSTRUCTION

\section{CASE STUDY}

Azuma House.

Tadao Ando.

Tadao Ando is a well-established Japanese architect who develops an architectural identity in his designs using the framework of critical regionalism (T. Schielke, 2019). Throughout his work in Azuma House, Ando implements the use of light and natural elements, combined with the modern use of concrete (figure 8). This approach demonstrates a tension between universal modernisation and the idea of a rooted culture, creating an architectural space that establishes connections between new works and pre - existing regional characteristics.

The overarching significance of this case study lies in the tactile sensibility of its architecture. Azuma House showcases sensorial qualities through intricate attention to materiality, texture, and light (figure 8). As identities are made up of the multiple ways in which we perceive and receive the world through our senses, these sensorial qualities sustained in the design of Azuma House are of considerable importance in designing to create an embodied experience that connects people with the past, whilst also addressing the present and future setting. 
IDENTITY CONSTRUCTION CASE STUDY

\section{Tacubayas.}

Luis Barragan.

The work of Mexican architect Luis Barragan applies the approach of critical regionalism through exercising a regional attitude toward design. Barragan's design of Tacubayas (figure 9) built in 1948, represents one of the most internationally transcendent works of contemporary architecture to date, being the only individual property in Latin America to have achieved the recognised honour as a UNESCO World Heritage site (M. Sveiven, 2011.).

As an architect, Barragan is the creator of a purely local art form, incorporating traditionally popular materials into modern design. In the design of Tacubayas, Barragan applies the methods of critical regionalism in various ways. Colours and light play a central role, both standing as fundamental elements of the space's architecture. He places a big emphasis on the technical domain of material, alongside close attention to daylighting, as natural light gives spaces different character throughout the day and in various times of the year. Fundamentally, Luis Barragan designs through a sensual, earthbound approach using water, rock, and vegetation, creating a constant connection between architecture and the natural environment of the local context. 


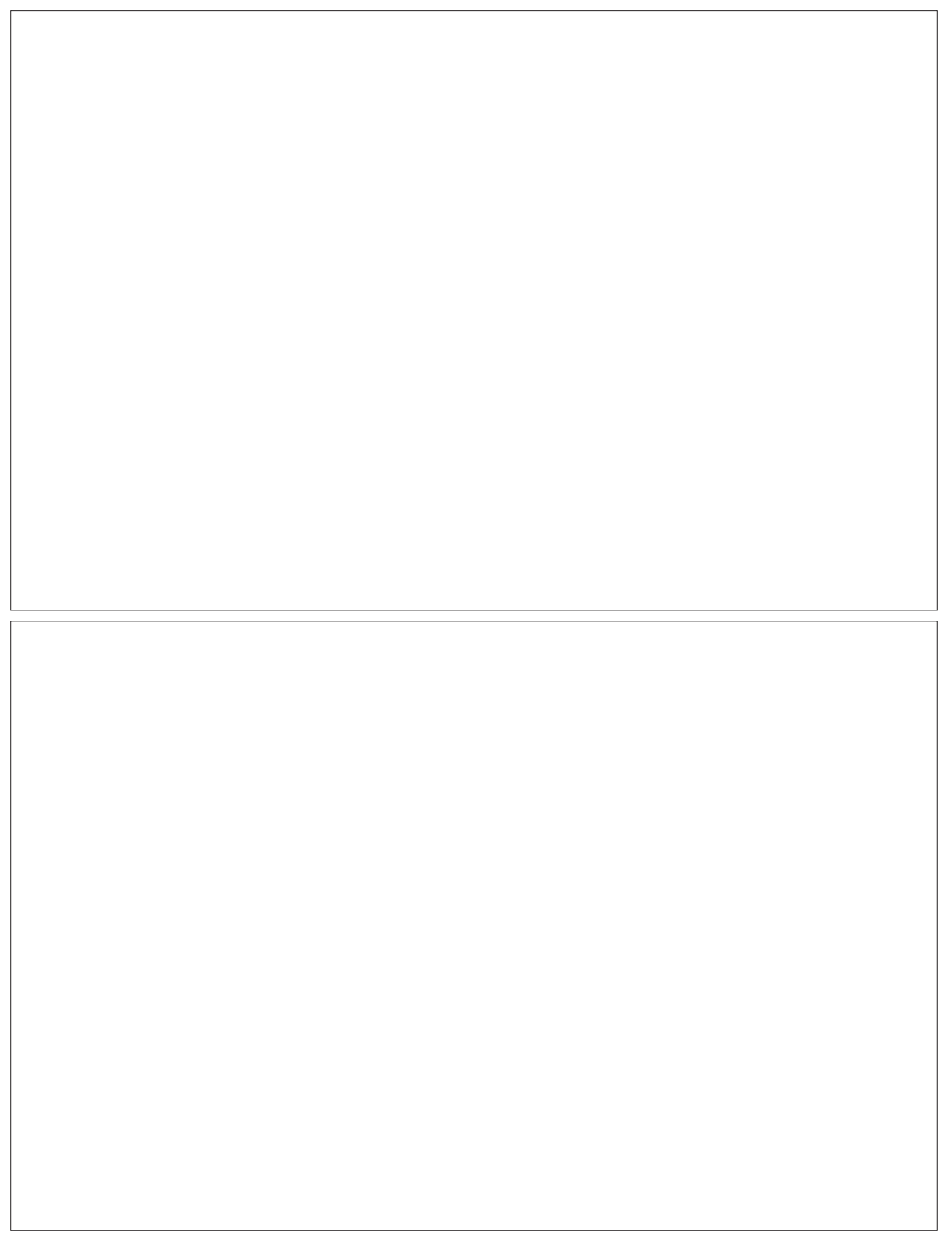

Fig.9. Tacubayas. 
IDENTITY CONSTRUCTION CASE STUDY

Tolo House.

Alvaro Siza.

Portuguese Architect Alvaro Siza is regionalist in his approach to design, making creative use of the local context and topography of his sites. Located on a steep hill in northern Portugal, Siza's design of Tolo House anchors the local topographic conditions of the site into the configuration of the architectural design (figure 10).

The steep foundations of Tolo house confronted Siza with a difficult building site, in which he took the opportunity to approach the design through embracing, instead of fighting the natural environment (A.S. Vieira, 2011). As Tolo House begins at the top of the hill, it gracefully reveals itself as you descend down the outdoor staircase. The natural climatic conditions of the site are utilised through considered spatial orientations, where despite the frontal exposure to the hot sun, the architecture is cooled by the earth on the surrounding three sides. In essence, Tolo house establishes its architectural identity through showing sensitivity to local materials, craft work and light. 


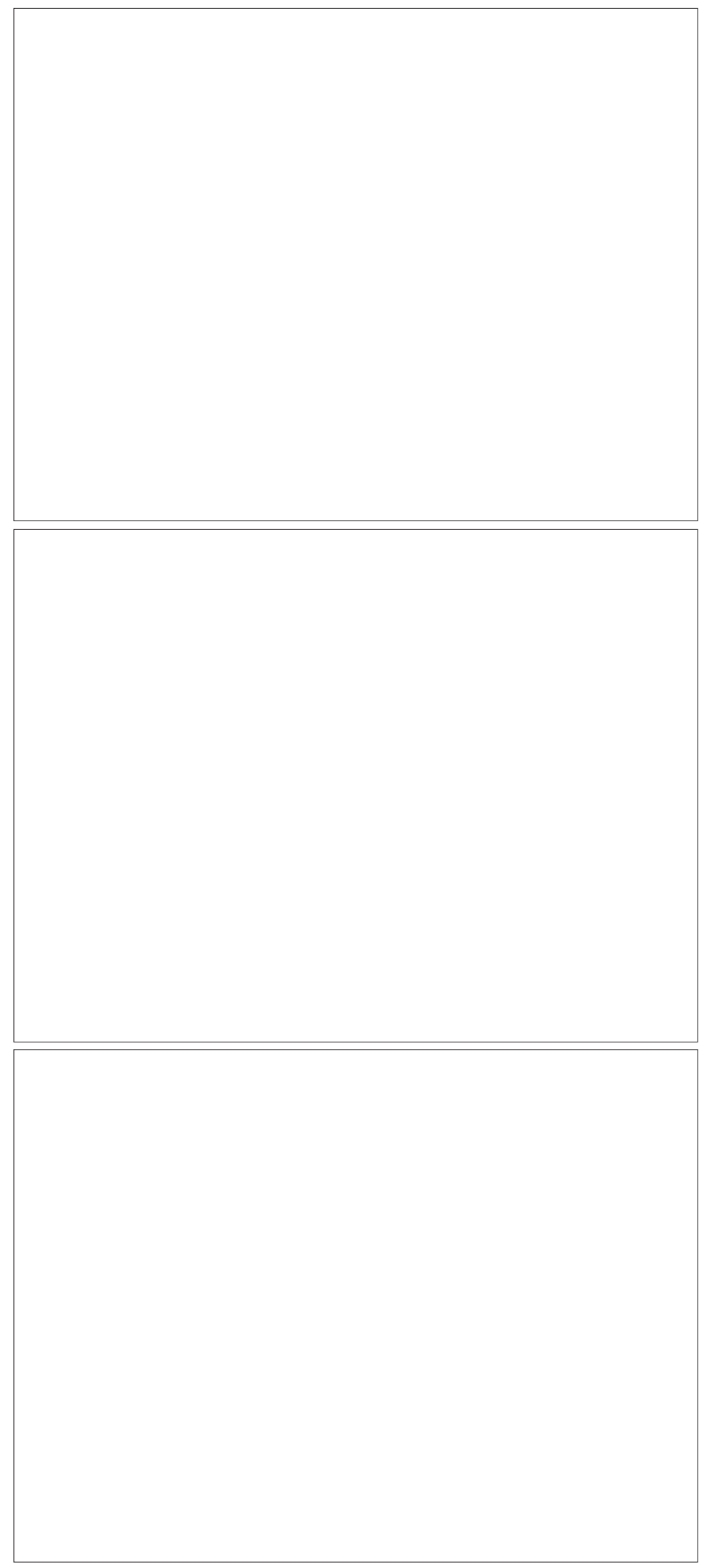

Fig. 10. Tolo House 


\title{
IDENTITY CONSTRUCTION
}

\author{
Constructing an 'architectural identity'.
}

\section{CONCLUSION}

Inthescopeofthisresearch, a methodology towards constructing an architectural identity has been recognised through primarily acknowledging notions of meaning and memory. In turn, meaning and memory can be translated into architectural form through exploring the design qualities of the past and present, critical regionalism and embodiment.

As stated, meaning is created through a biological response to the physical environment. This research looks to foster this meaning in design through exploring the approach of critical regionalism. Memory is endorsed through the history of an urban landscape, thus, placing the importance of acknowledging the past and present in design. Embodiment stands as an overarching concept, looking to contribute to and further conceptualise meaning and memory in an experiential manner, an important tool in building a stronger relationship between people and place. 


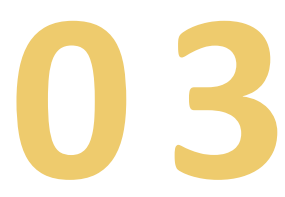

\section{SITE HISTORY (THE PAST)}

Details a past analysis of the site. Explores the relationship that was once acclaimed between people and the environment and the past context of Wellington Civic Square before its present - day state. 


\section{CULTURAL AWARENESS}

\section{DISCLAIMER}

Tikanga Māori is a necessary part of touching on 'the past' in this thesis. Tikanga Māori simply translated means Māori custom. The history of Māori customs stands as a very extensive topic. This thesis will only address a fraction of this topic, specifically interpreting and understanding the key features of Tikanga Māori in a condensed manner with relevance to the researched site of Civic Square. As a Pakeha student, my primary understanding of Māori Tikanga is simple and thus, the following research has given me the opportunity to broaden my knowledge and apprehension of traditional Māori customs. 


\section{INDIGENOUS PERIOD}

\section{0 'S - 1800}

Prior to the arrival of Europeans in New Zealand, Māori had settled on the land according to the interest and influence of tribal (iwi) or sub - tribal (hapu) grouping (N.Z. Ministry for Culture and Heritage, 2020a). Māori lived as communities in villages or fortified settlements called pa. The architecture within each pa was uniquely attributed to the iwi, type of dwelling and the location (W.J. Philipps, 1952).

Prior to colonisation in New Zealand Māori had settled on the land. Their intervention in the landscape and its forms were minor compared with what occurred when Pakeha arrived. Water was of great importance to Māori people, with the lack of land mammals and the large coastline of Aotearoa, many early settlements were located close to sandy beaches as canoes could be easily landed, there was fresh water available, and there was a good supply of food. Māori bought their fishing skills with them from Polynesia and adapted them to the colder stormier environment. Seasonal Kainga (villages) were located around the coast, providing for the harvesting, and drying of fish (Wellington City Council, 2013).
For Māori, water is the essence of all life as it is linked to their tribal identity. Water comes from Papatuanuku (mother earth) and it embodies ancestors within the culture. Historically, water was a valued resource for Māori, providing mahing kai, hagi stones, cultural materials and access routes to important settlements or other historic sites (Wellington City Council, 2013).

When Māori first arrived in Wellington, the indigenous forest cover is believed to have extended over most of the land, with interspersed areas of grasslands (Wellington City Council, 2013). They Māori learnt to use the forest as a survival resource and continued to use the forest as a means of life until the arrival of Europeans. Māori would collect seeds and berries seasonally from the rich supply of indigenous plants. Building materials were acquired locally, with structural timbers obtained from the forest, and raupo and harakeke/flax for thatching gathered from the swamps. The larger indigenous totara trees were used to build waka which in turn were used for fishing, transporting goods, and transporting people in migrations (Wellington City Council, 2013). 


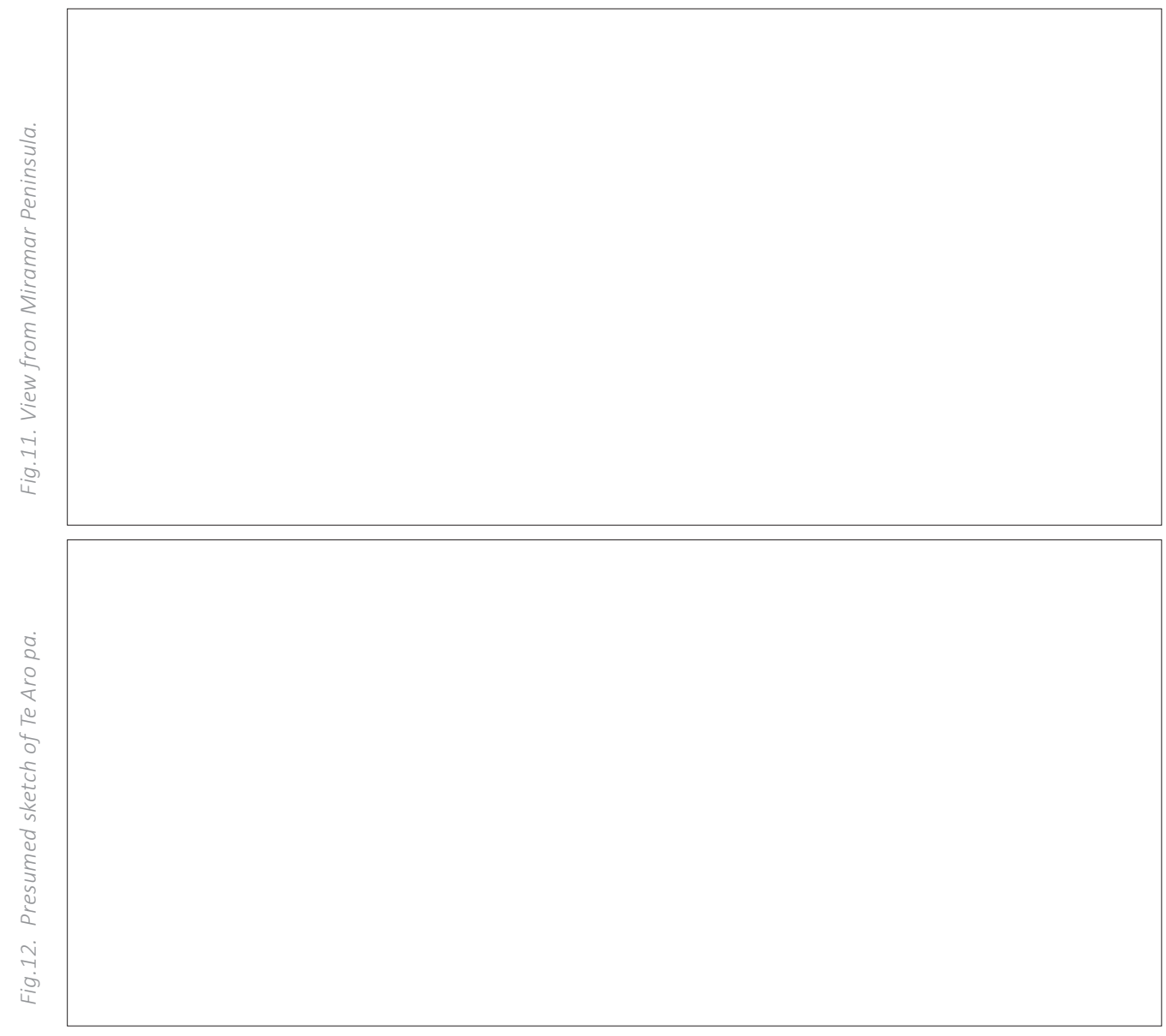




\section{COLONISATION}

\section{$1800-1974$}

Māori's presence in the landscape and its forms was inconsiderable compared with what transpired when Pakeha (New Zealanders of European descent) arrived. Upon European settlement, vegetation was removed in a methodical manner, clearing the way for settlement and farming. Trees were employed as firewood and as a construction material. By the 1860s, Wellington and its flora were stripped with the exception of the remaining scattered but substantial pockets of forest (Wellington City Council, 2013).

It is believed that European settlers, builders, and architects worked to develop architecture in response to the local climate and culture, reflecting the indigenous structures of New Zealand. However, it can be argued that instead of Pakeha culture developing a new architecture reflecting vernacular structures, they employed and regenerated the stylistic approach to European Architecture (B. McKay, 2004).
In the early 1800 s, the arrival of European settlers introduced a change in patterns and way of life. The first European settlers to Wellington set about utilising the area's resources in a fashion that would have astonished Māori people. Vegetation was cleared for farming, timber, heating and cooking and the immediate area around Lambton Harbour was stripped within a few years. Europeans imported plants, animals and technology which dramatically and permanently changed the lives of Māori people (M. Derby, 2013). 


\section{BICULTURALISM}

The treaty of Waitangi was established in 1840. It was created to arrange a common set of laws and agreements of cohabitation for Pakeha and Māori in New Zealand. The treaty aimed to protect the rights of Māori in regard to keeping their forests, fisheries, land, and treasures whilst at the same time handing over sovereignty to Pakeha (N.Z. Ministry for Culture and Heritage, 2020b).

The details and use of this contract continue to be debated to this day, with an ongoing dialogue over the nature of the relationship between Māori and Pakeha. Though the Treaty of Waitangi was intended to create unity, inconsistent understandings and breaches of the treaty have caused conflict over the years. However, from the 1970s onwards the general public have gradually built a stronger understanding of the treaty, making a greater effort to honour the treaty and its principles (C. Orange, 2012). This ongoing dialogue allows for Māori and Pakeha to connect through the sharing of methods, ideas, forms, and technology. The dynamic of this relationship portrays the growth of biculturalism in New Zealand, a relationship that this thesis is looking to acknowledge through the notion of architectural design. 


\section{WELLINGTON HARBOUR}

The very first humans to settle on the shores and harbours of New Zealand uncovered an enormous supply of food. Fish and shellfish were found along the shores, while flora and fauna reached the water's edge and different species of birds inhabited the dense bushes. The harbour offered Māori a secure supply of resources (Wellington City Council, 2013). Post colonisation, land reclamation was undertaken. The process of land reclamation bought pressure for areas of the harbour bed, invasively developing the harbour and in turn mangling its bountiful resources, perpetually changing the harbours primary operation as a wellspring of food. 

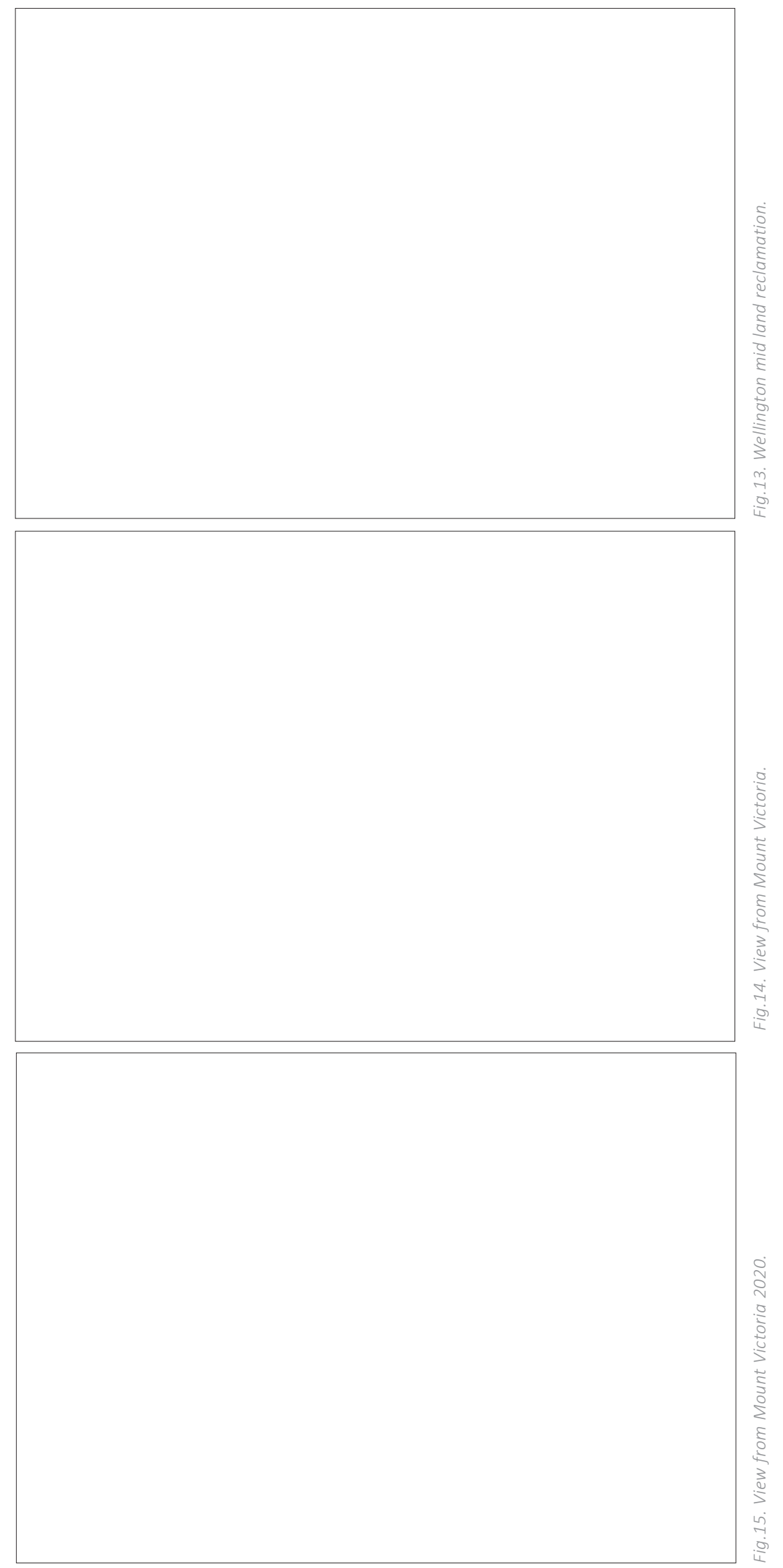


\section{WELLINGTON HARBOUR LAND RECLAMATION}

Reclamation in the early stages was initiated to offset the lack of flat land in Wellington and to bring the settlement closer to deeper water. Initially reclamation occurred in small private efforts and then after the 1855 earthquake it was carried out in a much more substantial manner. Reclamation only ended in the mid -1970s, by which time 360 hectares had been reclaimed from the harbour. Allied to reclamation, dredging of the harbour floor was (and still is) undertaken to enable ships to berth in the inner harbour (Wellington City Council, 2013).

After the city's reclamations were complete, the major waterfront construction project implemented by Wellington City Council deliberately chose a path toward redevelopment that emphasized the attraction of the waterfront. Architecturally, the waterfront development has been designed to enhance the city's role in tourism and complement the promotion of itself as the events capital of New Zealand (S. J. Page, 1996). However, this research recognises the negligence of history in this urban scheme and aims to further enhance the role of the waterfront and its relationship between people and place through building upon a connection between the narrative of this site's historic land habitancies. 


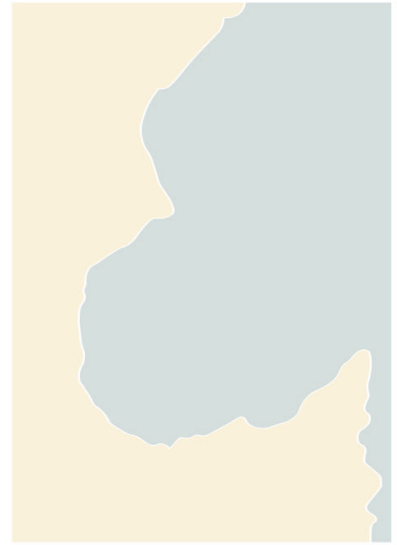

PAST

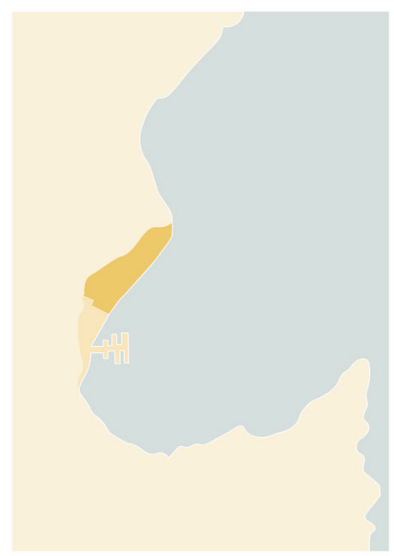

1876

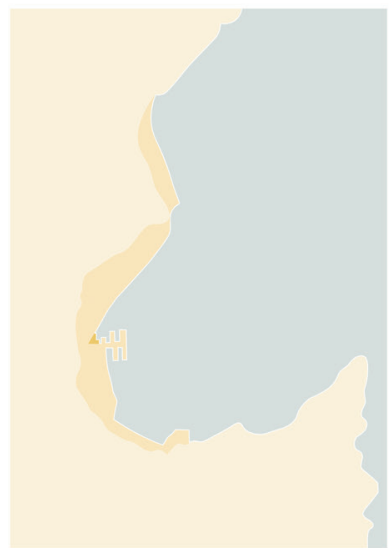

1893

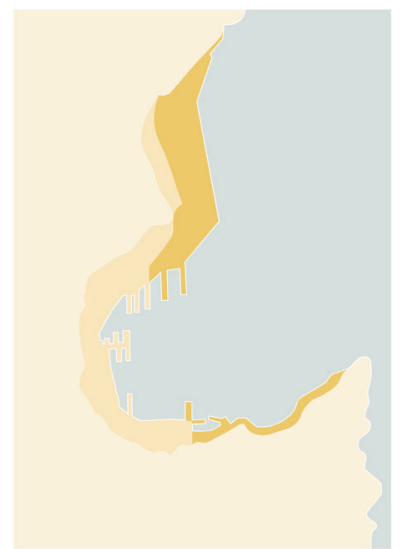

$1906-27$

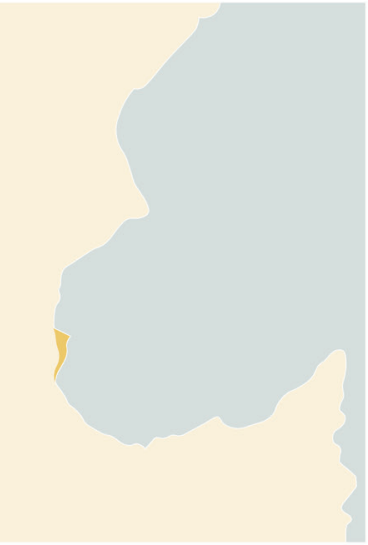

$1857-63$

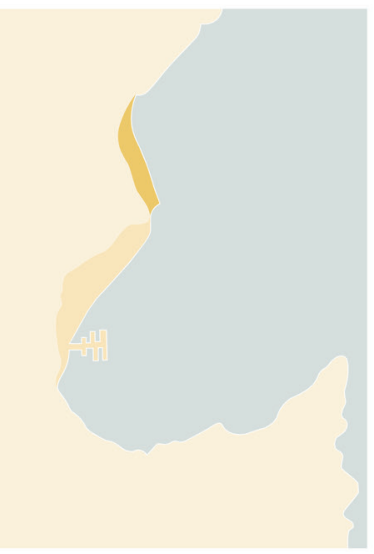

1882

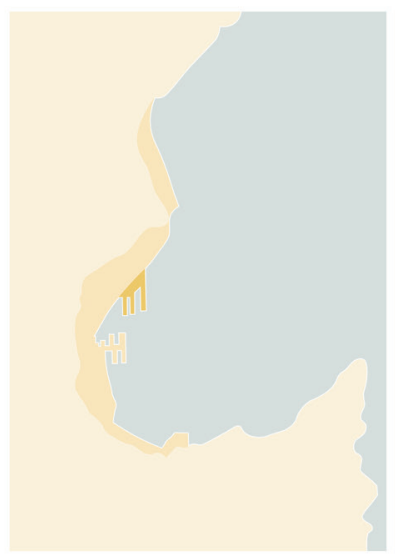

1899

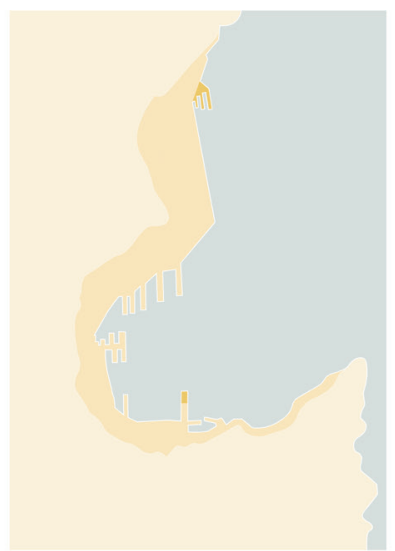

$1928-55$

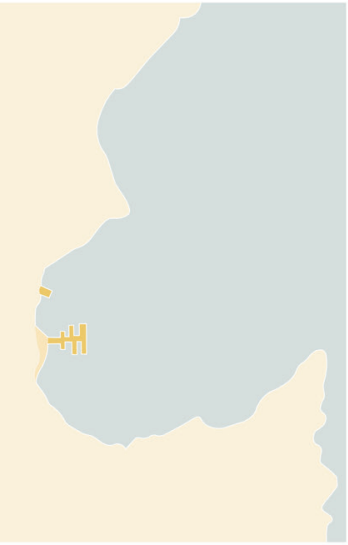

$1864-5$

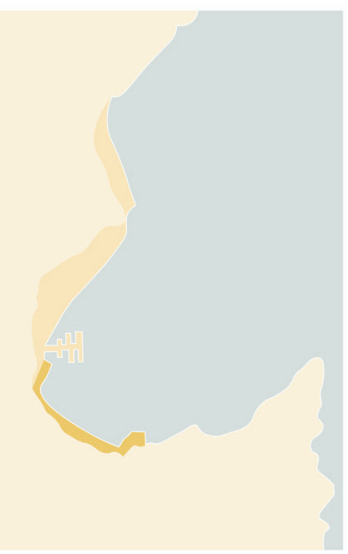

1886

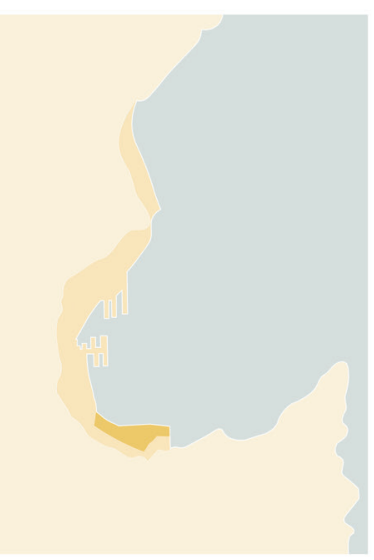

$1901-4$

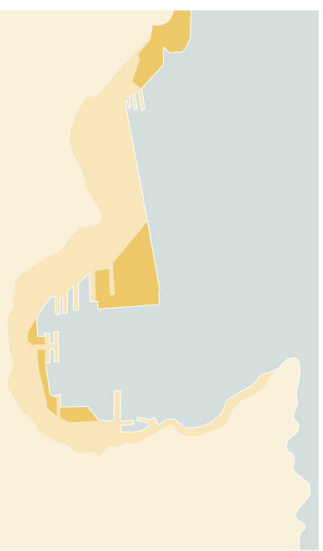

1956

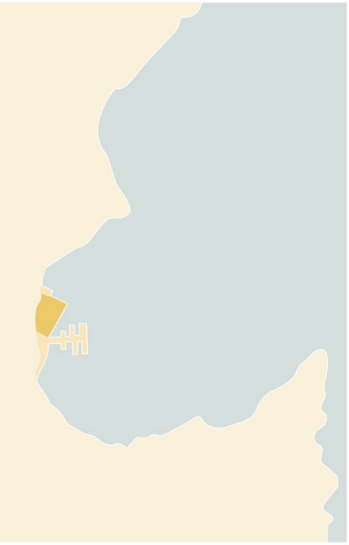

$1866-7$

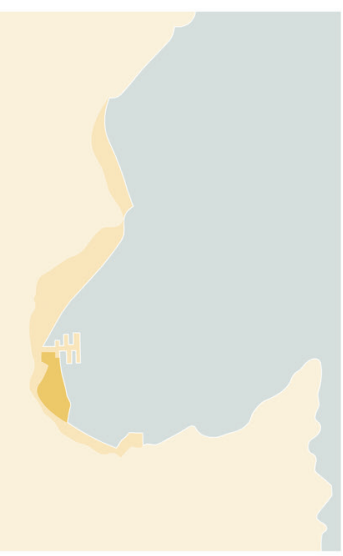

1899

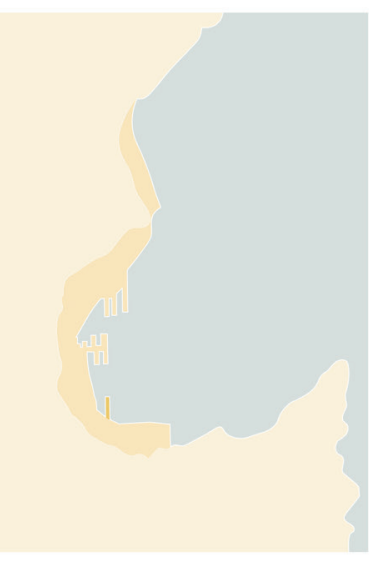

1905

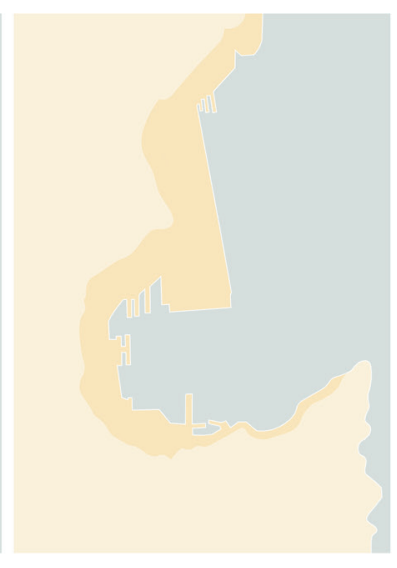

PRESENT 


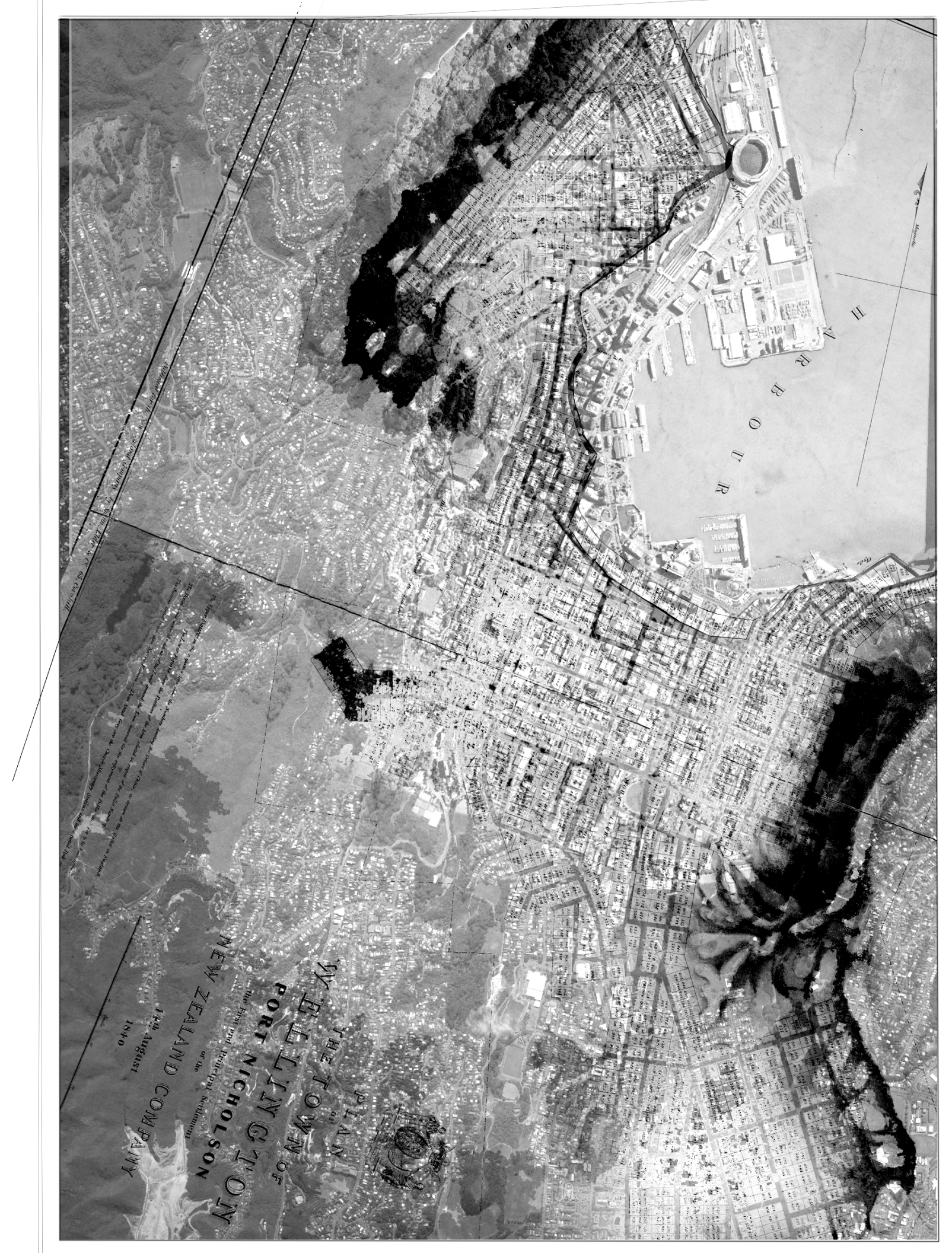

OLD \& NEW SHORELINE MAP OVERLAY 

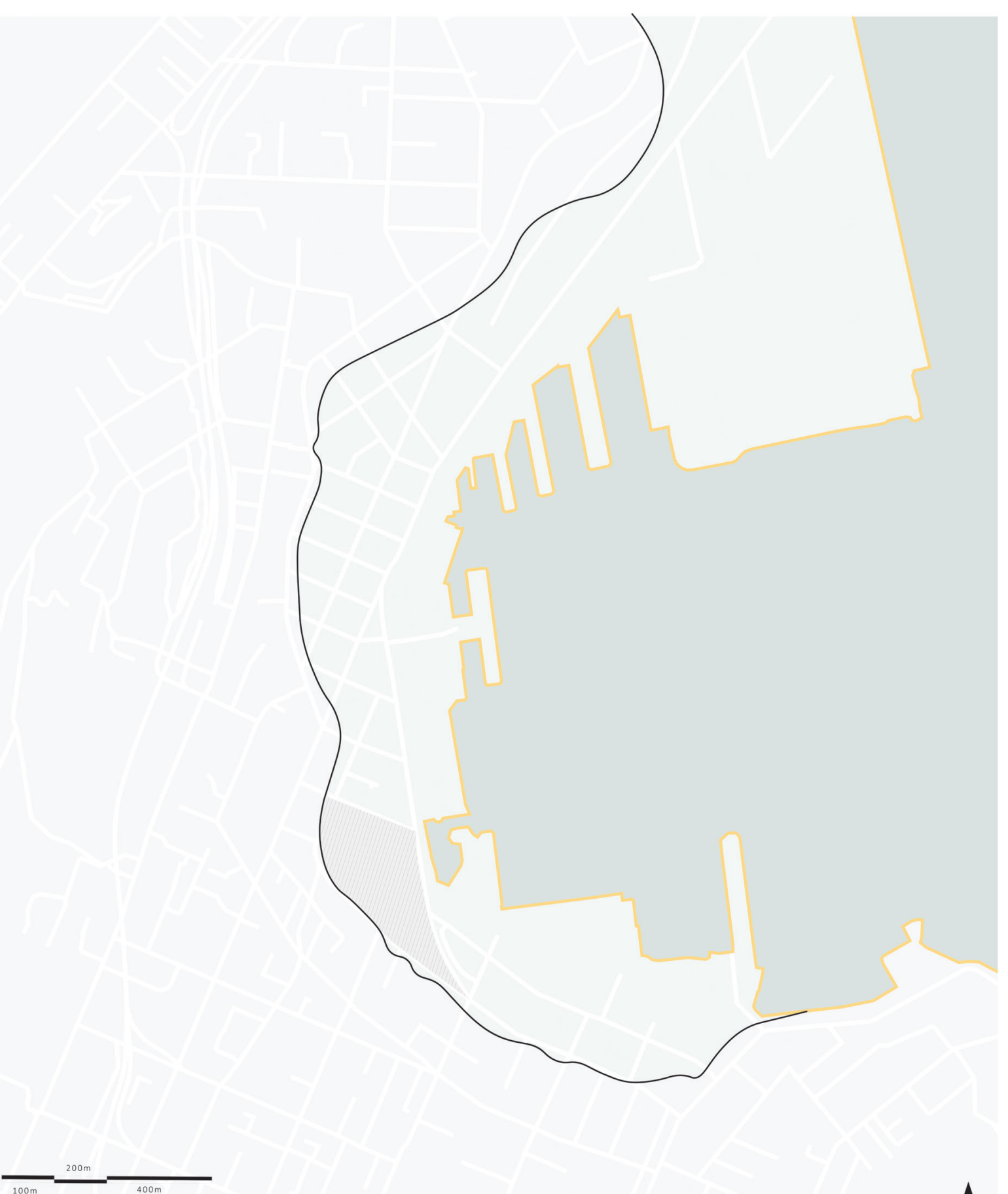

$\Lambda$

- Old ShORELINE

a CURRENT SHORELINE

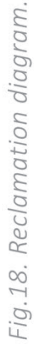

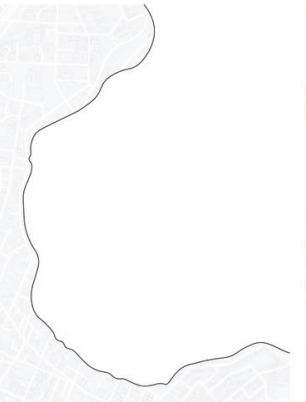




\section{SITE HISTORY (THE PAST)}

\section{CONCLUSION}

It is evident that Wellington is an old city with copious layers of topographic and environmental depth. With the harbour water and undulating terrain greatly contributing to the city's identity, the population that occupy Wellingtons Streets today are lacking this knowledge of place. This analysis of the past will act as a driving force moving forward, searching to further enhance the role of the waterfront through building upon a connection to the narrative of this site's historic past. 


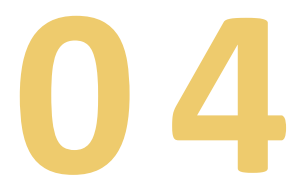

SITE ANALYSIS (THE PRESENT)

Wellington Civic Square present - day site analysis. Analsyses the current Civic Square environment and gives emphasis to subsequent design opportunities. 


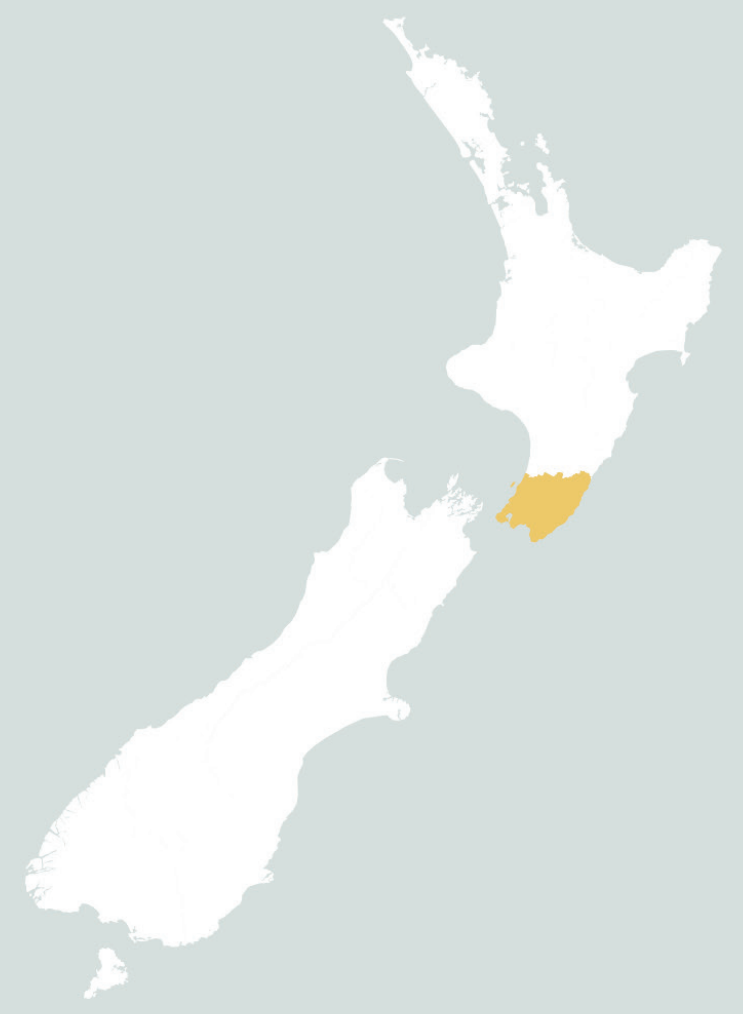



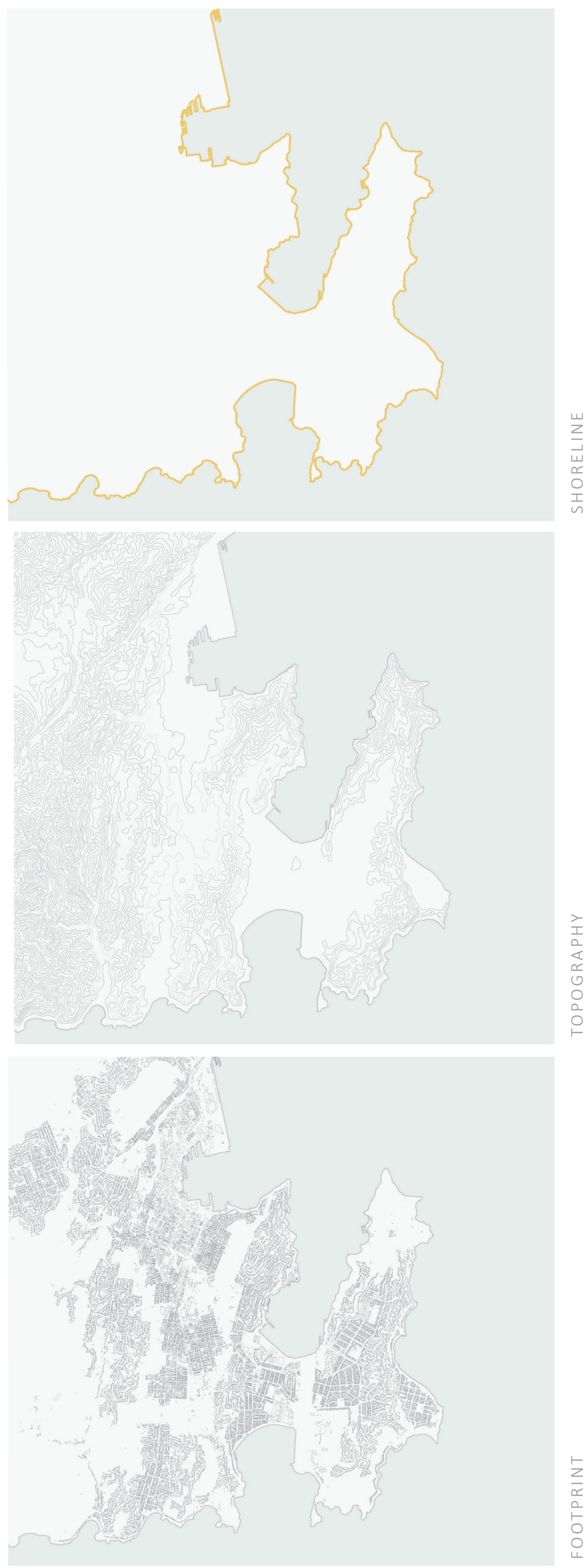


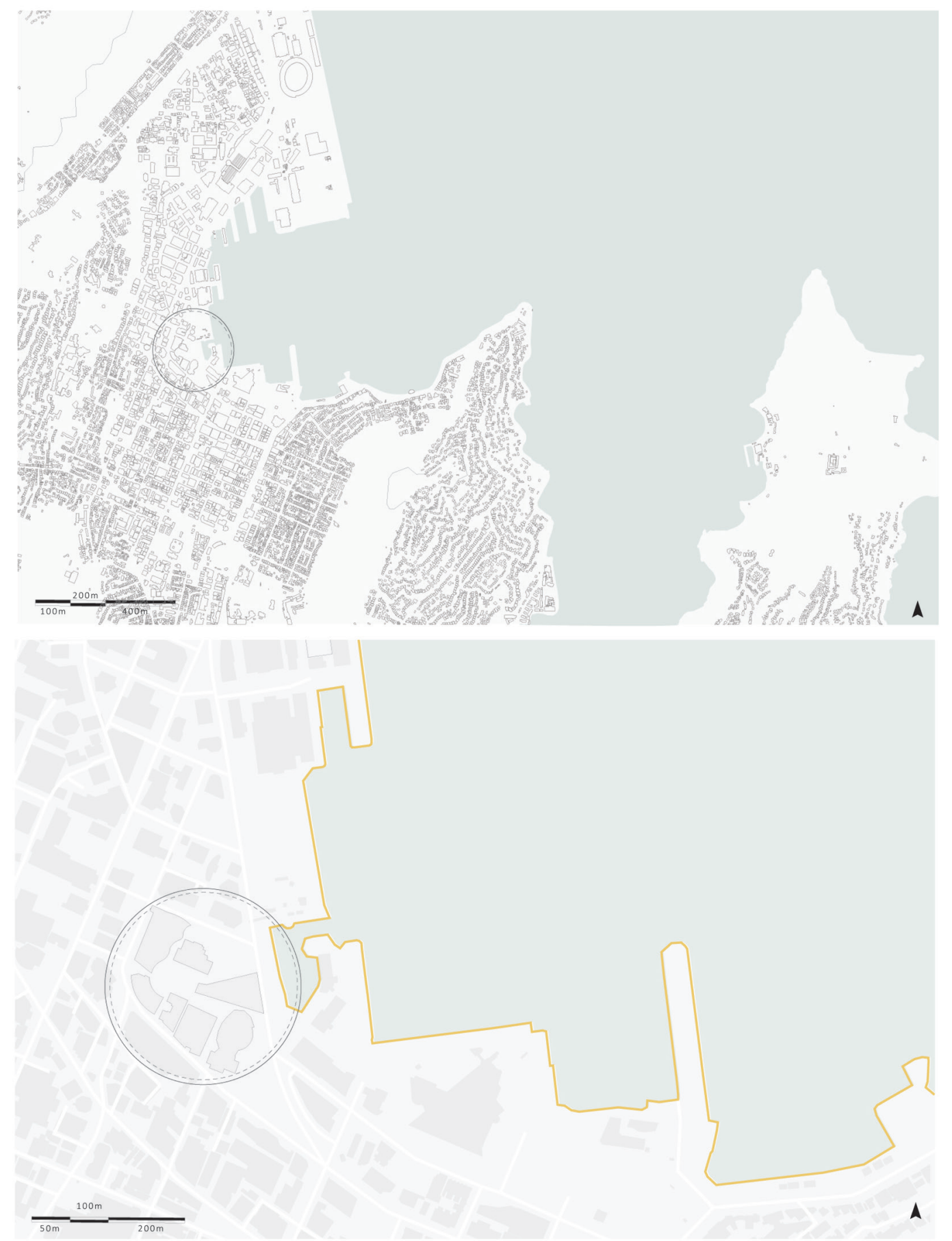




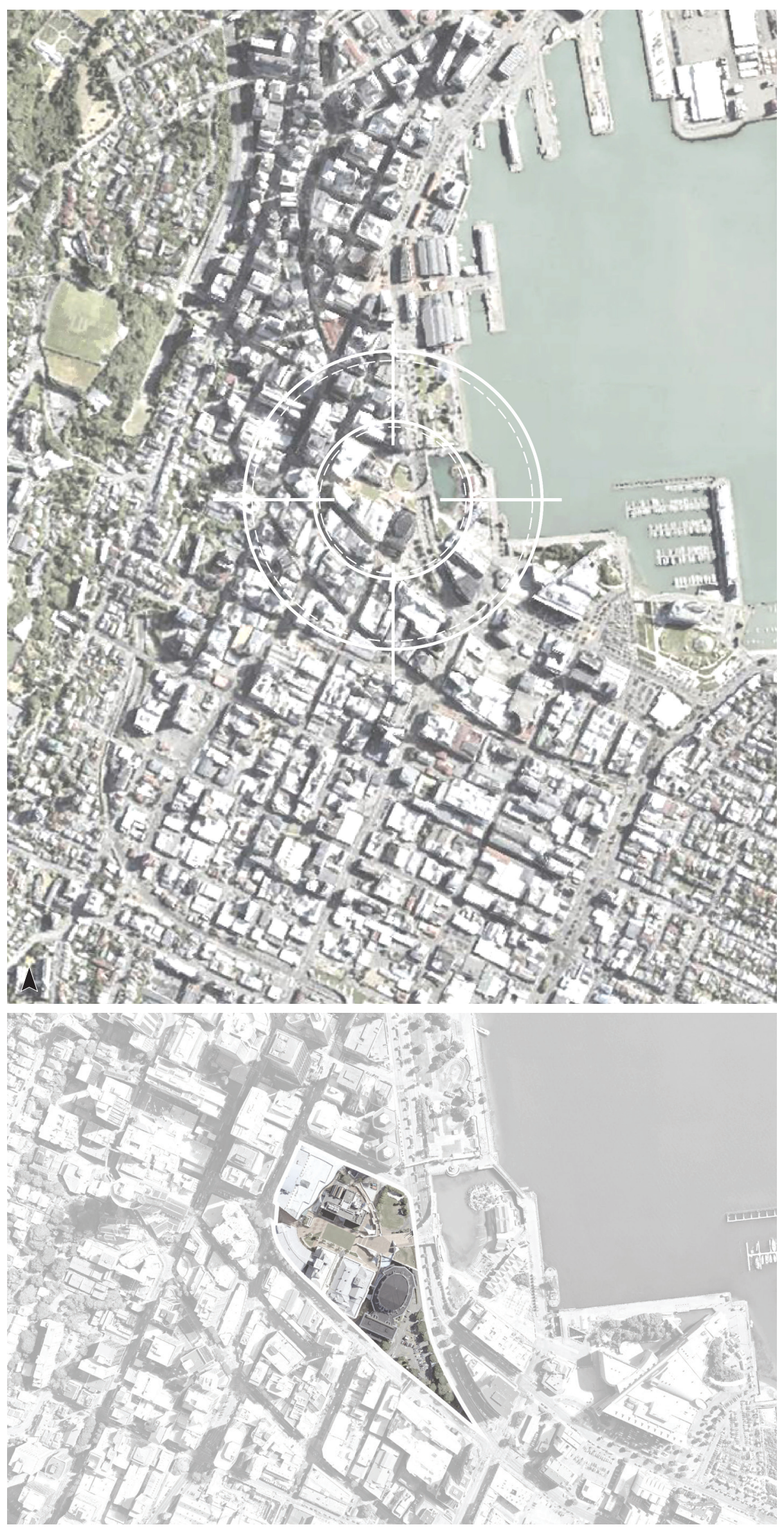




\section{CIVIC SQUARE}

\section{SITE DESCRIPTION}

Wellington's Civic Square was initially inspired by the public squares of Europe. Wellington was lacking a formal civic space within the city and in the early 1990s Wellington City council decided to build its own. Work on Civic Square first started in 1987 and was completed by 1992 (C. Maclean, 2015). The assemblage of new and refurbished buildings around the square were collaboratively shared amongst Craig Moller and Stephenson \& Turner with Athfield Architects undertaking the Wellington Central Library, Civic Carpark and Square, Capital Discovery Place (Capital E) and the City side of the bridge over Jervois Quay (Athfield Architects Ltd, n.d.).

The Squares development began with a master planning exercise, where a number of existing municipal buildings on Mercer Street were reconsidered, creating a series of new buildings and spaces to establish the Square (Athfield Architects Ltd, n.d.). Although Civic Square is relatively new, with a number of buildings and features of recent vintage, the area is fundamentally defined by a collection of important historic civic buildings. Before the site was restructured into an enclosed public square, the area was defined by three existing buildings. Figure 27 shows the site in its pre - civic square state, of which the Wellington Town Hall, Central Library (now City Gallery), and the Administration Buildings stood on three blocks of land, bounded by Mercer, Wakefield, Harris and Cuba Street.
Amongst these existing buildings the Wellington Town Hall and City Gallery are of very high heritage value (Wellington City Council, 2015a).

Civic Square was constructed at the site of a neglected public carpark, plotted between the Town Hall and the then Central Library (now the Wellington City Gallery). Upon the design of Civic Square, a new Wellington Central Library and civic administration block emerged on the western side of the square. The Michael Fowler centre had already been completed in 1983 and though the old theatre on the north - east corner of the site initially stayed put, it was eventually replaced by the now Ilott Green. In the Squares original designs, a pedestrian route was considered at ground level across the Jervois Quay traffic route. However, this scheme was later abandoned as it was decided that instead the square should rise up, over the Quay on a wide pedestrian bridge (the City to Sea bridge), to touch the water at the lagoon. In the centre of the site, an underground carpark was built, accommodating to council staff and to underground access to the Town Hall and Capital E (Wellington City Council, 2015a). 


$$
\#
$$



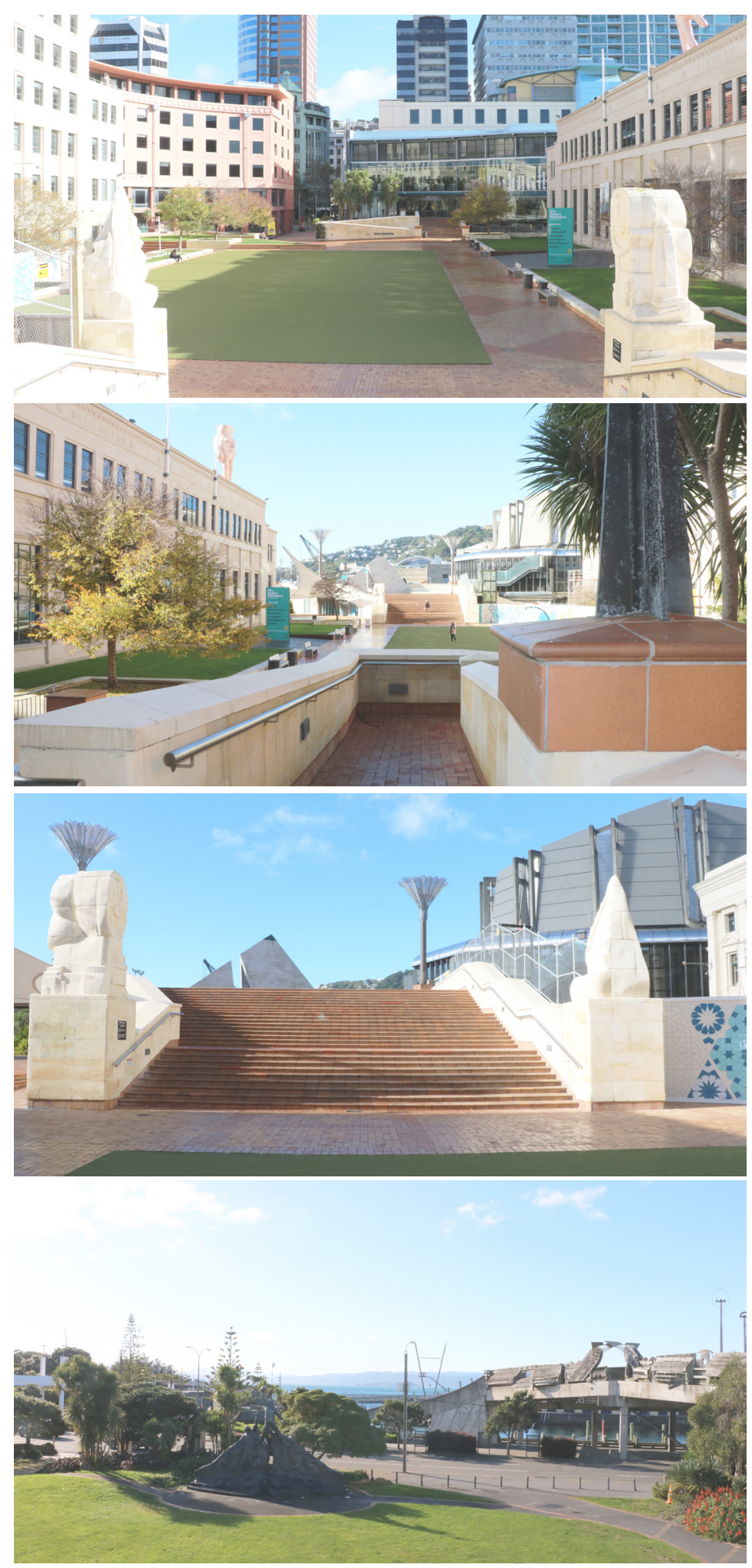

Fig.29. Civic Square 2020 


\section{PRESENT DAY}

The Civic Square precinct is defined by the Wellington City Library, the Wellington Town Hall, the City Gallery Wellington, Capital E, the Wellington City Council, and the Michael Fowler Centre (Figure 30). Civic Square and its surrounding buildings are now seen as iconic Wellington landmarks, and in the early years of the square, featured large in the lives of residents and visitors. Architectural details and commissioned work drawn or placed on site specifically by Athfield Architects have become highly valued features of Civic Square, appreciably contributing to the sweeping aesthetic of the space (Wellington City Council 2015b).

\section{DESIGN AESTHETIC}

According to Athfield's, the overarching designed vision of Civic Square was considered to equally understand the city's emerging relationship with the harbour whilst also acknowledging the importance of new and historic urban planning and civic markers (Athfield Architects Ltd, n.d.). Athfield's played with immersing stories of the city into the fabric of the square, looking at architecturally translating Kiwi myths such as the eye of the fish, the fishing up of Wellington and the role of Maui in the formation of Aotearoa's landscape. Though the design of the square became profoundly iconic in its contemporary nature, Athfield's designed in a subtle manner to avoid being explicit and risking the stories behind the designs becoming simplistic or cliched (Athfield Architects Ltd, n.d.).
This subtle approach to an architectural narrative introduced to the site by Athfield's, is one that this design process will also follow, looking to avoid constructing an architectural identity with a simplistic image. This thesis is looking to align with the existing built environment through respectfully contributing to the site, opposed to overthrowing the existing architecture. There is no intention to reproduce the postmodern aesthetic of the square, but instead use design interventions to further develop the square in a contemporary manner. The design process will be navigated in a direction of which, the new will be easily devised from the old, seeking to create an architectural journey from past to present across the site.

\section{TE NGAKAU}

In 2018 Civic Square was renamed Te Ngakau, meaning 'the heart of the City?. The Squares location stands at a significant connection point, truly creating 'the heart of the city' as people can walk between Wellington's waterfront, the Golden Mile and our the principal arts, cultural and performance venues (Wellington City Council 2015b). This research is looking to further embrace Te Ngakau, ensuring that Civic Square is continually strengthened to be the heart of the city based upon both location and its built relationship between people and place. 


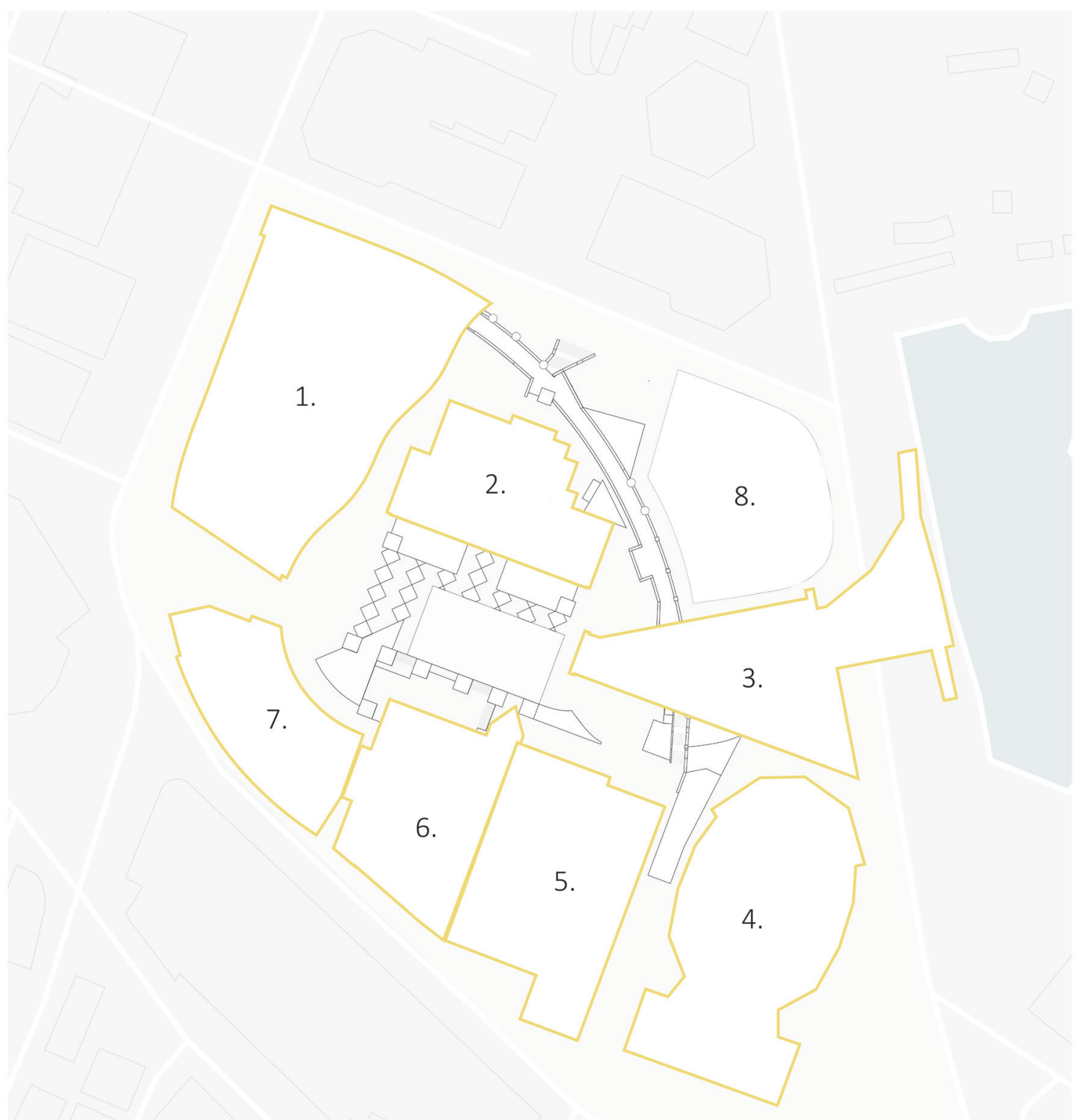

$25 \mathrm{~m}-100 \mathrm{~m}$

SITE PLAN

1. Wellington Public Library

2. City Gallery Wellington

3. City to Sea Bridge

4. Michael Fowler Centre
5. Wellington Town Hall

6. Municipal Office Building

7. Civic Administration Building

8. llott Green 


\section{RESILLIENCE CHALLENGES}

Civic square was significantly affected by the 2013 Cook Straight and the 2016 Kiakoura Earthquakes. As a result, concerns have arisen around the seismic resilience of many of the squares buildings and structures, prompting ongoing discussions and decisions around the future development of the square (Wellington City Council, 2015b).

The Wellington City council has carried out earthquake assessments of the buildings within the Civic Precinct. These assessments are a part of a city wide programme to make Wellington Safer in the event of earthquakes. The Civic precinct is riddled with seismic problems, in turn creating an extremely vacant square. Upon assessment, the Civic Administration Building was damaged in the 2016 earthquake and has been closed ever since. The Wellington Central Library has been closed for nearly two years and after a long period of deliberation, the council has agreed to strengthen the valued building, opposed to demolishing it. The Town hall has been closed for several years and is currently undergoing seismic strengthening. The Office Municipal Building has also been classed as unsafe for occupation, with the recent decision having been made to demolish the building, as strengthening was no longer considered economically viable (G. Campbell, 2020).
The current temporary nature of the buildings within Civic Square makes for an uncertain future for the space. However, the squares topical emptiness and prospective redevelopment provides fresh opportunity to redevelop the precinct into a more active public space. With a focus on the square's future, there is opportunity to revitalise the way in which the civic space is used and its relevant needs as the urban centre point of Wellington City. 


\section{CLIMATE ANALYSIS}

When identifying a location within Civic Square to begin design development, a site was sought which would be both positively affected by the climatic conditions of the site, and negatively affected by the static nature of architecture. 


\section{SUN PATH SIMULATION}

To understand the climatic stance of the site, figures 31 and 32 simulate the sun path in both the peak of winter and summer. The diagrams indicate that in summer, the central and North - eastern areas of the site remain greatly exposed to the sun throughout the day.
In the winter months there appears to be a lot less central sun exposure to the site, however the North - Eastern periphery remains somewhat exposed.

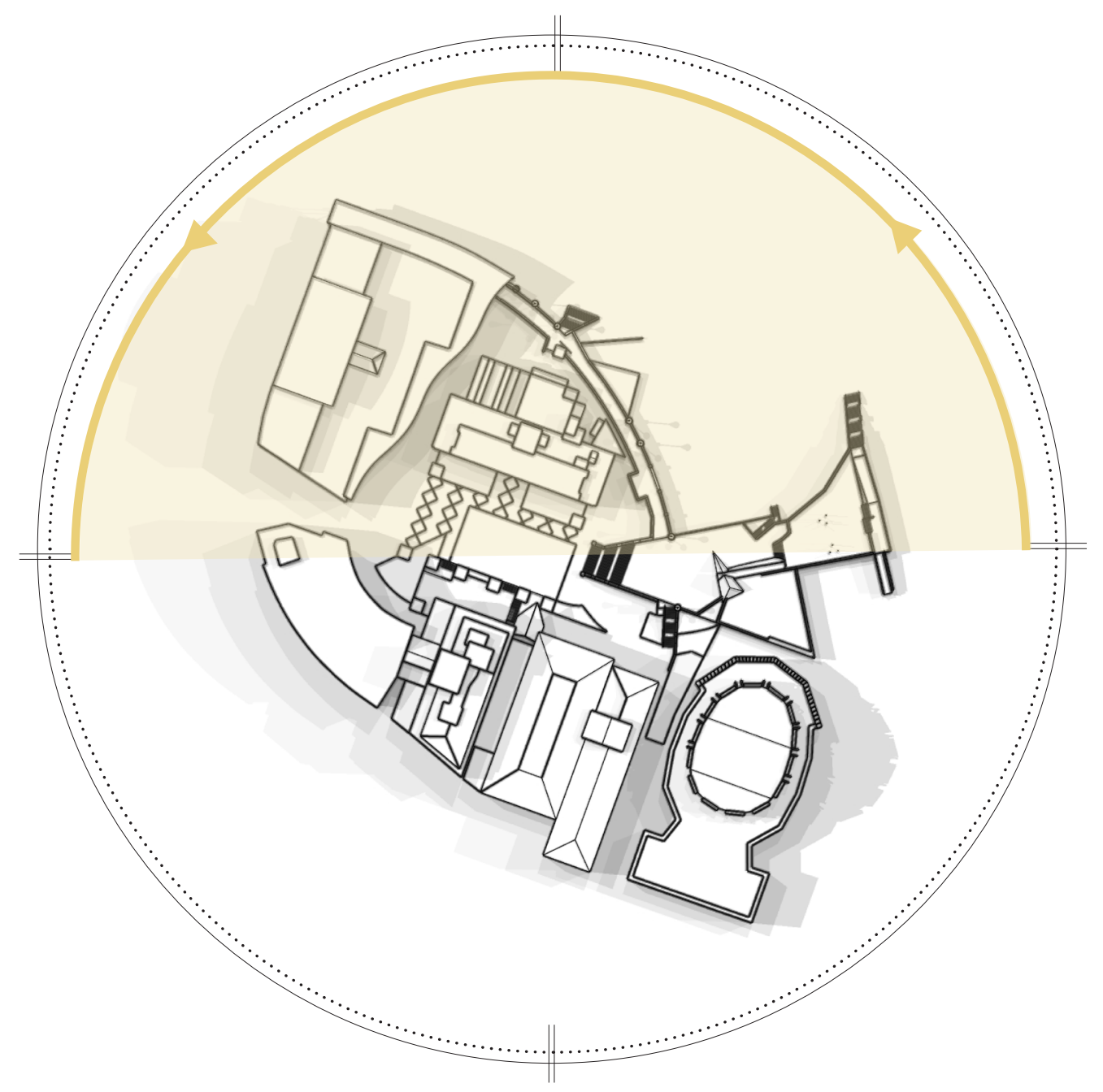

SUMMER SUN 
FEBRUARY 8:00

FEBRUARY 10:00

FEBRUARY 12:00

FEBRUARY 14:00

FEBRUARY 16:00
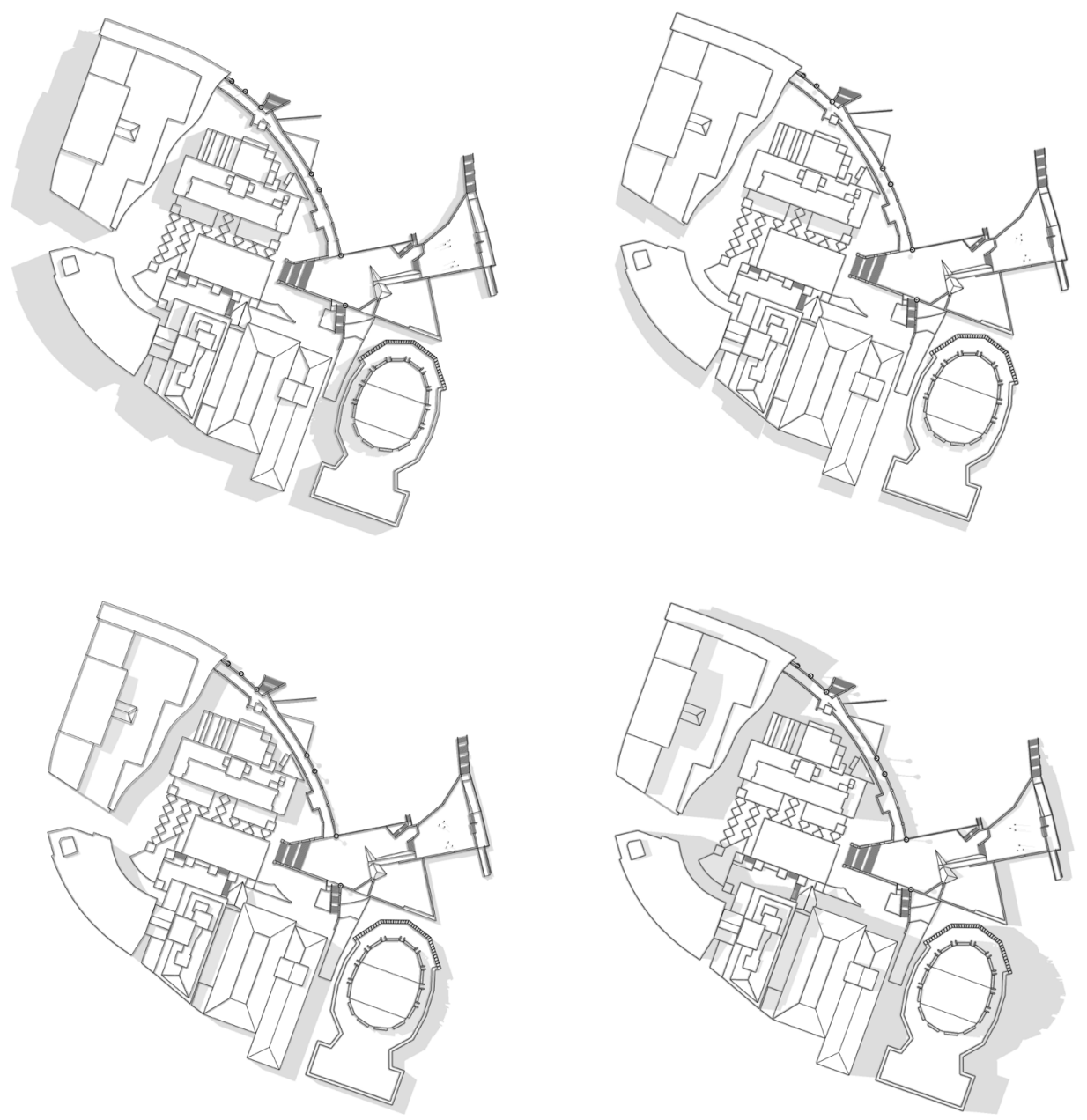


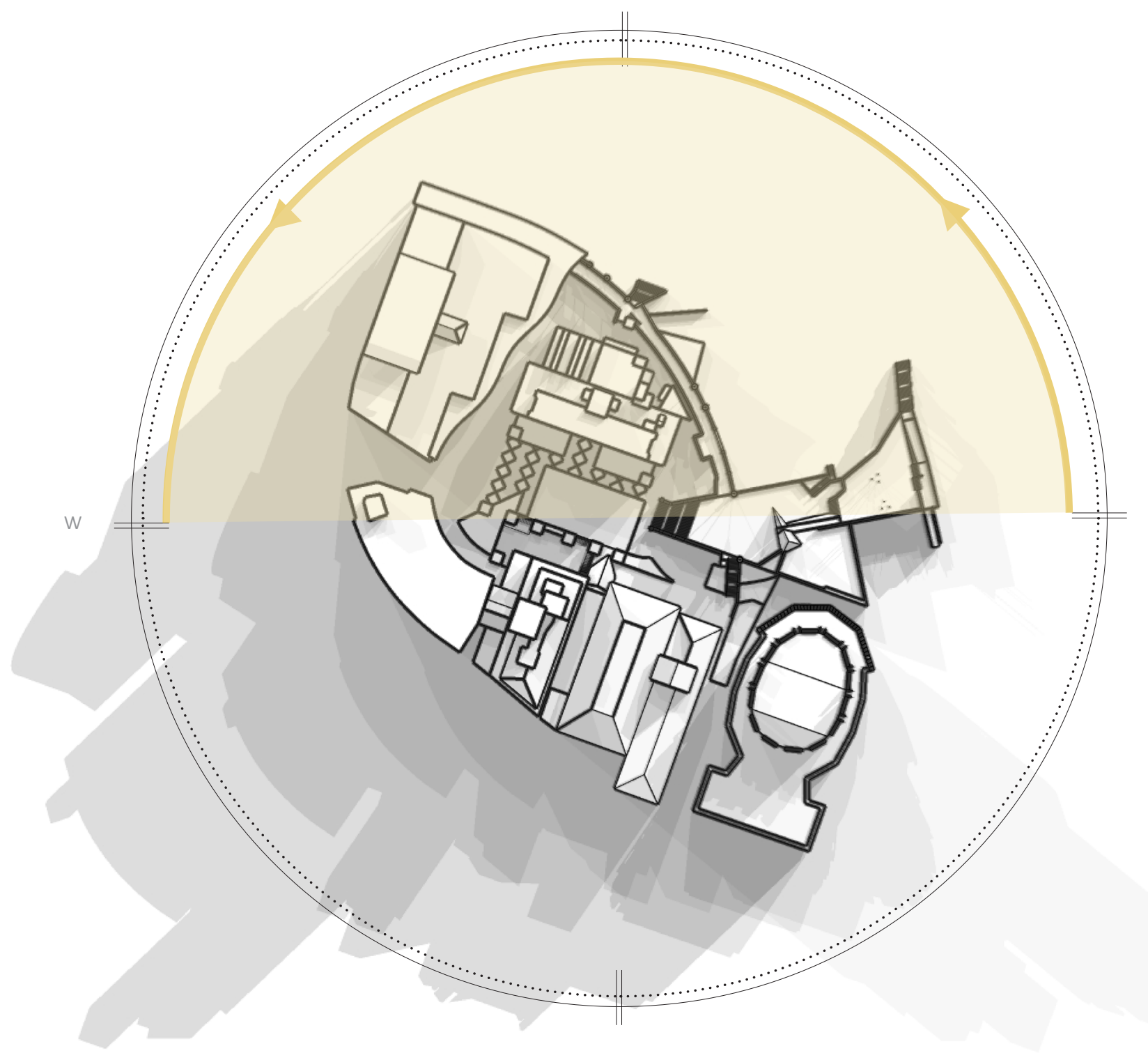

WINTER SUN

$25.2^{\circ}$ 


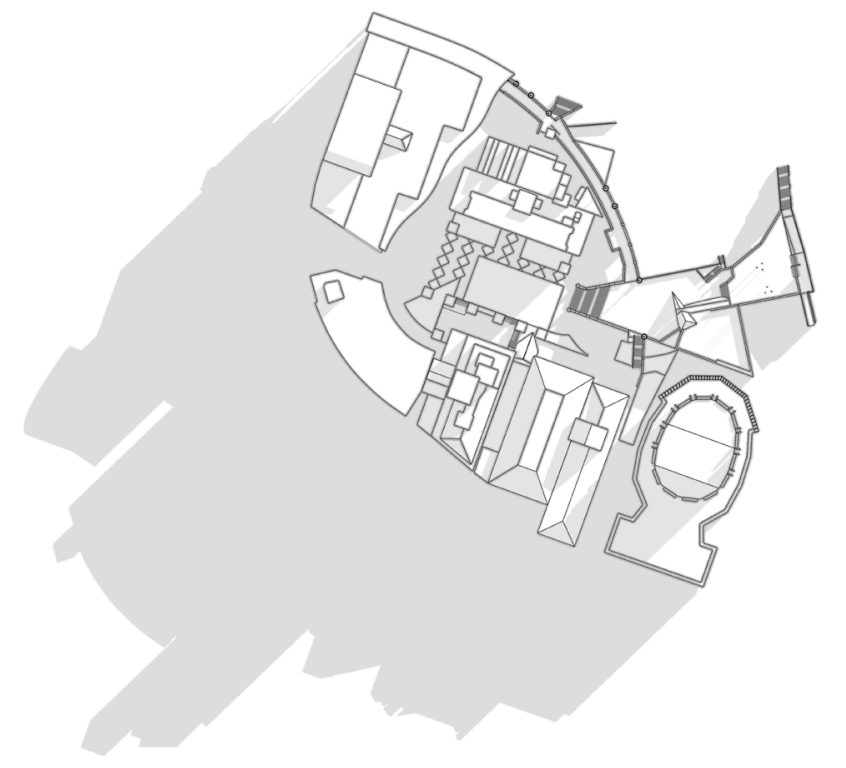

JULY 10:00
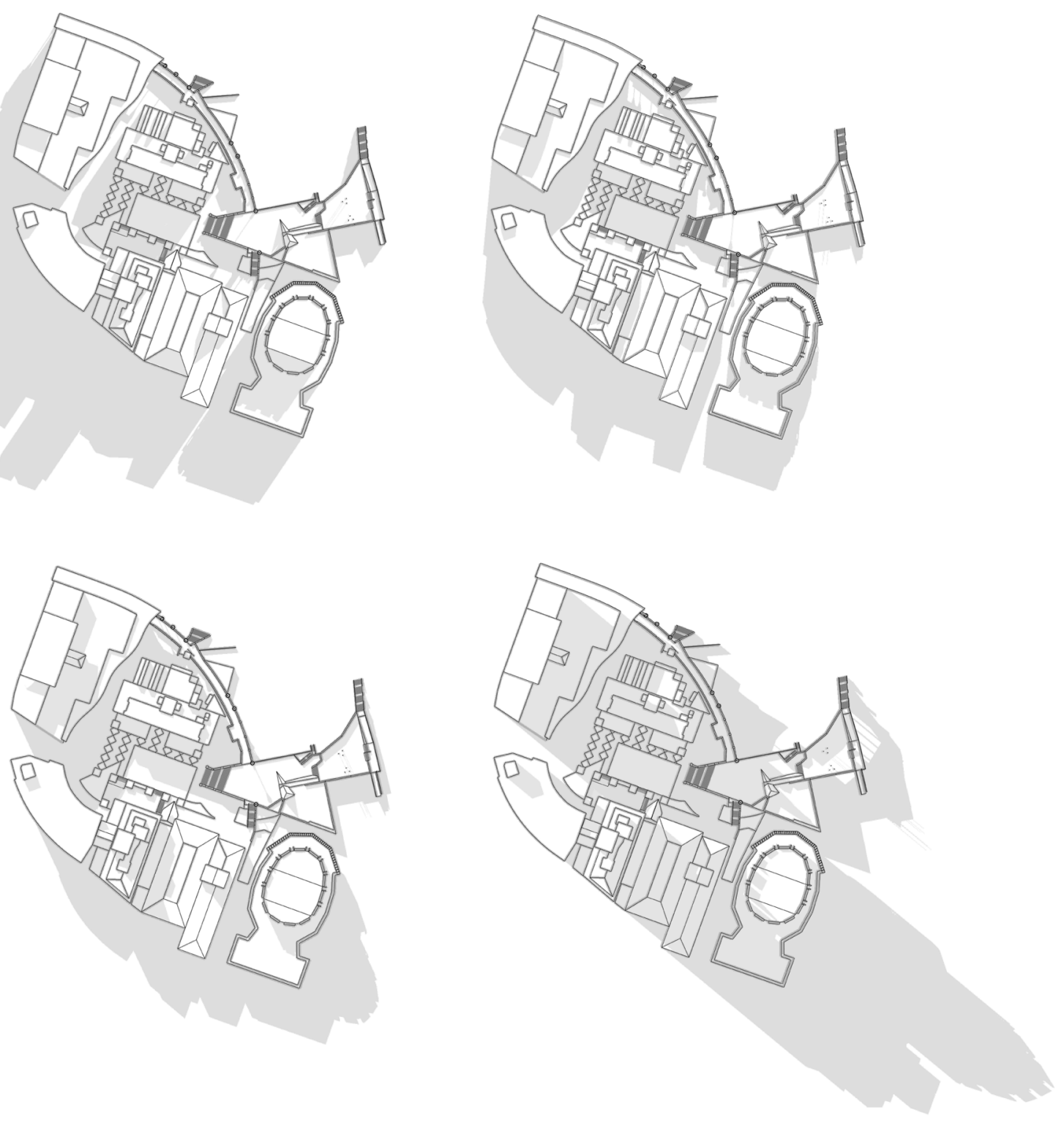


\section{WIND ANALYSIS}

Figure 33. Mean annual wind frequencies (\%) of surface wind directions from hourly observations at selected Wellington stations. The plots show the directions from which the wind blows.

Wellington is informally known as the windy city. Research indicates that the city endures high wind levels during the months of spring, while the autumnal months tend to be the most settled. Gusty north - westerlies alternate with southerlies.
North - westerly winds are predominant in the spring and summer, while southerlies are most common in the winter months.

The effects of Cook straight in combination with Wellingtons surrounding hilly terrain produces 6 prevailing winds in the City. These prevailing winds are either northerly or southerly. As indicated in the wind rose (figure 33) the northerlies are more frequent than the southerlies, but both can produce equally severe winds.

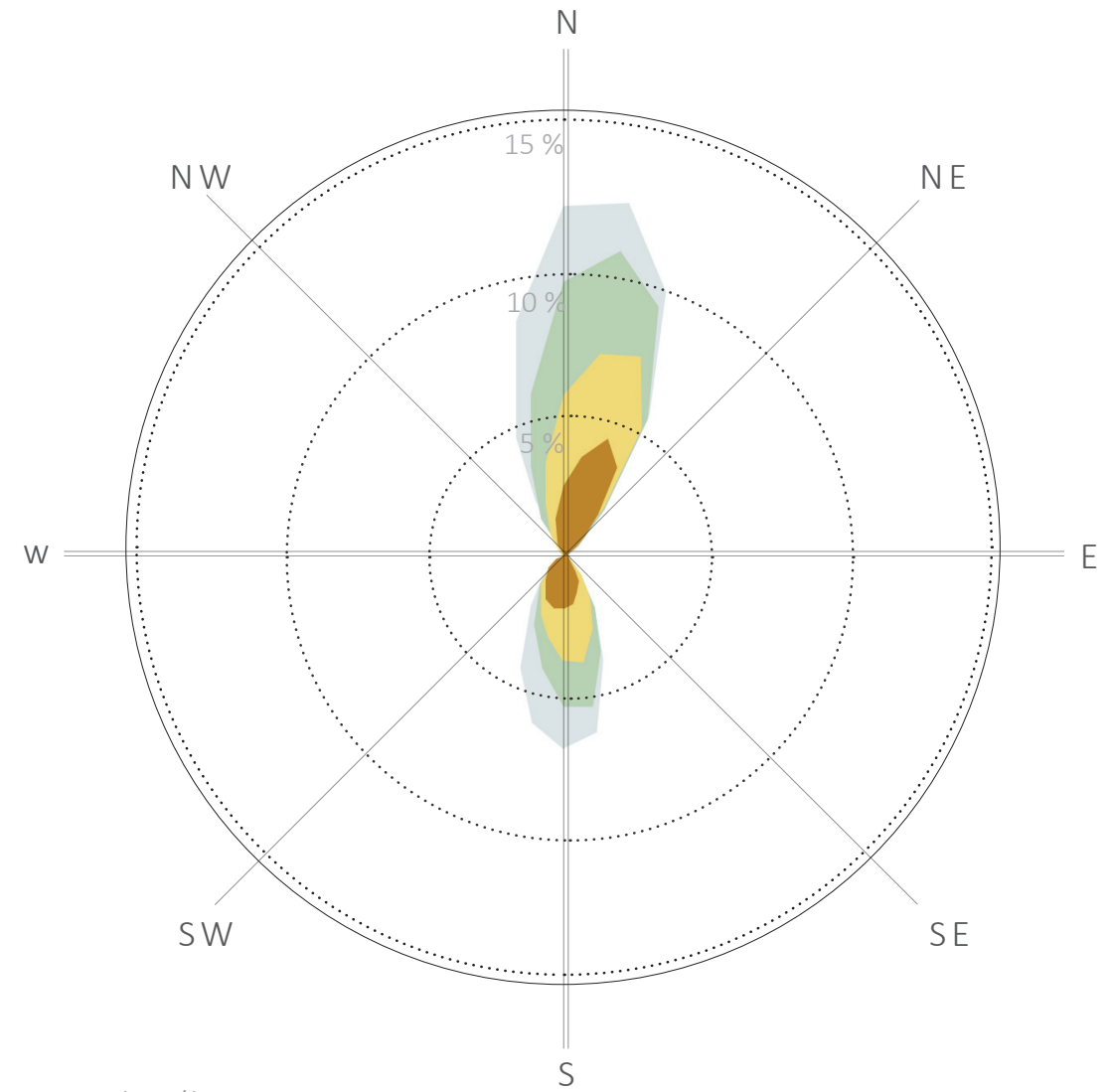

$1-20 \mathrm{~km} / \mathrm{hr}$

Mean speed $2.62 \mathrm{~km} / \mathrm{hr}$ 


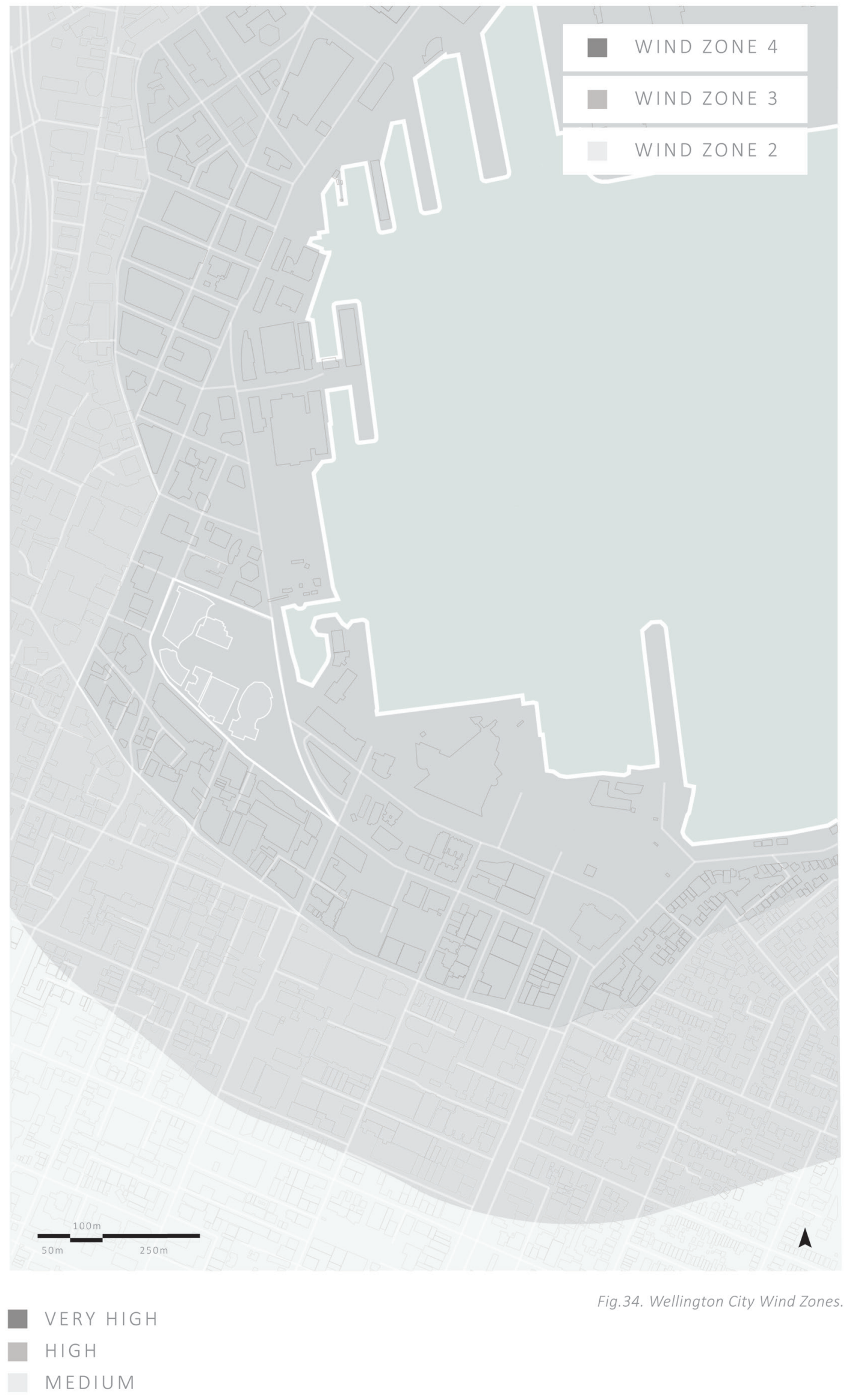




\section{A VISUAL JOURNEY}

Through carrying out multiple site visits, a visual journey through civic square was created, looking at the site both vertically and horizontally, searching for points of pause and movement.

Significant view shafts were identified as a way of sourcing opportunity to later build upon a visual connection to the surrounding natural environment. Horizontally the site has significant visual depth with multiple points of pause as identified in figure 36 . View shafts head out in the eastern direction, with key focal points pulling towards either the Wellington harbour or Mount Victoria. 

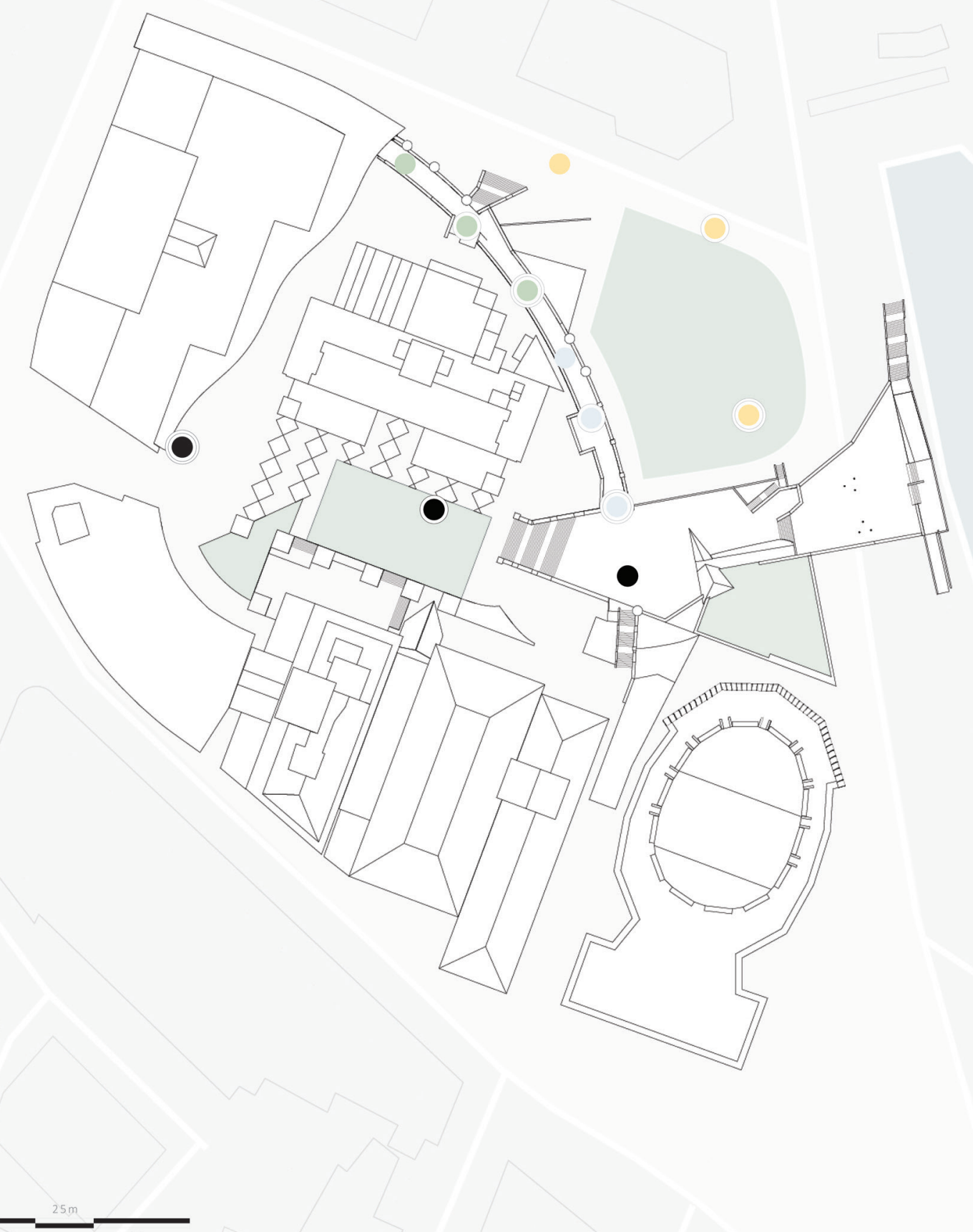

VIEW SHAFT LOCATION KEY
- Series 10 Series 3
- Series 2 Series 4 

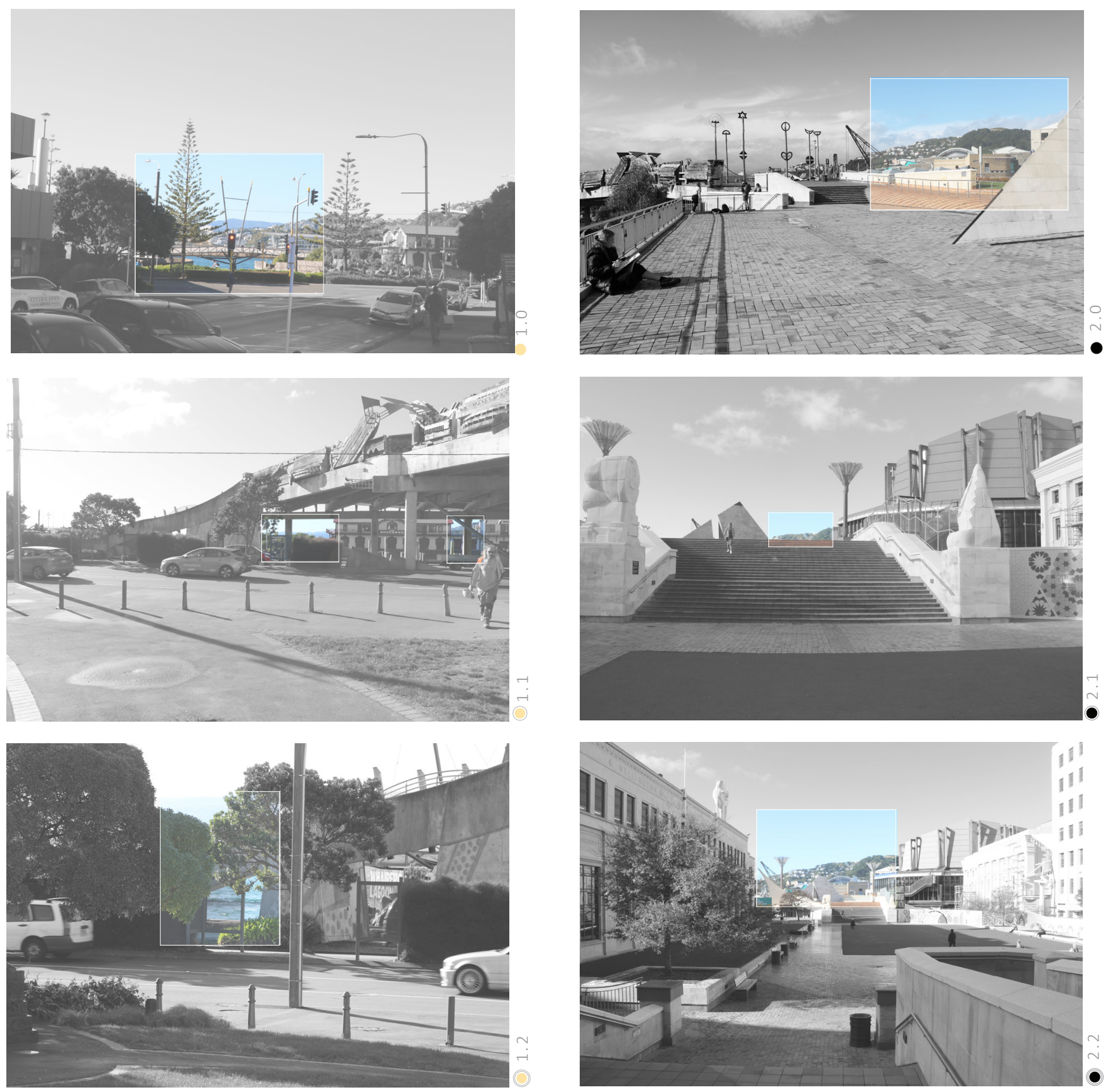

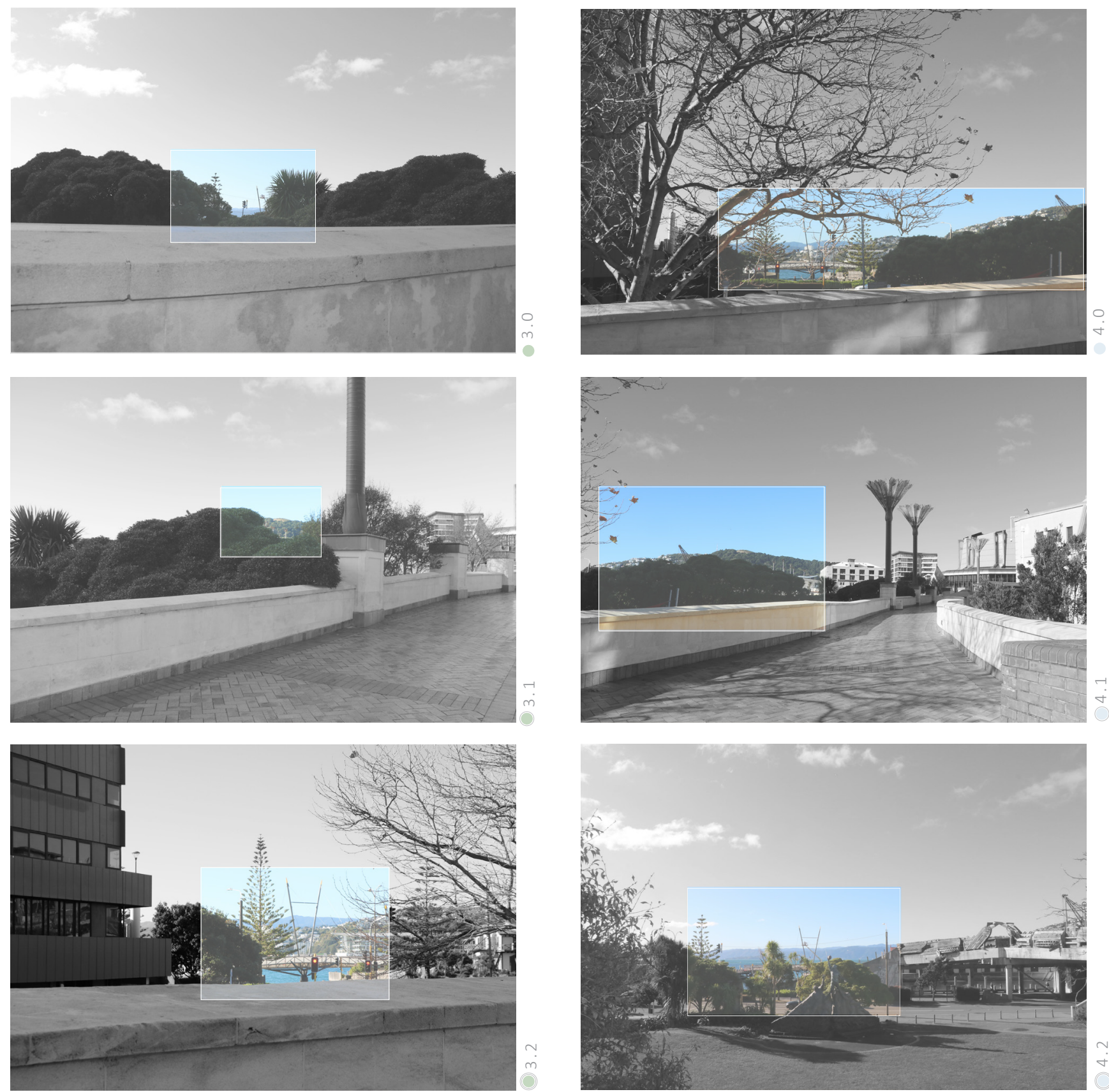


\section{VERTICAL ANALYSIS}

When looking at the site through a vertical As the site stands on reclaimed land, the lens, there is opportunity to highlight the underground level is vulnerable to flooding layers of the site that have formed from the with the ocean pushing up against its floor. past through the journey to land reclamation.

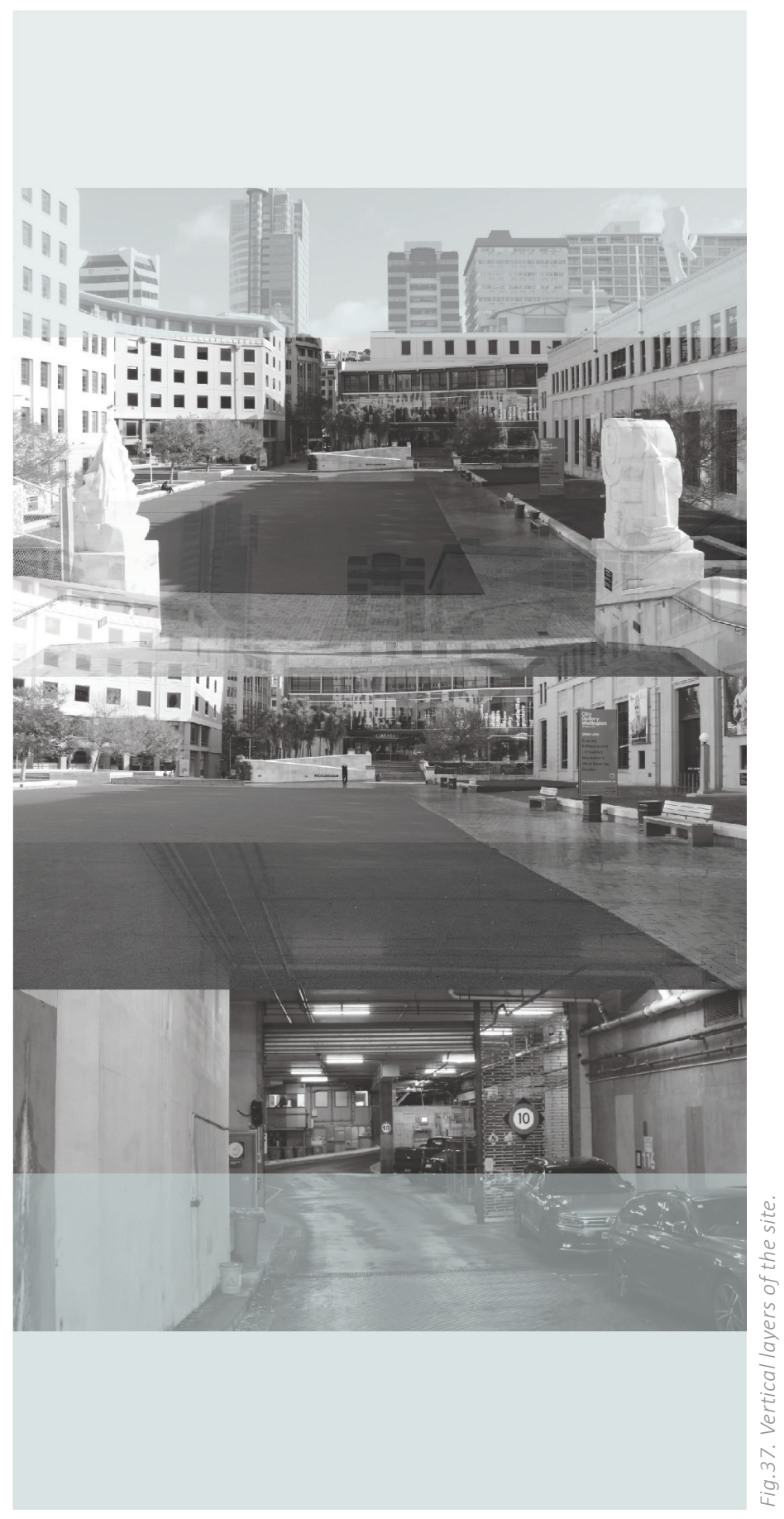




\section{SITE ANALYSIS (THE PRESENT) CONCLUSION}

\section{CHOSEN SITE}

Upon analysing the site in its current state, the chosen area for design redevelopment is the walkway that connects the northern entrance of the site to the Eastern, as indicated in figures 38 and 39.
This location provides prime opportunity to explore the qualities of critical regionalism and embodiment, as it is significantly subjected to the site's contextual conditions of wind, sun, and view shaft exposure. This chosen area also encourages an enclosed public square, as currently the north eastern is the only open expanse of the site. Developing this edge of Civic Square enables the square to become an intimately enclosed interior space.

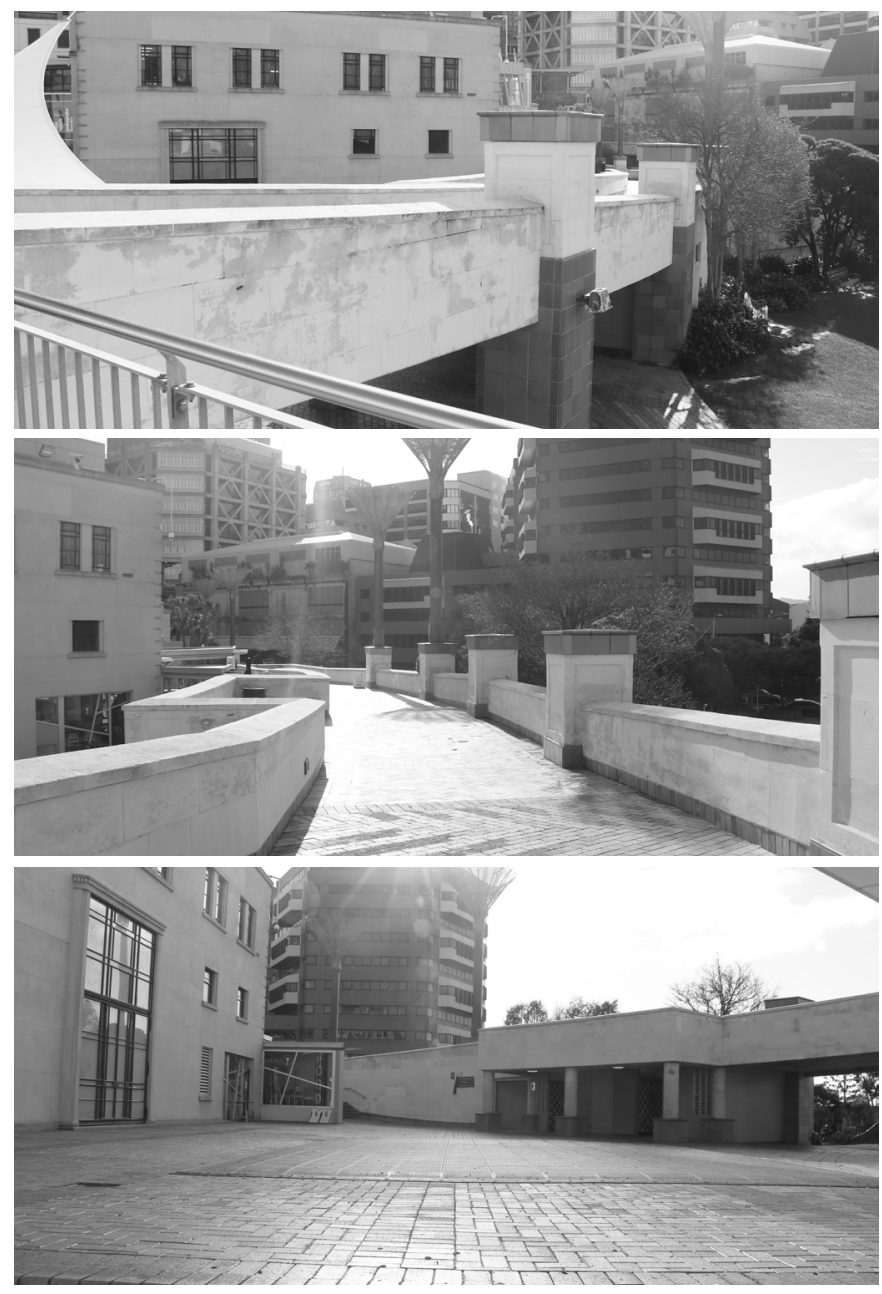

Fig. 38. Chosen site. 


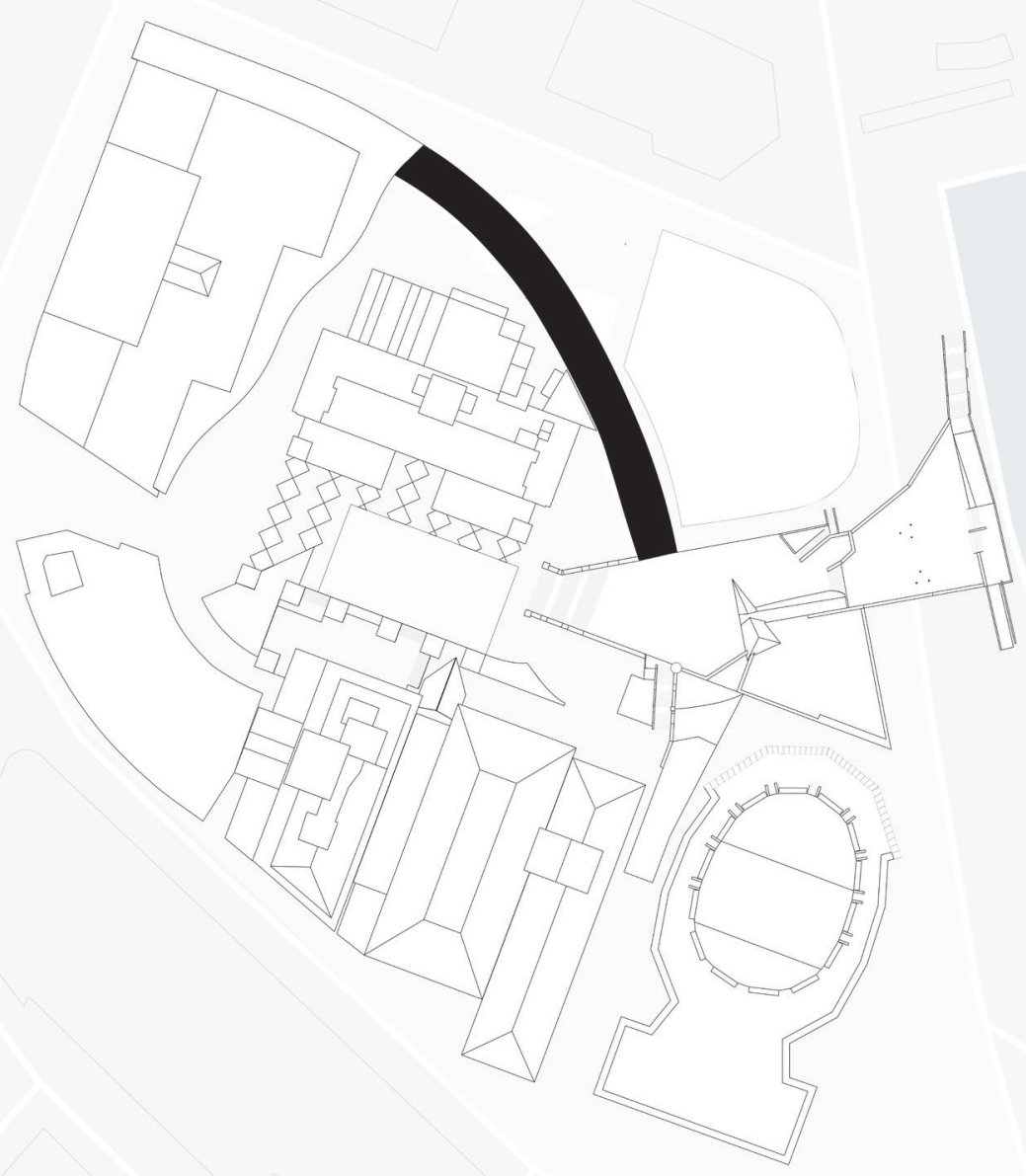

$\Lambda$

Fig.39. Chosen site.

SITE SELECTION

EXISTING SITE WALKWAY 


\section{5}

\section{CONCEPTUAL DESIGN DIRECTION}

This chapterfocuses onfostering identity construction through building from the research in the theoretical context chapters, specifically conceptualising the theory of the past. Drawing on the researched narrative of Civic Squares past, this chapter investigates methods for translating the intangible nature of the past into tangible form. This process looks to establish strategies and design techniques to facilitate the conceptual design development, searching for an innovative approach toward integrating the narrative of Civic Squares past into the bones of the final design. 


\section{WAI - Water}

As previously stated, pre colonisation, water was, and still is for Māori, the essence of all life. This connection Māori hold with the water alongside the direct site significance of water regarding the land reclamation project, has given well founded reason to use water as a key driving force in the initial design process.

The conceptual notion of water is explored through questioning how the fluidity of water can be introduced into the tectonics of architecture. These three water colour paintings demonstrate my thought process where I look to conceptually transition the abstract notion of water from fluid to tectonic (figure 40). These paintings then influenced further research into defining the design properties of water in which I assigned the key words of layering, flux, and tessellation to its meaning.

Layering, Flux and Tessellation have been identified to reflect the parameters of water and thus, can be used as design parameters moving forward, conceptualising the notion of water in an non explicit manner. 

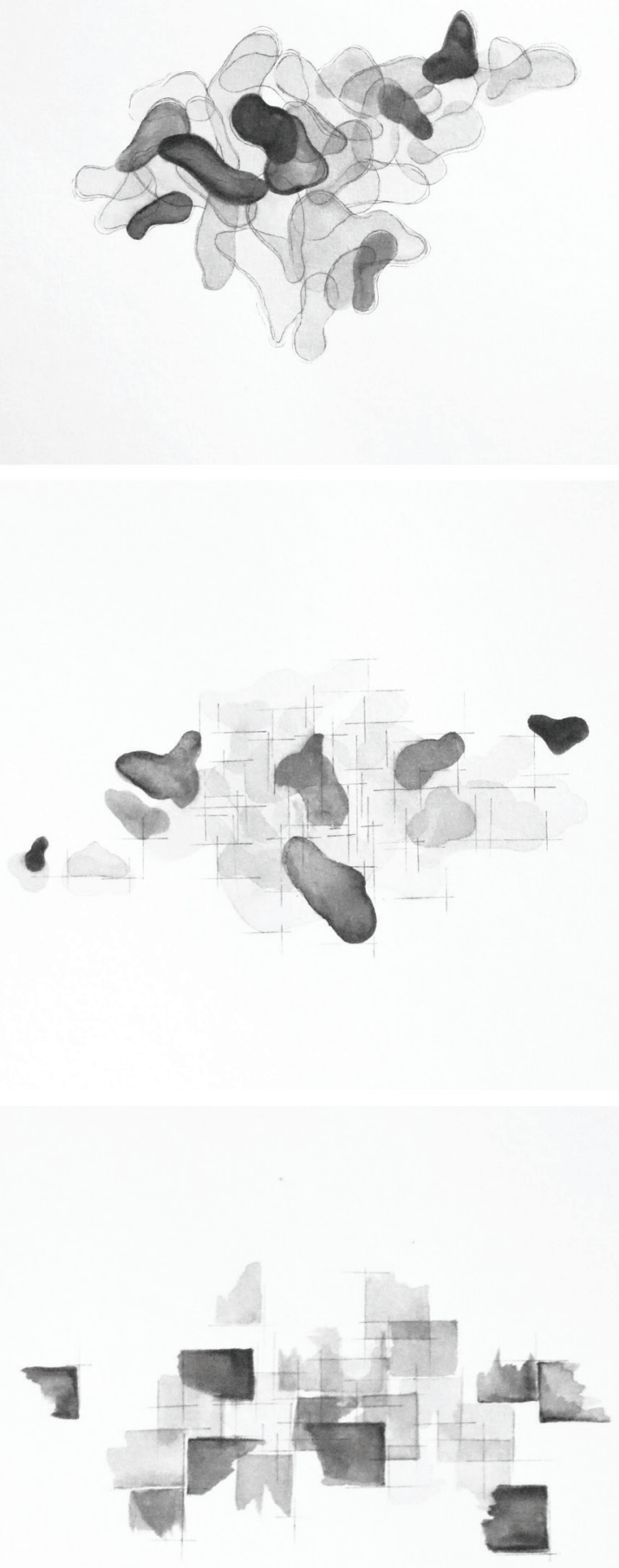

TRANSITIONING FROM FLUID TO TECTONIC 
CONCEPTUALISING NOTIONS OF THE PAST

Transitioning from fluid to tectonic

\section{LAYERING}

Noun

To form or arrange one thickness of something over another.

\section{FLUX}

Noun

1. A flowing or flow.

2. The flowing in of the tide.

3. Continuous change, passage, or movement.

\section{TESSELLATION}

\section{Noun}

A tessellation is created when a shape is repeated over and over again. There are three types of tessellations: Translation, Rotation, and reflection.

1. Translation - A tessellation which the shape repeats by moving or sliding.

2. Rotation - A tessellation which the shape repeats by rotating or turning.

3. Reflection - A tessellation which the shape repeats by reflecting or flipping. 

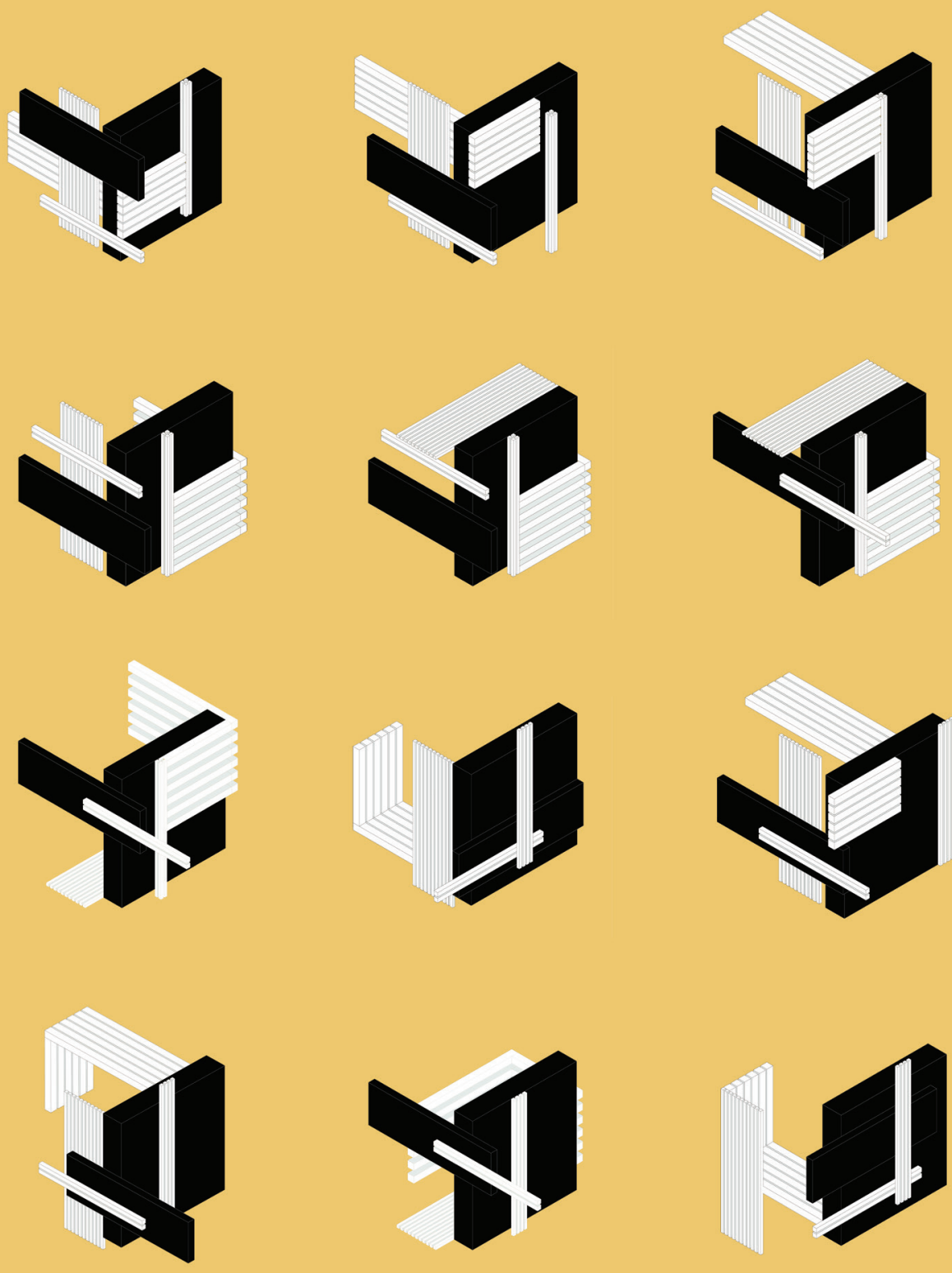

LAYERING + FLUX + TESSELLATION 
CONCEPTUALISING NOTIONS OF THE PAST

\section{LAYERING, FLUX \& TESSELLATION}

Leading on from the modeling exercise I began intuitively sketching using these same design properties, creating these visuals composed of the layering of lines (figure 42). Through exploring the tectonic expression of water in my drawings, a visual connection to the concept of weaving become significantly evident. The design principles I associated with water correspondingly aligned with the design principles of weaving. This prompted further research into the notion of Māori weaving and the significance of this motif to site. 

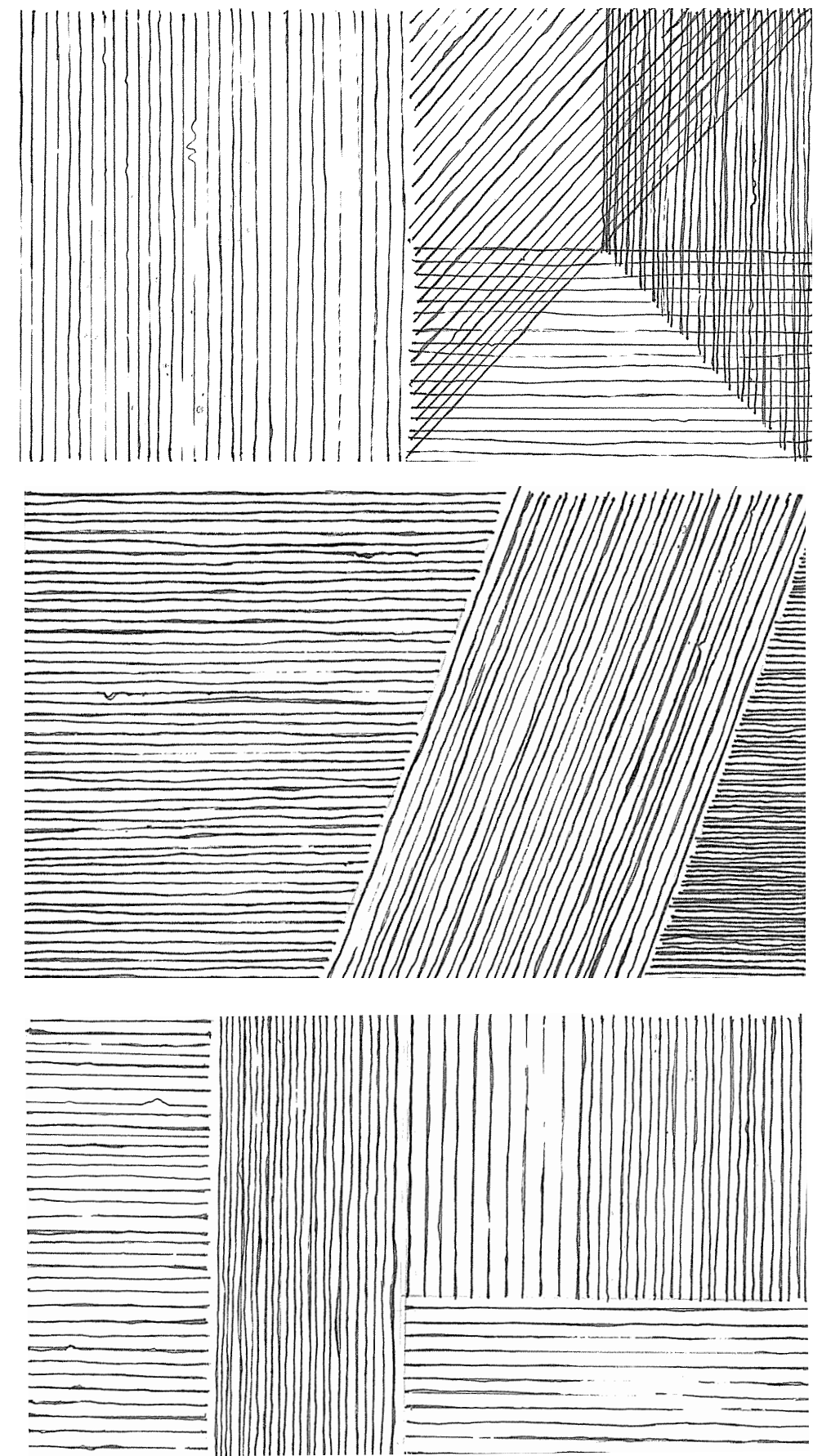
CONCEPTUALISING NOTIONS OF THE PAST

\section{THE TRADITIONAL ART OF MAORI WEAVING}

The motif of weaving is held valuably in Māori culture. Its pattern is embraced as strands of the land, stories, and ancestors, weaved together to form the foundation of Māori identity (Rongowhakaata, 2017). With regard to the site, weaving is of great significance. When the site was a coastal settlement pre-colonisation, weaving, also known as lashing, was used as the structural binding for wakas. This pattern of lashing is there for remembered as conveying memories and experiences as well as carrying one from place to place.

"The strands of our wheua tipu, Korero, and tipuna - land stories and ancestors weave together to form Te taka pau Rongowhakaata, the foundation of our identity."

Te Takapau a Rongowhakaata (Rongowhakaata, 2017). 

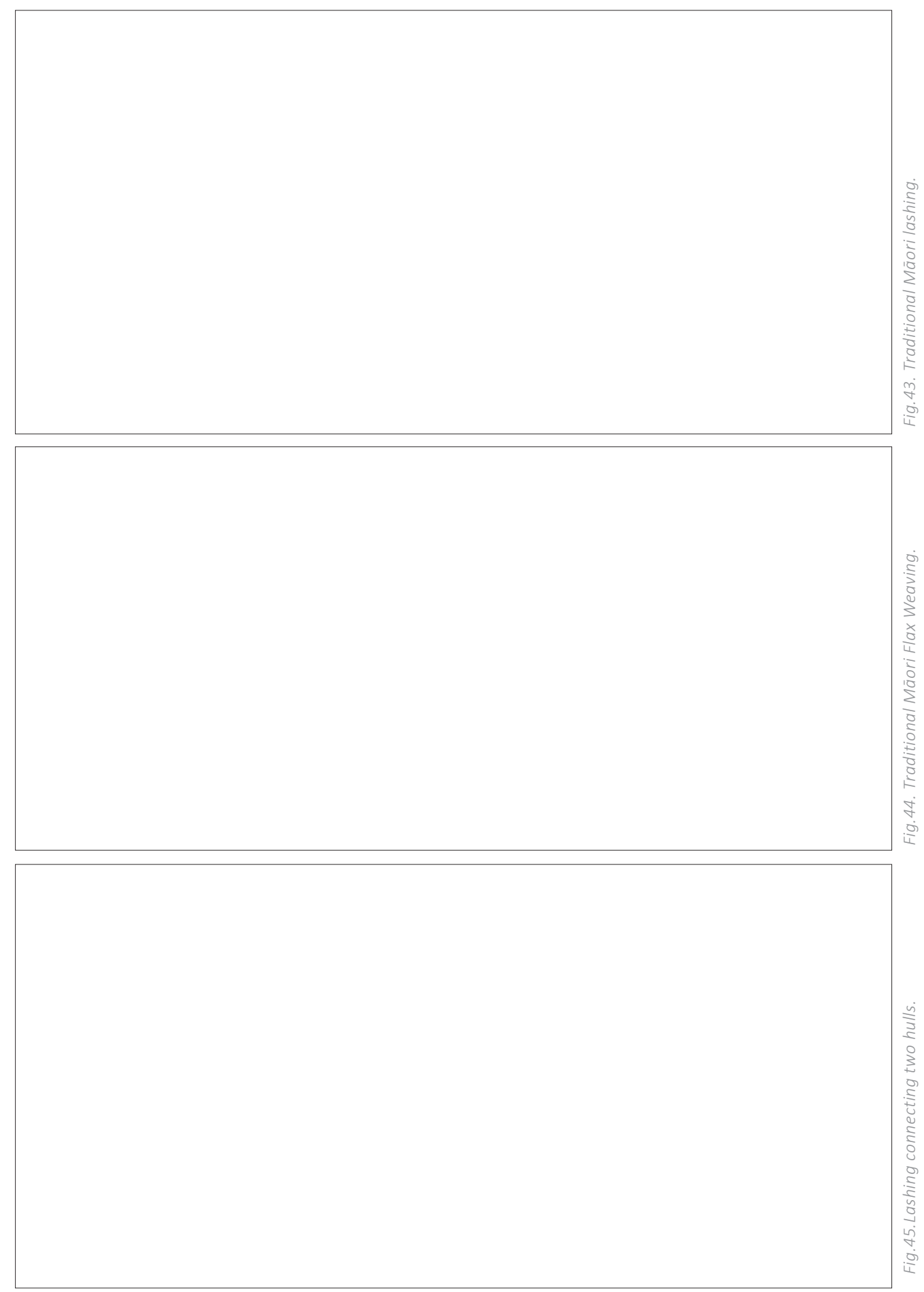


\section{TRANSLATION}

Upon researching methods towards transforming the cultural motif of weaving from art to architecture, the concept of translation transpired. The concept of translation looks at the idea of using the Māori motif as an act of respect rather than appropriation (F. Pound, 1994).

In the 1994 publication "The Space Between," Francis Pound develops an understanding of the ways in which one may approach the transformation of cultural motifs from object to image. In his publication, Pound questions the work of key Pakeha artists from the 1930s to 1950 s as a way of analysing varying approaches to the idea of "primitivism," while also addressing notions of cultural appropriation and its presence in New Zealand art during this time period (F. Pound, 1994).
Of key relevance to the design progression of this thesis is the chapter centred around the notion of translation. Pound makes use of the methods of philosopher Jacques Derrida to give grounds to the idea that the translation of Māori motifs is an act of respect, further offering that translation is a necessary process in the adulation of the original. This means that if an original work is to evolve through the notion of translation, the work must endure the process of critique, reworking, interpretation, and revitalisation (F. Pound, 1994). This defined process of translation seeks to extract the original (traditional Mãori weaving) to revitalise its cultural image. 
TRANSLATION CASE STUDY

Te Kaitaka, Auckland (2014)

Te Kaitaka is a property sales and marketing suite located in Auckland, designed by Fearon Hay Architects in 2014. This building has a symbolic design influence of the prestigious 'Kaitaka.' Kaitaka is a woven cloak made of muka (flax fibre) strands. The interwoven strands of the Kaitaka have been architecturally translated in the design of this building through the use of an interlocking steel mesh system. This mesh system drapes down form a green roof of which featuring native coastal grasses and flaxes (figure 46). The initial intent of this building was to revitalise the surrounding area for a growing urban community of which the precedence of the cloak was intended to stand as a precedent for new architecture (Fearon Hay Architects, 2014).

Fearon Hay approached this design using common building techniques paired with a newly developed system to demonstrate a greater level of craft. The development of the steel cloak was carried out by separate designers, Cameron McAuley \& Justin Groves. McAuley and Groves moved through the design process in a developmental, hands on manner in order to convey the Kaitaka's movement, sheen, vibrancy, and flexibility. As designers they connected physically and directly with the intricate craft of the Kaitaka in order to provide a successful architectural outcome for the symbolic façade of this building (Aasarchitecture, 2014).

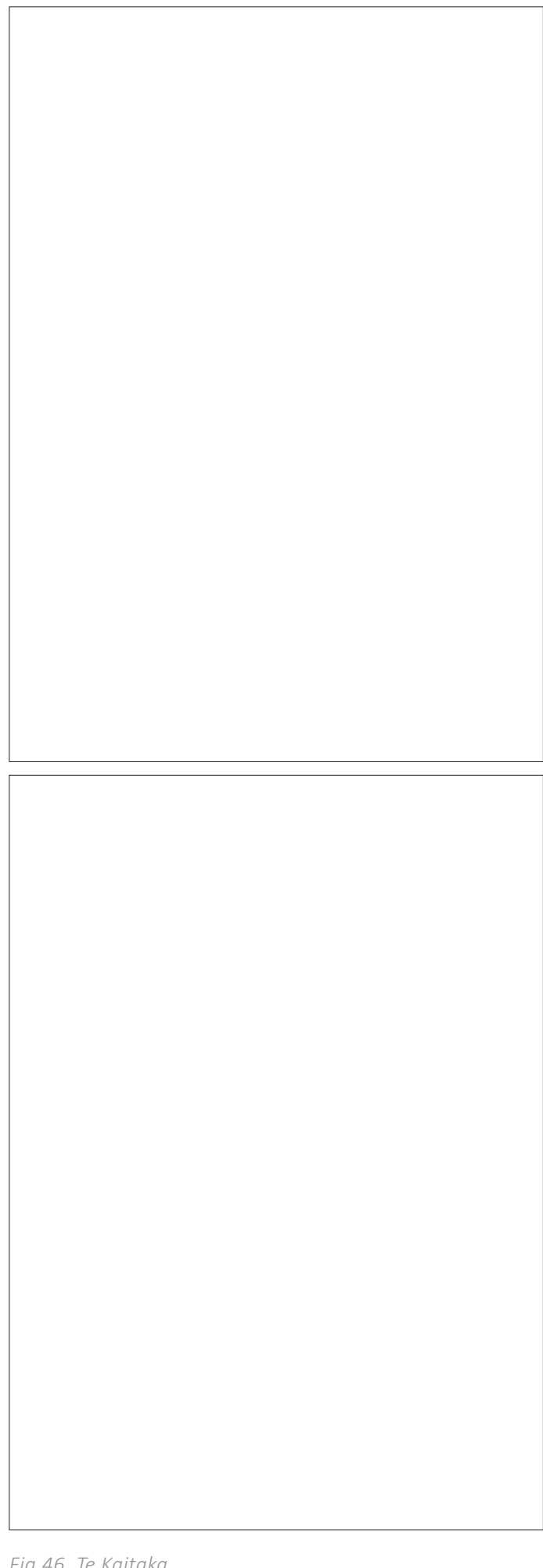


TRANSLATION CASE STUDY

Kopupaka Reserve, Auckland (2016)

Kopupaka Reserve designed by Isthmus Group, expresses a powerful gesture to Māori culture through design. Kopupaka is an Urban Wetland project of which serves the purpose of both a storm water filtration system and an urban park. The Wetland respectfully acknowledges Māori Culture through design in translating the concept of hinaki (eel baskets) which innovatively take on the architectural form of a river - wall system (figure 47). The overall design of this urban space is based upon Māori design principles with overlapping references to the horticultural history of the site. The integration of public amenities such as walkways, bridges and lookout points are intended to ensure the narrative of the site will continue to evolve as social and recreational engagement continues to change (Isthmus, 2016).

This urban reserve not only provides a place for social interaction, but also appreciably values the ecology and health of the landscape. The key design innovation of this architecture is the dynamic integration of both large scale landscape infrastructure alongside the smaller scale elements incorporated for human interaction This case study explores a balanced cultural and environmental approach to design. 


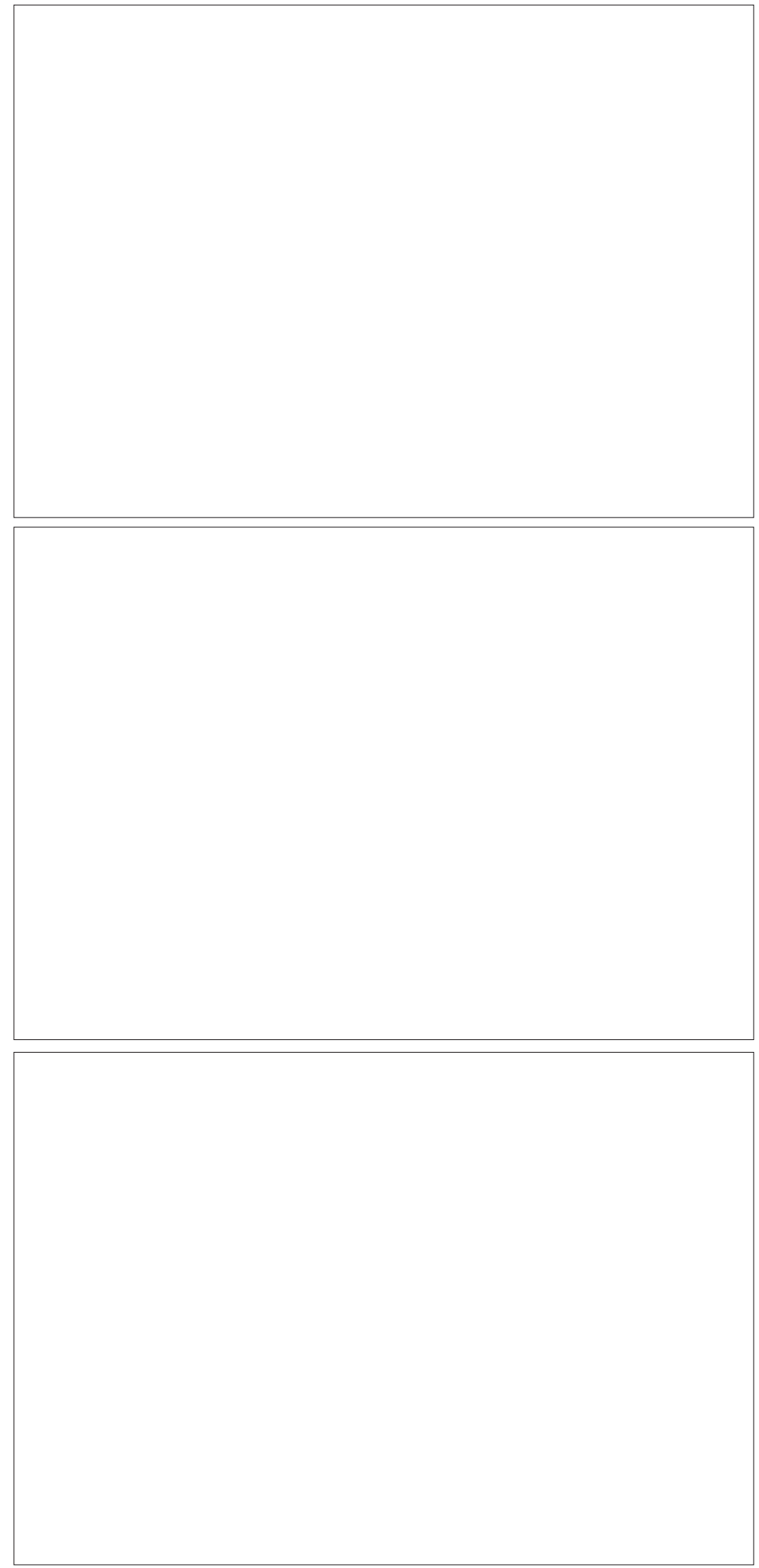

Fig.47. Kopupaka Reserve. 
SOPOLEMALAMA FILIPE TOHI

\section{TRANSLATION}

The relevance of Sopolemalama Filipe Tohi's sculptural work as a case study is primarily drawn from his methods of translation, but also the specific cultural motif of which his work surfaces from. Tohi is known for studying the Tongan traditional art of lalava, a decorative rope lashing (D. White \& K. Johnson, 2004). Tohi has diligently studied the complexity of Tongan lashings, design patterns, and in essence a cultural language. This concept of lalava is in the same nature of traditional Māori weaving, thus Tohi explains the sense of identity this cultural motif renders, "I like the patterns the lashings make because they remind me of how Pacific people are connected," he says. "The rope is like an umbilical cord that binds canoes and houses and people together." (F. Tohi, 2016).
The method of translation is greatly explored within Tohi's work, as shown in figures $48,49,50$. Filipe Tohi reverses, rotates, and unravels customary lalava patterns, emphasizing their infinite possibilities. This a very similar process to that of the previous mass modelling exploration of layering, flux, and tessellation (figure 41). 

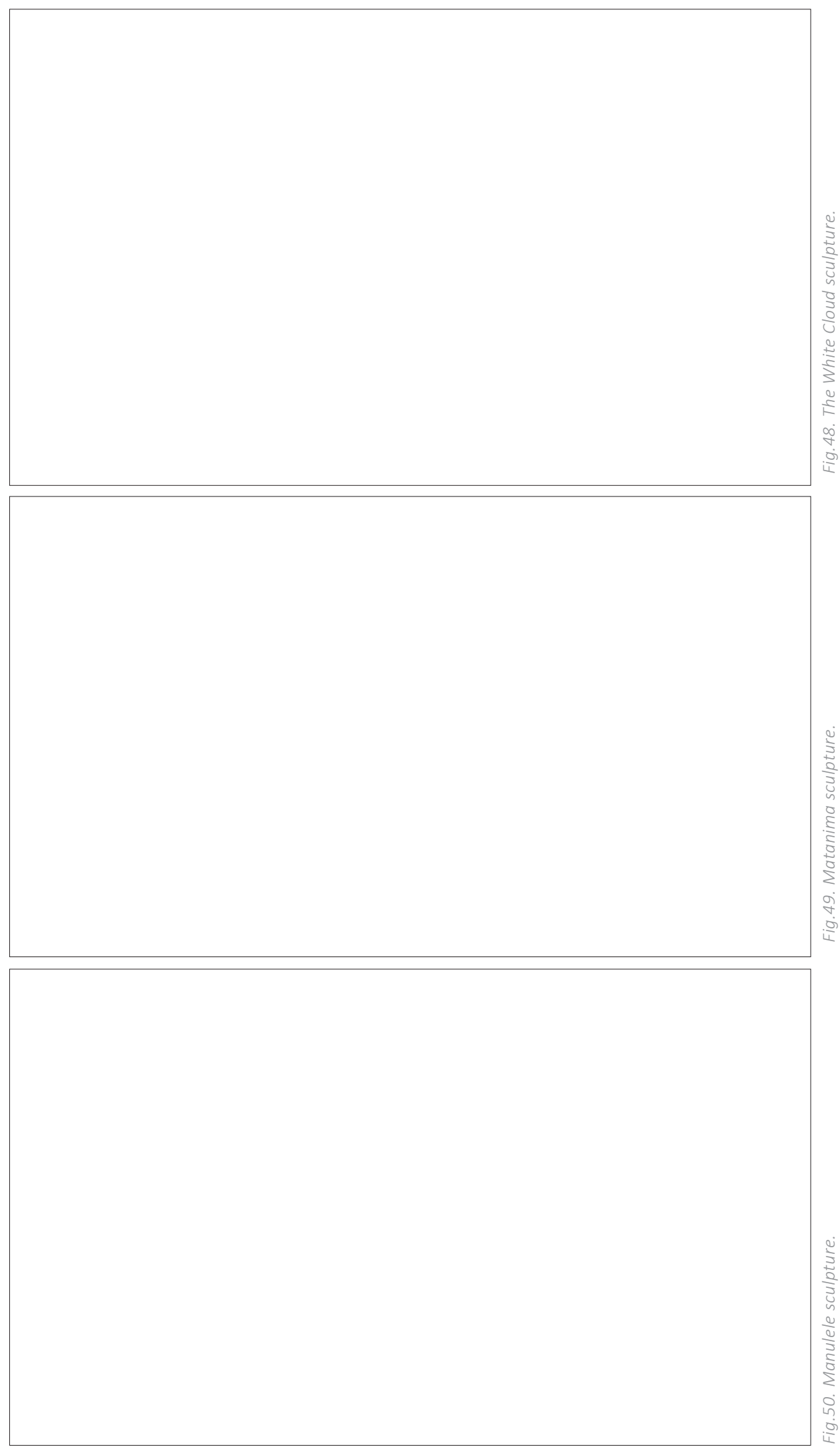

FILIPE TOHI

THE ART OF LALAVA 


\section{ENGAGING IN THE NOTION OF TRADITIONAL MAORI WEAVING}

\section{ANALOGUE PROCESS}

In re - entering the design process following this theory of translation, I began with finding form through drawing. Figure 51 explores this idea of translation. This drawing has been generated with the intention of copying the visual of weaving, following the translation methods of Pound, "No translation would be possible if in its ultimate essence it strove for likeness to the original." Pound explains that within the culture of copying, comes mis-transcription. Within these mistranscriptions, new potentials for translation are presented (F. Pound, 1994). Thus, the act of copying is the beginning point in my design process toward translating the motif of weaving into architectural form.
Following on from the notion of copying, the second set of drawings (figure 52) works at identifying a method of drawing that aligns more closely to the technique of weaving. This set of drawings exercises the method of weaving in which the process both inscribes meaning and layers over new information. Adjusting tension and tightening the flax could be deemed similar to the action of increasing pressure on the drawing tool. From this exploration it can be concluded that the act of weaving and the act of drawing become similar through the way in which they are performed and their subsequent layered outcome. The outcome of these drawings illustrates the expression of weaving, showing the more layers added, the greater depth acquired. This act could be further interpreted into architectural construction through the layering of tectonics, adding depth through the interaction between architectural elements.

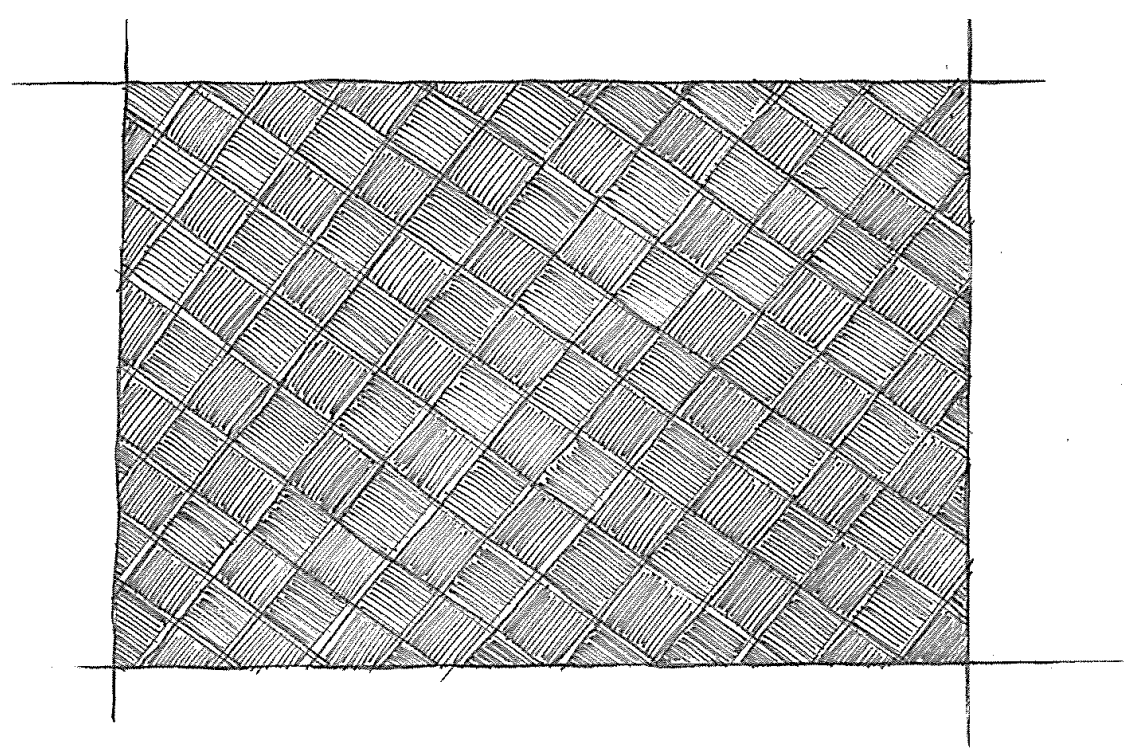




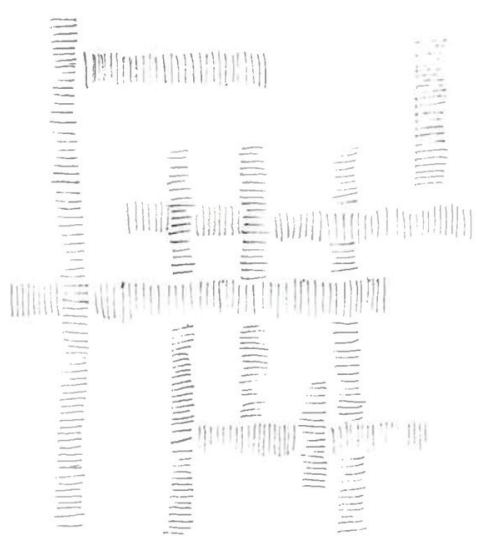

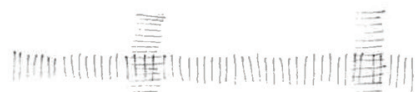

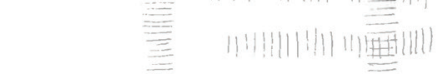

$$
\begin{aligned}
& \text { 言 }
\end{aligned}
$$

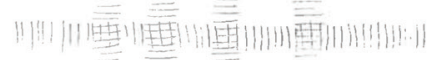

$$
\begin{aligned}
& \text { 害 }
\end{aligned}
$$

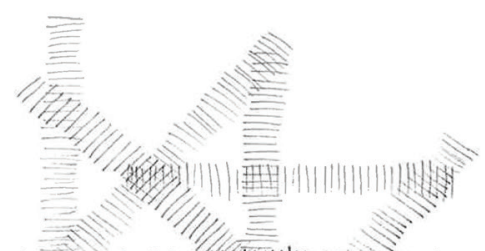

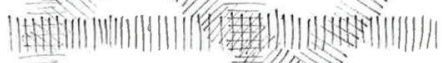
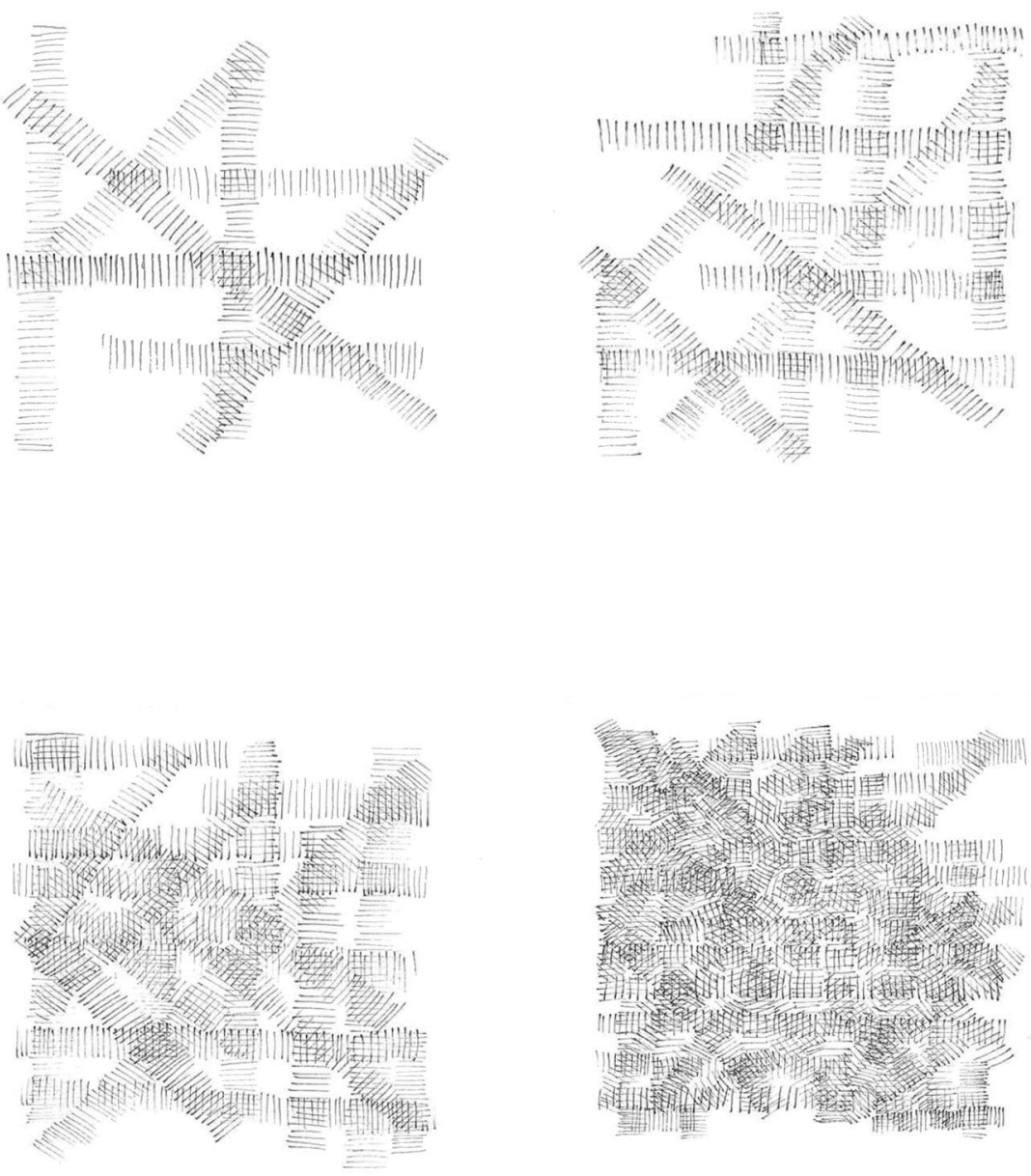

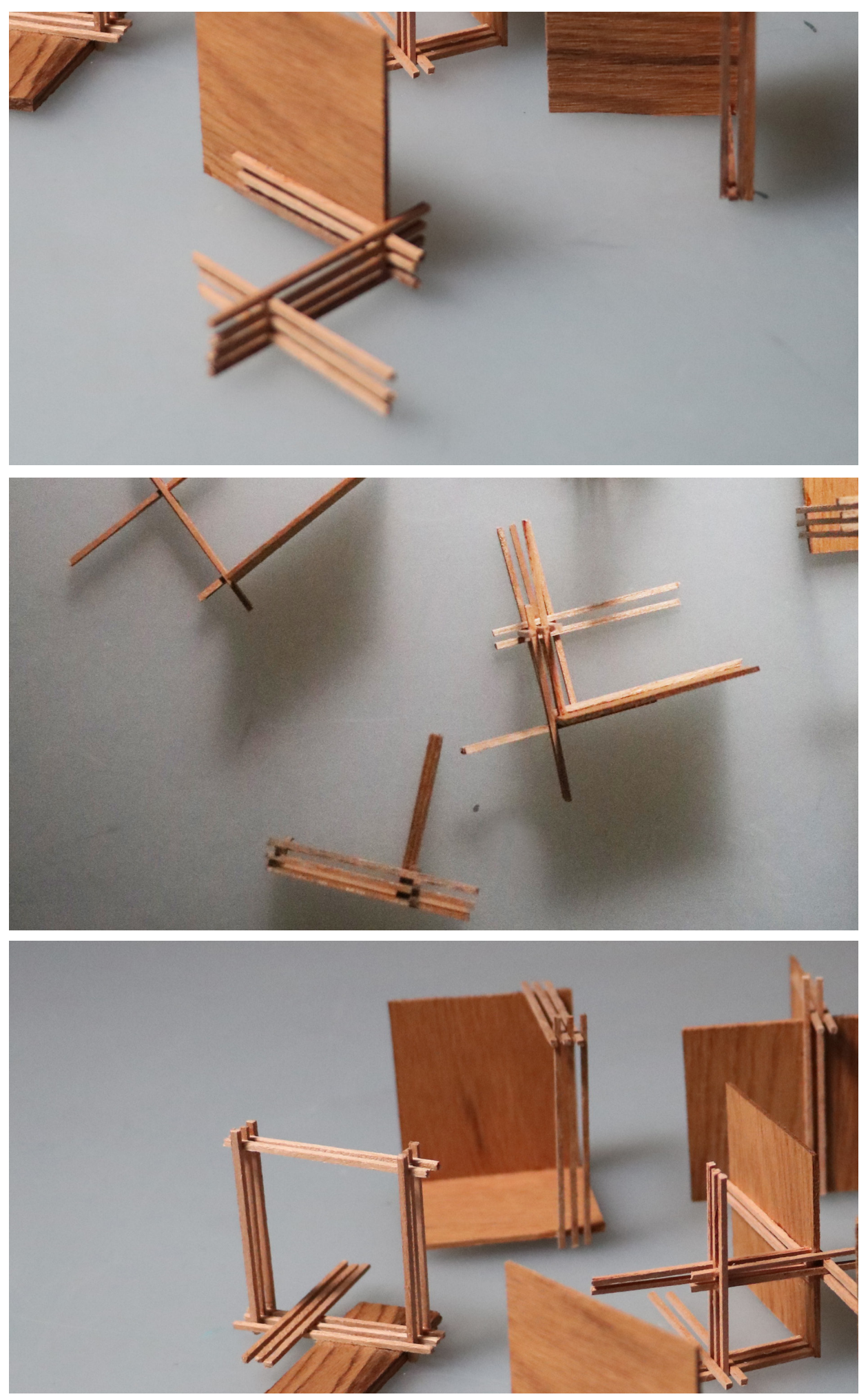

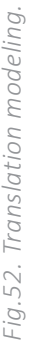

2D TO 3D

MARQUETTE MODELING 
ENGAGING IN THE NOTION OF TRADITIONAL MAORI WEAVING

\section{ANALOGUE PROCESS}

Following the methods of Filipe Tohi, figure 52 illustrates finding form through drawing, and then further turning these drawings into small wooden marquettes (figure 53). These forms work towards taking the tectonics of weaving from two dimensional to three-dimensional form.

The simplicity of these models restricts the layered, interconnected suggestion of weaving. Moving forward to the next stage it is clear that to reach the same visual depth achieved in the $2 \mathrm{D}$ drawing process, a more detailed exploration of the relationship between tectonic and form is needed, looking further into the interplay of tectonic layers . 


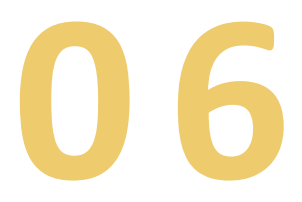

\section{HUMAN SCALE INSTALLATION}

This chapter explores the possibility for small scale design installations to create spatial qualities that emotively activate notions of social identity, place attachment and sense of place. These small-scale iterations implement and review the design techniques established in the previous chapters and work towards fostering a greater relationship between people and place through design. 


\section{HUMAN SCALE INSTALLATION}

The following design development explores four interventions of which each concept plays with the researched design qualities (past and present, critical regionalism and embodiment), looking to reinterpret the sites architectural identity. Theses design explorations are searching for continuity in the face of change where takings from the environment's past and present come together to create a future architectural identity.

The following iterations look to translate the notion of identity into architectural form through incorporating notions of meaning and memory. The cultural context of the sites history and memory is interpreted through tectonic explorations using the design properties of layering, flux, and tessellation, abstractly referencing the composition and motif of Māori weaving. The tectonics of the architectural form in these designs are intended as a recognition of the past, while the present is found in the designs through understanding the interaction between the architecture and the climatic and contextual conditions of the site.

The early stages of the conceptual design process began through sketching using the design properties identified, playing with creating form through a tectonic exploration (Figure 53). 


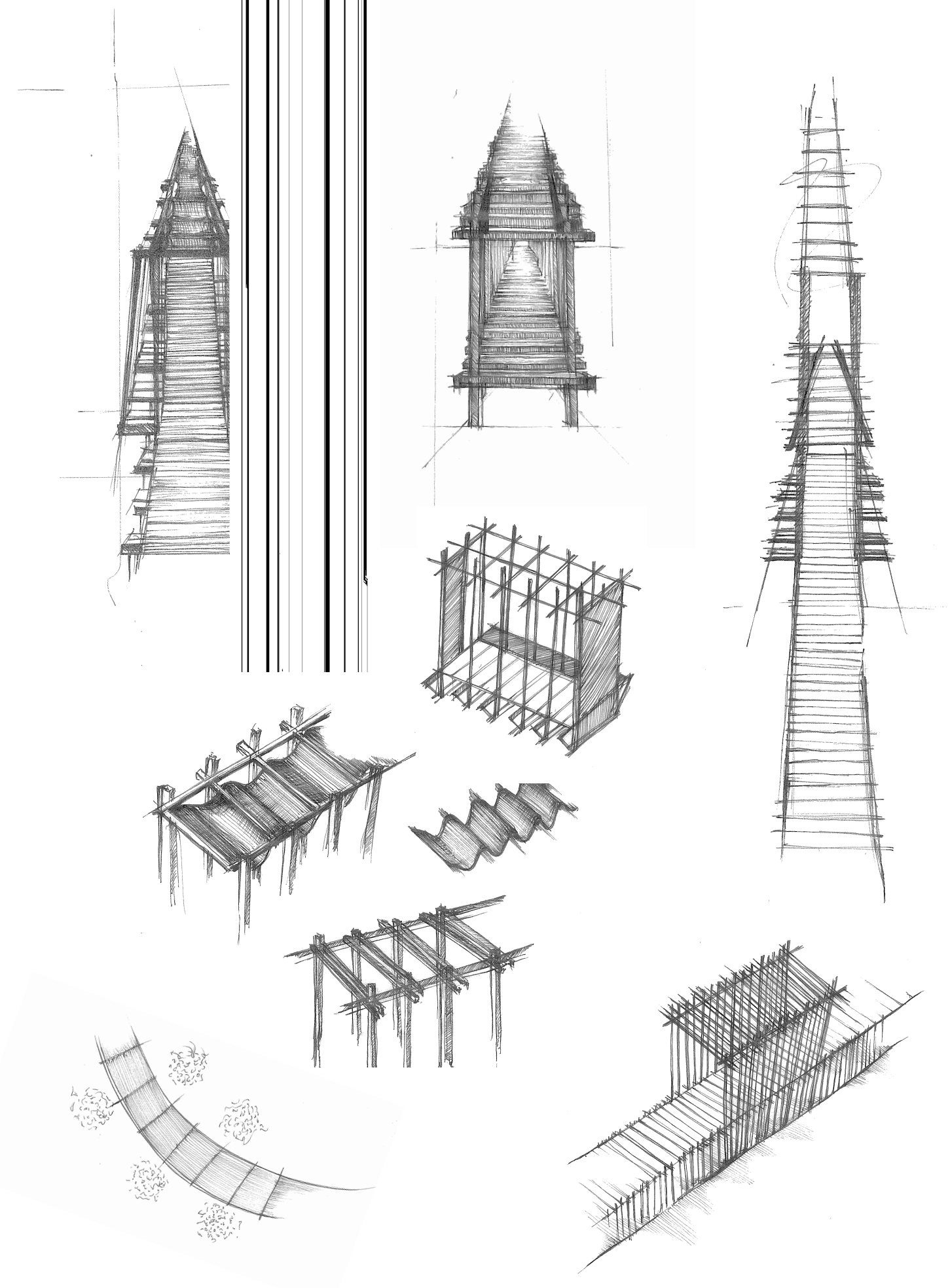




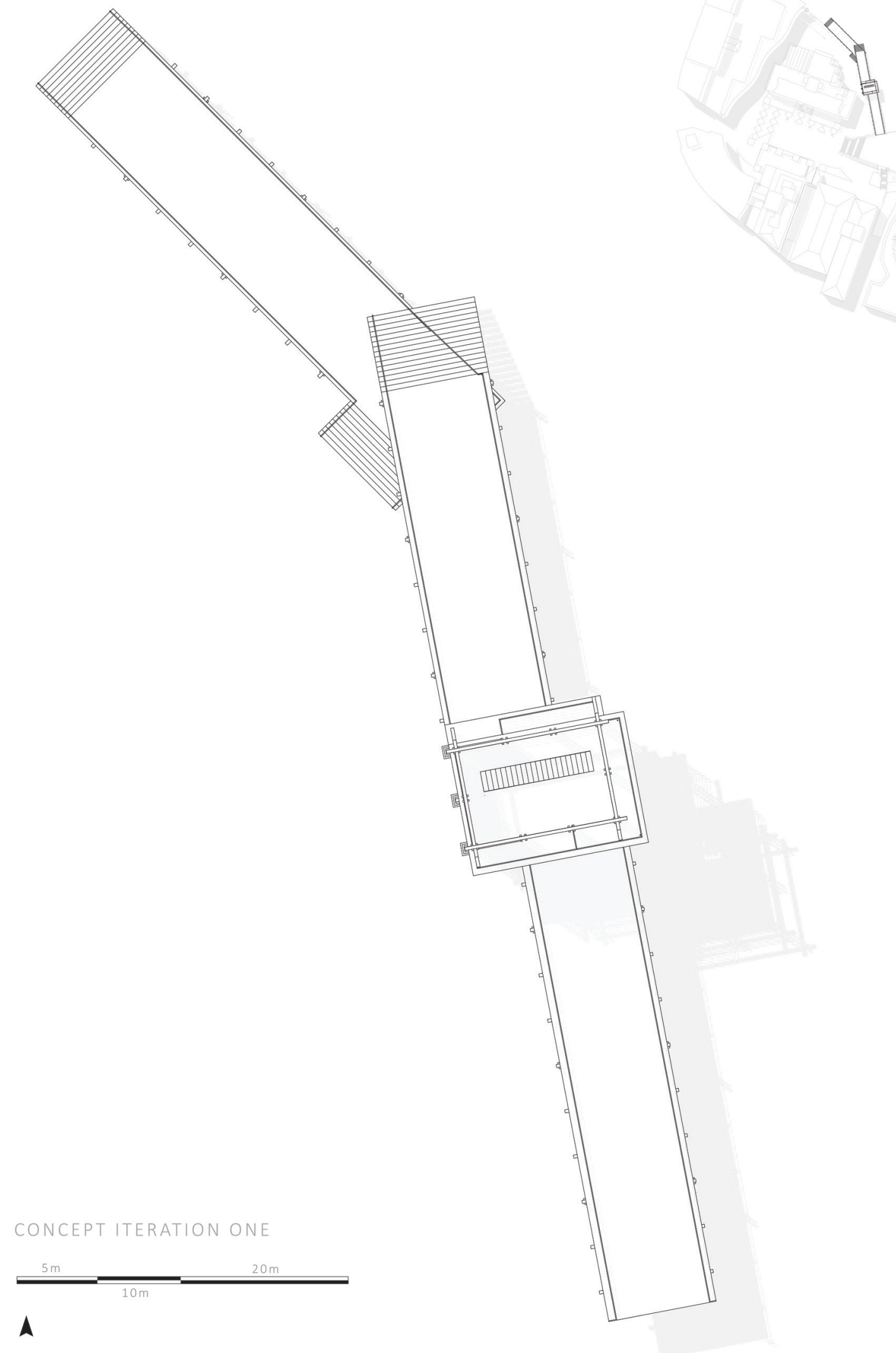



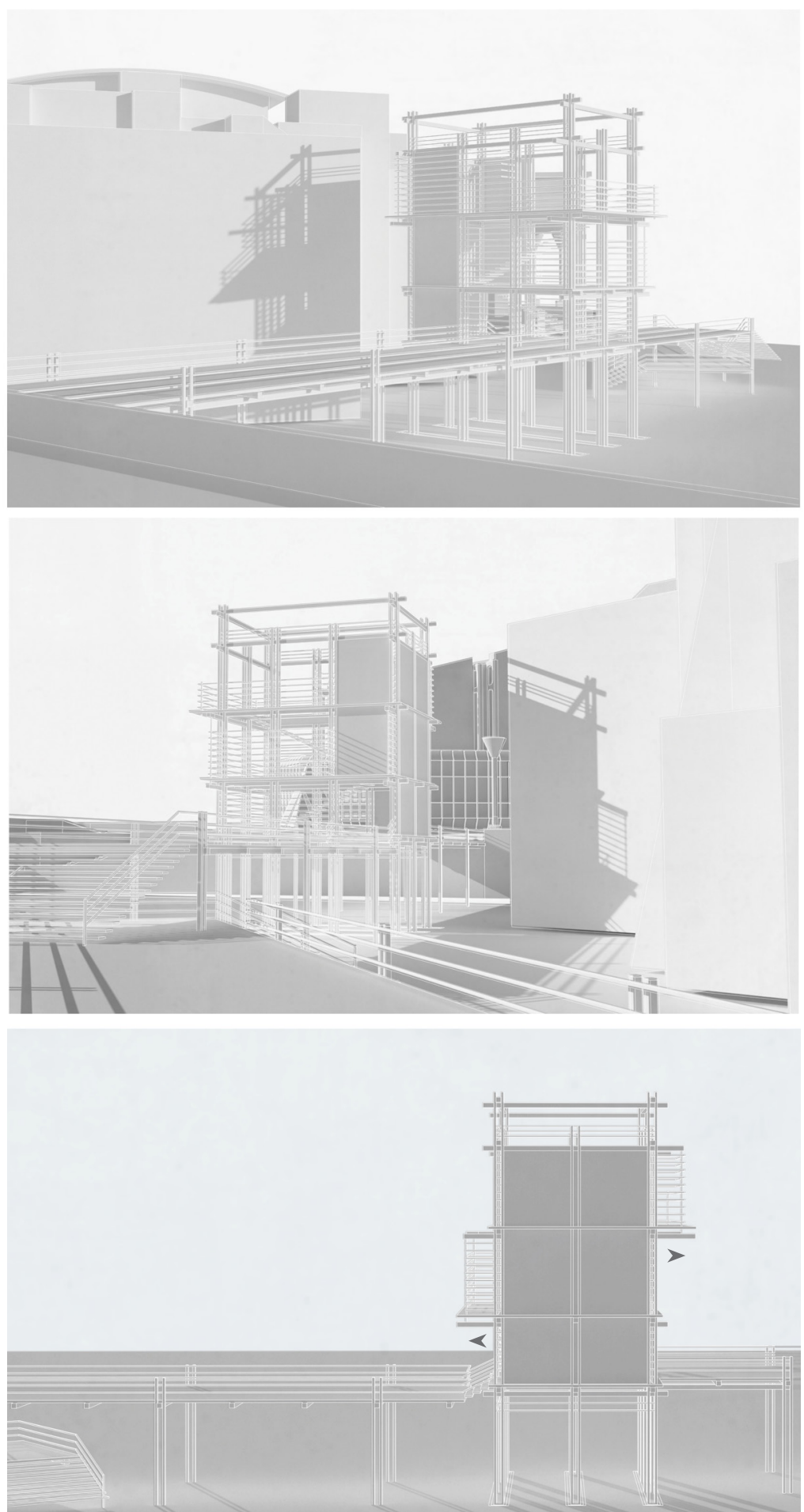

View Shafts

- Mount Victoria >

- Wellington Harbour 

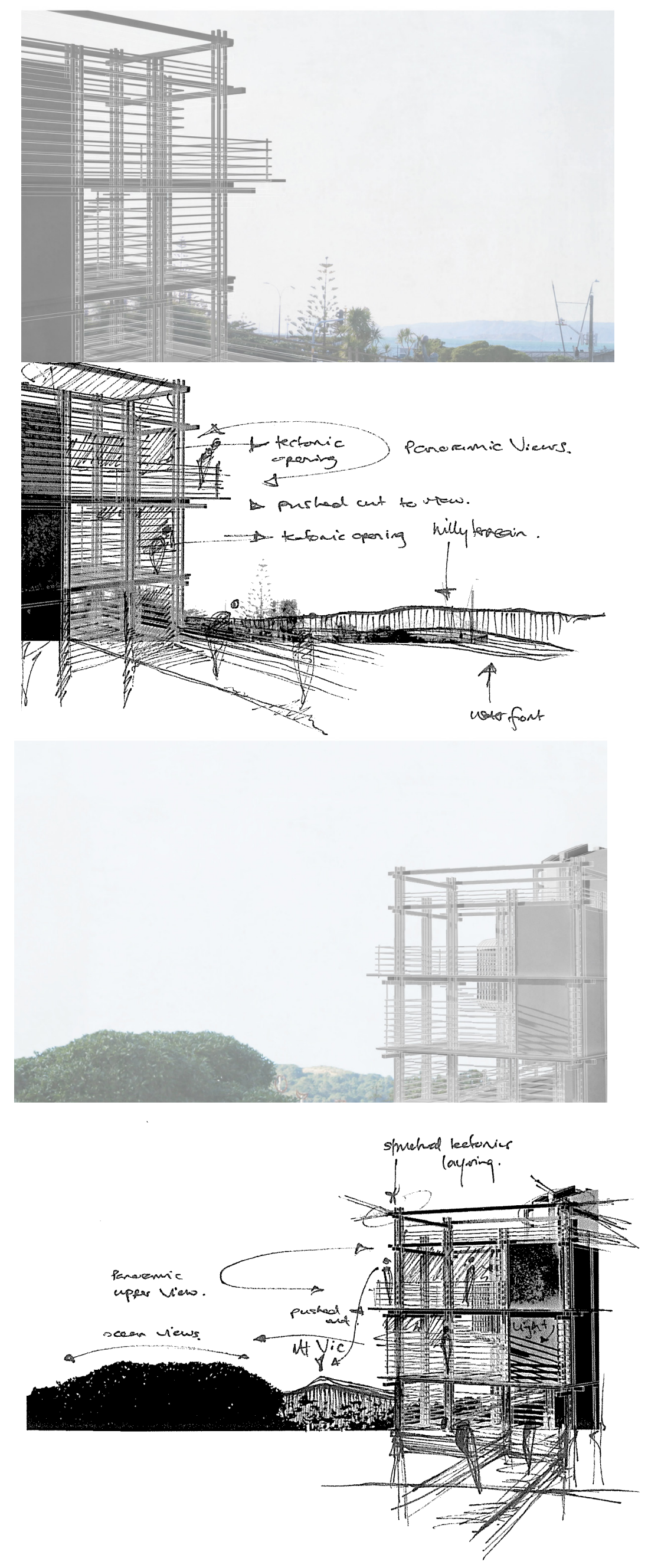


\section{CONCEPT TWO}

Concept Two in plan works in a similar manner to concept one, from which the journey of the pathway shifts again at the same key points as concept one, reflective of the adjacent view shafts.

Concept two follows a simple structure, as the key features of this design revolve around an emphasis on layering. The layered planes alongside the interlocking of tectonic components as seen in figure 58 , further foreground the forms layered composition. The tectonic cuts in this concept again play with natural light, giving the pathway a changing character throughout the day. 


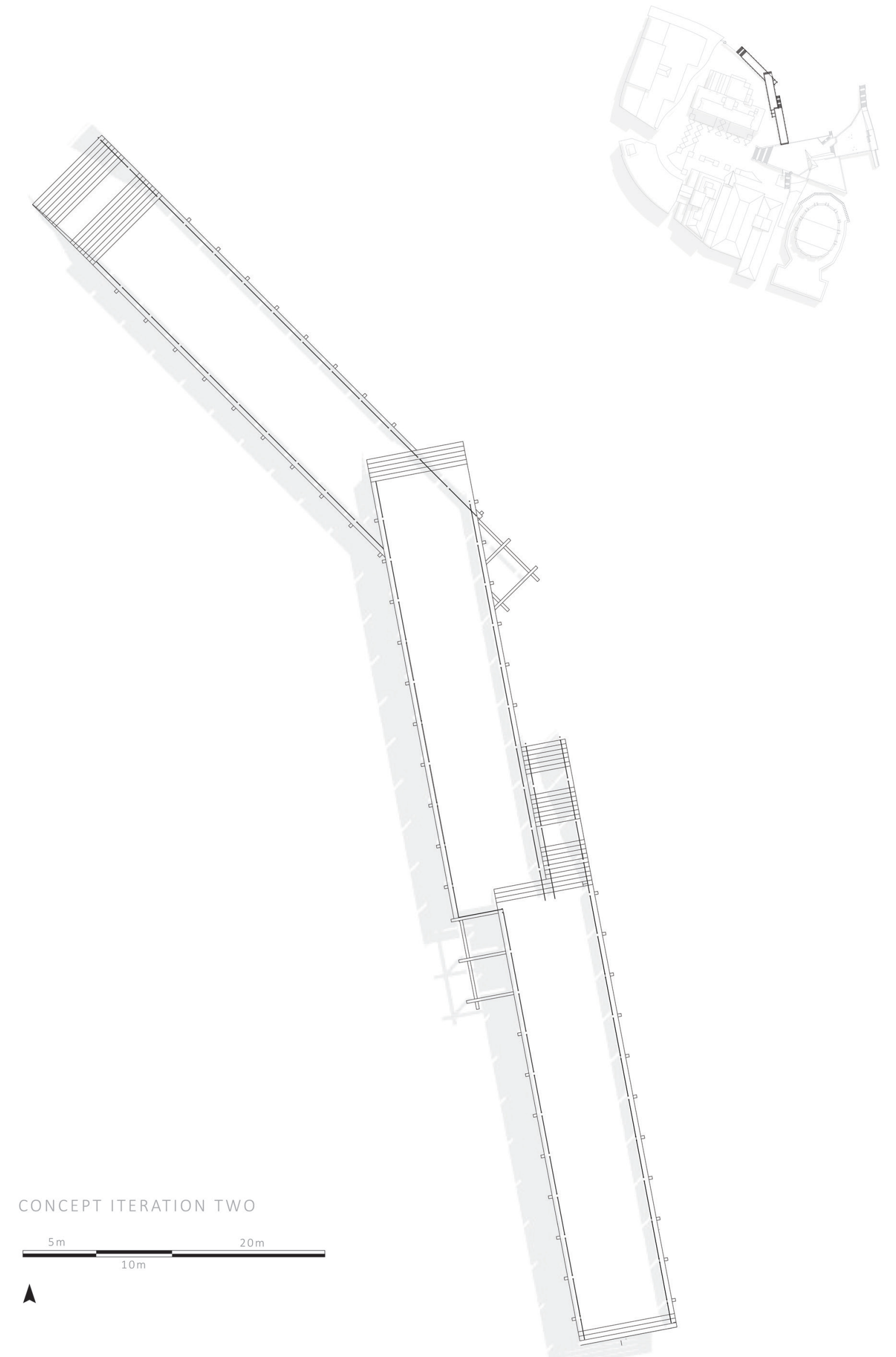



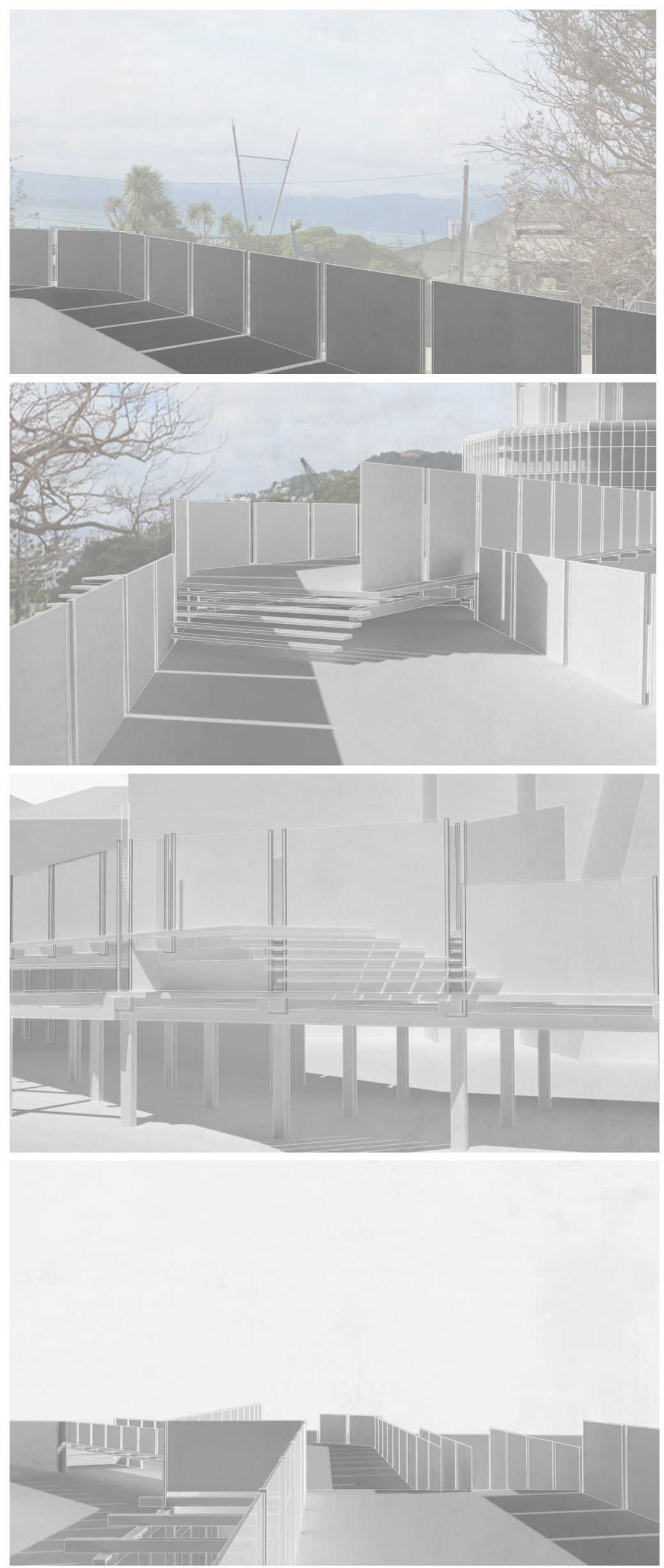

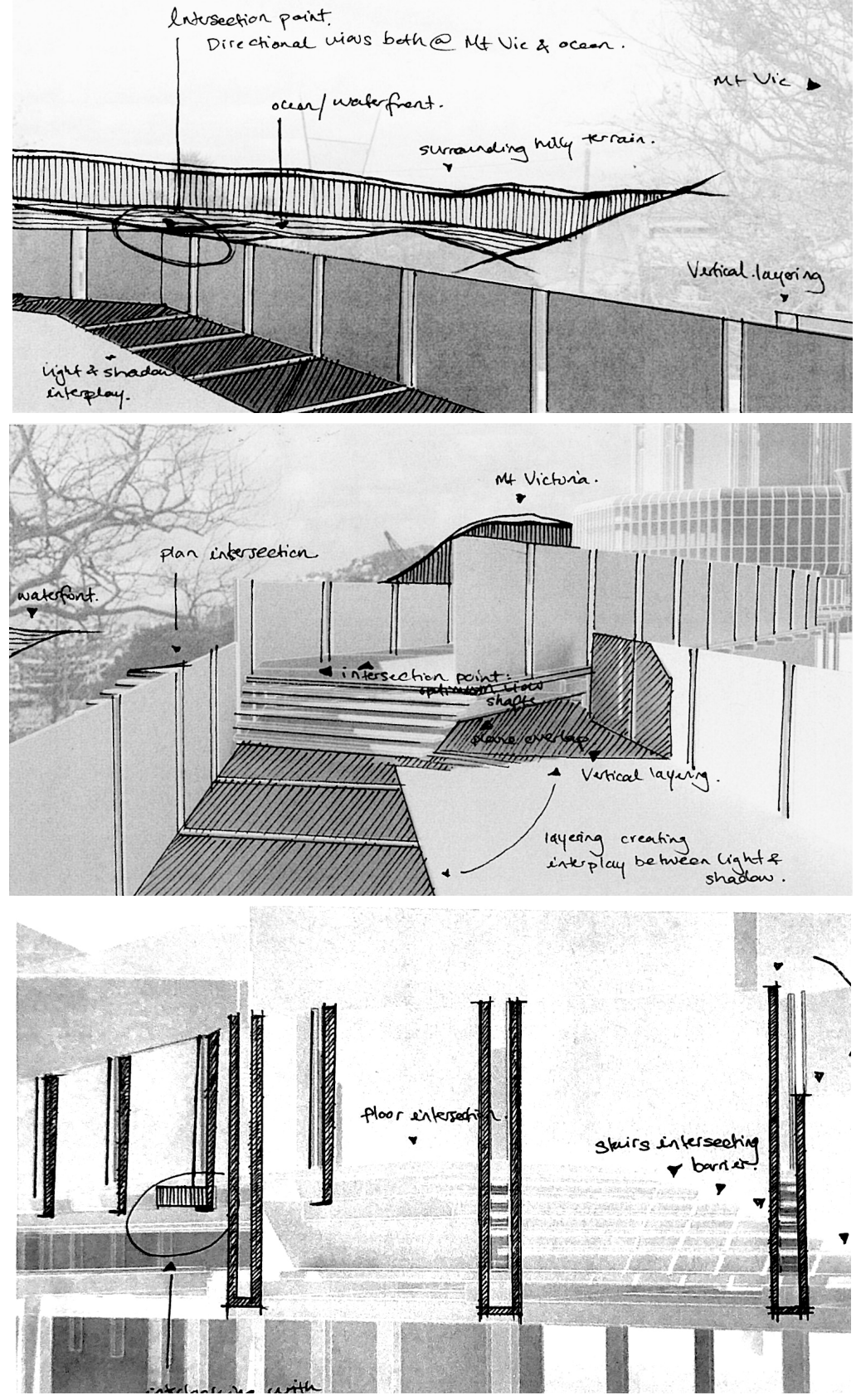


\section{CONCEPT THREE}

Concept three approaches the environment in a different manner to concepts one and two, with greater attention given to creating clean and linear tectonics to provide a simple structure to give focus on the form's interaction with wind. Regardless of the concept's focus on simplicity, the form again shifts forward in plan to capture optimum views.

The shadows generated by the form's tectonic framework (figure 59), though systematic, still generate depth in the layering of shadows. This design seeks to take the contextual surroundings as its main source of inspiration, playing with both wind, light, and shadow. It explores the potentials of an embodied experience through the interactions between the sites prevailing winds and fabric. Fabric is placed in the central third of the design in the upper framework as annotated in figure 60 . 


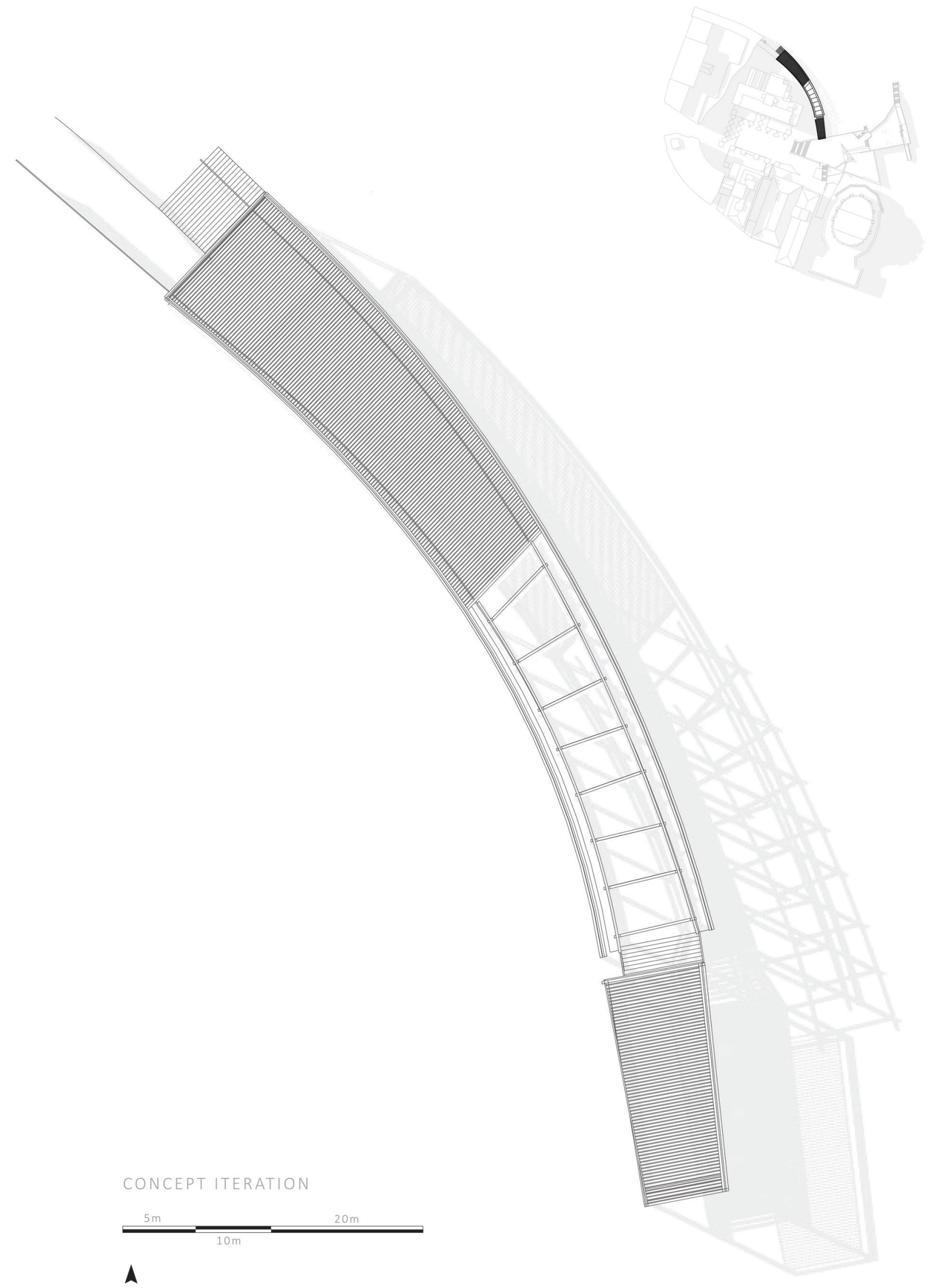



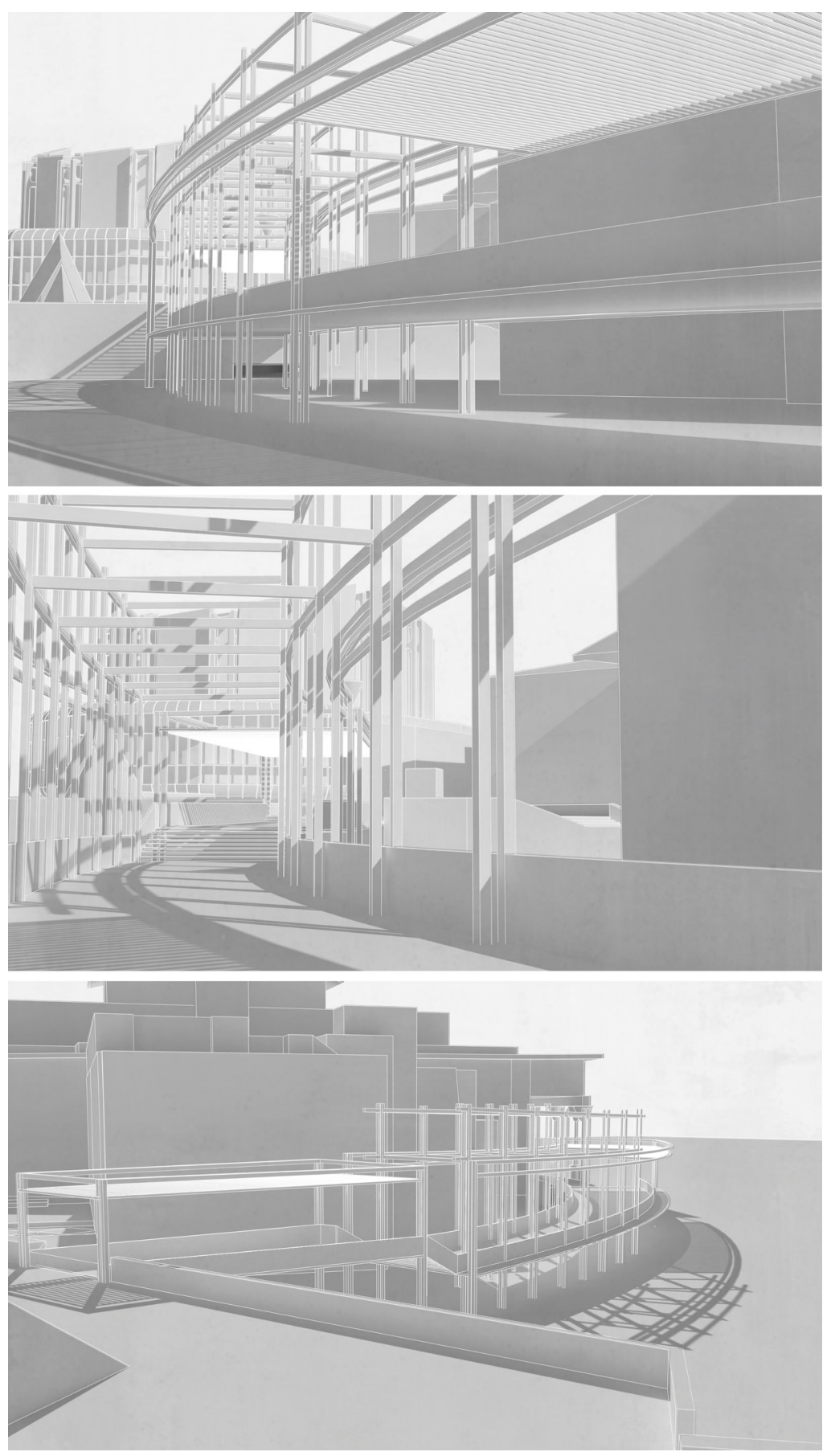


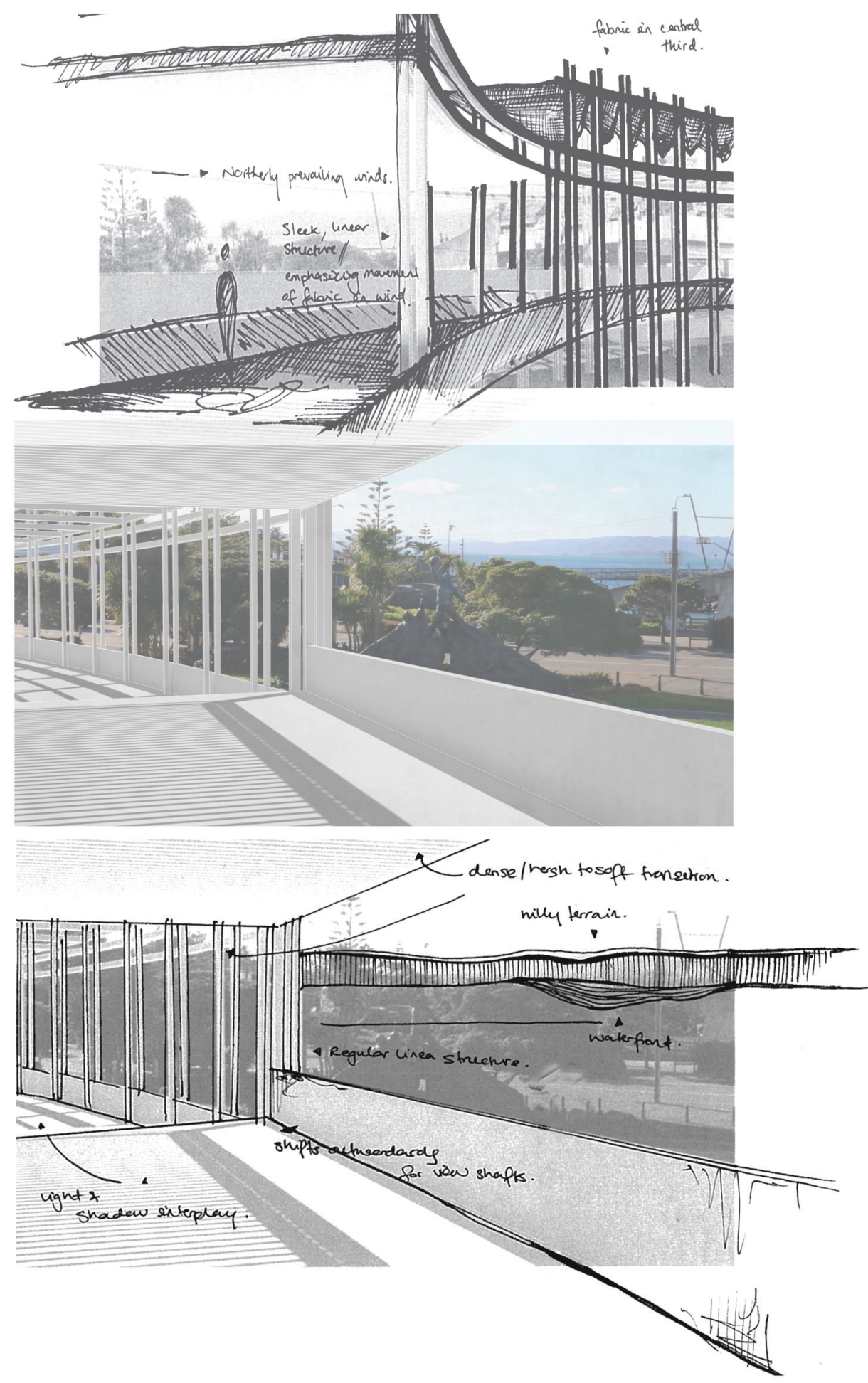


WIND SIMULATION

MODELING EXERCISE

To simulate the prospective interplay between the wind and fabric, the prevailing on site winds were reproduced as shown on the diagram (figure 61) through testing on a physical model.

The outcome of these tests and trials demonstrates the successful effects of the intended on-site interaction between the prevailing winds and the architectural form, illustrating the notion of flux through a dynamic, embodied experience that directly connects with the surrounding environment. This design operates to connect with the senses through both sound and sight. 

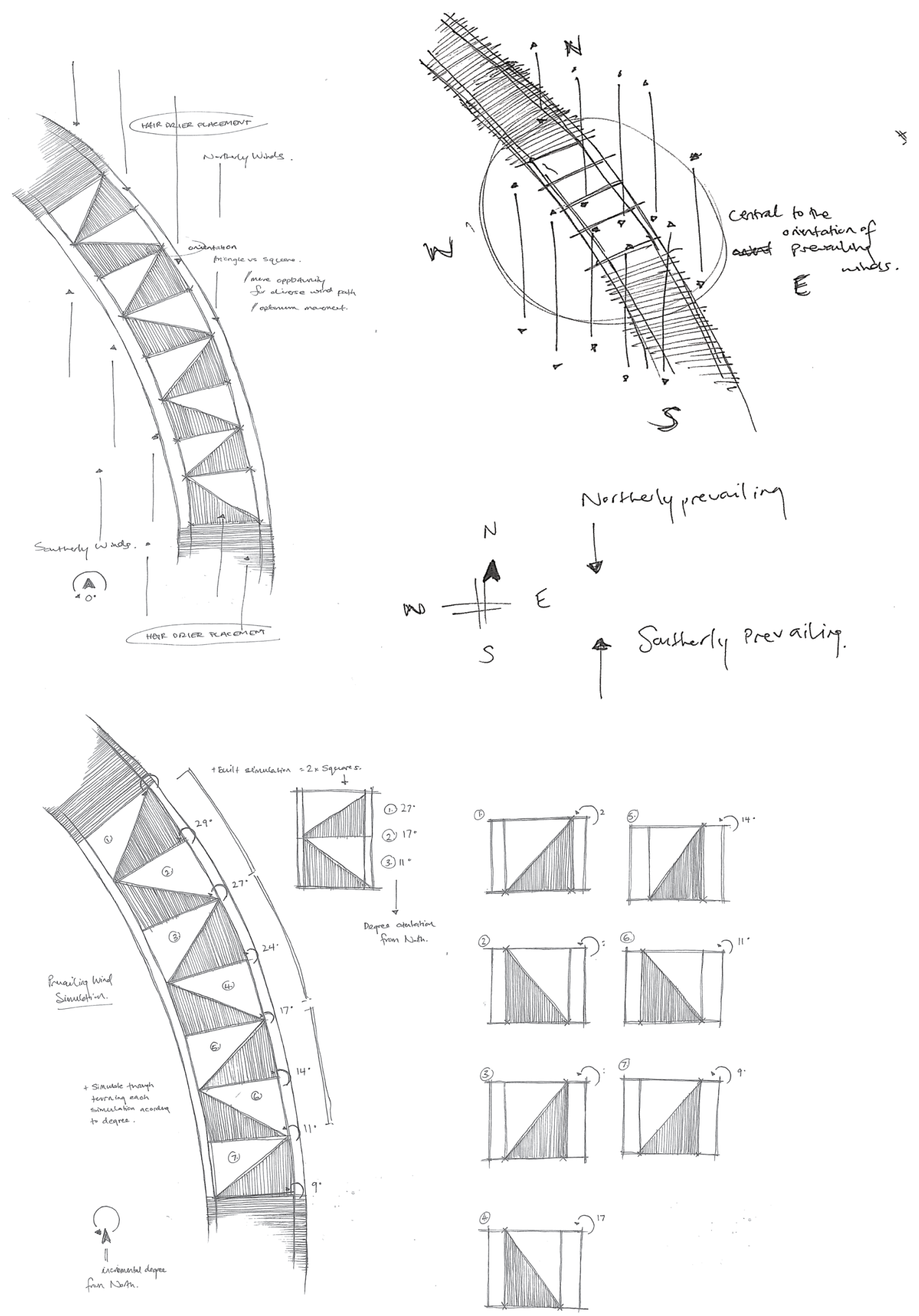

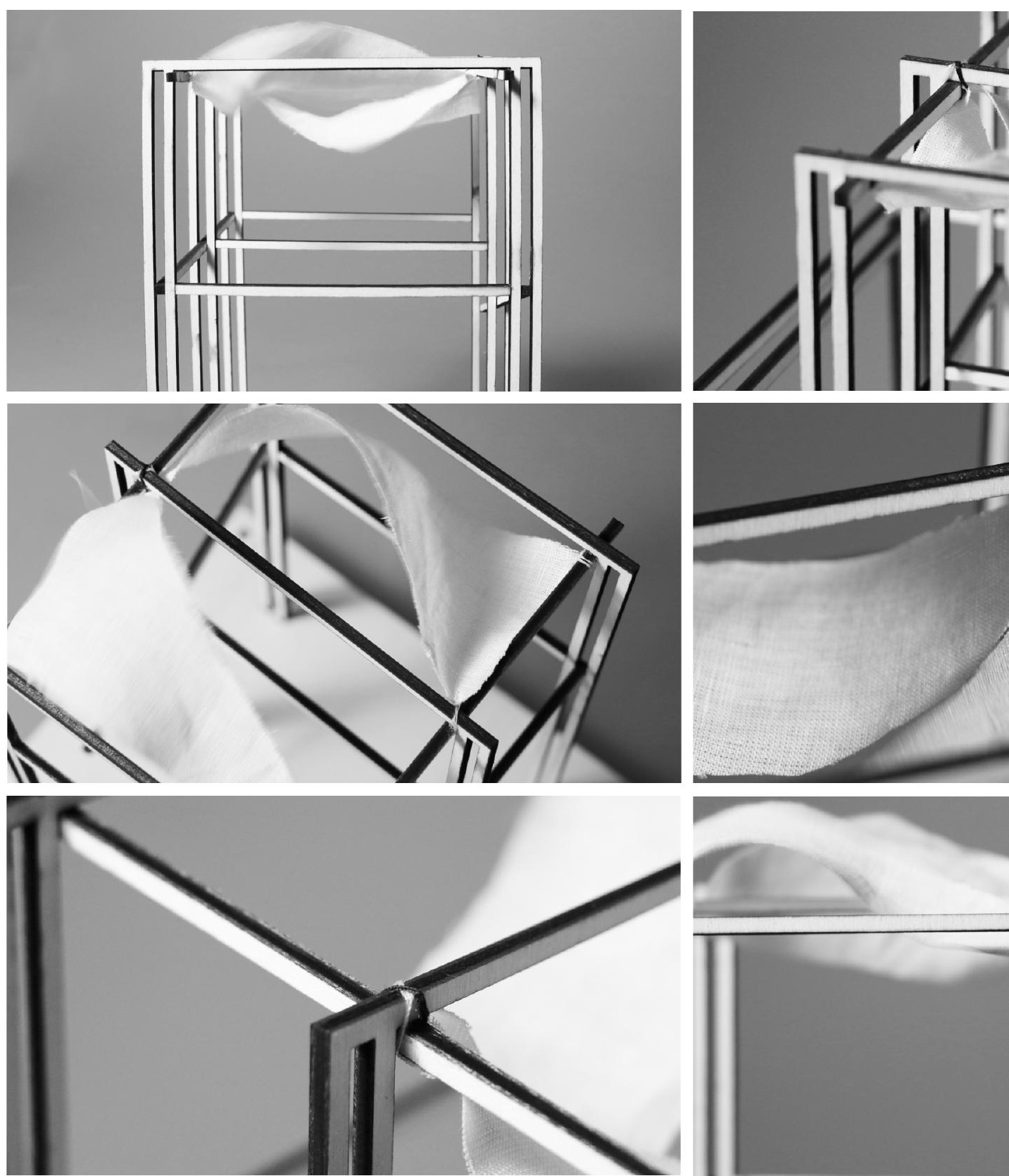

WIND SIMULATION

MODELING EXERCISE

Fig.62. 


\section{CONCEPT FOUR}

Concept four strongly relates back to the graphic is chapter 5 (figure 37) highlighting the vertical layers of the site. Reflective of the site's vertical layers, this intervention encompasses five divisions.

The first layer follows the tidal path of the old shoreline pre - land reclamation (figure 64). This layer consists of varying linear cuts in the ground, manipulating the tidal path of the old shoreline whilst also exposing pockets of the sites underground layer.

The second layer sits just above the ground plane. Layers 3 and 4 slightly creep above each other whilst layer 5 extrudes above the site, directing to views of the waterfront and Mount Victoria.

Again, like the other iterations, this concept follows the conceptual principles of layering, flux and tessellation with the tectonics of the form creating a dynamic visual with the depth of layers both on its own and through light and shadow. 


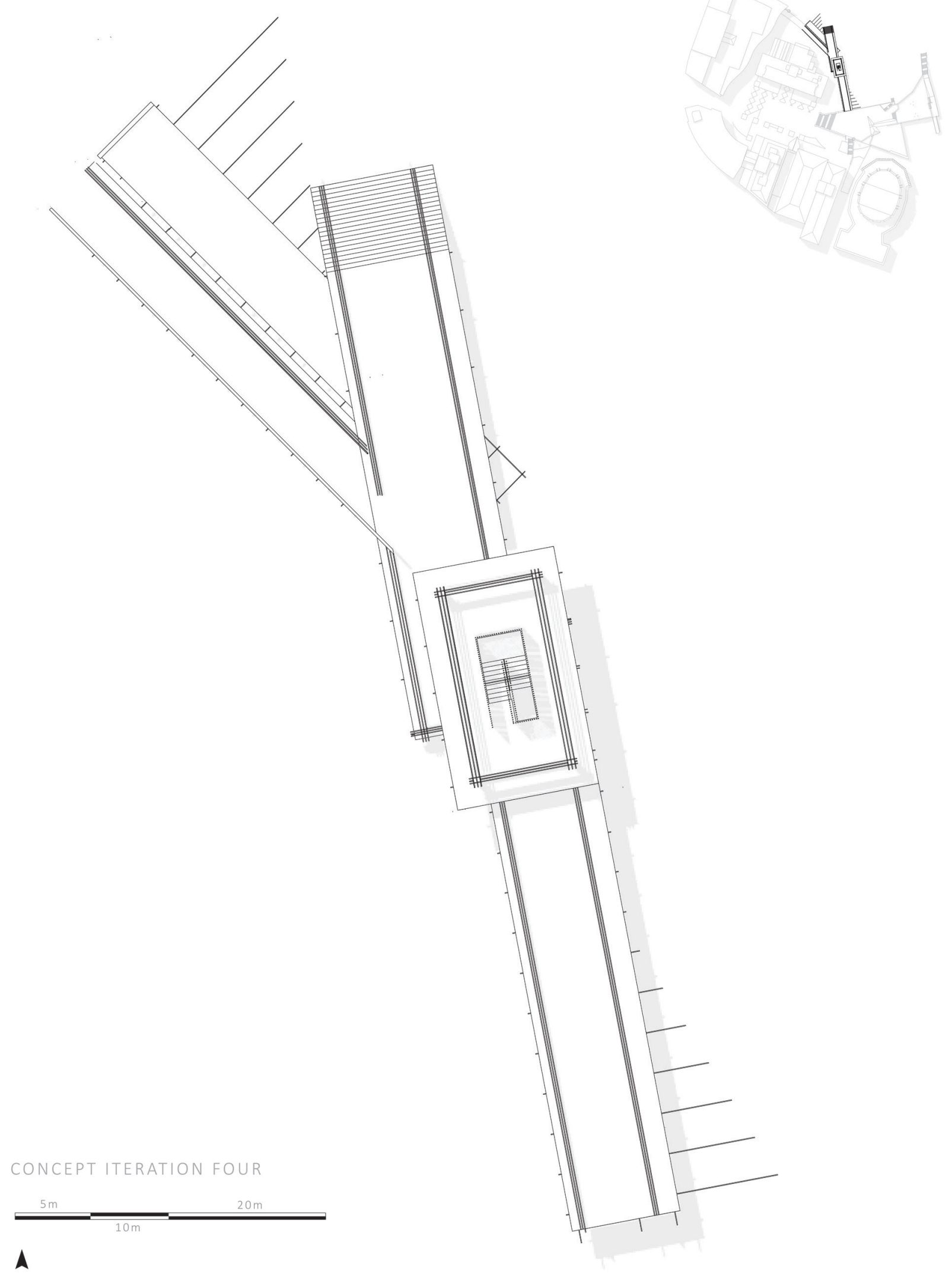



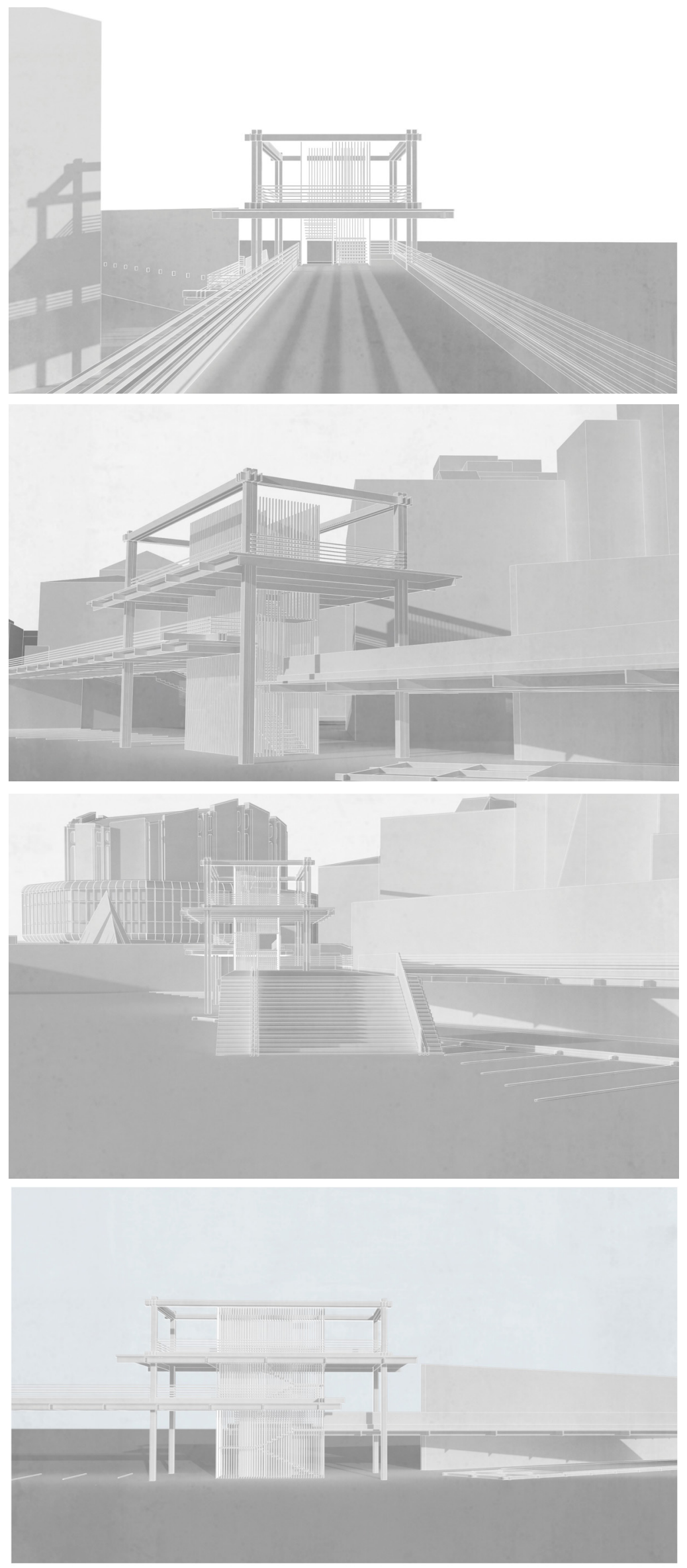


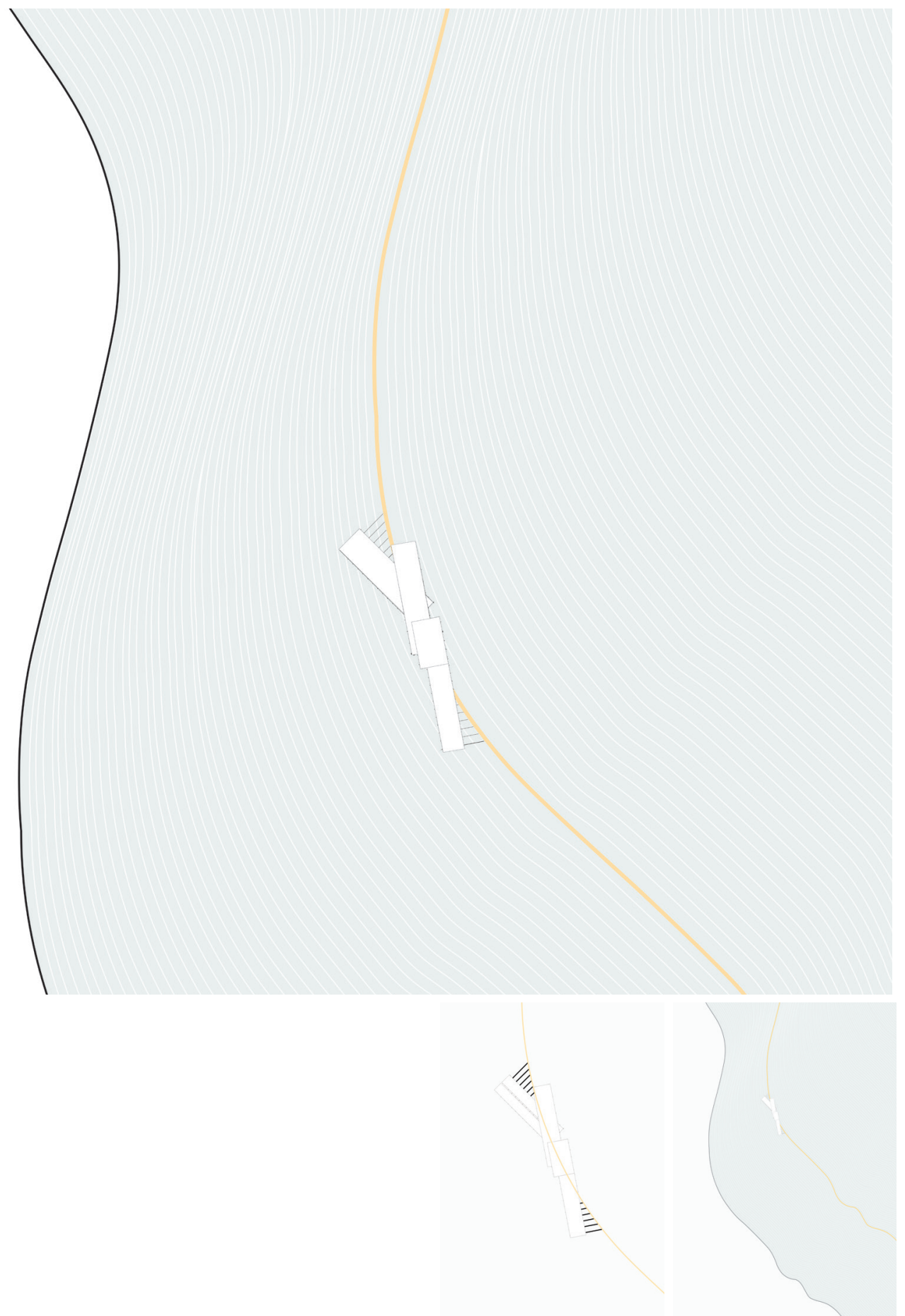

- old shoreline 

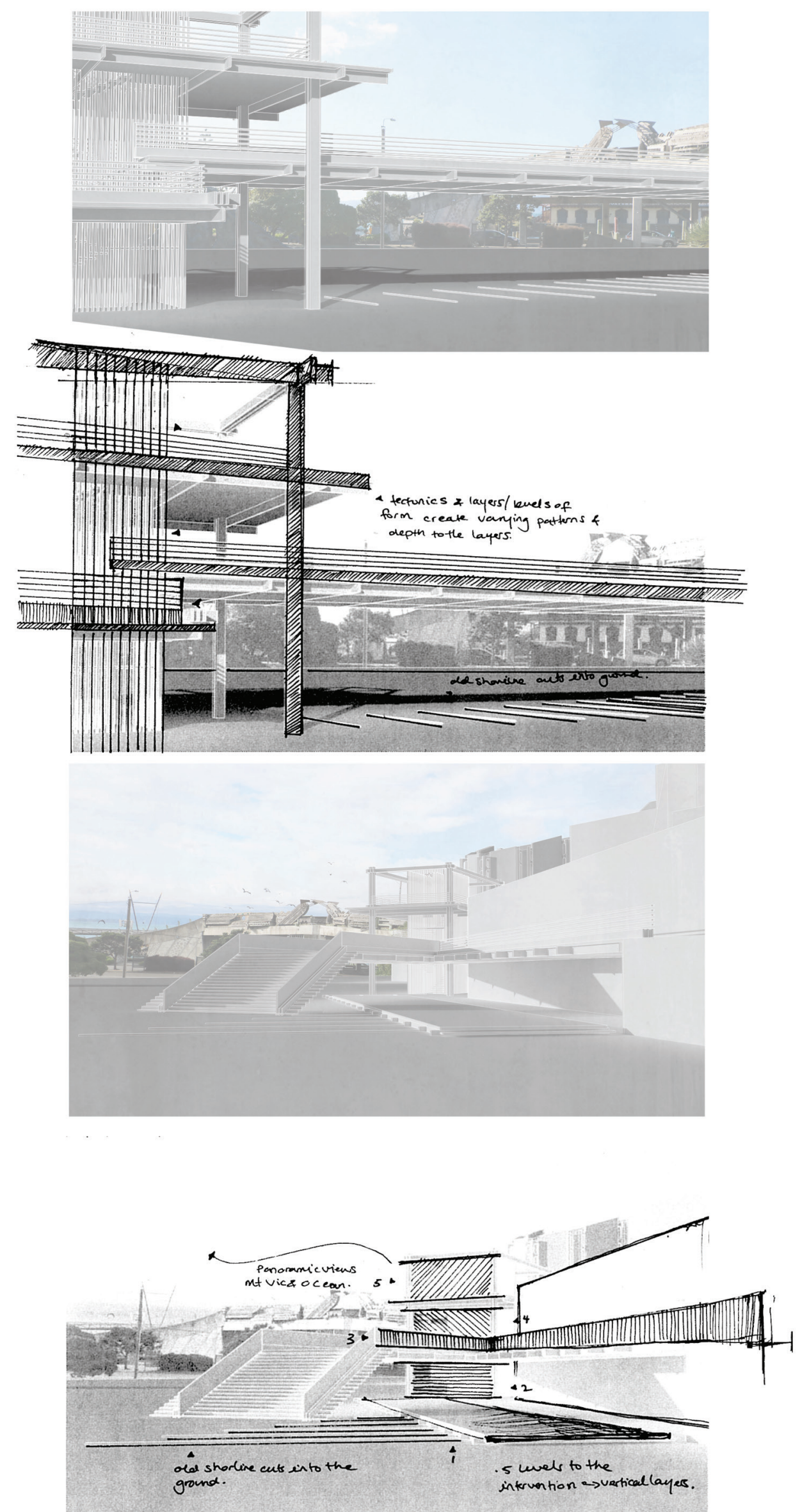


\section{CRITICAL REFLECTION}

\section{MID REVIEW}

The mid - review was a formal discussion around the thesis work up until this point. The mid review largely critiqued the strength of the overarching concept of this work regarding sense of place and its application throughout the conceptual design phase. The reviewers critiqued the formal design qualities of the research and their subsequent success in the design process.

Reviewer one discussed the importance of circling back to the key idea of sense of place throughout the design process. Moving forward in the formal design process it is important to keep coming back to the initial vision of this research, reflecting upon the aims to ensure that the architecture is responding to the desired outcome.

Another key critique from reviewer one touched on the importance of emphasizing the human scale upon visualising the final designs. It is important to bring it back down to the human scale, rendering the direct experience of the concepts.

Reviewer two responded positively to the approach of interacting with the climatic environment through the wind, light and shadow and felt that these aspects came out the strongest in the conceptual design phase, successfully grounding the architecture at the site. However, they felt like the framework of the architectural interventions presented too much of a contrast to their surroundings and did not settle into the site. The foundations of these interventions would be strengthened with a much more resolved and detailed exploration between the proposed new architecture and the existing site.

Reviewer two also acknowledged an important understanding regarding the pragmatic nature of the architecture. Moving into the public scale design, it is important to progress primarily with a pragmatic approach to design. Meaning the initial questions should centre around the programmatic needs of the site and the intended experience this proposed building seeks to offer. This critique was helpful in restructuring the imminent approach

Reviewer three appreciated the current unresolved nature of Civic Square, confirming its need for a refresh. This reviewer commented on the proposition and contradiction of the design proposal, discussing that there is a latent contradiction from putting something new into something old. This discussion touched on the importance of resolving how the new relates to the old in the next phase of design.

Reviewer three also commended the richness and depth of the initial watercolour drawings however, felt as though the richness of these drawings had been lost when shifting into the design work. How might this level of depth be enriched into the architecture? 


\section{CRITICAL REFLECTION}

\section{MOVING FORWARD}

Leading on from the mid - review, the power of understanding what creates successful public space was highlighted. The mid - review emphasised the importance of considering the makings of good public space and then using the researched design techniques of meaning and memory to then build the detail and depth of the design. The following chapter will explore Civic Design strategies and qualities of successful public design. 


\section{7}

\section{FORMAL DESIGN DIRECTION}

This chapter explores theory towards creating successful public space, researching the possible direction of the designs overall pragmatic composition. The spatial parameters and program of the design are identified. This chapter is all about public space criteria and the creation of good public space. 


\section{WHAT MAKES A SUCCESSFUL PUBLIC SPACE?}

Successful public spaces are regarded as those places where celebrations are held, social and economic changes occur, friends run into each other, and cultures mix. When public spaces work well, they serve as the stage for public life (PPS, n.d.).

'Project for public spaces', an online source aimed at discussing the necessity and ideas behind placemaking, reveal the essential characteristics to consider. Figure 66 illustrates these researched characteristics in constructing a 'great place' (PPS, n.d.).
FOUR PRINCIPLE CHARACTERISTICS:

\section{SOCIABILITY}

A public space that fosters social interactions, tends to build a stronger sense of place or community attachment.

\section{USES \& ACTIVITIES}

Uses and activities activate public spaces, enhancing the spirit of the spaces

\section{ACCESS \& LINKAGE}

A successful public space prioritises accessibility. A space that is easy to get through and to, visible from both up close and at a distance.

COMFORT \& IMAGE

Theoverarchingimageand comfortability of a space is key to creating a successful public space. Comfort includes the spaces perceived safety, cleanliness, and accessibility to public seating. 
WHAT MAKES A GREAT PLACE?

KEY ATTRIBUTES

INTANGIBLES

MEASUREMENTS

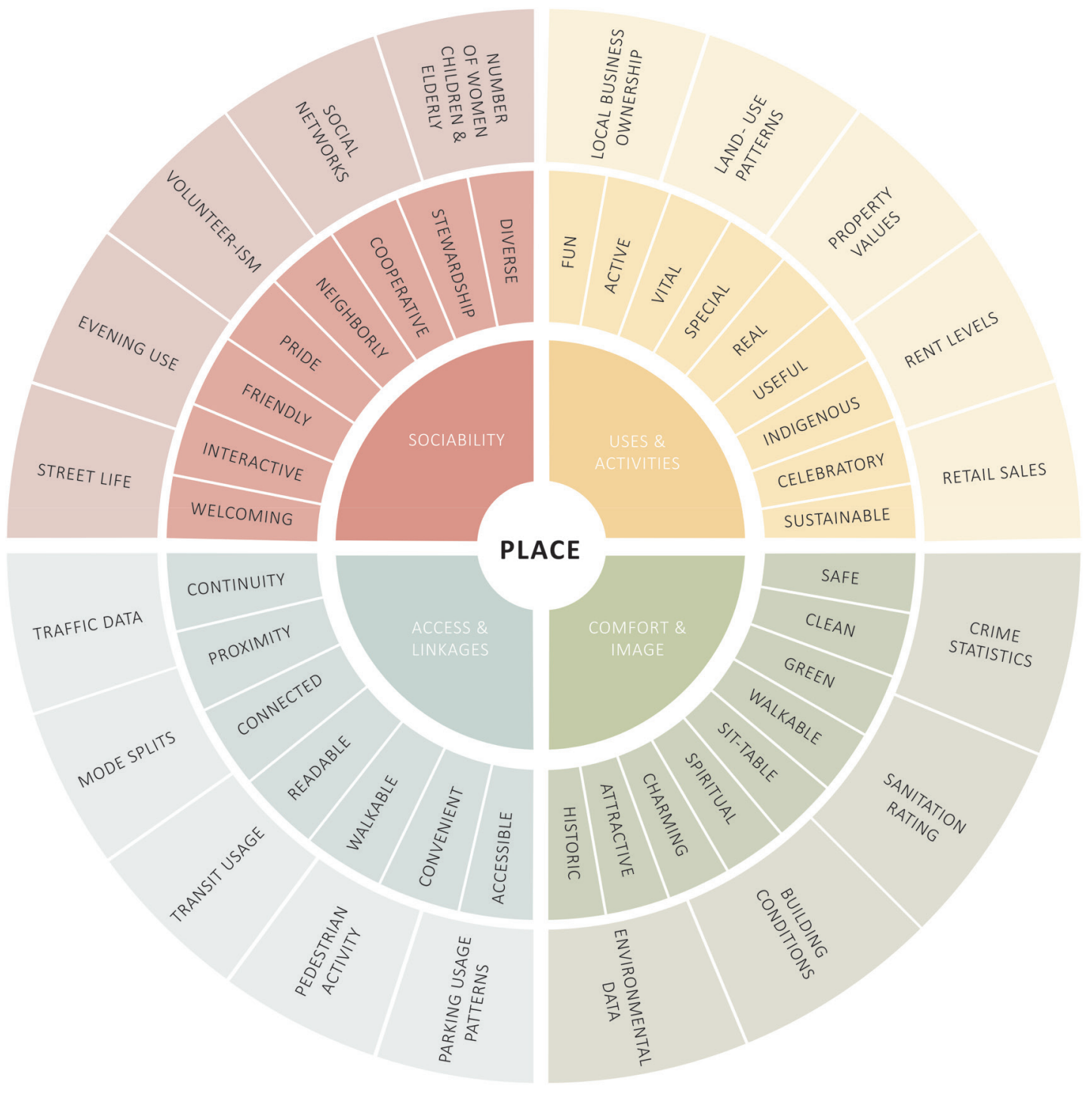




\section{CIVIC DESIGN GUIDELINES}

\section{CREATING AUTHENTIC CONNECTIONS THROUGH PLACE}

Public spaces are often places for social interactions, where people come together to create a better community. Recent research carried out by the Center for Active Design confirms that public spaces have the ability to facilitate community connection, trust, and involvement (Center for Active Design, 2018).

INTRODUCING ASSEMBLY: CIVIC DESIGN GUIDELINES

Assembly's Civic Design Guidelines are a highly regarded resource in establishing well designed and well-maintained public spaces that work towards creating and building a stronger community and sense of place (Center for Active Design, 2018).

The Assembly guidelines have been constructed through the cumulation of four years of research and collaboration. The guidelines capture the input from over two hundred studies and dozens of expert advisors (Center for Active Design, 2018). The collaborative process used to establish these guidelines provides evidence - based design and maintenance strategies. 


\title{
ASSEMBLY: CIVIC DESIGN GUIDELINES
}

Upon analysing the Assembly Civic Design document, the following identifies the guidelines of relevance to Civic Square and the impending phase of public design.

\section{ENHANCE COMMUNITY CONNECTION}

\author{
Put Pedestrian needs first \\ Expand Transportation. \\ Diversify land use.
}

Safe, attractive, well connected public spaces foster spontaneous opportunities for social interactions, creating environments that cultivate unplanned encounters, community events, or interaction amongst people of diverse backgrounds and perspectives. Well - connected communities help promote an inclusive environment where all people can engage in civic life. Assembly's extensive research demonstrates that well - connected communities are associated with a range of positive life outcomes, including improved physical and mental wellbeing. Their research makes a case around civic life that reinforces the inherent value of walkable, bike-able, transit - accessible communities (Center for Active Design, 2018).

Designing architecture that prioritizes pedestrians subsequently strengthens the quality of a public space. Designing with a considered approach to pedestrian use may be achieved through creating visual interest along a footpath, orientating main entrances and sign-age toward pedestrian paths and footpaths opposed to driveways, parking lots, and garages, or through encouraging shops to activate their frontages.

\section{PRIORITISE MAINTENANCE}

\section{Improve with Trees and Plantings. Encourage community Gardening. Celebrate Unique Natural Assets.}

With relevance to the design process, it is important to consider appropriate materials. The maintenance timeline of materials is relevant, as the degradation of public space is inherent and therefore the lesser need for strict upkeep will assist in keeping a cleaner more inviting public space. 


\title{
IMPROVE NATURE
}

\author{
Improve with Trees and Plantings. \\ Encourage community Gardening. \\ Celebrate Unique Natural Assets.
}

Nature is known to enrich the civic life of communities (Center for Active Design, 2018). The influence of nature can be seen in Urban parks, as they demonstrate the ability to support civic trust and participation in public life through creating opportunities for intercultural and intergenerational interaction.

Through celebrating the natural characteristics of an environment, such as waterfronts, parklands, or other unique features, a source of community pride and attachment to place is established. Research shows that designing with a focus on the sites natural abilities initiates a heightened pride in community and sense of community identity (Center for Active Design, 2018).

Designing architecture that celebrates the unique and natural assets of a site can be achieved through creating spaces that reflect and responds to local geography. This may be attained through incorporating native plants, notable focal points or signage referencing the ecological and historic significance of the site (Center for Active Design, 2018).

\section{CELEBRATE COMMUNITY IDENTITY}

\author{
Use local arts to inspire and engage. \\ Connect Diverse cultures. \\ Preserve and Re-purpose Historic Assets. \\ Showcase local food.
}

Opposed to imposing a singular aesthetic, the most successful design efforts authentically respond to a community's unique identity. A design that captures local identity has the ability to boost community pride and trust, both being key component of civic life (Center for Active Design, 2018).

Connections to civic life can be created through inviting the community to create and install public exhibitions, fostering community participation amongst diverse groups. Research also suggests that knowing public exhibitions are locally created can strengthen civic trust, prompting the idea that their city provides opportunities for residents to participate in their community (Center for Active Design, 2018).

Implementing historic buildings, local landmarks, and public spaces into civic design fosters a rich sense of connection to place, furthermore, enriching civic life. This research also acknowledges food to be an important part of peoples cultural and regional identities, thus putting local food forward fosters community pride and encourage participation in public life (Center for Active Design, 2018). 


\title{
MAKE PUBLIC SPACE WELCOMING
}

\author{
Create welcoming entrances. \\ Use positive messaging. \\ Make navigation intuitive.
}

People respond to cues in their environment, essentially gravitating toward spaces that they feel welcome. Research proposes that small changes in design and messaging can significantly influence people's sense of welcome, ultimately shaping a spaces strength of civic life. Designing with an eye towards creating welcoming environments opposed to promoting privatization, fencing and heightened security, fosters civic growth, encouraging all community members to actively participate in public life (Center for Active Design, 2018).

\section{MAKE PUBLIC SPACES WELCOMING}

\author{
Provide seating options. \\ Illuminate Public Spaces for buildings. \\ Provide water and restrooms. \\ Tailor Design to Local Climate.
}

Designing comfortable public space ultimately encourages visitors to stay longer and return more often. Research form the Assembly civic engagement survey indicates the importance of comfortable spaces in fostering civic life. Amenities such as seating, lighting, drinking fountains and restrooms are associated with superior levels of civic life. Design features that support comfort are especially important in building a more inclusion space, facilitating participation of certain groups such as women, children, and seniors (Center for Active Design, 2018).

\section{MAKE SPACE FOR ACTIVITY}

\author{
Provide space for programming and events. \\ Support informal interactions. \\ Reclaim underutilised structure.
}

Danish architect Jan Gehl discusses the key for sparking activity in public spaces in his 1986 publication, Life Between buildings. Here he notes that the key attitude towards design is to plan through the perspective of the pedestrian (J. Gehl, 2011) Jan goes on to explain the need for civic design to engage in intimate, friendly public space that support a wide range of activities.

Assembly's research suggests a clear relationship between community activity and the success of civic life. Opportunities to gather with other community members have been proven to foster a sense of shared values, in turn supporting civic trust (Center for Active Design, 2018).

“People are attracted to other people." - Jan Gehl (J. Gehl, 2011). 
TEMPORALITY VS PERMANENCE

EXPLORING THE 'FLUX' OF SPACE AND TIME

Understanding change in public architecture.

The responsive nature of architecture is a successful building tool in developing good public space ((P. Beesley \& O. Khan, 2009). Therefore, it is integral to design with an understanding of the reasons, procedures, and principles of change to better generate architecture that responds to time and change.

Looking at the current temporality of Civic Square, the future of the site is evidently unknown. No design can be considered without associating concepts of time and change (S. Durmus, 2012). Change can occur in various ways and does not simply represent the physical shape of the building. Change in architecture cannot be avoided as the constant changing of human and environmental behaviours forever alters the context of a space. 


\section{CATEGORISING ARCHITECTURAL COMPONENTS}

\section{Shearing the layers of change:}

In the book 'how buildings learn' Stuart The six layers (Site, Structure, Skin, Brand introduces a diagram called Service, Space plan, Stuff) continuously 'shearing the layers of change' (figure influence each other to reshape a building 67), categorising responsive architecture over time. This thesis will refer to this with respect to rates of change. Brand theory in approaching the design of the introduces the concept of 'shearing public scale building intervention. layers' to explain the different rates of change among building's components.

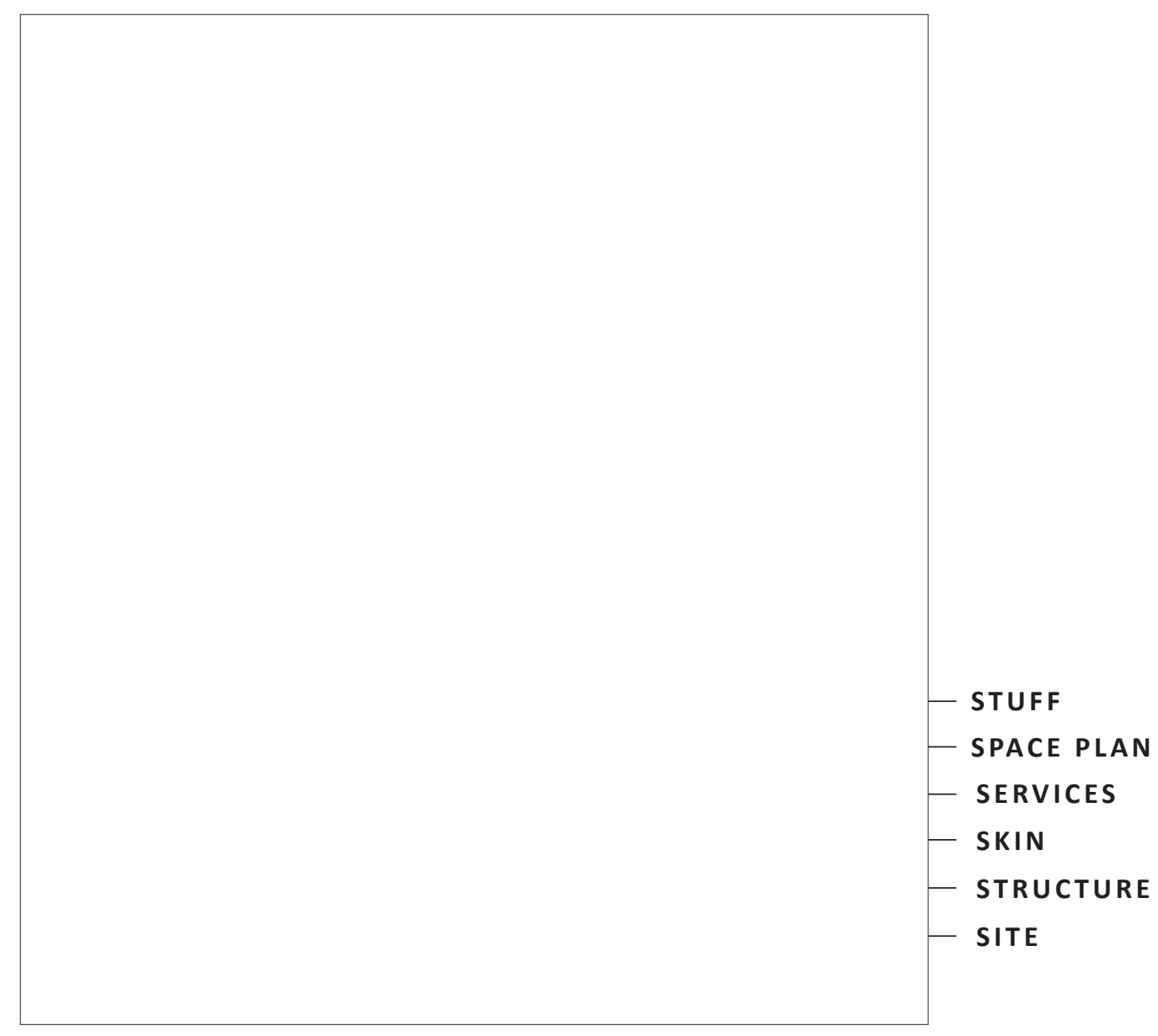


TEMPORALITY VS PERMANENCE

\section{STUART BRAND 'SHEARING LAYERS'}

The 'Shearing layers of change' diagram demonstrates strong evidence that buildings are dynamic rather than simply static objects.

\begin{tabular}{|c|c|c|}
\hline \multirow[t]{5}{*}{ SLOW } & SITE & CIVIC SQUARE \\
\hline & STRUCTURE & $\begin{array}{l}\text { FOUNDATION \& } \\
\text { LOAD- BEARING ELEMENTS }\end{array}$ \\
\hline & SKIN & $\begin{array}{l}\text { EXTERIOR SURFACE } \\
\text { (FACADE) }\end{array}$ \\
\hline & SERVICES & $\begin{array}{l}\text { OPERATING SYSTEMS } \\
\text { HEATING SYSTEM, ELECTRIC WIRING... }\end{array}$ \\
\hline & SPACE PLAN & $\begin{array}{l}\text { INTERIOR FLOOR PLAN/ } \\
\text { LAYOUT }\end{array}$ \\
\hline FAST & STUFF & $\begin{array}{l}\text { THINGS IN AND AROUND } \\
\text { THE BUILDING }\end{array}$ \\
\hline
\end{tabular}




\section{RESPONSIVE ARCHITECTURE}

\section{DESIGNING FOR CHANGE IN PUBLIC ARCHITECTURE}

As recognised in figure 68, every building encompasses aspects of a fixed, passive, and static entity. Simultaneously, every building also has a changeable body of which its appearance, permeability and affordances for activity have the capacity to respond to change from the environment and the needs of its inhabitants (M. Meagher, 2015).

According to Brand, architectural design needs to be adaptive, responding to an understanding of temporal change and informational flows across each physical layer of a building (S. Brand, 1994). Adapting to shifts in weather and changes in the needs of people requires a certain degree of flexibility, thus this theory looks towards developing architectural elements with the ability to adapt and change. In the scope of this thesis, responsive architecture refers to any building component designed for adaptation to change in its surroundings. In effect, architectural responsiveness primarily alludes to either changing patterns in usage through the activities of the building's inhabitants or changes in the exterior environment (M. Meagher, 2015).

\section{APPLYING RESPONSIVE THEORY}

Employing responsive elements into the development of this design further builds on the concepts of movement, swells and tides (flux), ultimately contributing to the narrative of the site through a constant flux of movement and rhythm. A responsive approach to design unleashes the opportunity to use responsive building components as expressive and potentially subversive elements of the architecture (M. Meagher, 2015). With the aim of creating successful public space, this theory proposes an architecture that acknowledges change, responding to change not only though modulation of conditions in the interior but correspondingly change in the external environment.

Integrating responsive components into architectural design extends the opportunity to enhance the experience of a space through giving expression to the fleeting, changeable aspects of the environment (M. Meagher, 2015). In turn the following design process will explore the possibilities for responsive components to not only accommodate to the timely needs of the inhabitants, but also to ground the sites architectural identity, engaging with the past and present (interaction with changing wind \& light - flux, layering and tessellation), critical regionalism (drawing on the ever-changing natural environment) and through embodiment (generating a sensorial experience from change).

This thesis looks to explore the use of responsive components and their capacity to inform the way that architecture is both conceived and experienced. Architectural responsiveness will be used as a key driving tool in developing the public building, as the responsive elements of buildings have the ability to play an important aesthetic and cultural role in the construction of engaging architectural spaces. 


\section{THE FUTURE}

\section{Responding to the pragmatic needs of civic square}

The site analysis in chapter five highlights the current temporary nature of Civic Square. The square's current emptiness, due to the ongoing seismic complications, has left an exceedingly lifeless environment as the heart of Wellington city. The uncertain future of the existing buildings in civic square offers the opportunity to reconsider the way in which the civic space is used and its relevant needs.

The current scheme of the Civic precinct does not generate an exceptionally thriving public environment. As the ground floors of the square do not breathe a desired sense of warmth and welcome, there is opportunity to rethink how the development of a new public building can contribute to the programmatic needs and experience of this space. Through a focus on the social experience of this environment this thesis looks to re - activate Civic Square with a considered programmatic approach, re - energising the space with a more community focused, lively, and immersive strategy. Chapter nine introduces a civic design and identity construction framework that will be used to inform the final design outcome. 
PROPOSED PROGRAMME

LOCAL MARKETPLACE

TEMPORARY EXHIBITION SPACE

PUBLIC AMENITIES

The primary programme of the Through designing to capture local proposed public building design will identity, the aim of this programme is be a local marketplace. This building to boost community pride and trust will provide a seven - day indoor food across civic life. Research suggests 'market', comprising of a series of stalls that knowing public spaces are locally catering toward selling local produce managed can strengthen civic trust, and accommodating small businesses. prompting the idea that their city Spatially, this design will also cater provides opportunities for residents to to an exhibition space to facilitate participate in their community (Center temporary installations and public for Active Design, 2018). The civic design restroom facilities. Through supporting guidelines also acknowledge food to be local growers and businesses this space an important part of peoples cultural intends to respond to multiple guidelines established by the Centre for Active design, ultimately seeking to celebrate a community identity. and regional identities, thus providing an environment to foster the production of local food creates a well spring of opportunities to foster community pride and encourage participation in public life (Center for Active Design, 2018). 


\section{PROGRAMME CASE STUDY}

Riverside Farmers Market (2019)

The Creative Group

In the heart of Christchurch 's CBD, Riverside market is the home for small businesses that want to showcase their products. The conceptual brief of this design was to generate a space that exhibits an authentic and busy market style environment (The Creative Group, 2019).

The design of the Riverside marketplace greatly considers customer flow, spatial transitions, and the overall customer interaction with the farmer's market. Through leaving the entire shopfronts open (figure 69), customers are granted access to directly interact with the product. The shopfronts are built with enamelled steel posts and beams, enabling signage suspension, decorative details, and the suspension of products. Along with this, the front counters each run the entire shop length, optimising on countertop space for product positioning, tastings, and presentations (The Creative Group, 2019).

Christchurch's Riverside market is a fresh take on inner city life. Riverside is an extremely successful, vibrant public space ultimately offering a unique inner - city shopping experience for the local community and visitors to enjoy . 


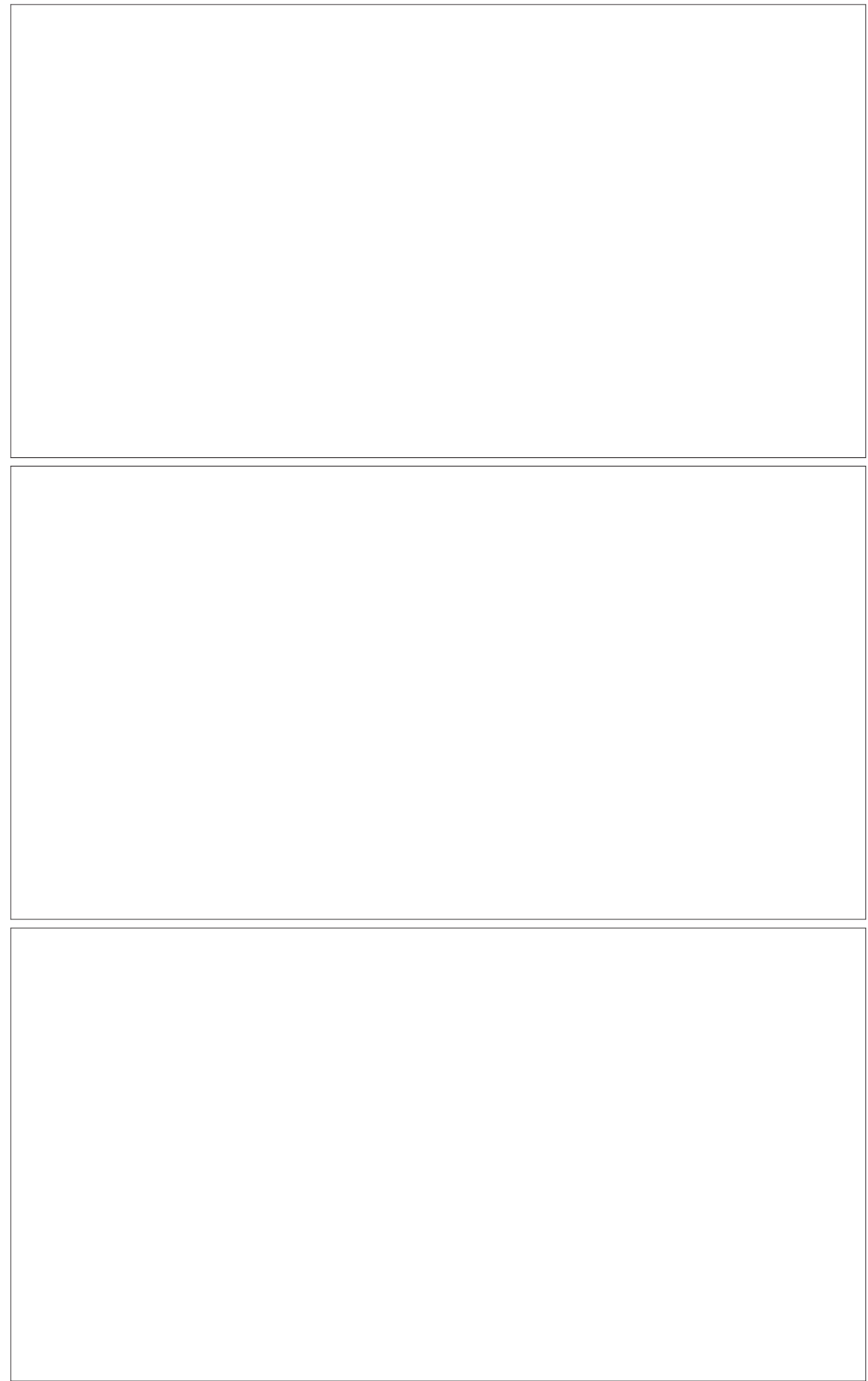

Fig.69. Riverside market. 


\section{PROGRAMME CASE STUDY}

Street food market, Amsterdam

uXUS

This case study is a food court in the Amsterdam Airport Schiphol, bringing the outdoor vibrancy of a street food market into the newly redesigned airport lounge.

The intent behind this design was to break away from standard food court design through offering a unique experience. This marketplace scheme offers a selection of locally produced treats, inspired by the city of Amsterdam. Intentionally referencing the city's diverse food markets, wood crates and boxes and fresh food displays reinforce the market theme and sense of place.

The overall scheme of this food court serves travellers with a mix of choice, convenience, and hospitality, evolving the traditional airport food court into its own unique and contexutally connected food experience (UXUS, 2016). 


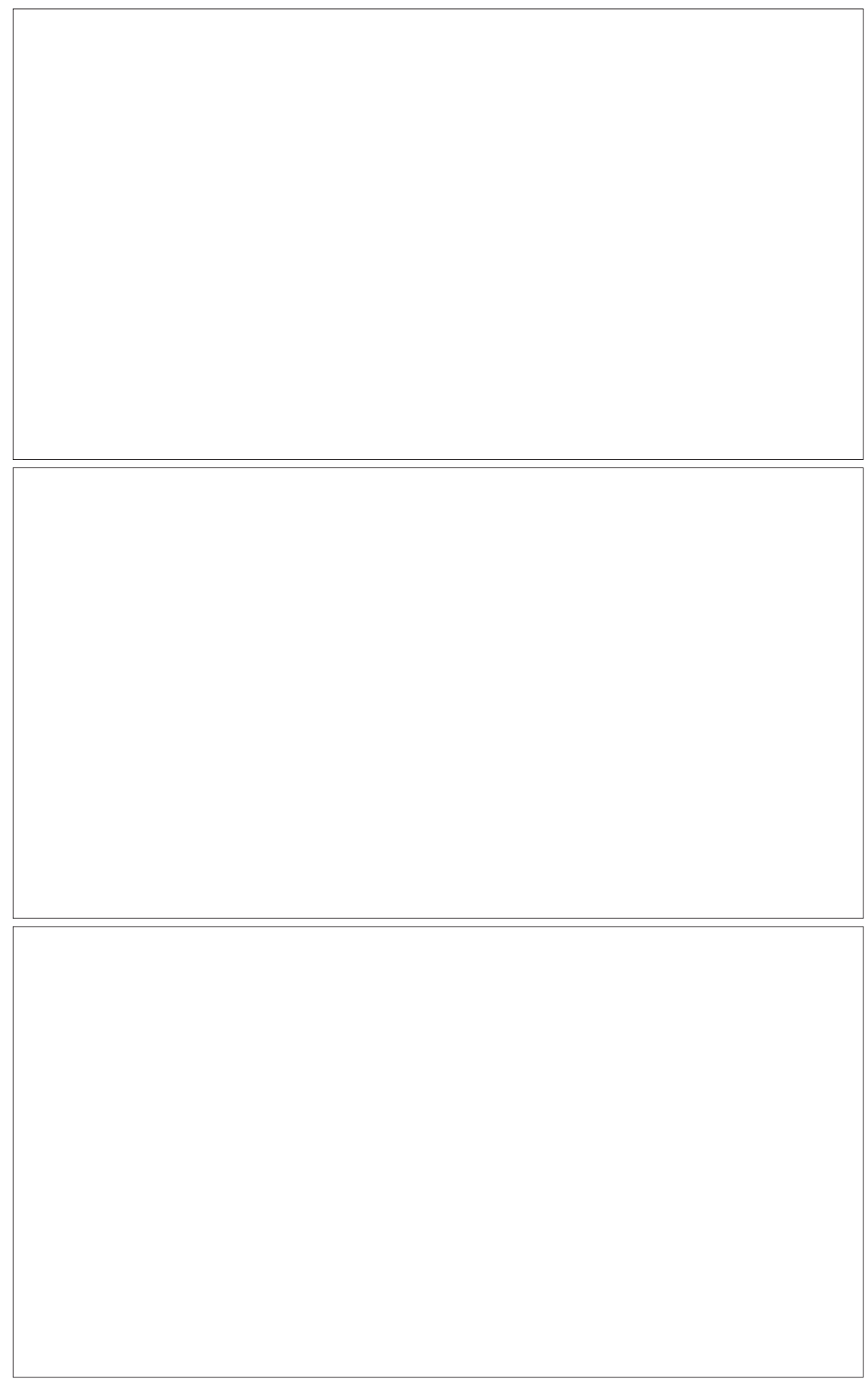

Fig. 70. Amsterdam Street food market. 


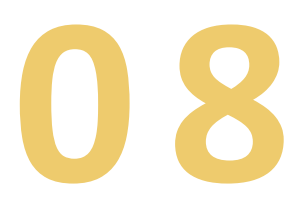

\section{PUBLIC SCALE DESIGN DEVELOPMENT}

Through takings from the research in chapters six and seven, this chapter investigates how design techniques can be used to activate space through a public scale design intervention. This chapter further develops the ways in which the character and identity of Wellington's Civic square can be utilised to inform a future architectural identity. 


\section{DESIGN FRAMEWORK}

The following design process begins with considering the pragmatic needs of the space, with focus on meaning and memory. The formal design is generated from the established Civic Design framework and is further shaped by the proposed framework which seeks to construct an architectural identity, ultimately striving to develop a strong sense of place. This design process considers an approach to civic design that looks to primarily improve the quality of public space, with the critical exploration being how that is achieved.

\section{PROCESS STRUCTURE}

\section{DISCLAIMER}

The design process is described and documented here in a linear manner. This is purely for the benefit of the reader; however, the way in which design was carried out was through a non - linear movement between varied analogue and digital methods. The design was developed in an iterative, interconnected manner, but in this chapter, it has been split into independent categories, unfolding the process through form development, spatial development, and detail development. 
ARCHITECTURAL IDENTITY FRAMEWORK

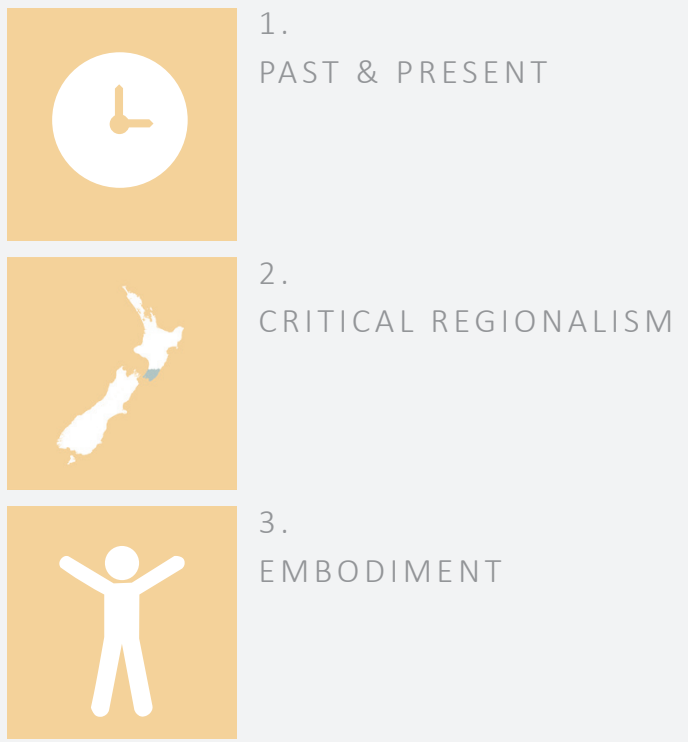


CIVIC DESIGN FRAMEWORK

Assembly: Civic Design Guidlnes

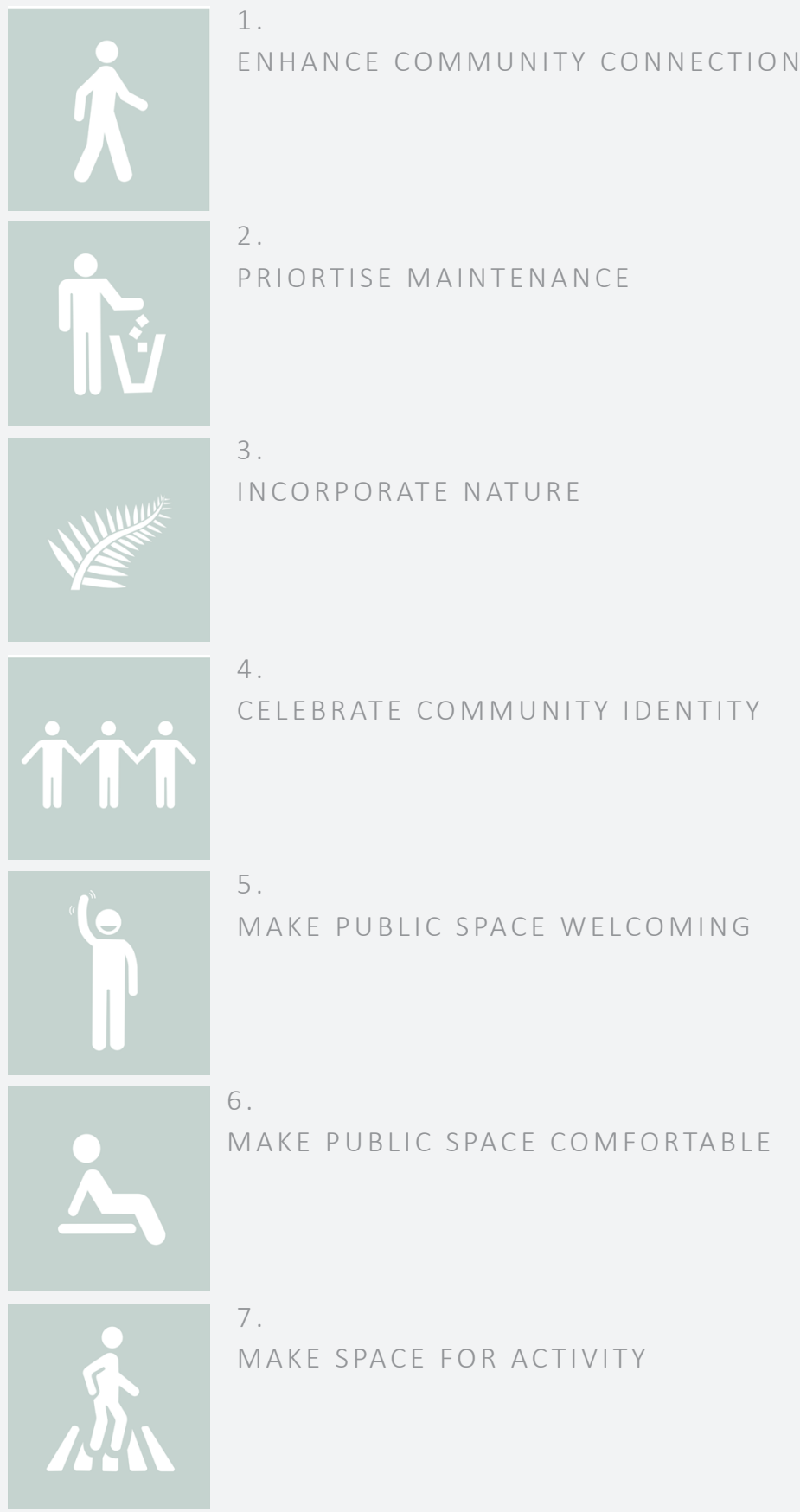




\section{PROGRAMME DEVELOPMENT}

The scope of the proposed programme has been designed to supplement the primary design outcomes. The design process is not focused on spatially designing the programme and thus, the programme has been integrated in a simple, general manner and is not a key focus of the final design outcome.

\section{LOCAL MARKETPLACE}

$1000 \mathrm{~m} 2$ floor area (as calculated for the riverside market case study). Crush space and marketplace booth installations.

\section{CORE}

$180 m 2$

Storage.

Rubbish room

Refrigerator.

Comms room

\section{PUBLIC AMENITIES}

Four female, four male.

One accessible female.

One accessible male.

\section{EXHIBITION SPACE}

Open plan space to support the transitory nature of its intended use (temporary installations). 
HUMAN SCALE DESIGN PROCESS (CHAPTER SIX)

\section{REFLECTION \& INTEGRATION}

Upon analysing the success' and failures of the human scale Design iterations, this process begins with extracting the strengths of each iteration to further integrate and resolve these.

The placement of the public building sits alongside the placement of the human scale intervention, intending to assist in creating an enclosed interior space within the square (indicated at the bottom of figure 71). The idea behind building towards an enclosed interior space is to create a more intimate environment with the intention of contributing to a safer space through stronger human surveillance whilst also hoping to foster greater social interactions.

As the proposed location of the building sits alongside the walkway intervention from the human scale design development (chapter six), the elements of the human scale interventions that will be further developed will be those that interact with the natural environment through climatic conditions. This will exclude view shafts, as the proposed placement of the public building interferes with the overall field of vision from the walkway. Key features of concept three worked with the interplay between wind and sun and their relationship with the architectural components. This chapter will describe the process of further developing and resolving the concept three walkway, and also document the development of the proposed public marketplace.
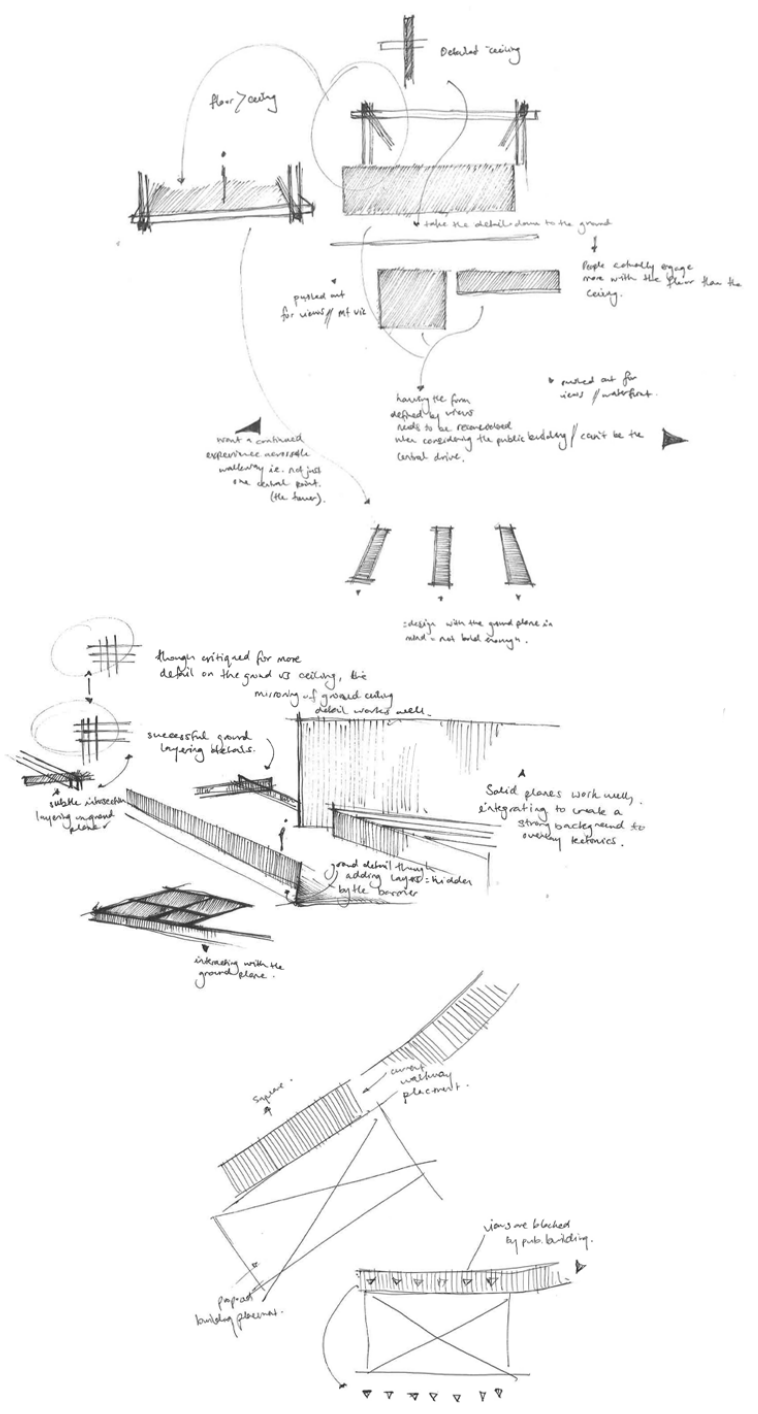

Fig.71. Conceptual sketching. 


\section{CONCEPT DEVELOPMENT}

Figure 72 investigates the process of visually translating the notion of layering, flux, and tessellation. These drawings explore the ability for the same tectonic to be arranged at different angles, ultimately defining varying spatial parameters through the process of layering, flux, and tessellation. This exploration will be further put into practice in the process of designing the walkway and marketplace, looking at translating the idea of layering, flux, and tessellation into architectural design through a tectonic exploration.

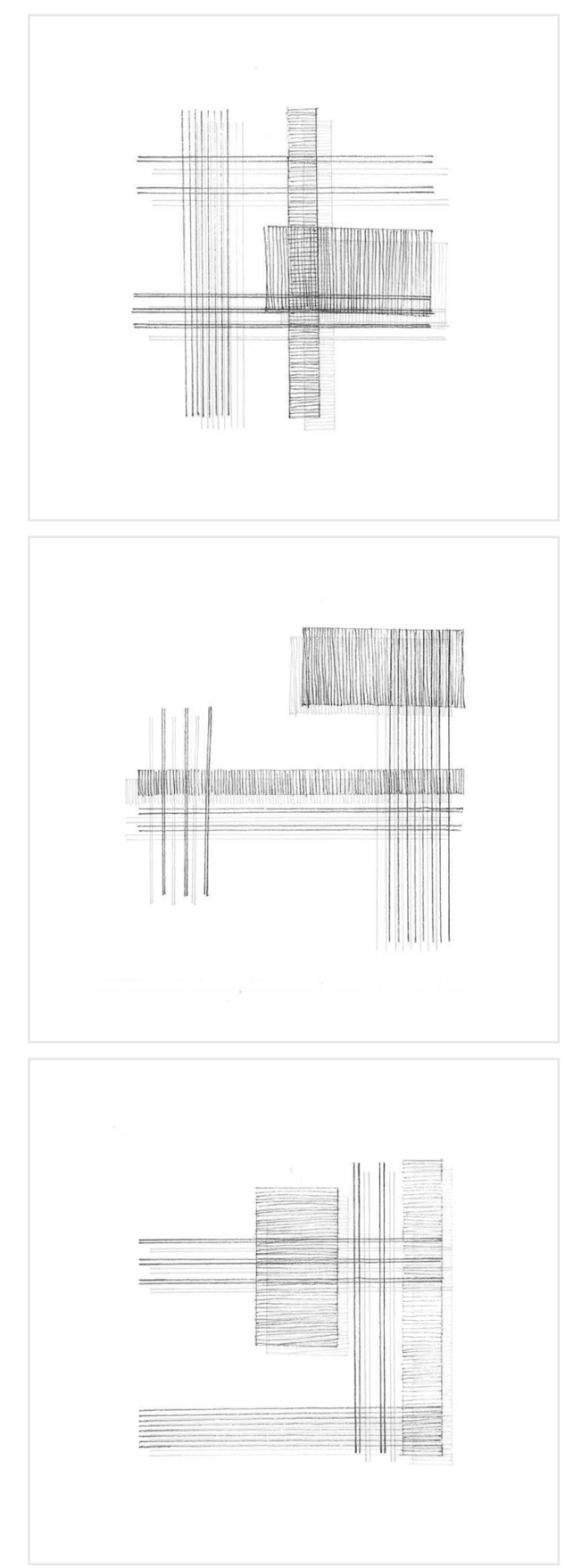




\section{FORM DEVELOPMENT}

Initial frame \& walkway relationship

The initial relationship between the walkway intervention and the marketplace is as indicated in below. The proposed marketplace sits alongside the walkway, further closing off the square and contributing to creating an 'interior space' within the square.
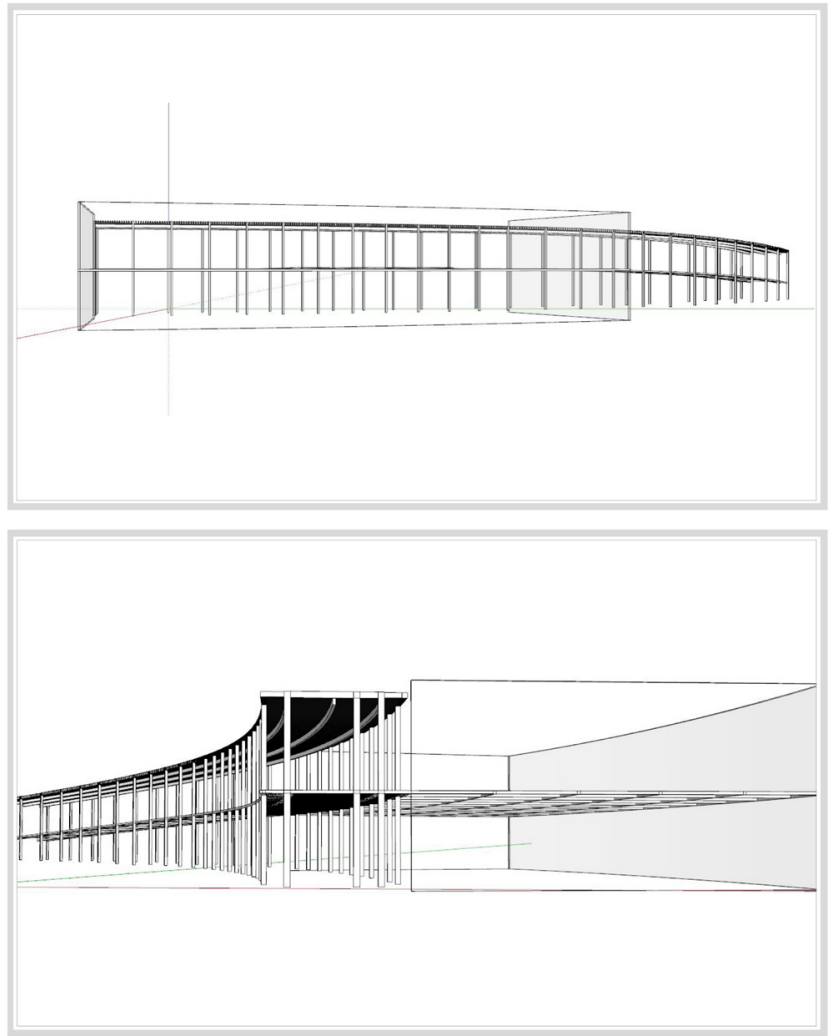

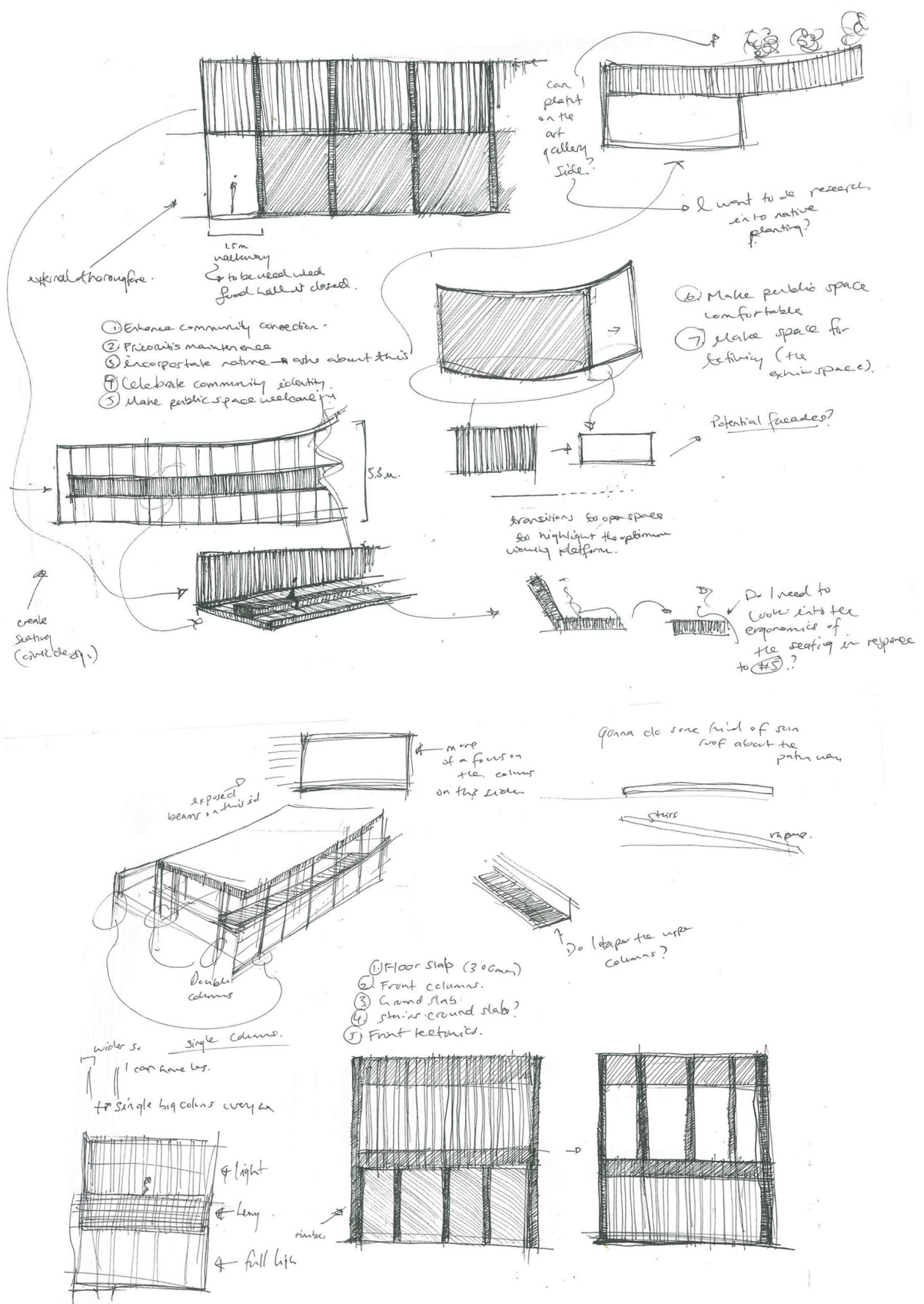


\section{FORM DEVELOPMENT SECOND LIFE INITIATIVE}

\section{FLOOR FRAMEWORK}

Exploring the 'flux' of space and time.

Given that the future of the Civic Square is unknown, it could be argued that it does not make sense to design something completely permanent when the current stance of the site is impermanent. In response to the unknownfuture of the site, and an ever changing urban environment, the mezzanine floor has been designed to be able to be uninstalled whilst leaving the floor framing structure intact. This is the key feature of this design in regard to responding to change, as incorporating the temporary second floor means that the space is transformative. The floor can always be uninstalled or further reinstalled to become a full coverage second floor. This creates a potentially responsive space, leaving an open plan opportunity for future building occupancy and programmatic use. Thus, the upper level of this building is primarily designed to stretch and contract with the flux of the future needs of the Civic Square. The design of a full second storey framework allows the space to be converted into a dynamic space accommodating to community use if and when suited to the site.
The open floor framing system consists of modular wood components. This design feature has been influenced by the 'second life' initiative developed by Modu Architecture (Modu Architecture, 2020). The open framework stabilizes the structural stance of the whole building while also supporting a temporary space for social encounters (figure 74). 

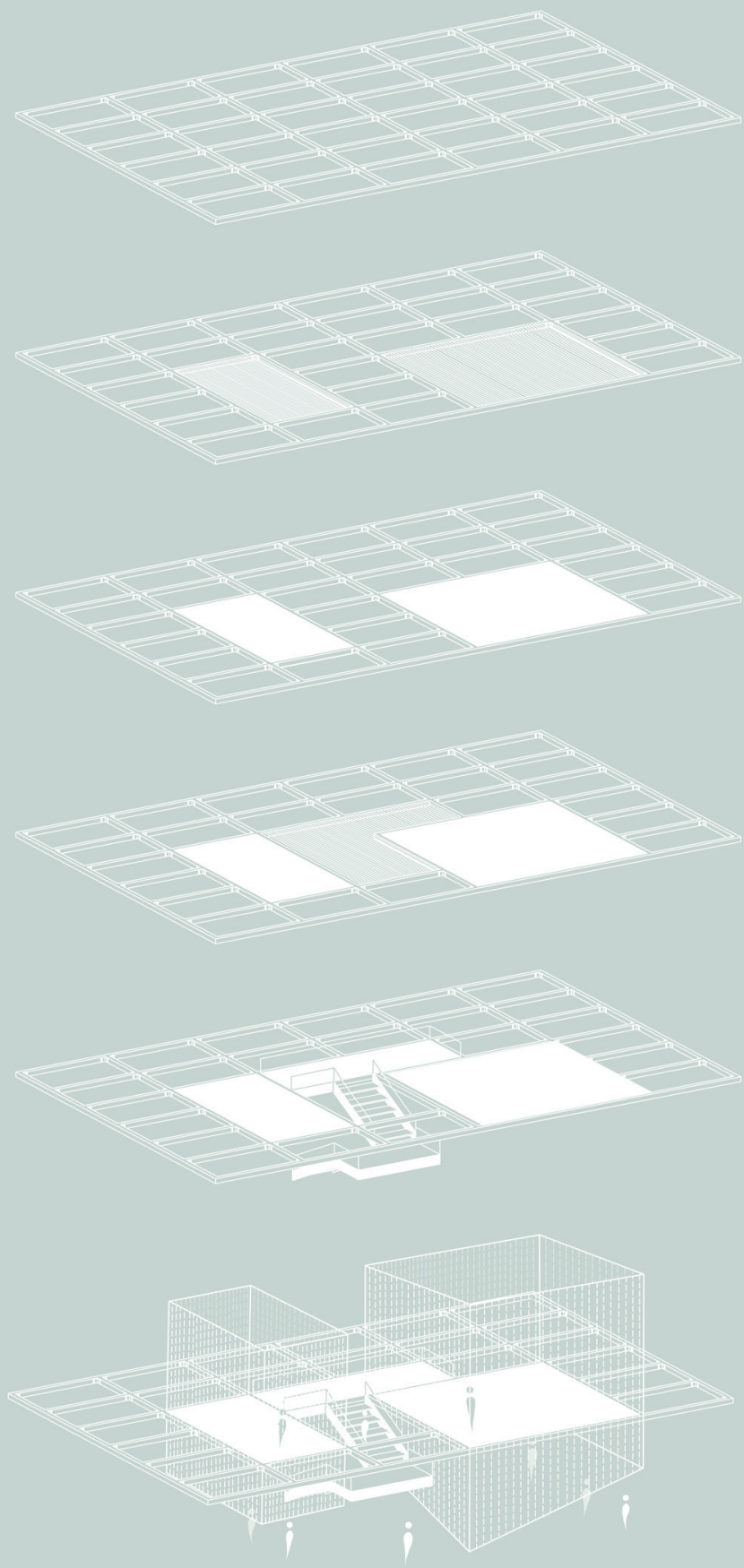

Fig. 74 . 


\section{FORM DEVELOPMENT}

\section{MEZZANINE}

The marketplace scheme opts for mezzanine space opposed to a second floor to primarily create a lighter interior environment. The mezzanine also assists in strengthening community involvement through presenting the ability to overlook the ground level, providing an authentic view of the local businesses and their production processes. The intention is for this space to act as an 'observation' deck. Thus, users of this space have full exposure to the marketplace, offering the ability for users to visually engage with the action below.
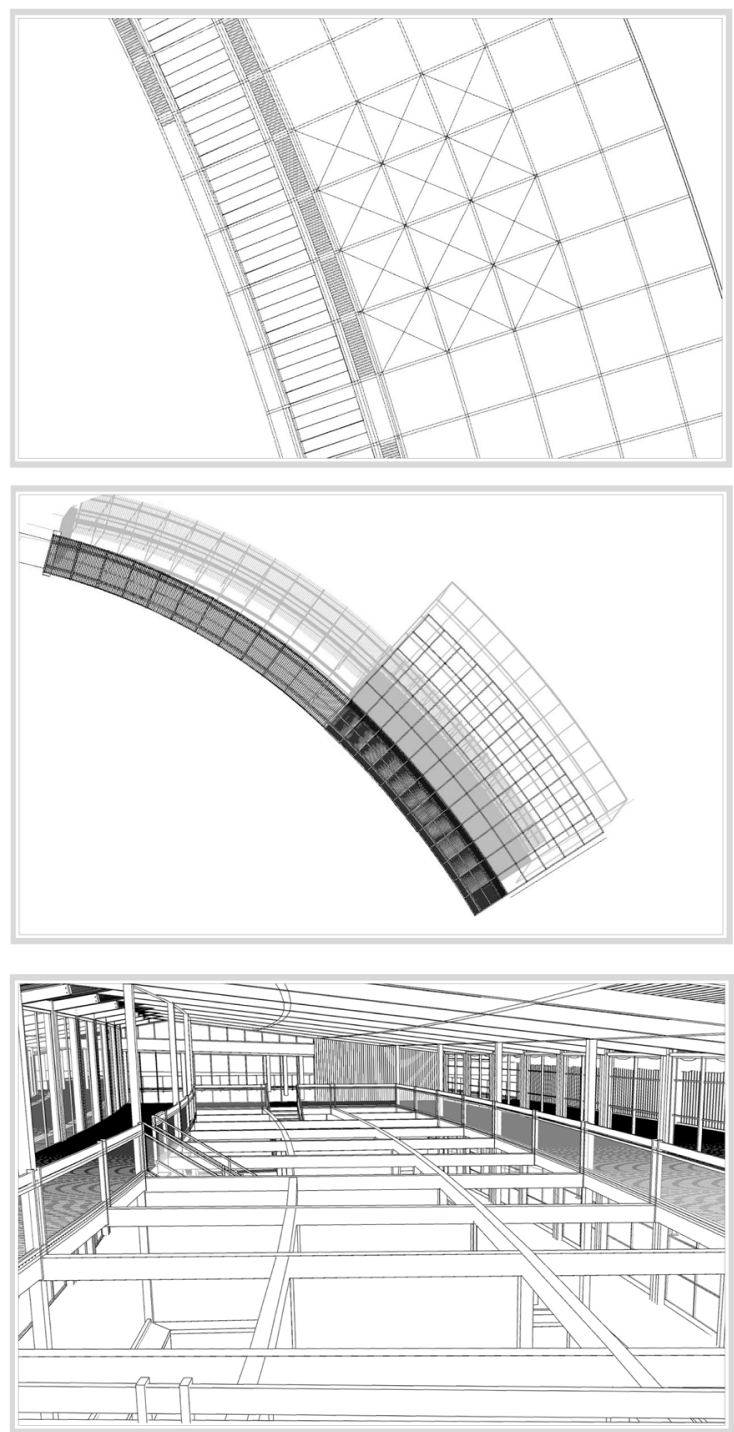


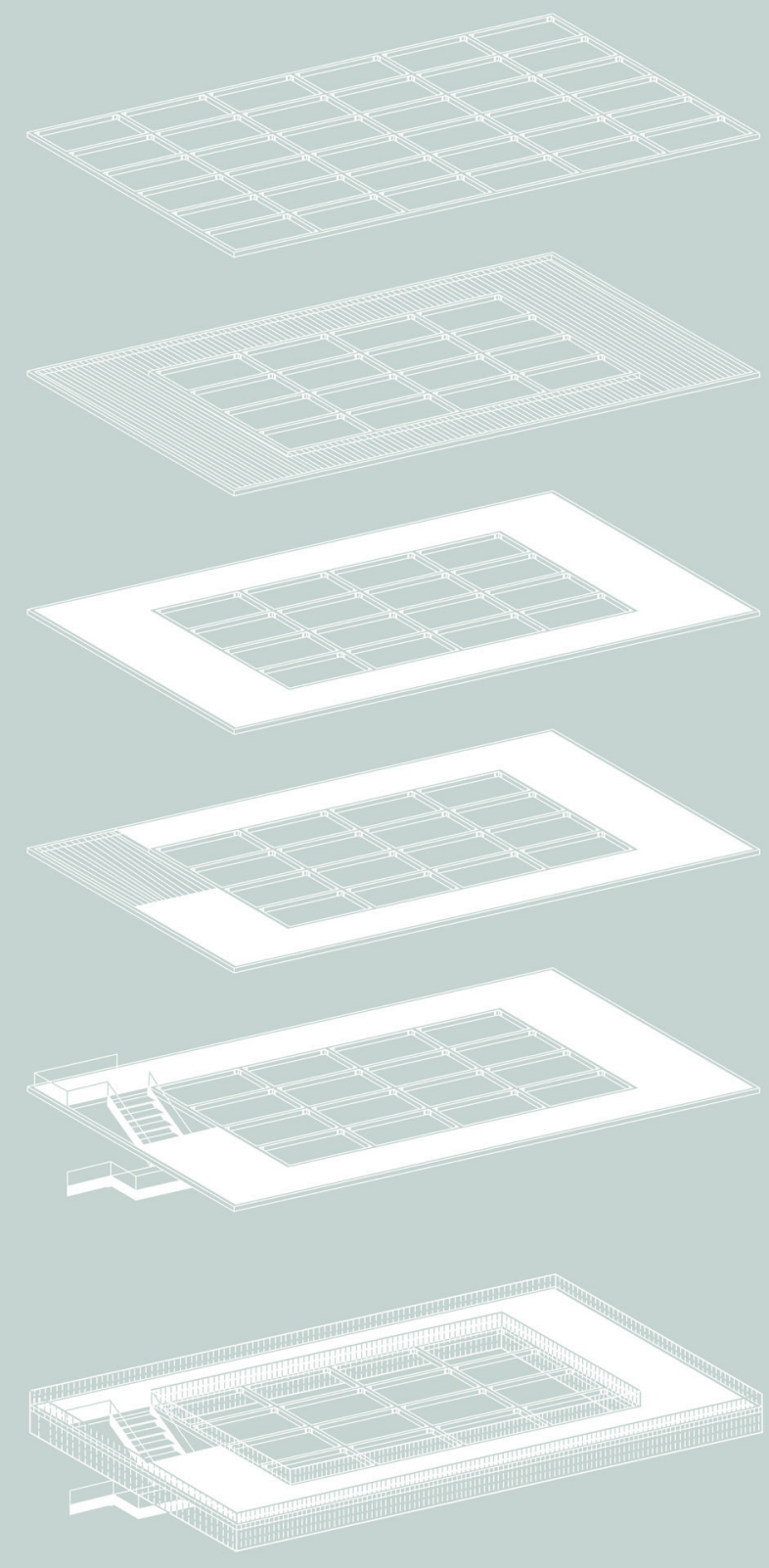

Fig.76. 
FORM DEVELOPMENT

Initial frame \& walkway relationship

Figure 77 indicates the development the walkway tectonics. The tectonics went through an interactive process of which the final composition has been defined through implementing the notion of flux. These tectonics create a spatial journey, incrementally changing as one moves through the walkway.
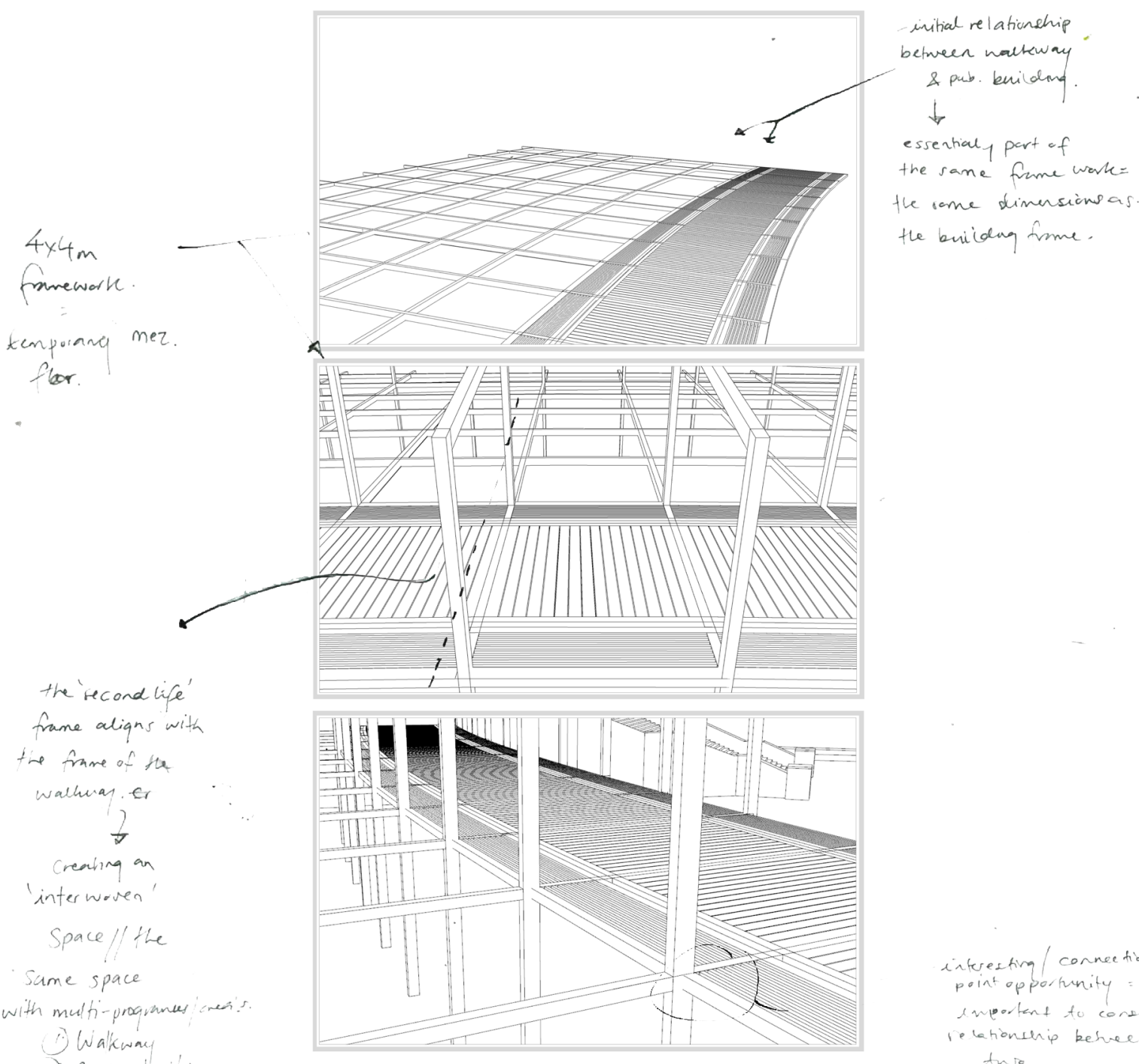

2) Public eviadin

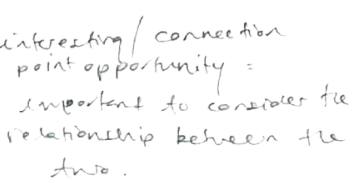


FORM DEVELOPMENT

WALKWAY DEVELOPMENT

Walkway tectonics - tectonic slope

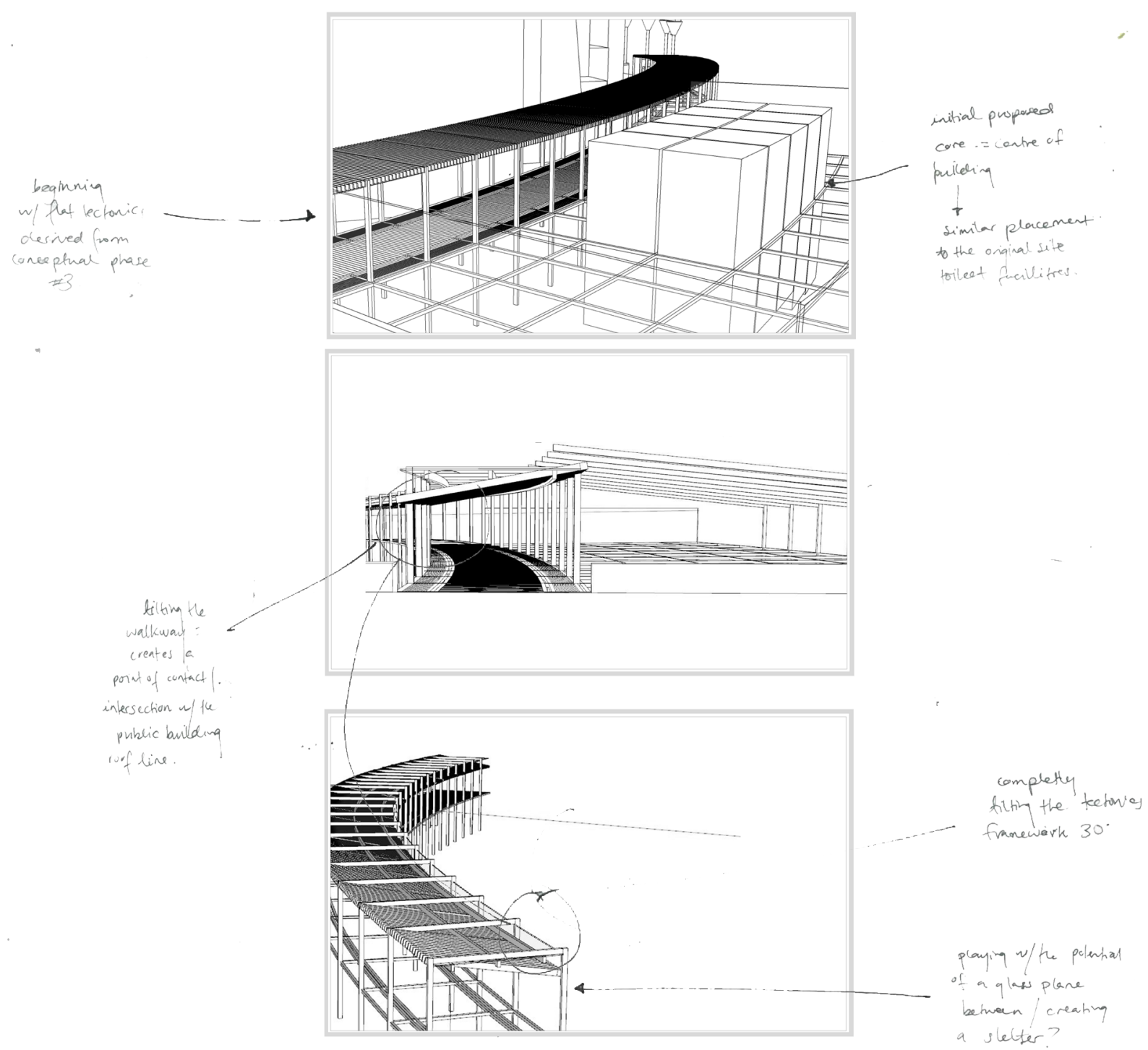

Fig.78. Digital development. 


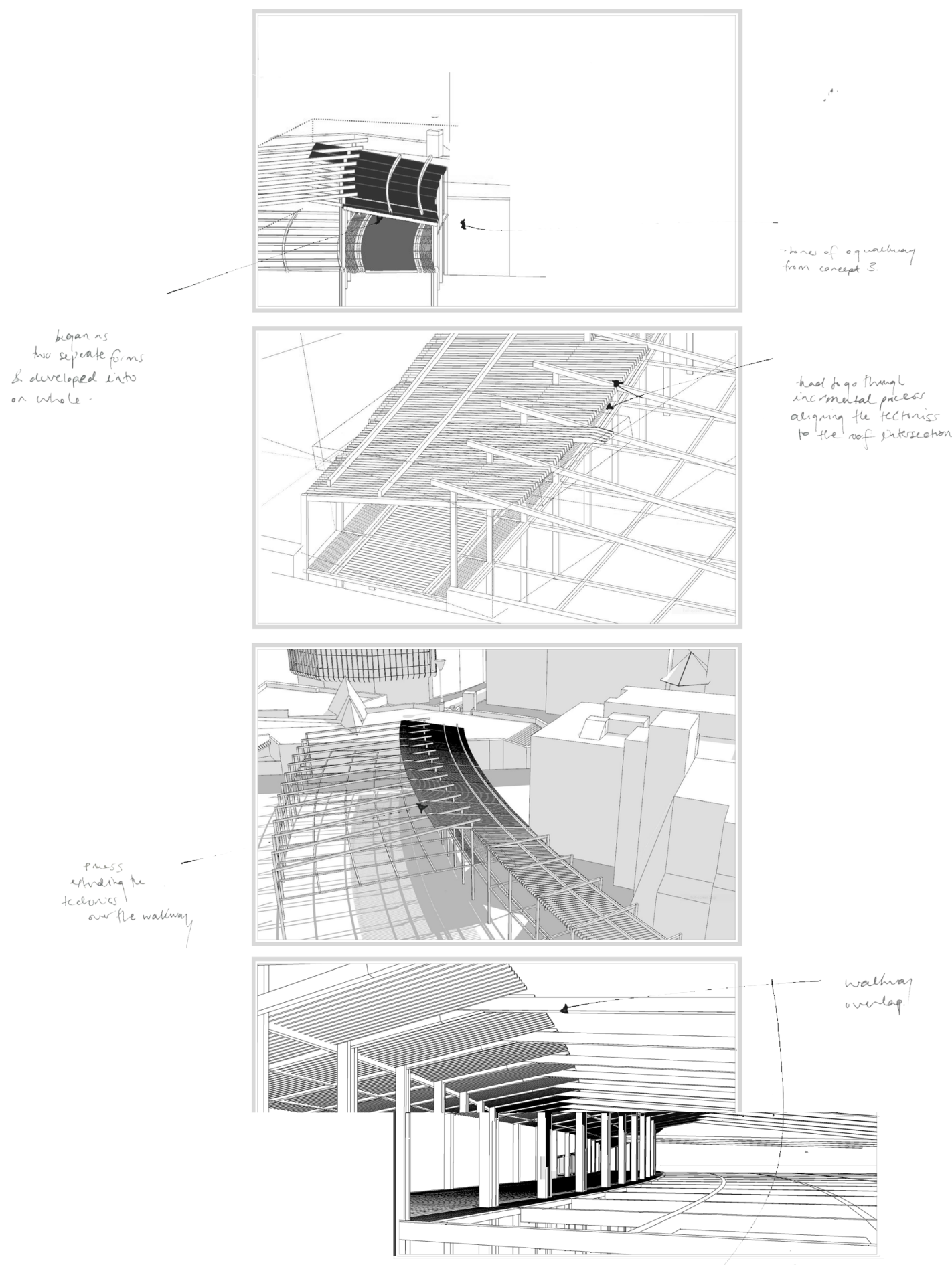

Fig.79. Digital development. 


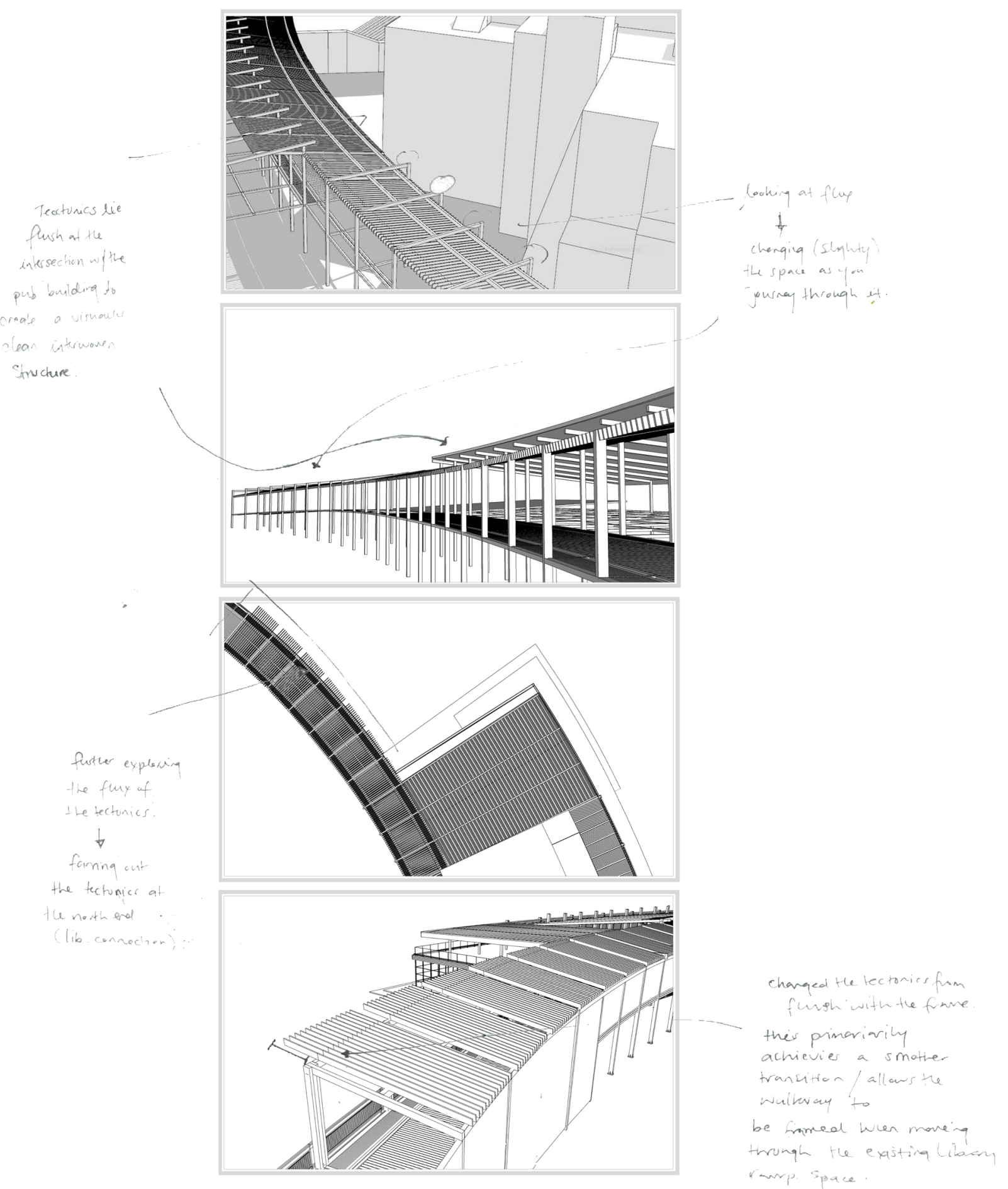


FORM DEVELOPMENT

PRIMARY STRUCTURAL ELEMENTS

FORM DEVELOPMENT
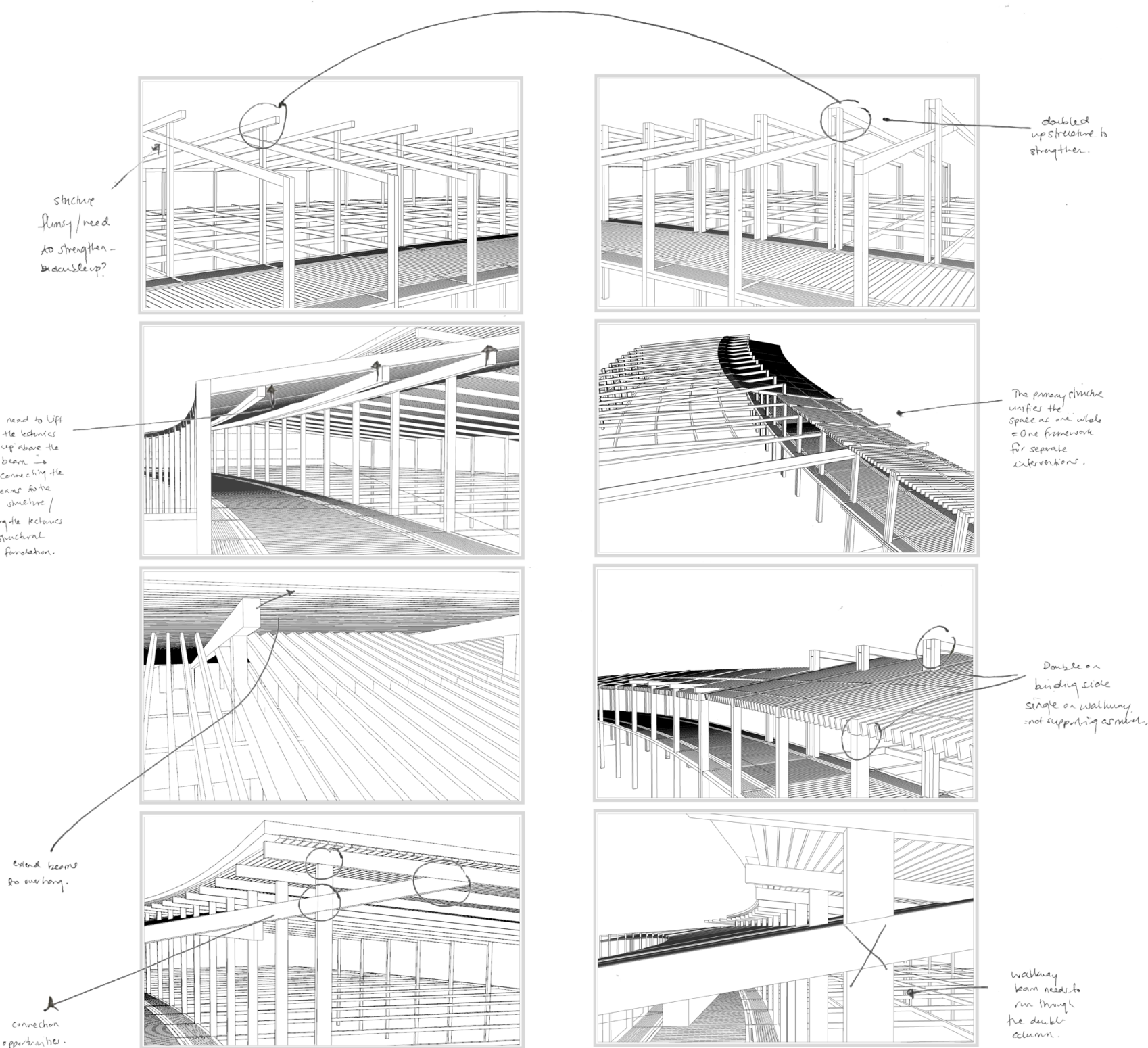

Fig.81. Digital development. 


\section{FORM DEVELOPMENT}

\section{CEILING DETAIL}

The initial ceiling development was derived through considering what the user would see when walking across the walkway intervention. After analysing the presupposed field of vision, the ceiling detail became a clear opportunity to enrich the spaces visual expression.

The process of designing the ceiling tectonic detail revisited the idea of translation and the Māori motif of weaving was implemented. This began with an analogue process, translating the act of Māori lashing as seen in figure 82 and shifting this optical into a two - dimensional surface (figure 83).

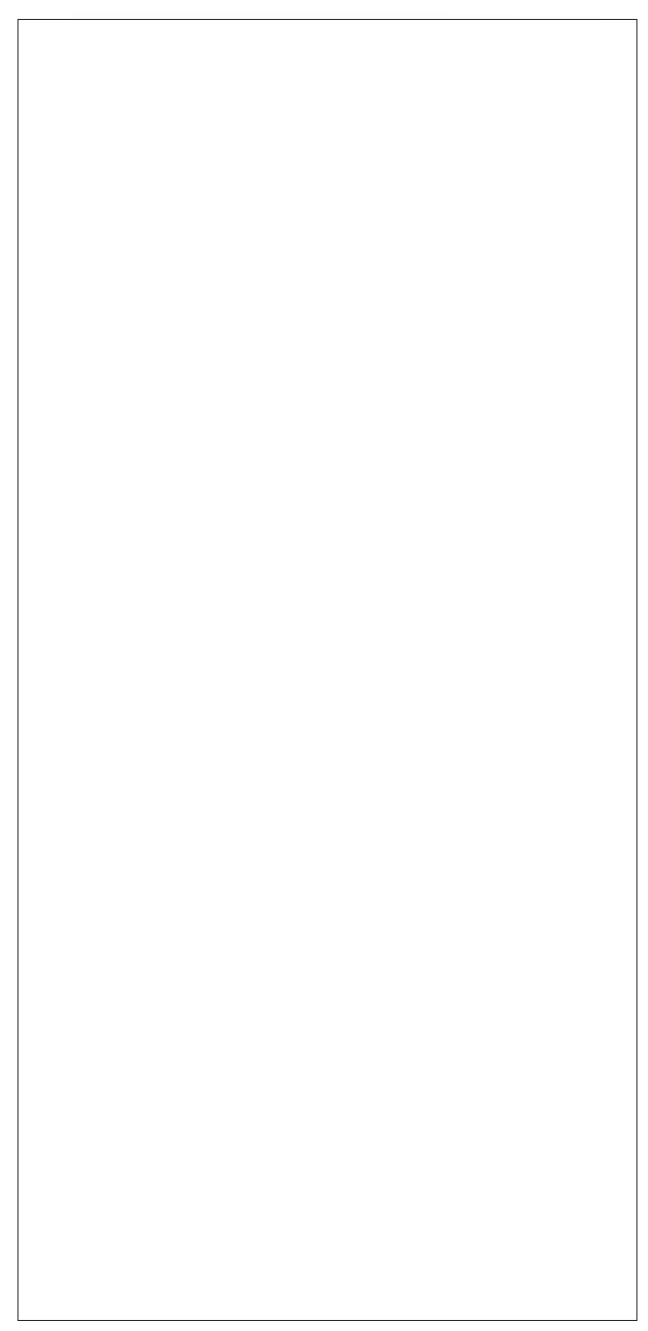



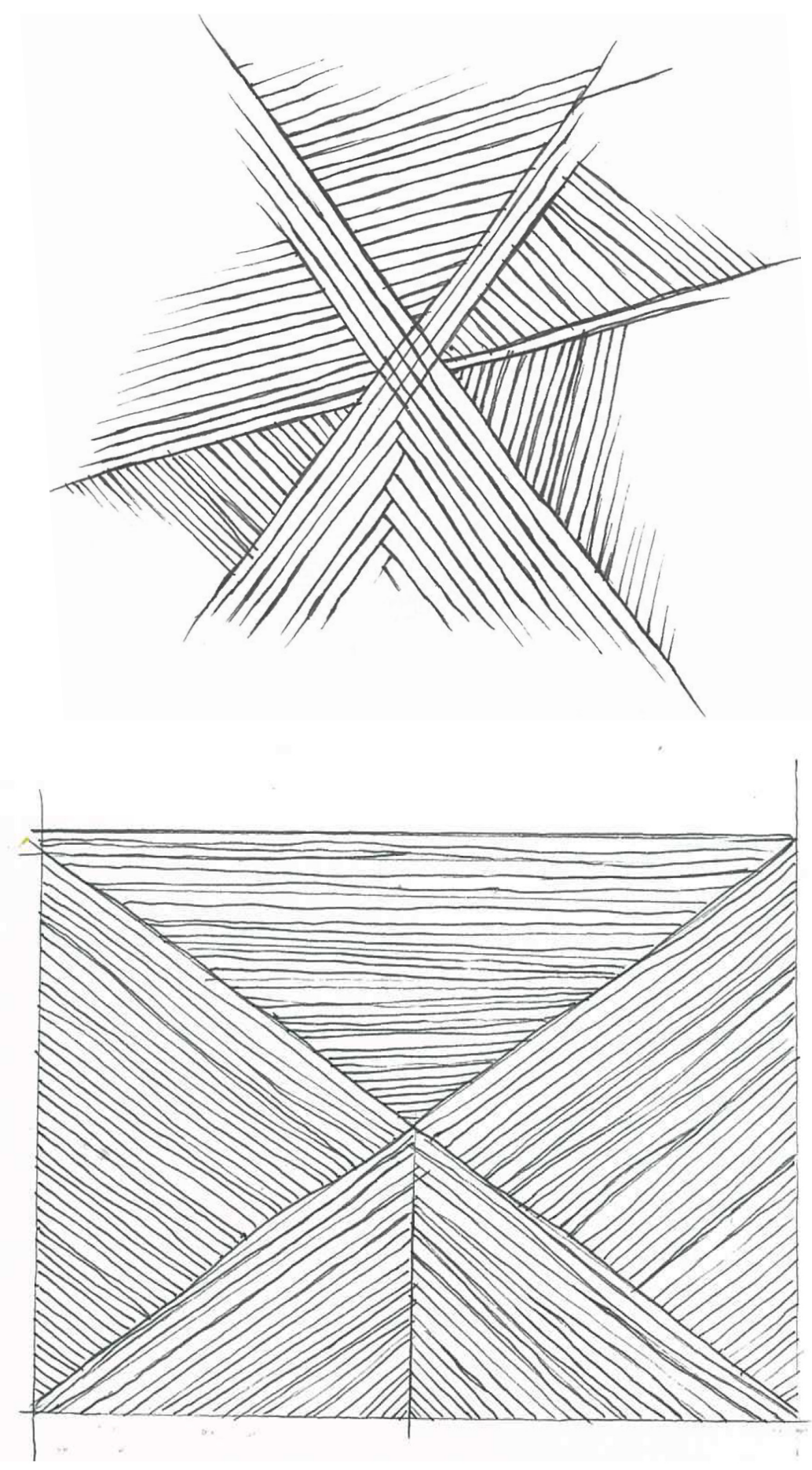
WALKWAY \& BUILDING INTERSECTION

\section{CEILING DEVELOPMENT}

This surface was then digitally modeled as the roof plane (figure 84). Reflecting on this exercise, the visual outcome was not the desired outcome, as when combined with the essential ceiling structure, the visual did not depict the clean simple aesthetic of the original lashing motif (figure 83).
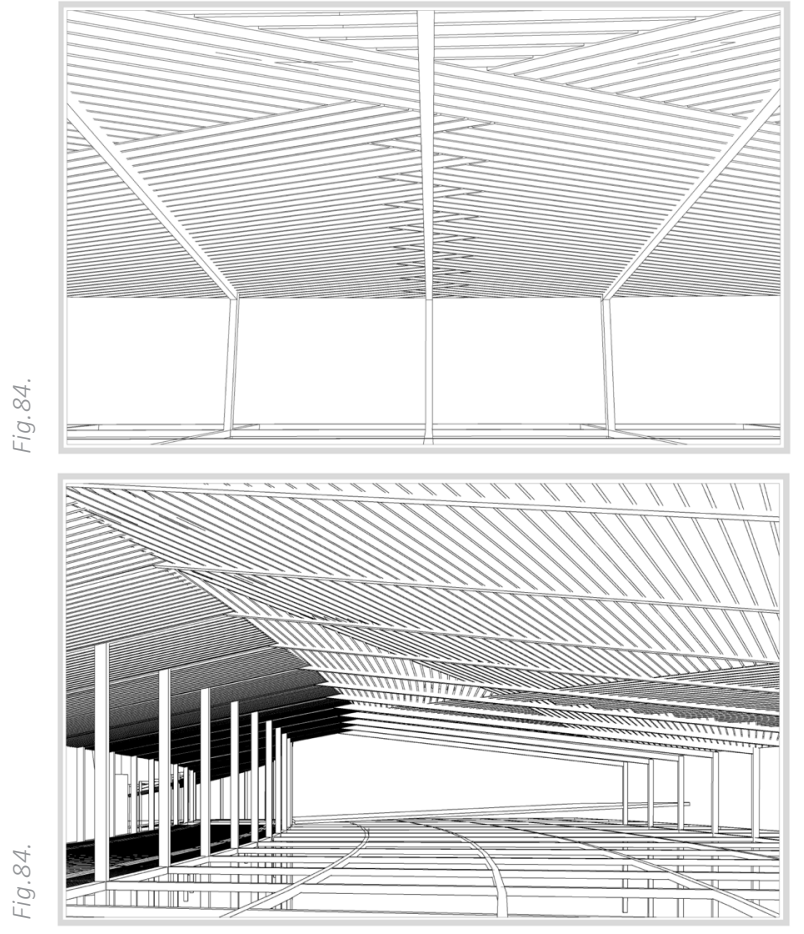
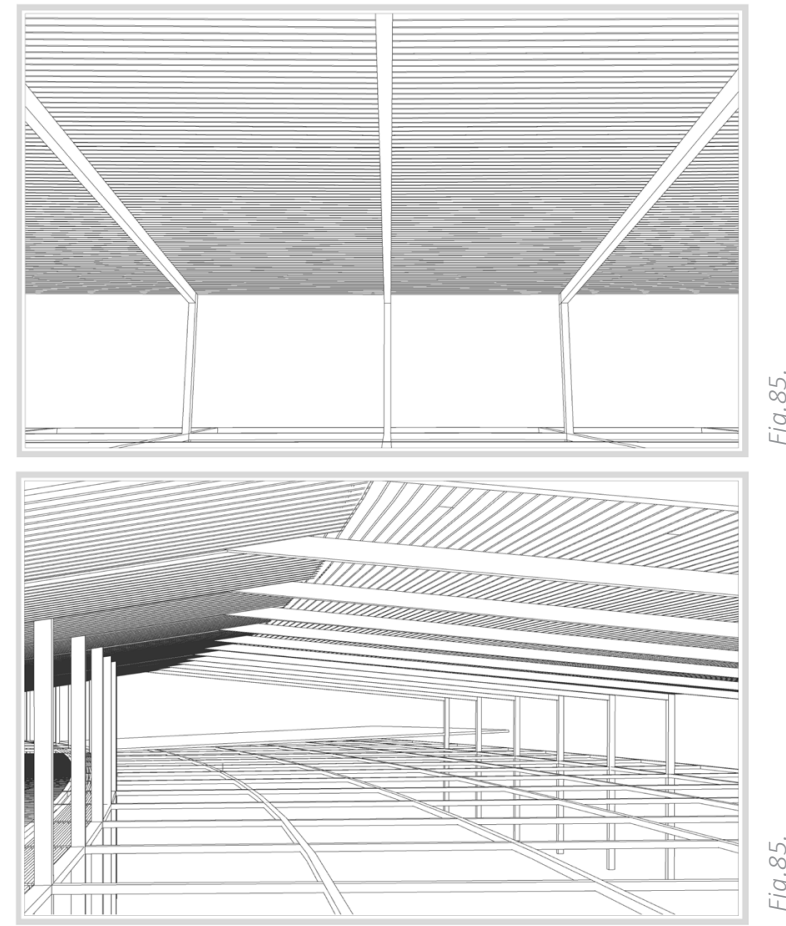


\section{CEILING DEVELOPMENT}

Further exploration led to remodelling the ceiling plane in a simple linear manner (figure 85) to instead focus on using the interaction between the walking tectonics and the marketplace ceiling as the focal opportunity for exploring a woven expression. Thus, the visual connection between the walkway and the marketplace ceiling translates the Māori motif of weaving into architectural form through creating visual depth with the layering of tectonics.
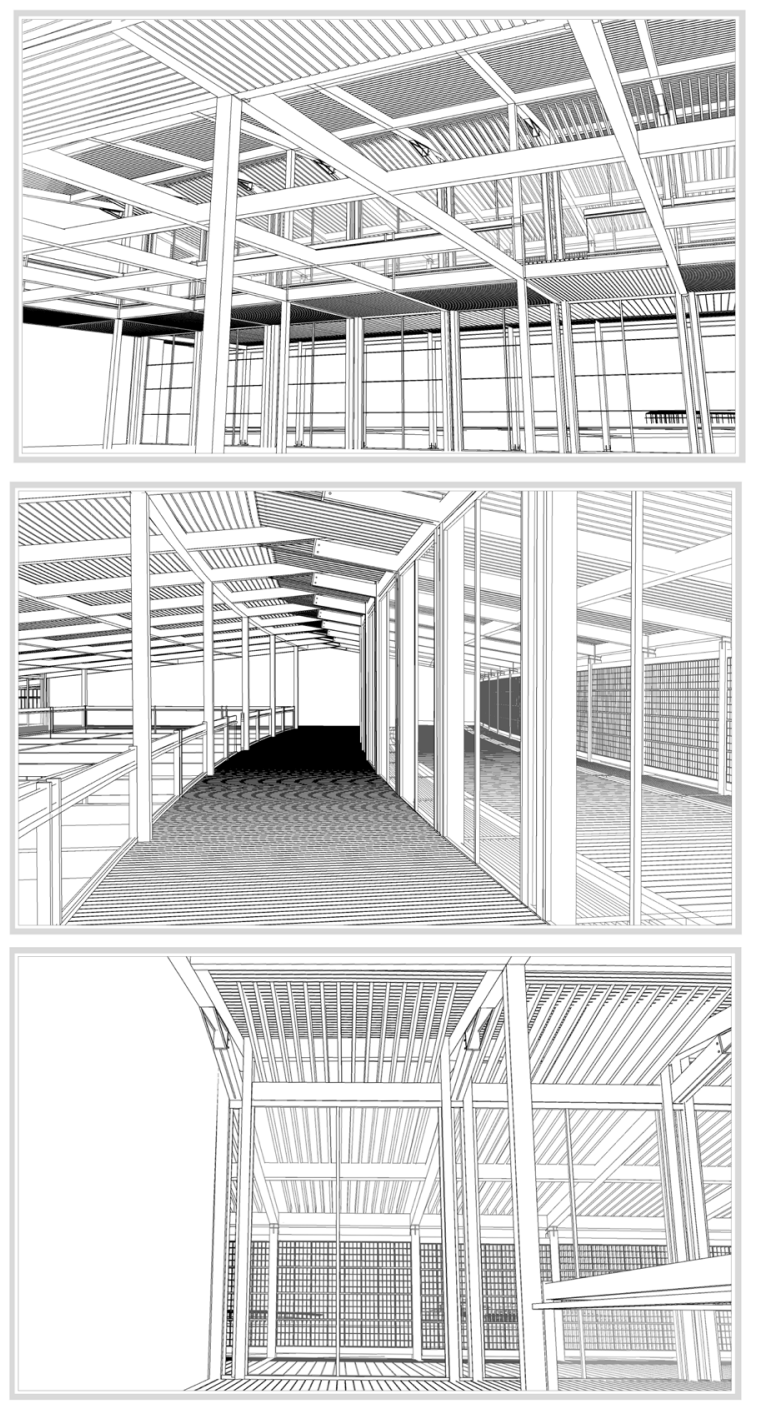


\section{FORM DEVELOPMENT}

\section{DAYLIGHTING}

Figures 87 and 88 illustrate a daylighting exploration. Due to the ceiling composition needing to remain visually unimpaired, daylighting into the upper floor was to be approached in a subtle manner. This process was achieved through digital and analogue exploration, testing and trialling until the desired approach was identified.
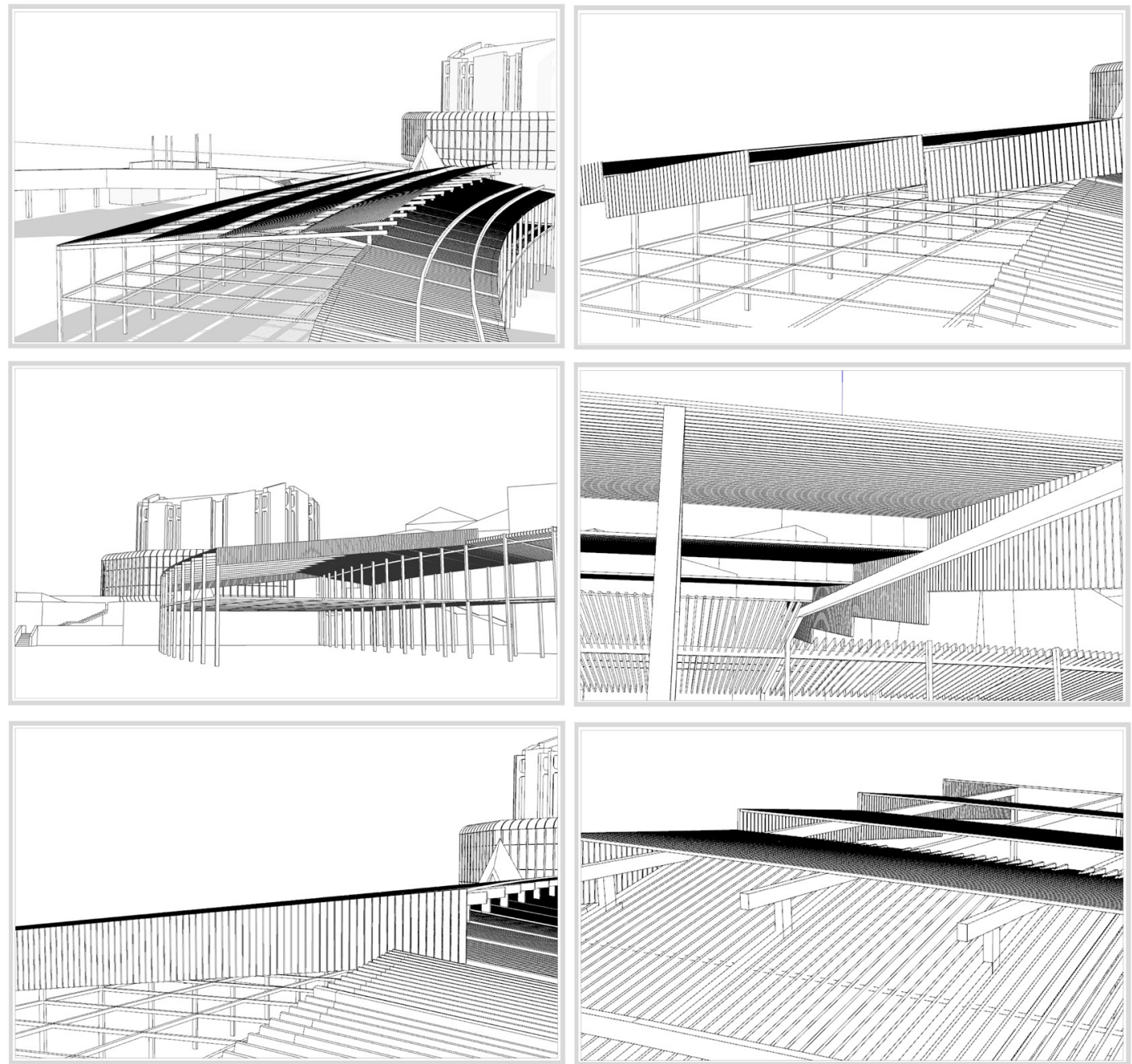

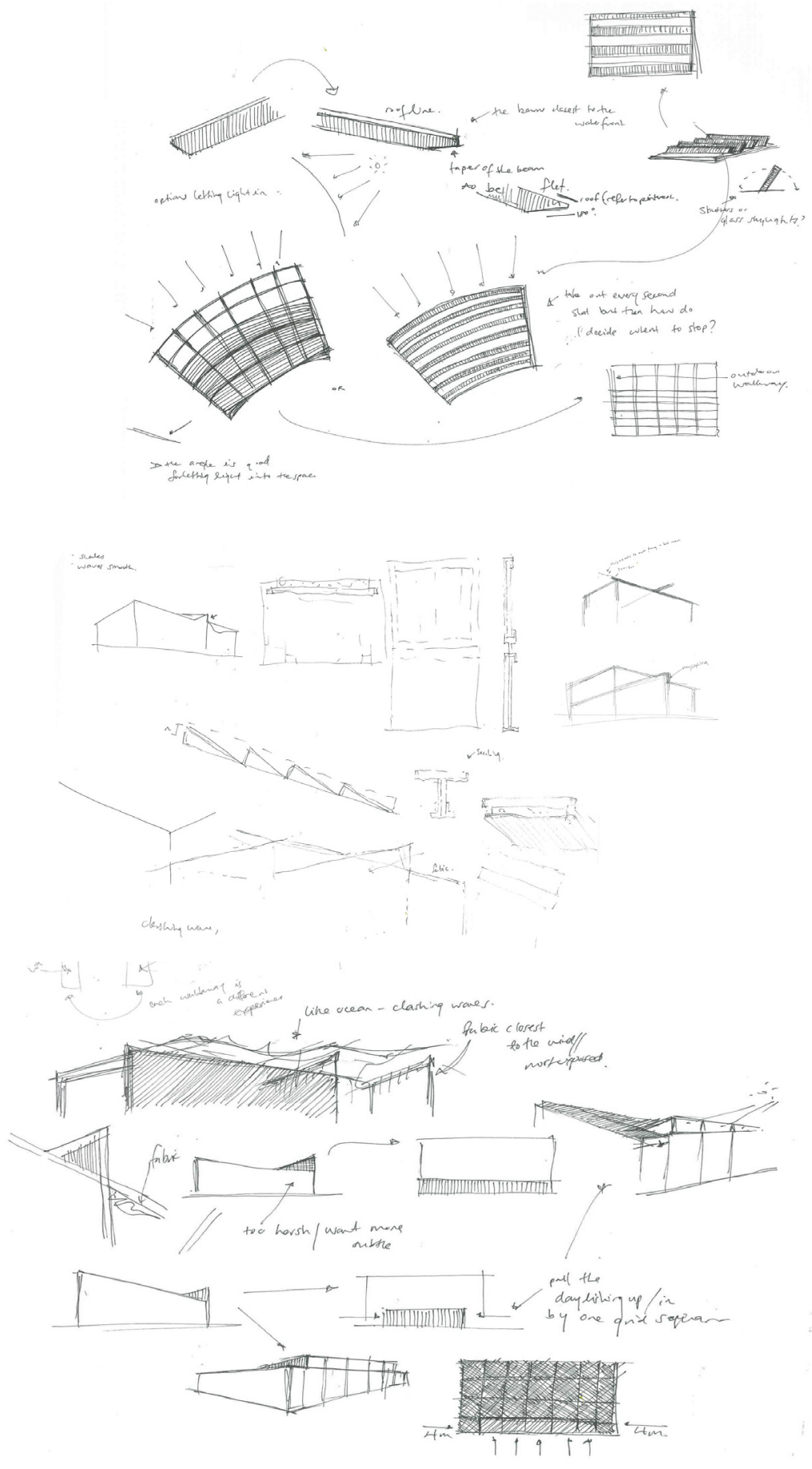
ROOF DEVELOPMENT

Figure 87 shows an initial exploration which was found unsuccessful due to its bold approach in the manner that it obstructed the flow of the ceiling detail. Figure 89 is the final outcome.
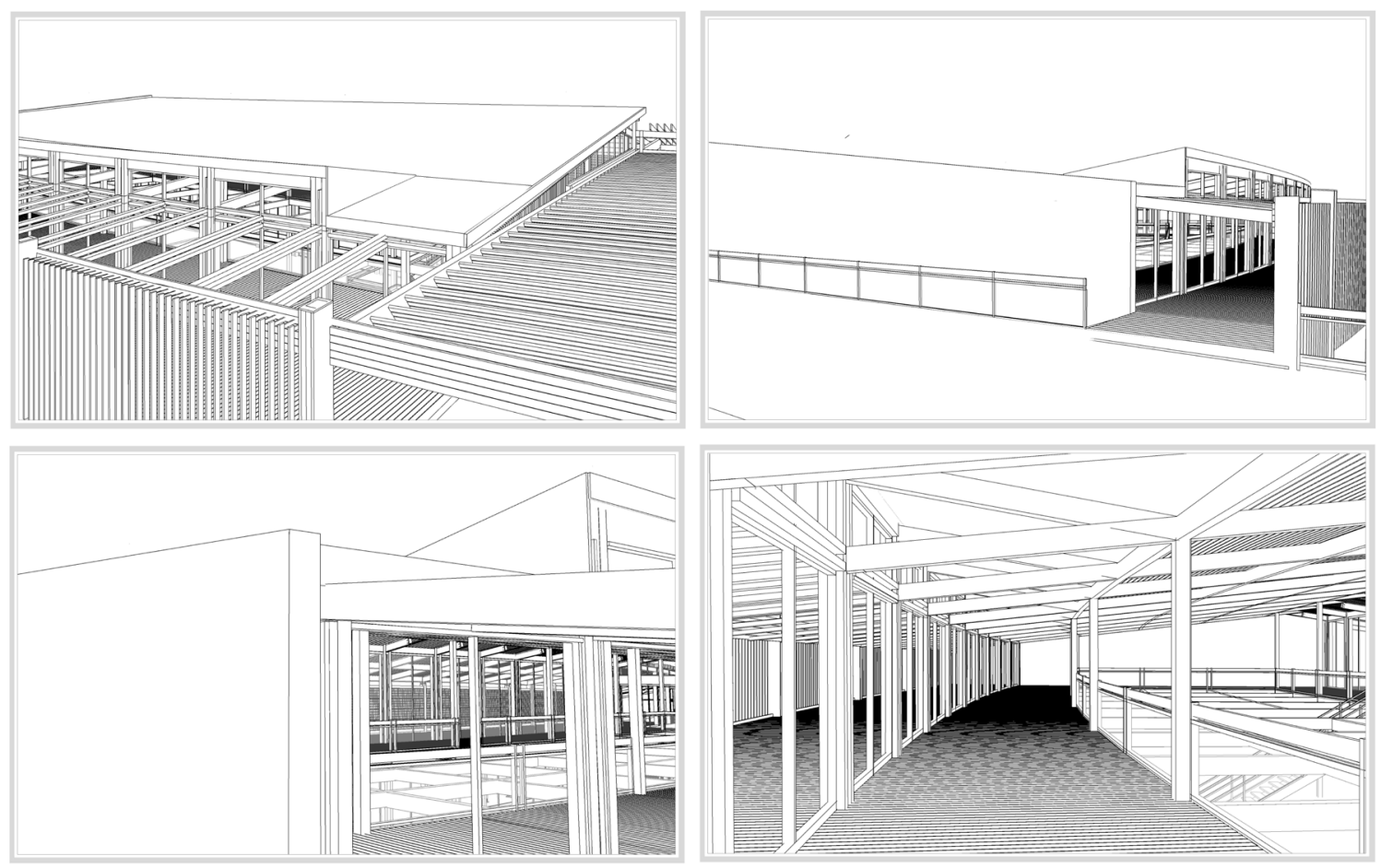


\section{SPATIAL DEVELOPMENT}

\section{WIND INTEGRATION}

This area of the design revisits the principles of critical regionalism explored in the human scale design process. The front façade of the building is identified as the façade directly facing Ilott Green (figure 30). The front facade faces the greatest exposure to the site's climatic conditions. This environmental exposure was influential in designing a space that plays with the interplay of light and shadow through a tectonic exploration. Wind was engaged through reintegrating fabric into the public scale design.
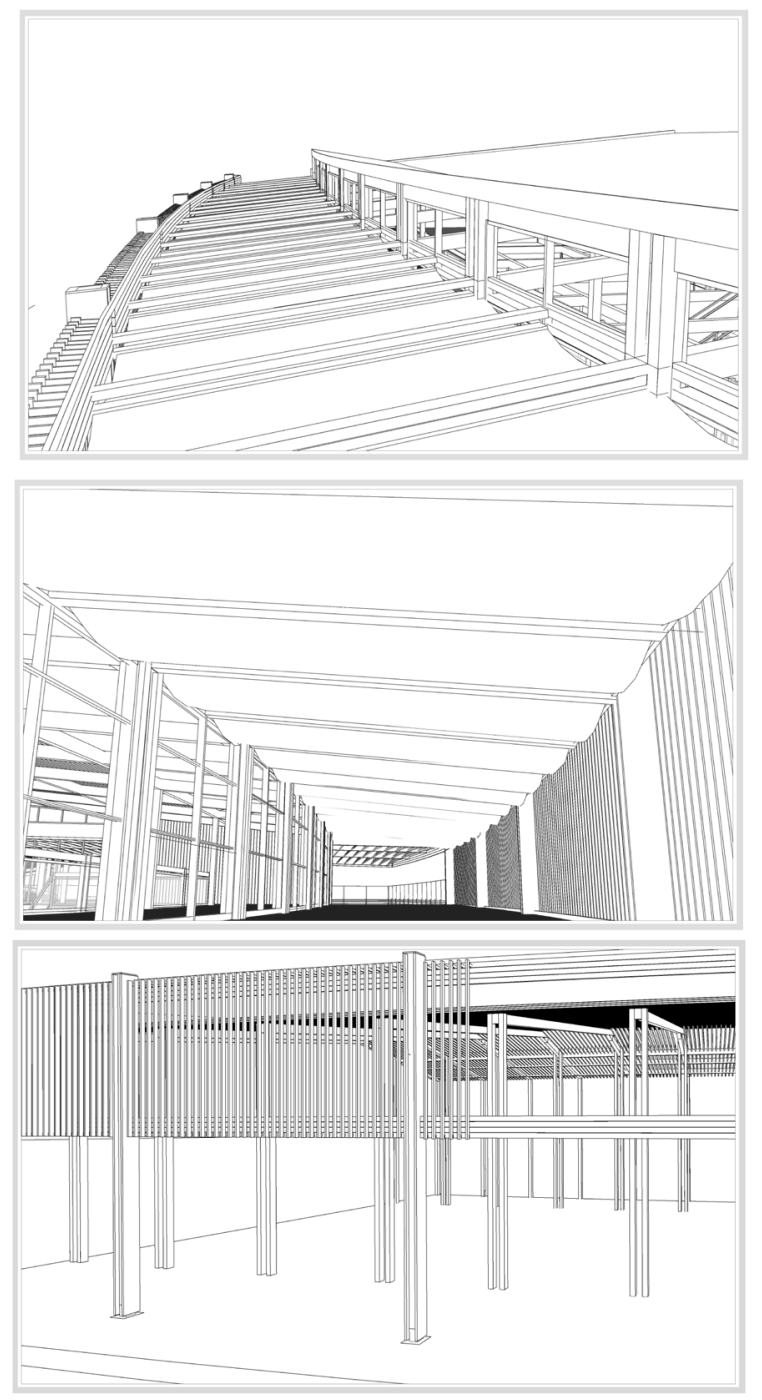


\section{SPATIAL DEVELOPMENT}

\section{EXHIBITION SPACE}

The core and the exhibition space were designed simultaneously, therefore for the purpose of curating this process in a linear format this account begins with the development of the exhibition space.

From the early stages it was clear that the exhibition space was to be treated separately to the marketplace environment. In doing so, the logical placement of this space was alongside the marketplace, however this meant that there would be an obstructive structure placed in the prime view shaft location as identified in the early site analysis chapters.

This influenced the lightweight design of the space - which aimed to avoid obstructing the view of the waterfront as little as possible.
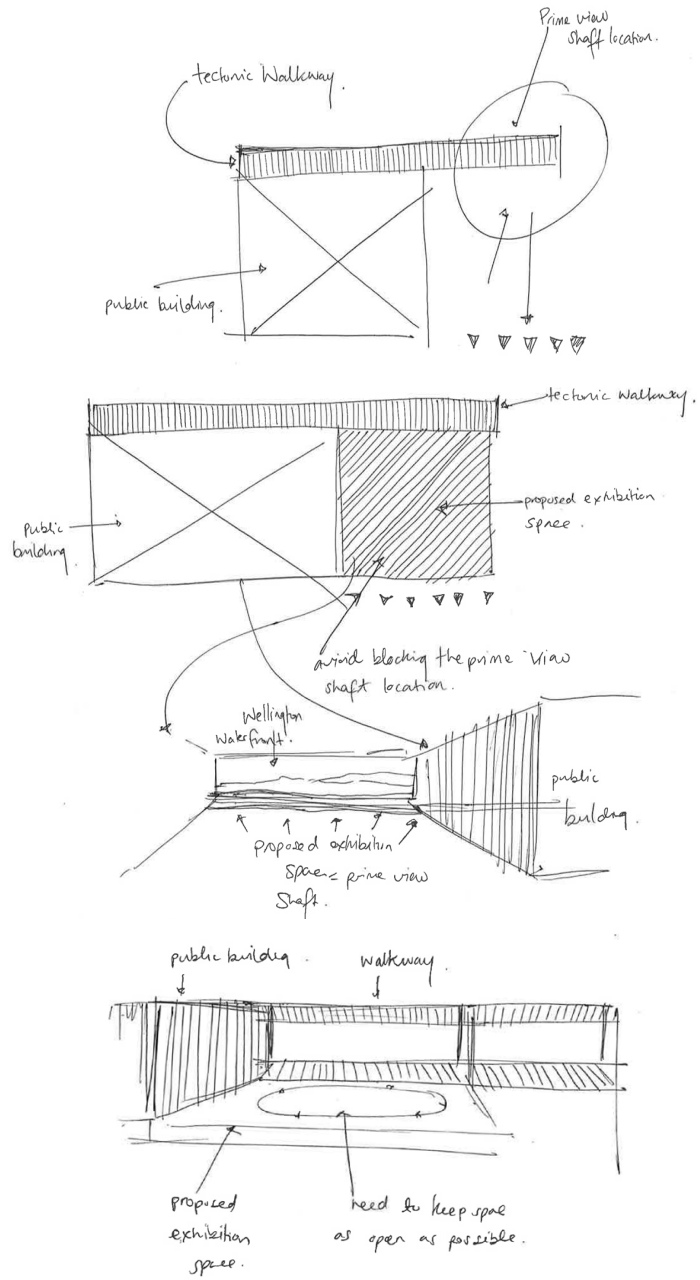

Fig.91. Spatial development sketching. 

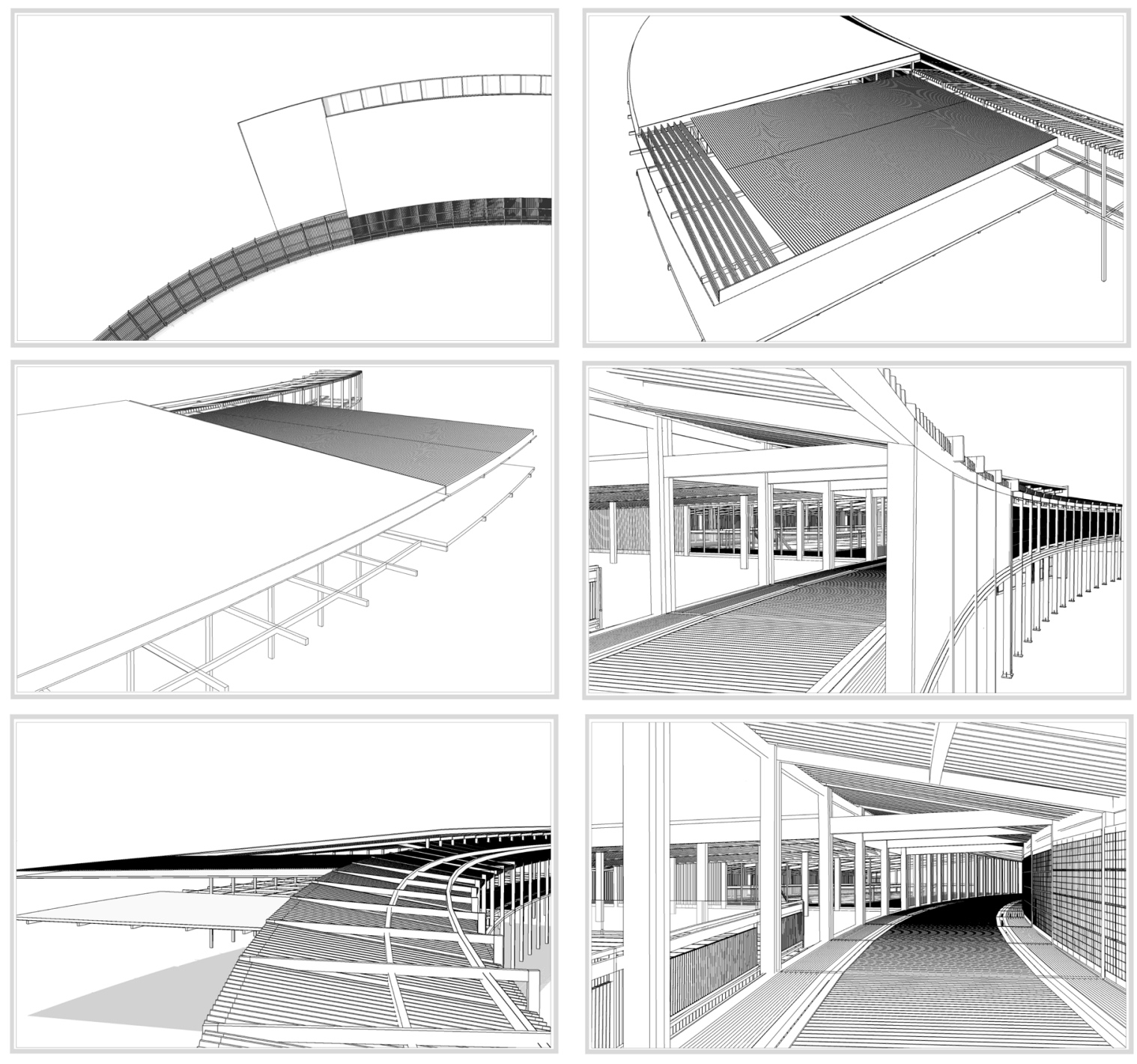

EXHIBITION SPACE

SPATIAL DEVELOPMENT 


\section{SPATIAL DEVELOPMENT}

\section{CORE \& EXHIBITION SPACE DEVELOPMENT}

The core was established through an iterative process, evolving with the development of the overall building design. Upon understanding the spatial constraints of initially placing the core in the centre of the proposed marketplace (figure 94), it made sense to create an 'extension' to house both the core and exhibition space, allowing the marketplace to remain an open plan area, allowing a space for greater social interactions.

It was important to consider the site vertically, and the core penetrates the vertical layering of the site. The core is designed with two levels for practical reasons, primarily enabling greater space for storage and waste, responding to the functional needs of the marketplace. This underground area also enables below ground service access for resources such as food delivery and rubbish removal.
1. Comms Room
4. Rubbish Room
2. Storage
5. Womens bathrooms
3. Refrigerator
6. Mens bathrooms
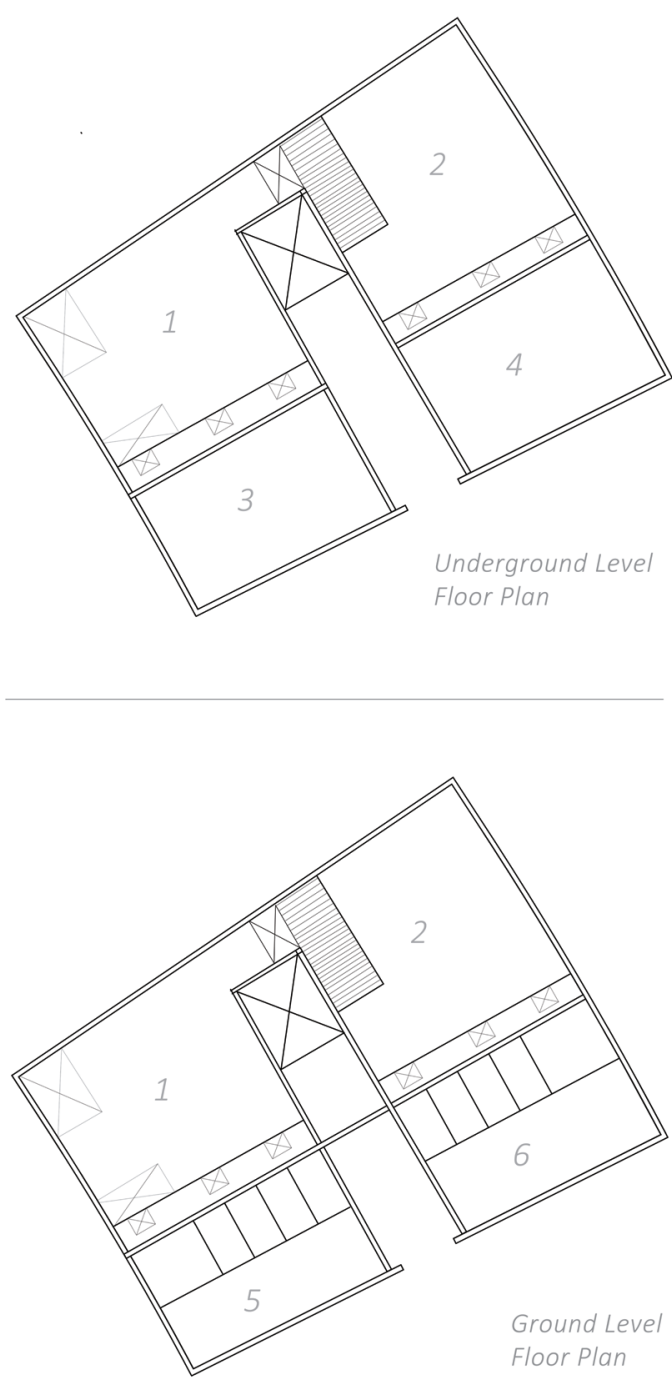

Fig.93. Core development plan diagram. 
CORE INTEGRATION

SPATIAL DEVELOPMENT

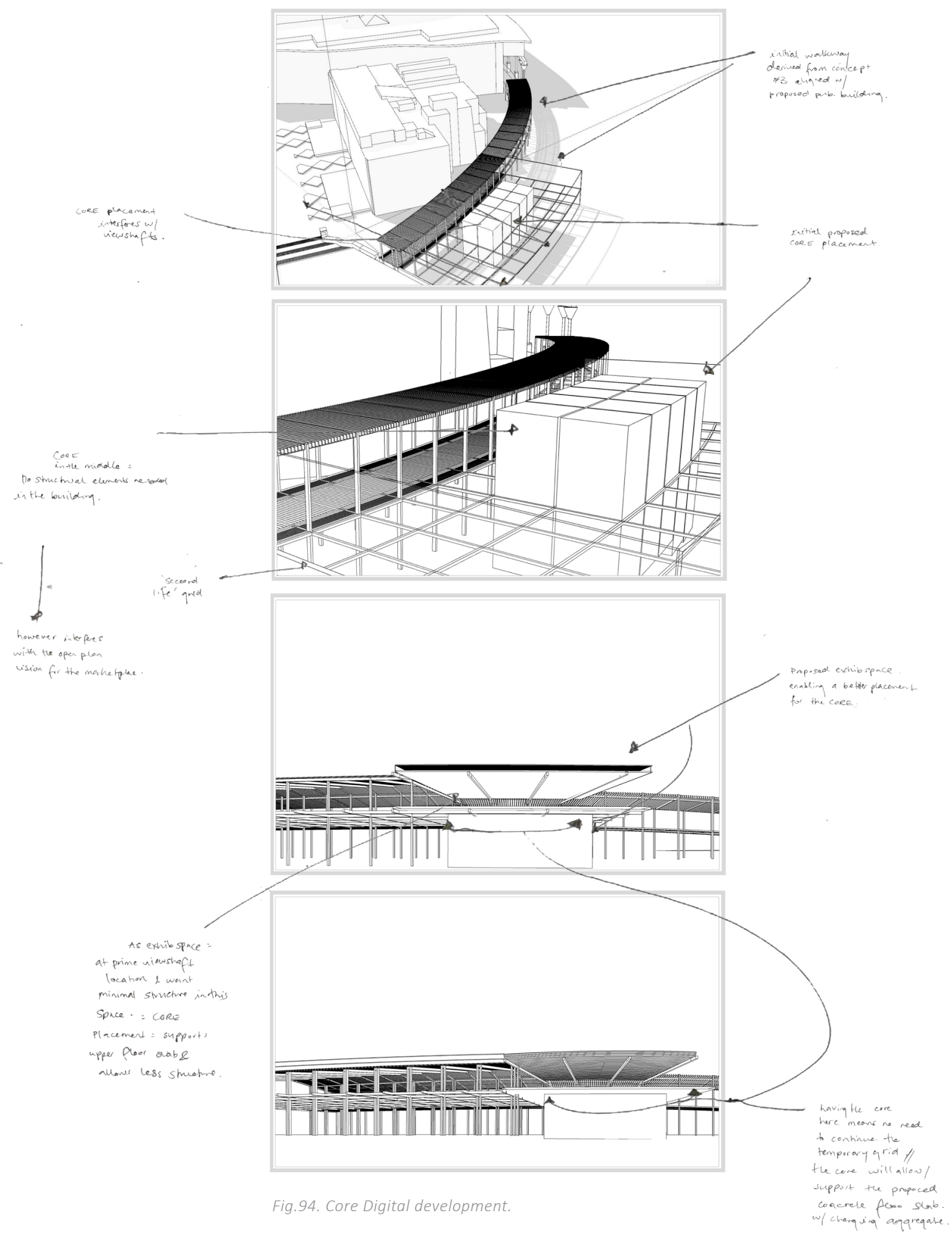




\section{SPATIAL DEVELOPMENT}

\section{EXHIBITION DETAIL \\ Exploring the qualities of surface}

The finishes of surface materials, the colour and texture of surfaces, and the 'built-in' objects and furniture are all elements that have the ability to contribute to the legibility of a building. The qualities of a surface such as colour, texture, hardness, form, and transparency have the capacity to create and enhance a buildings expressive potential and in turn, inform the overall experience of the architecture.

In exploring the qualities of surface, the exhibition space is designed to translate the notion of the past through re interpreting the design focus of concept four in the human scale design installation (chapter six). This detail aims to translate the layers of the old shoreline through responding to the identified design properties of water through layering, flux, and tessellation (chapter five). This design feature seeks to capture the tidal pattern of the old shoreline through both the interaction between light, shadow and surface and the composition of surface. 


\section{SPATIAL DEVELOPMENT}

\section{EXHIBITION FLOOR}

CASE STUDY

Area of Flux

The interplay between light, shadow, and surface has been achieved with inspiration drawn from this Kings Road project, a case study developed by HUT Architecture (figure 94). The louvre system used in this project in combination with the polished concrete floor effectively creates a dynamic aesthetic that alludes to the fluidity of water. Through incorporating this louvre system into the design, the space gives the impression of being in a constant state of flux, responding to the everchanging weather conditions of the site.

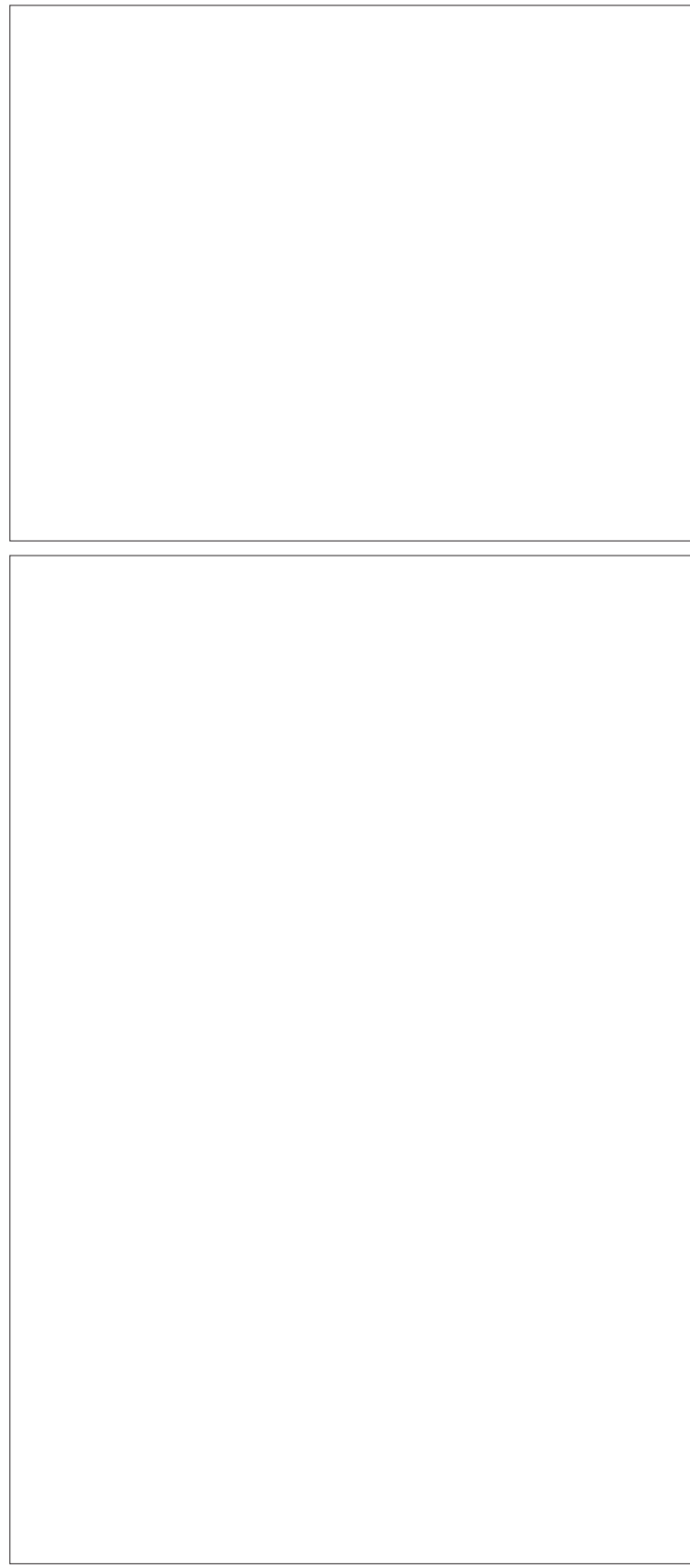

Fig.94. Kings Road, HUT Architecture 

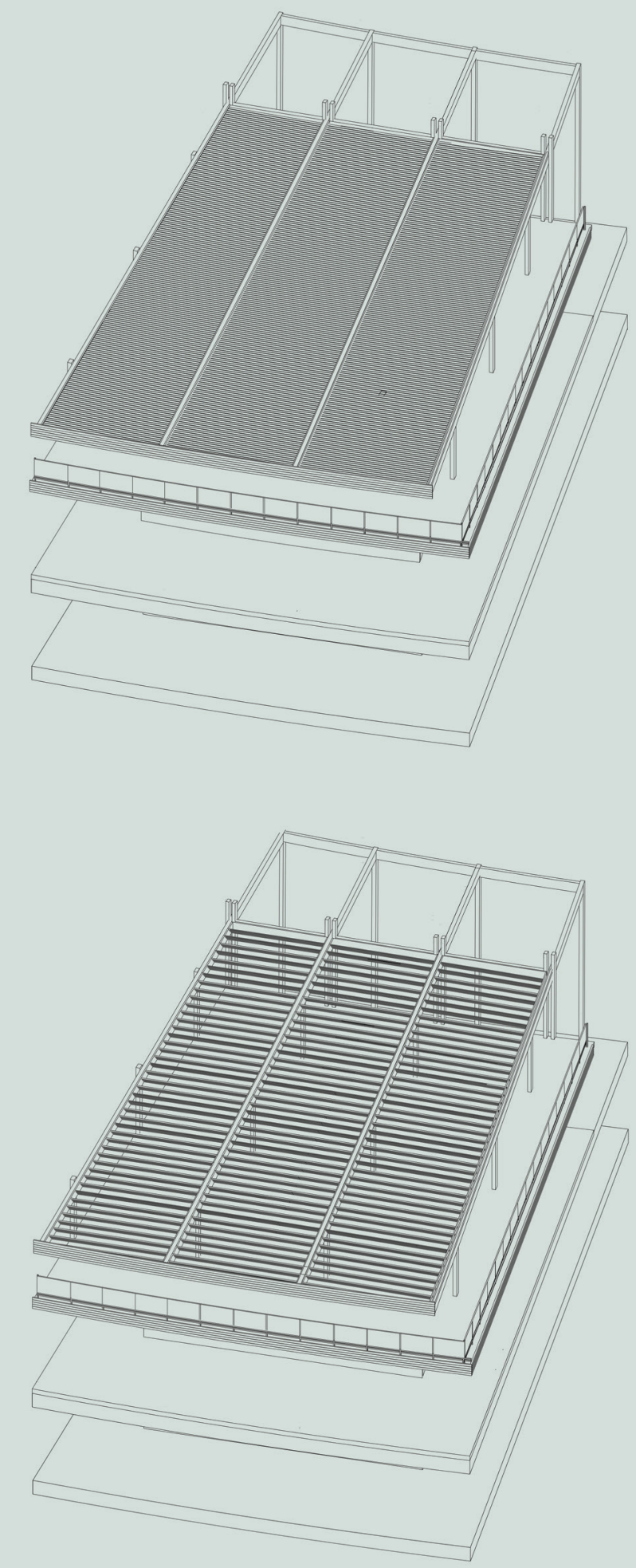
DETAIL DEVELOPMENT

Composition of surface

The qualities of the concrete surface allude to the old shoreline through exploring the subtle changing of the concrete's aggregate. Photographs were taken depicting the general flux of a shoreline capturing the marks left behind from the transitioning high and low tides (figure 96). Prior to reclamation, similar water marks were once left behind at this site. Drawing from these photographs, a watercolour drawing was produced to represent the proposed changing of the concretes aggregate (figure 97). 

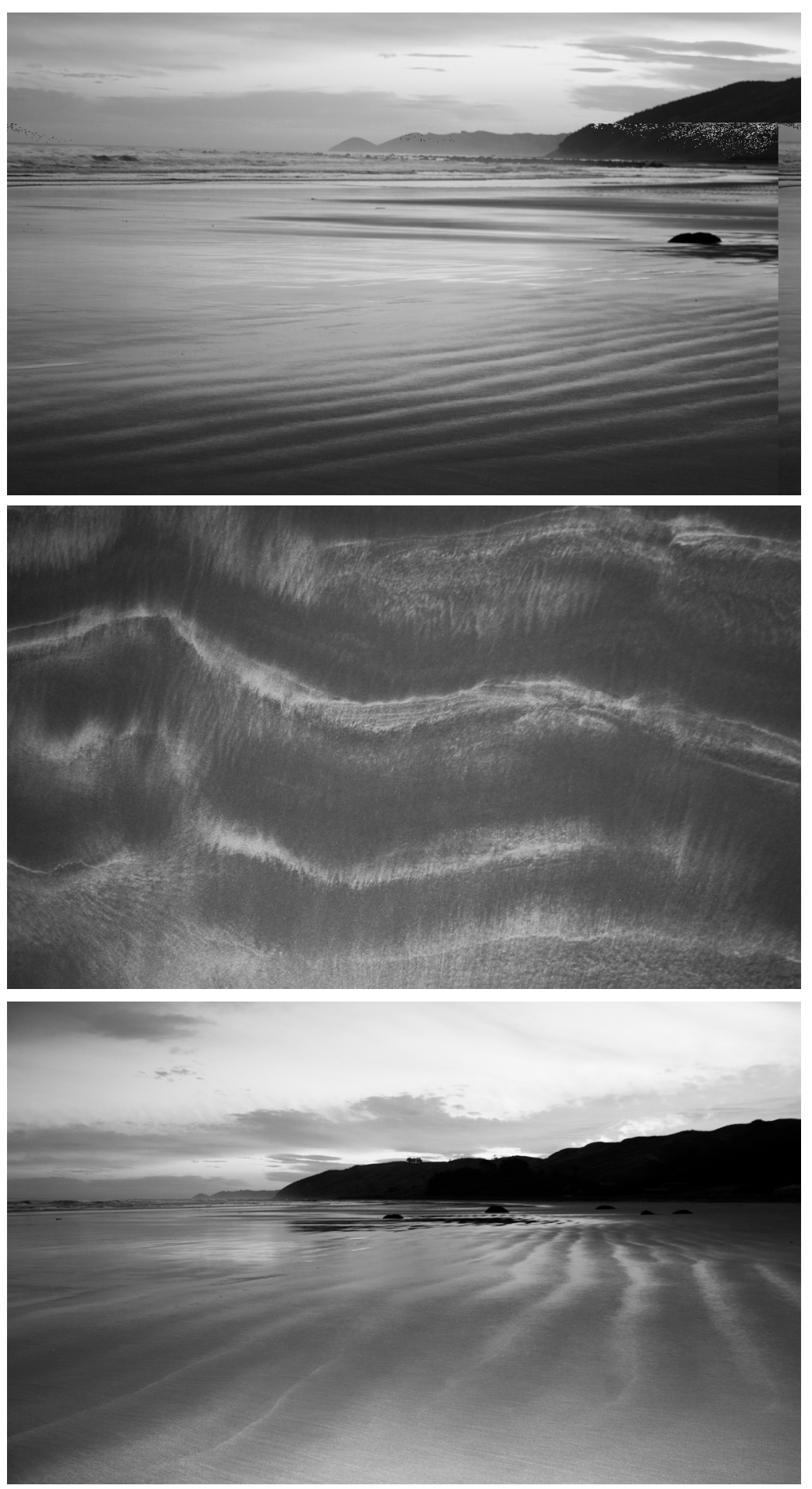


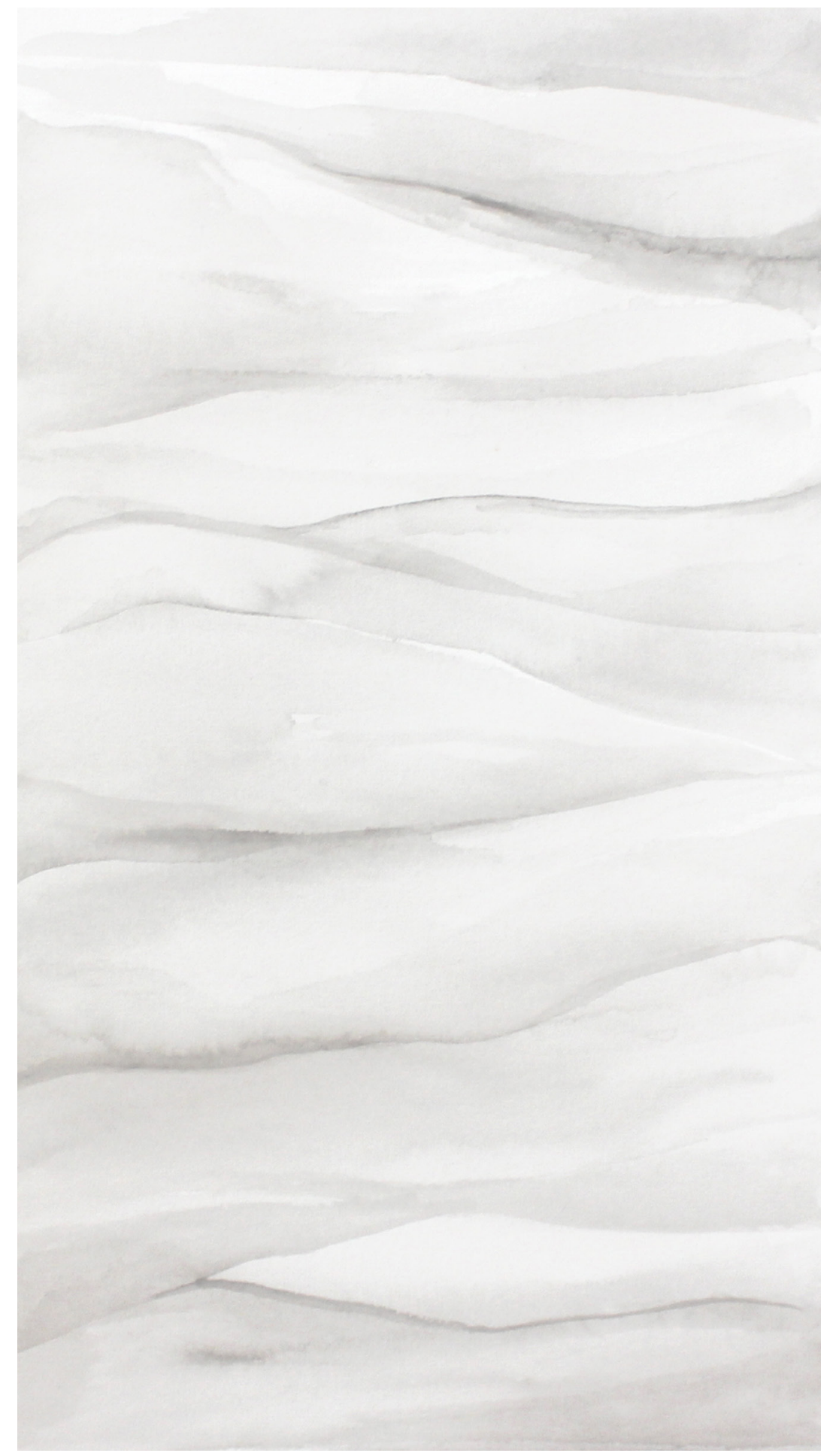




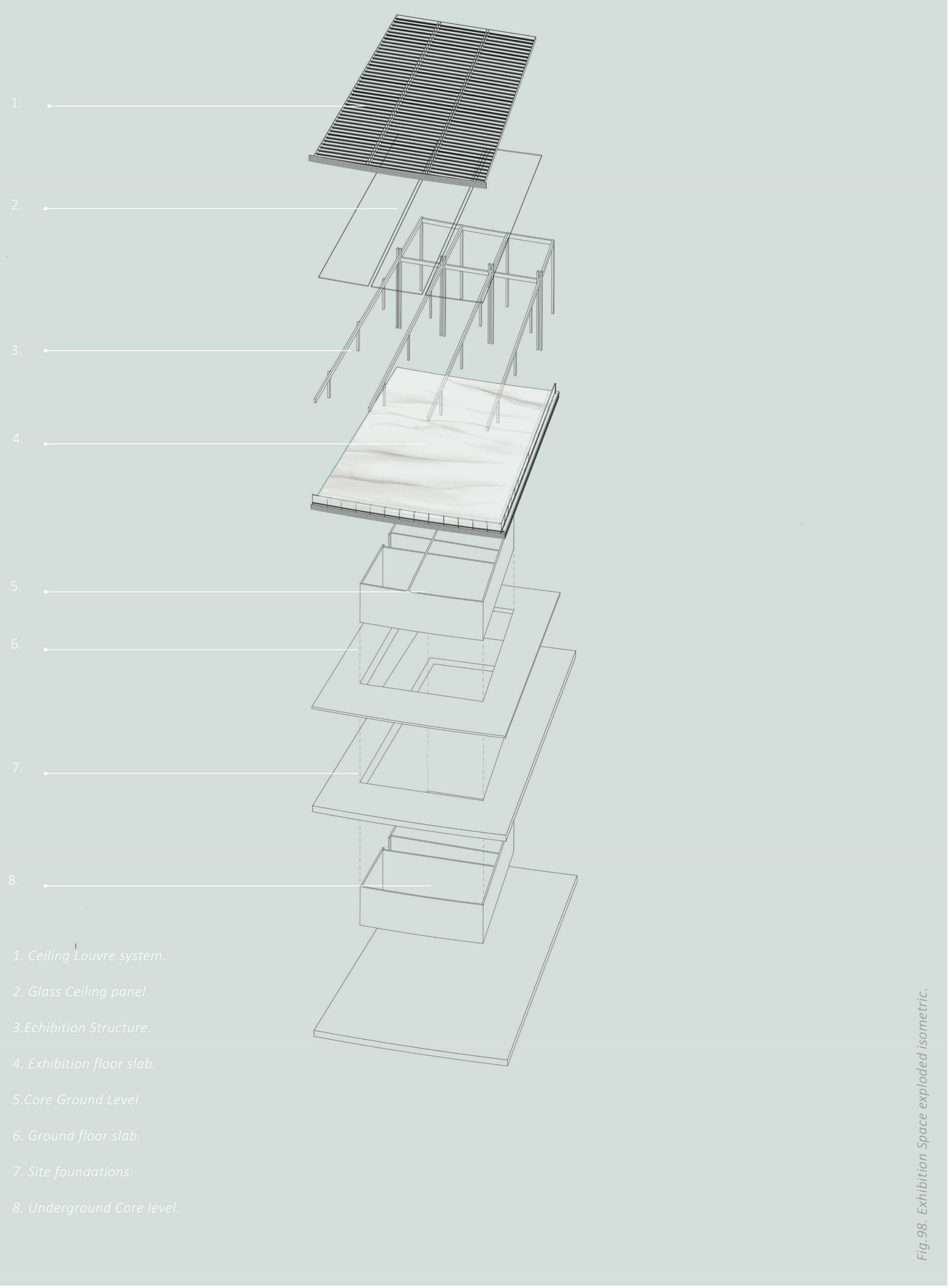




\section{DETAIL DEVELOPMENT}

\section{BALUSTRADE DETAILING}

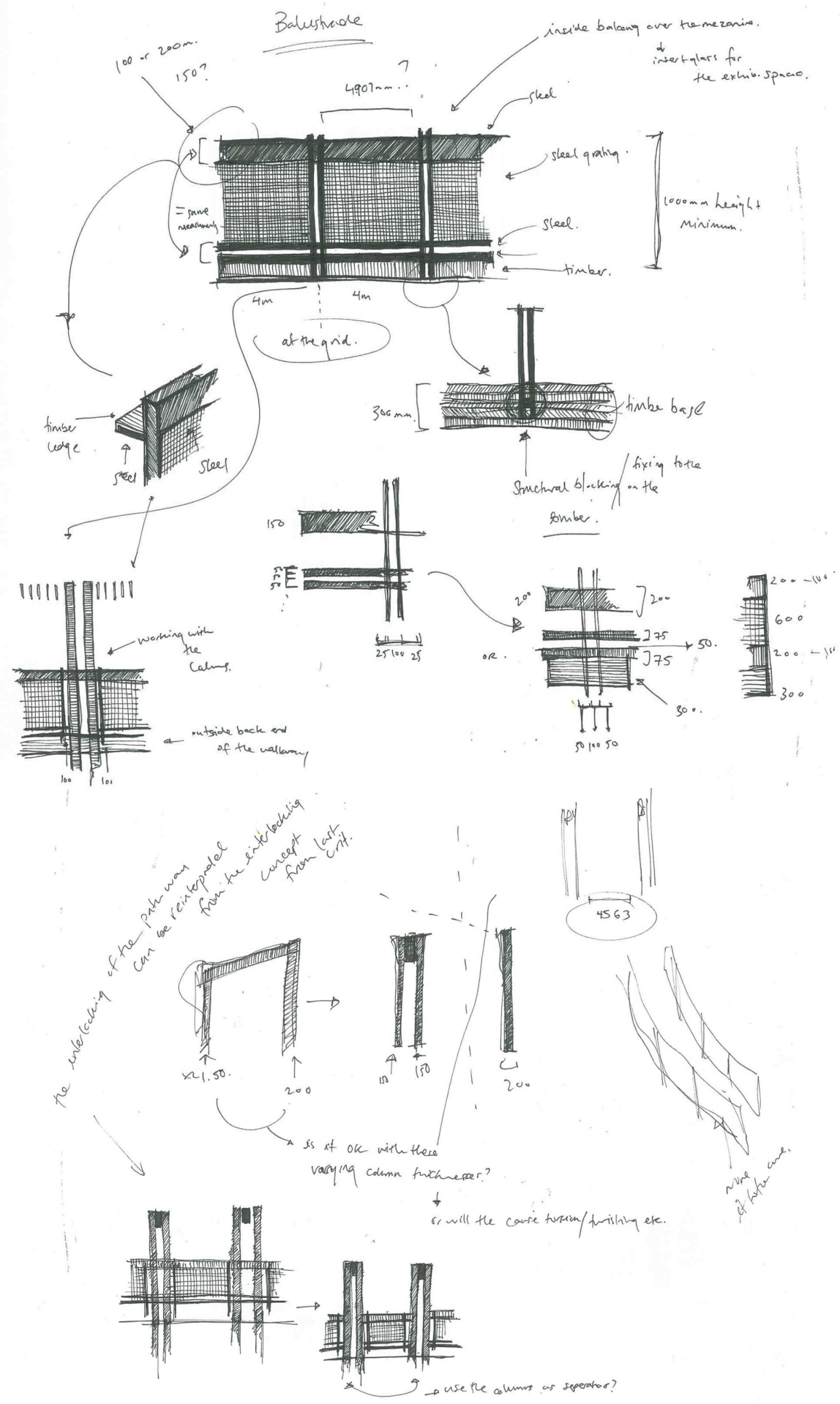


DETAIL DEVELOPMENT

The material makeup of the designed balustrades has been considered with relevance to the use of each space. The exterior balustrades are designed to be solely constructed from steel. Upon considering the maintenance of materials and due to the external placement of this balustrade, glass has been avoided. As the walkway is a public amenity, the lack of glass requires a lesser need for strict upkeep, assisting in keeping a cleaner and more inviting public space.
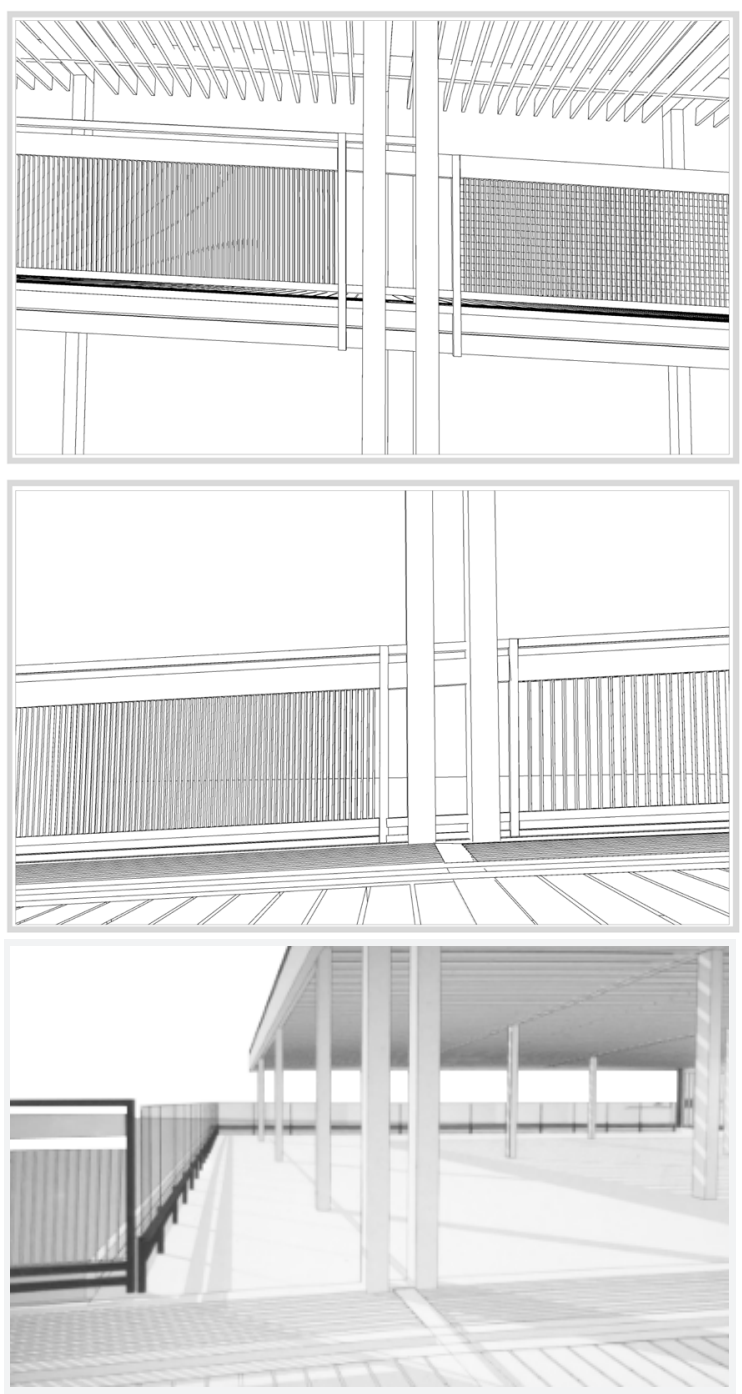

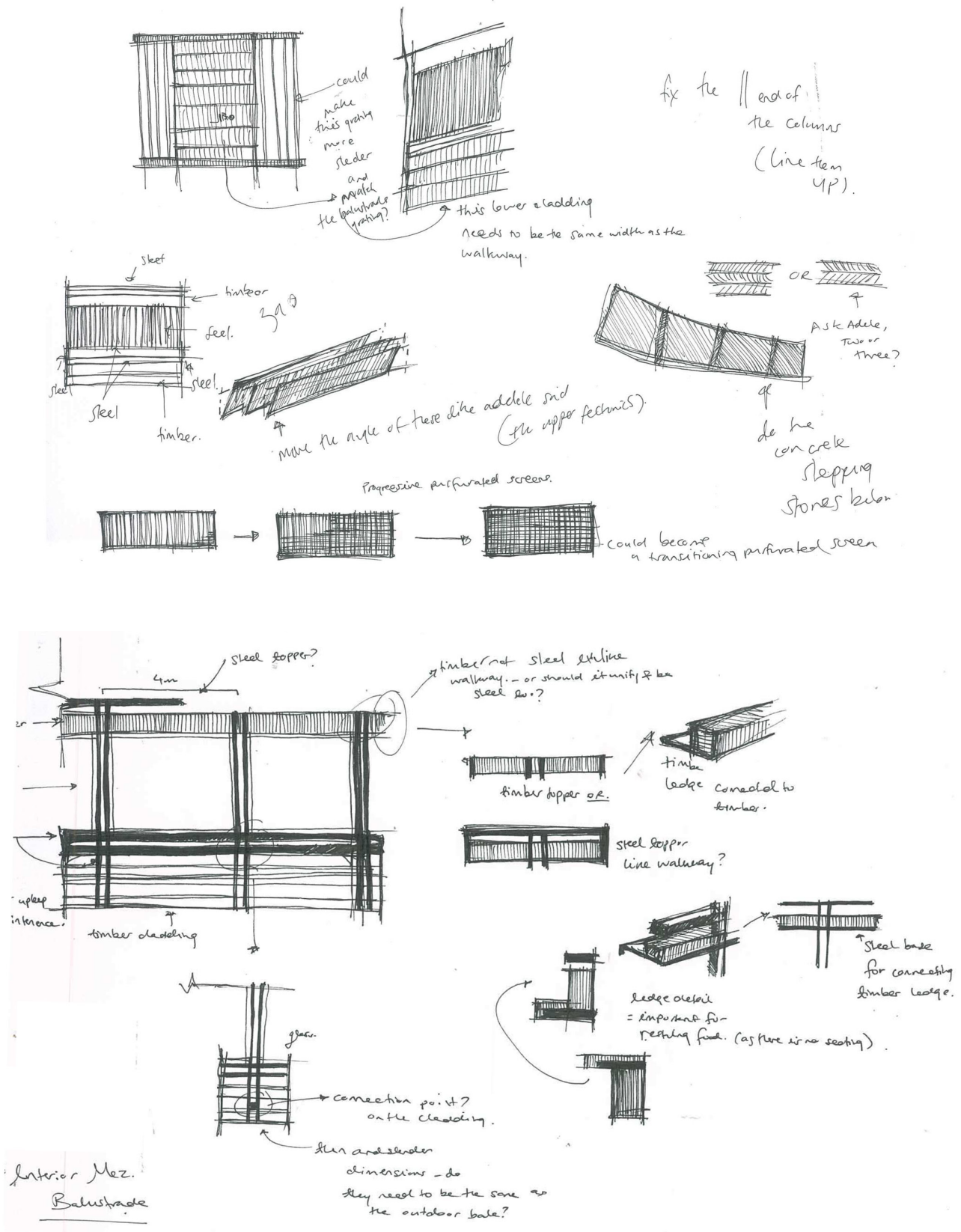


\section{DETAIL DEVELOPMENT}

\section{Exhibition Balustrade (figure 102).}

The exhibition space balustrade is designed to further enhance the unobstructive nature of this space. The seamless glass allows for a clear line of vision out to the waterfront, enabling the users view to directly the transition from the old shoreline rendered from the concrete floor detail, to the current shoreline projected through the waterfront viewshaft.

Interior marketplace Balustrade (figure 103).

The lightweight nature of the interior balustrade works to compliment the intricacy of the space, drawing a focus to the connections of contrasting designed elements.

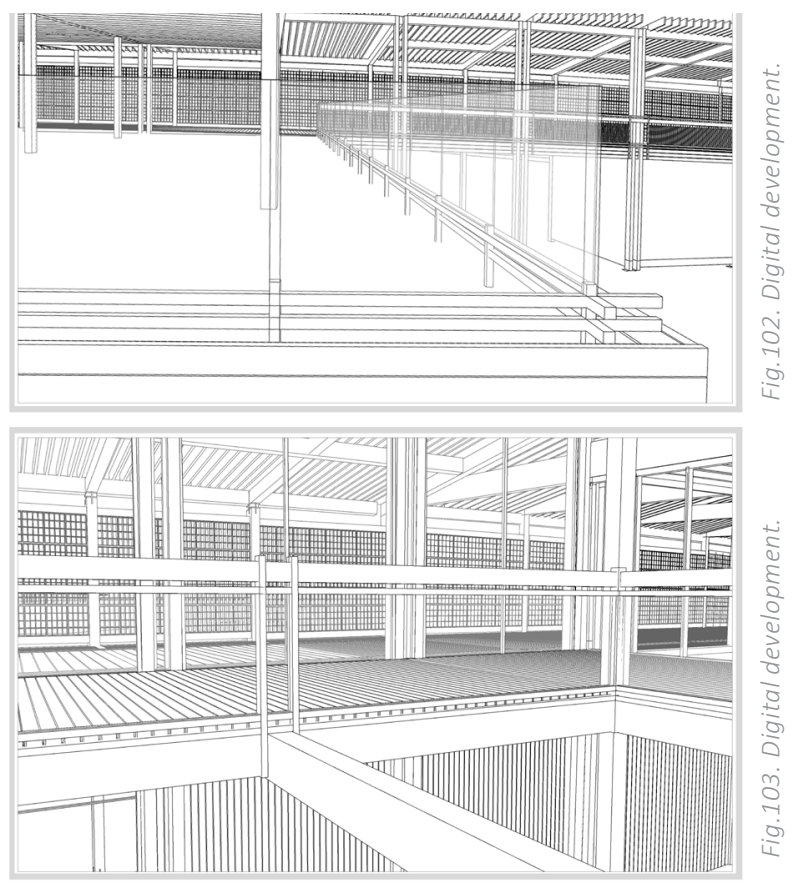




\section{DETAIL DEVELOPMENT}

\section{STEEL CONNECTIONS}

The layered tectonic curation of this design opens opportunity to explore the connections of the building's structural elements. It is important to create a different language to define these connections, enabling a visual separation between the tectonics and thus, creating depth amongst the layers.

The following details are designed with the same language, of which steel connections are used to not only strengthen the structural elements but add another layer to the building's overall framework. These structural connections look to symbolise structural bindings, 'weaving' the structural elements together to shape the foundations of the building.
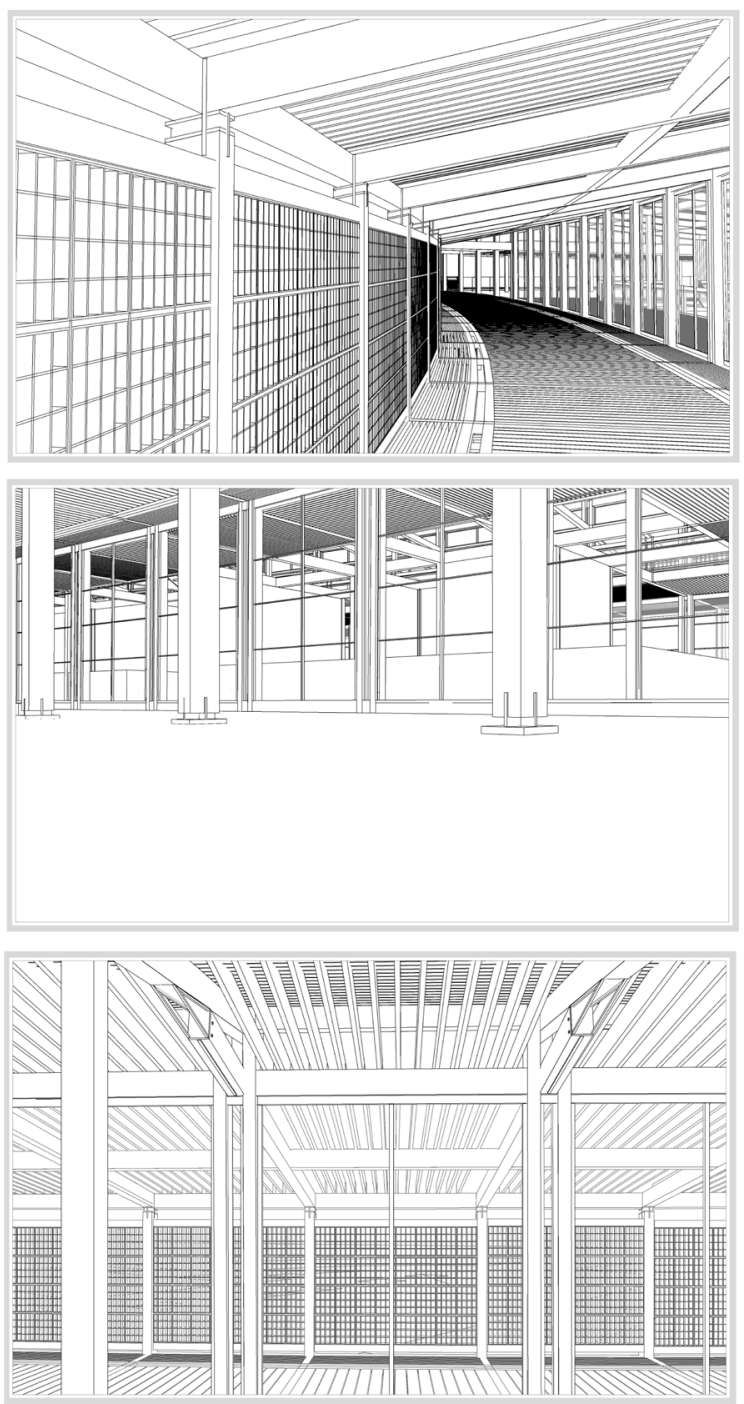

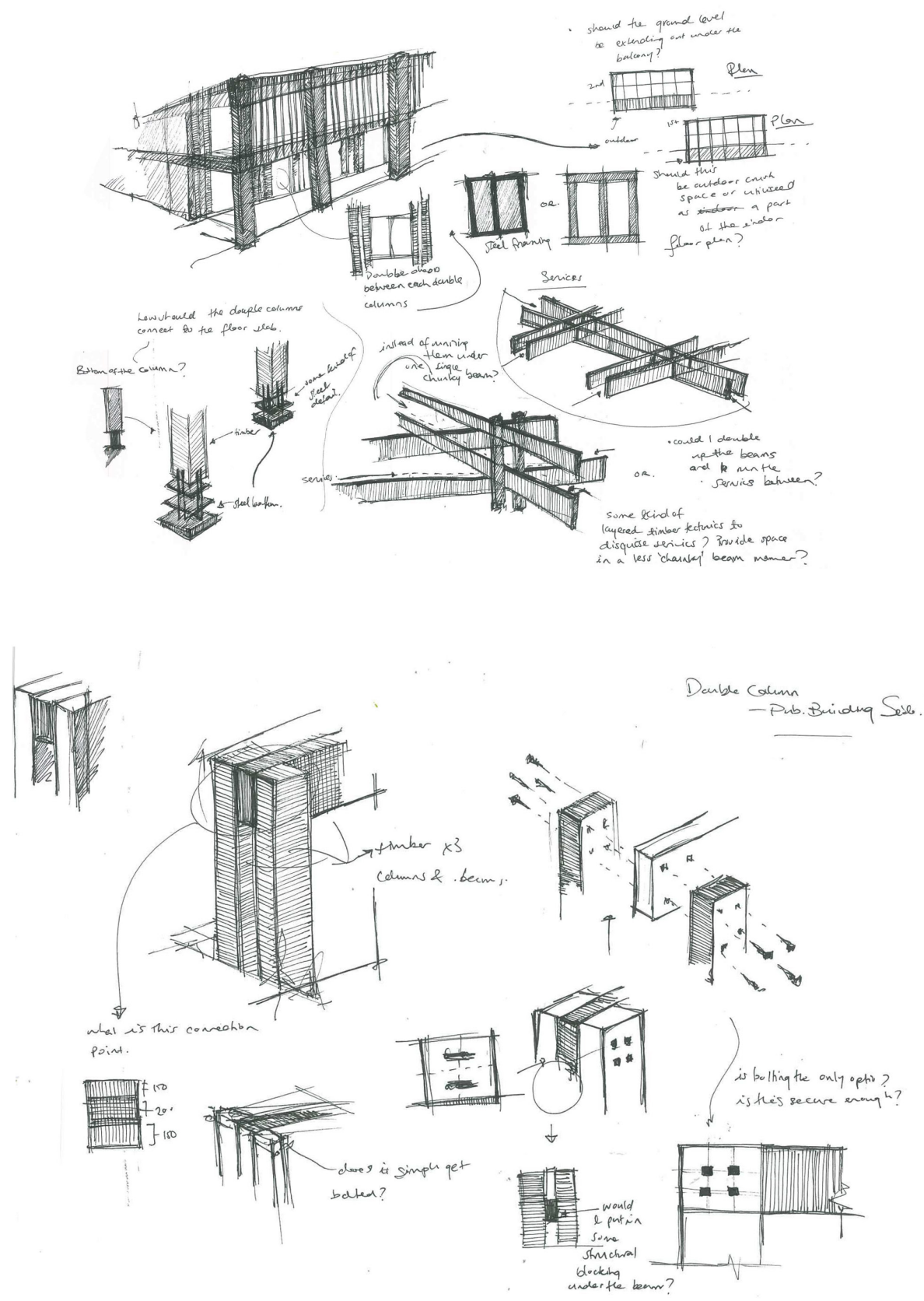


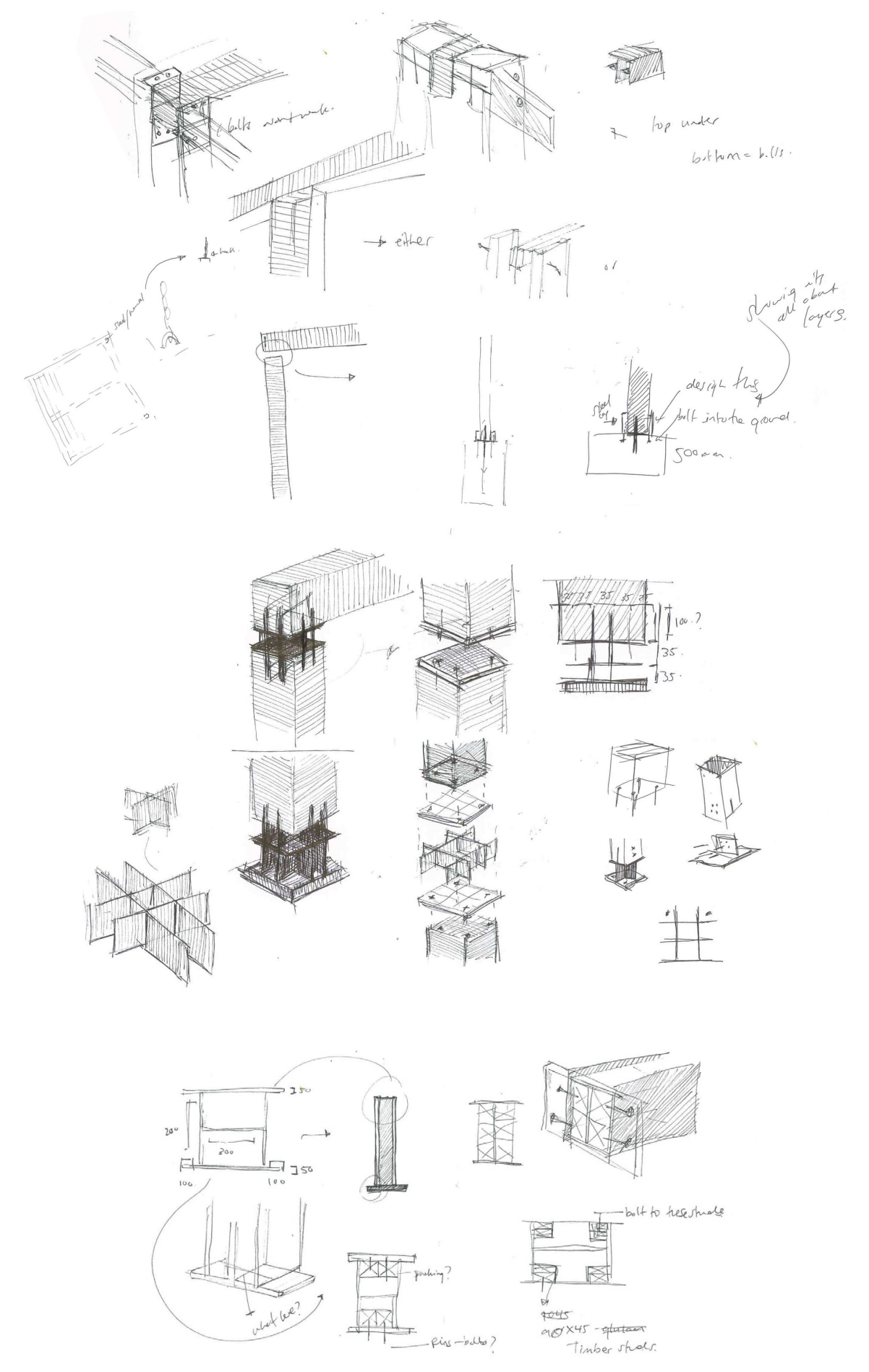




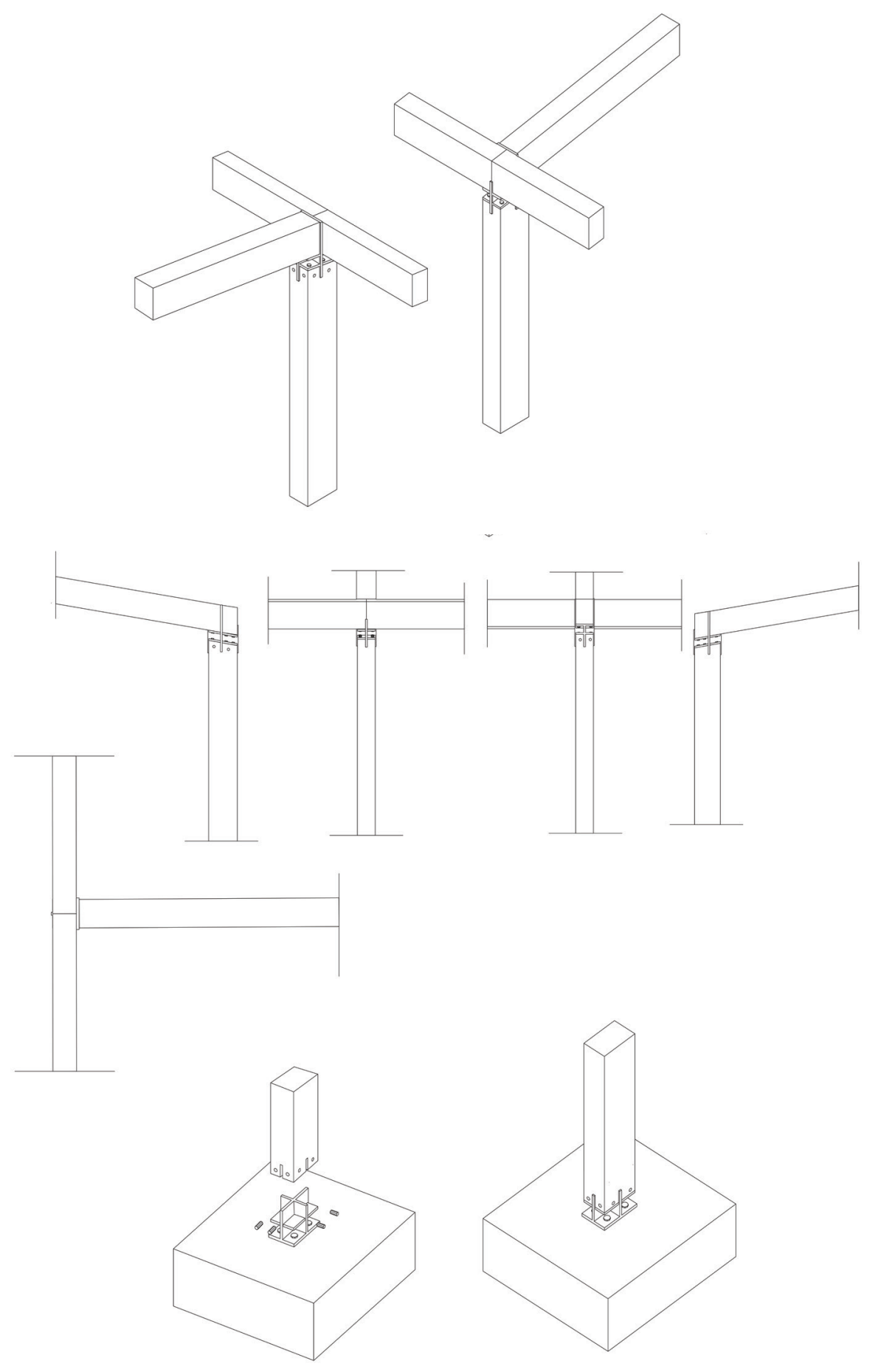

COLUMN TO BEAM JUNCTION

STRUCTURAL DETAIL DEVELOPMENT

Fig.106. Column to beam detail. 


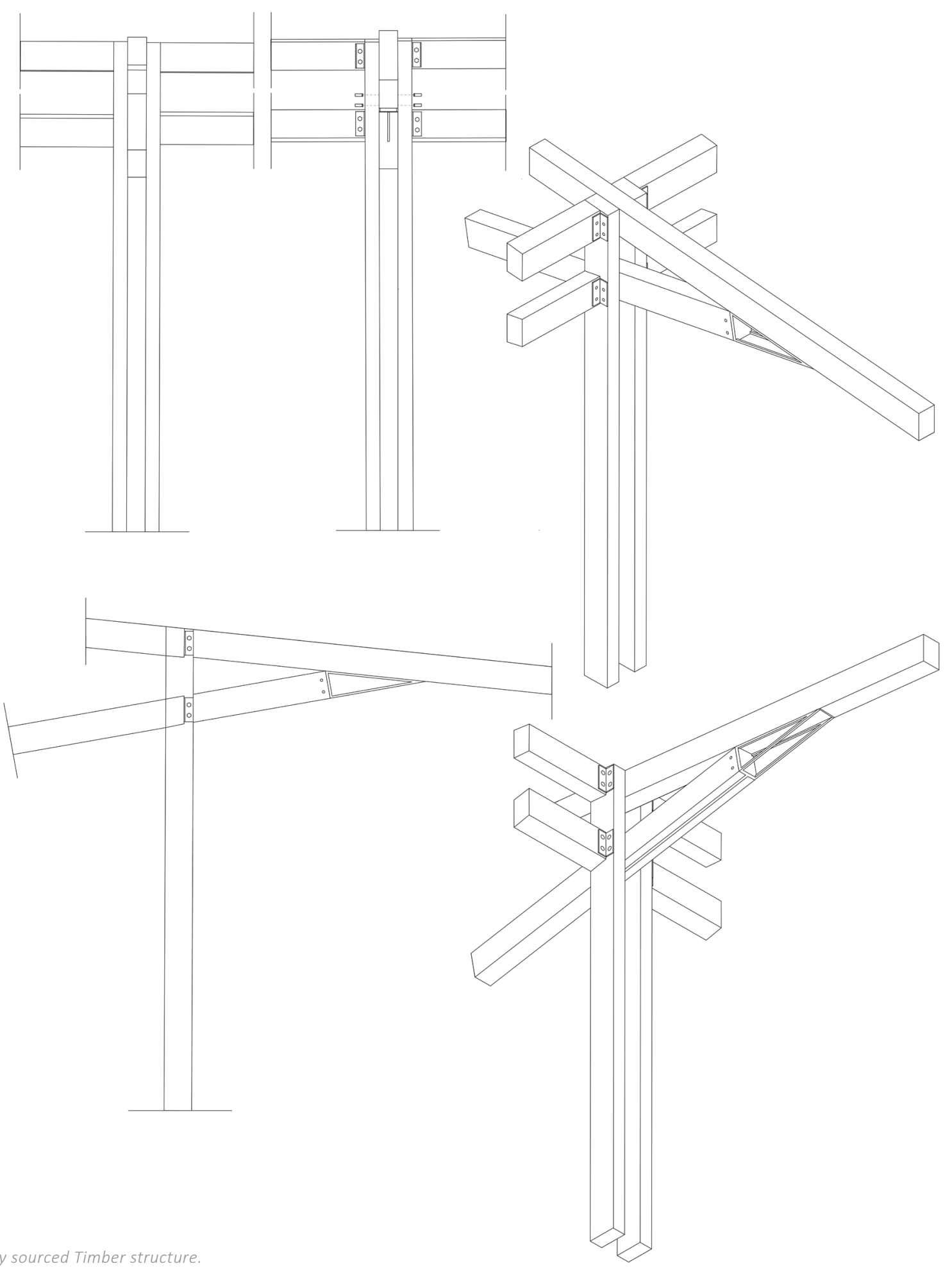

ocally sourced Timber structure.

Steel detailing.

WALKWAY \& ROOF JUNCTION

STRUCTURAL DETAIL DEVELOPMENT

Fig.107. Beam detail. 


\section{DETAIL DEVELOPMENT}

\section{TIMBER VENEER COLUMN DETAIL}

Located on the font façade, foregrounding the interior columns. Universal steel I beam, steel footing with timber veneer.
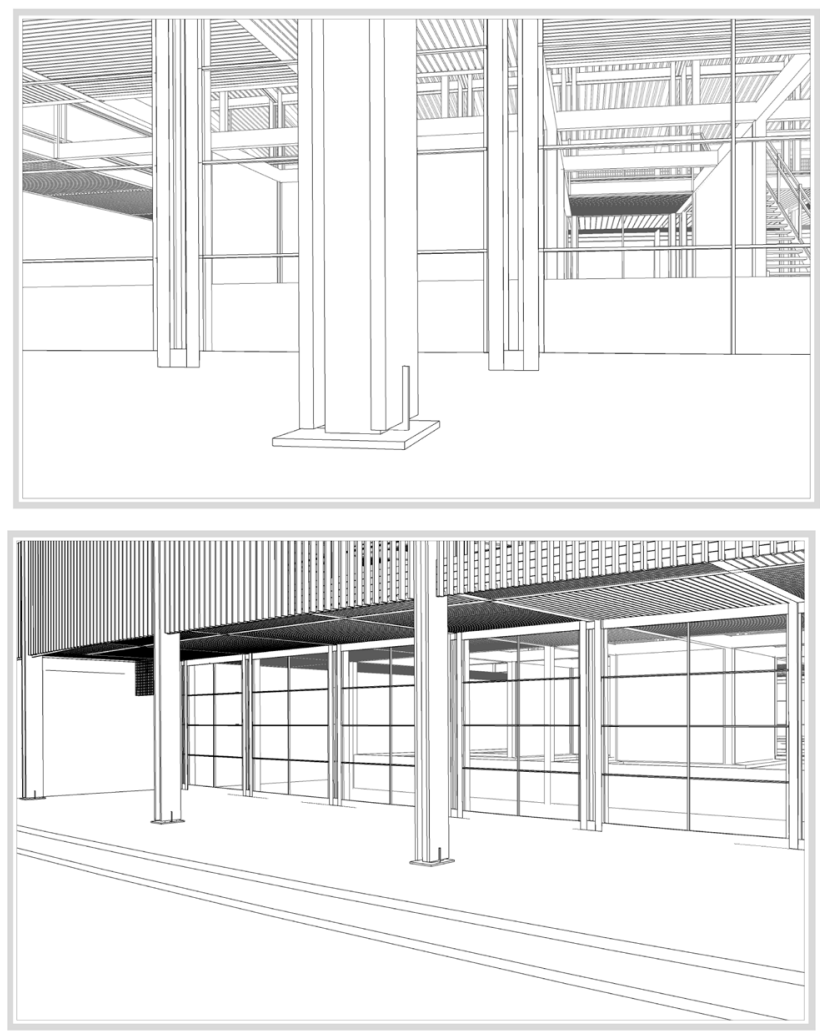

Fig.108. Column digital development. 

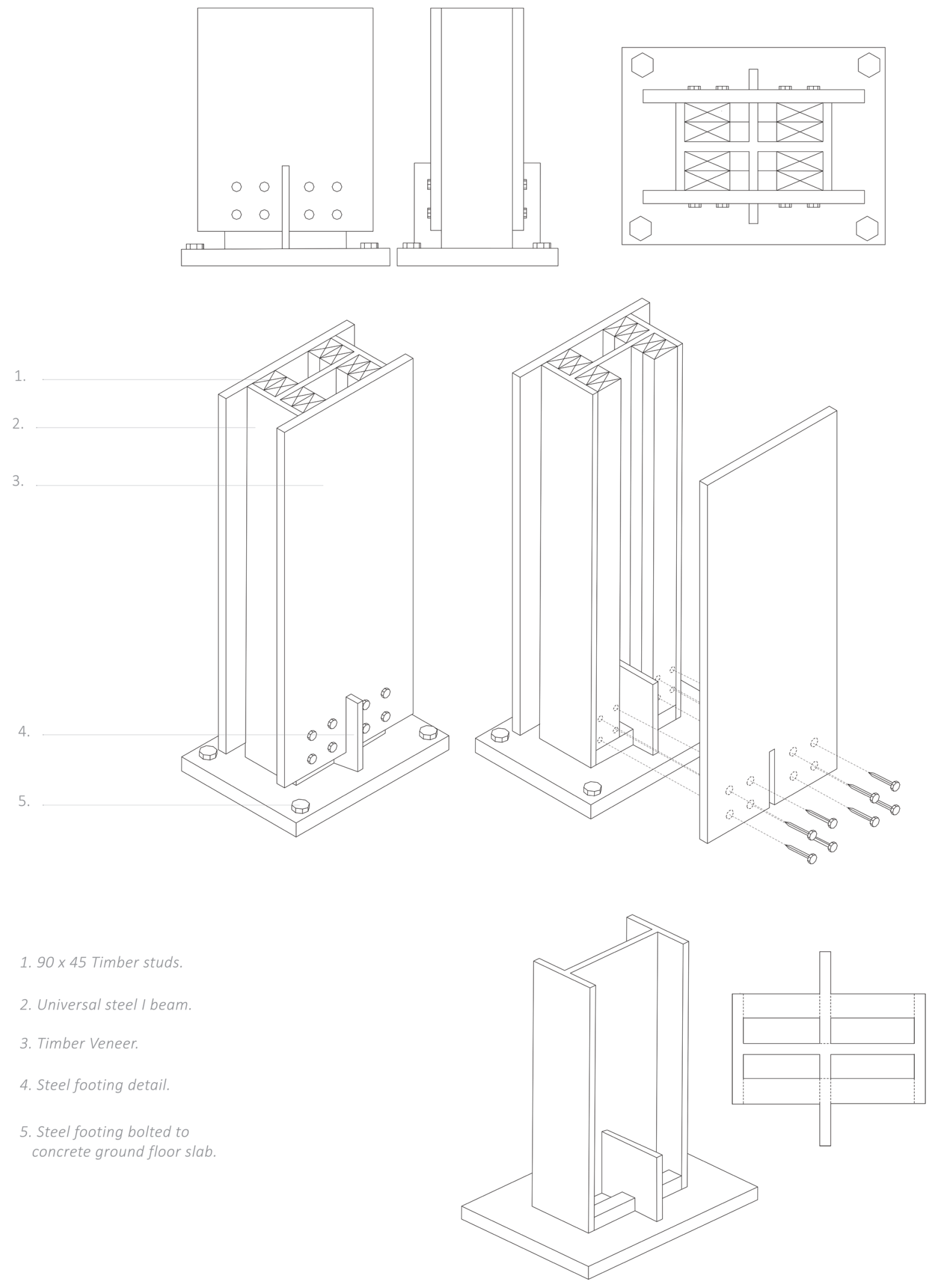

TIMBER VENEER

STRUCTURAL DETAIL DEVELOPMENT

Fig.109. Column detail. 
DETAIL DEVELOPMENT

\section{FLUX DETAILING}

Integrating the following responsive components into the design development extends the opportunity to enhance the experience of the space through giving expression to the temporary, changeable aspects of the environment.

Responsive elements have been integrated into the design process to inform the way that this space is both conceived and experienced. Through integrating responsive components into this proposed design, it offers the ability to engage with the past and present (through interaction with changing wind \& light - flux, layering and tessellation), critical regionalism (drawing on the ever-changing natural environment) and through embodiment (generating a sensorial experience from change). These responsive elements are identified as areas of flux. 


\section{DETAIL DEVELOPMENT}

\section{VERTICAL LOUVRE DEVELOPMENT}

Vertical timber louvre system located on the North wall. This is the prime position, as it is susceptible to frequent northerly winds.
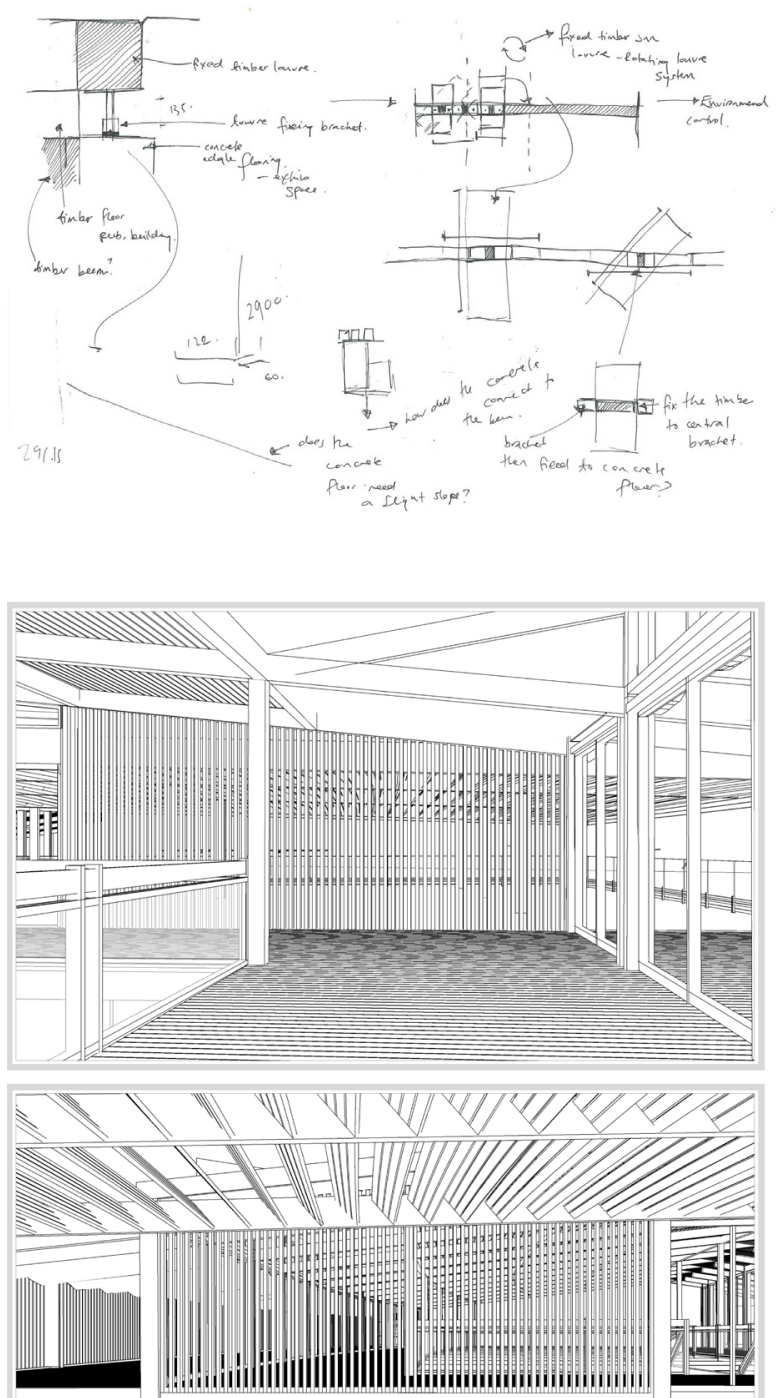


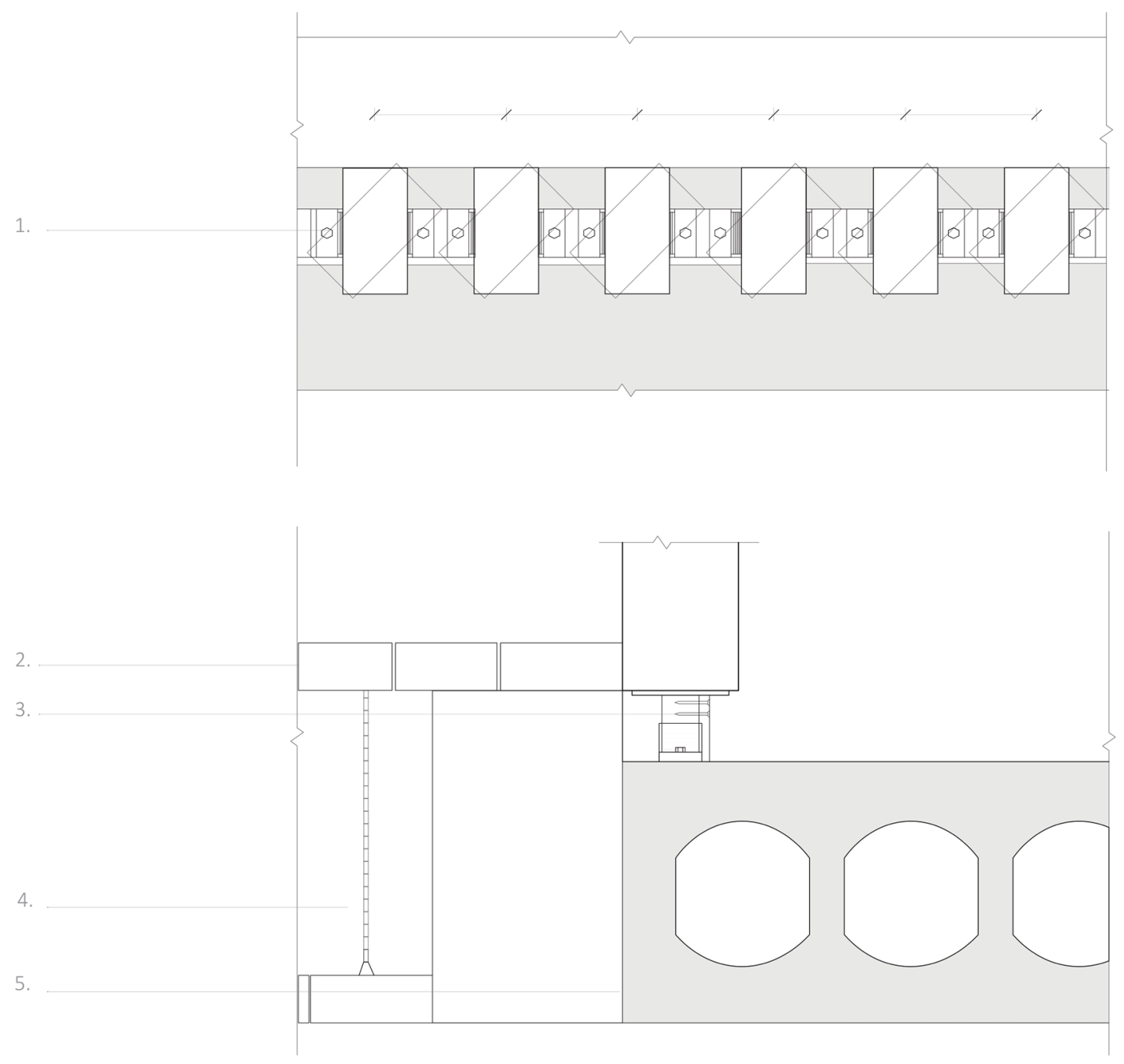

\footnotetext{
1. Fixed Timber Rotating Louvre system Environmental control.

2. Timber flooring system.

3. Steel cap concealing the Louvre system.

4. Suspended ceiling.

5. $200 \mathrm{~mm}$ Hollow core CHC Profile concrete slab.
}

VERTICAL LOUVRE SYSTEM

STRUCTURAL DETAIL DEVELOPMENT

Fig.111.Louvre Detail. 


\section{DETAIL DEVELOPMENT}

\section{MARKETPLACE DOOR DEVELOPMENT}

Outward opening doors held in position by a latch system. The entire front façade has the ability to be opened, strengthening the relationship between the interior and the environment and site.

This ease of access makes for a welcoming, attractive, well connected public space, opening up the space to foster spontaneous opportunities for social interactions.
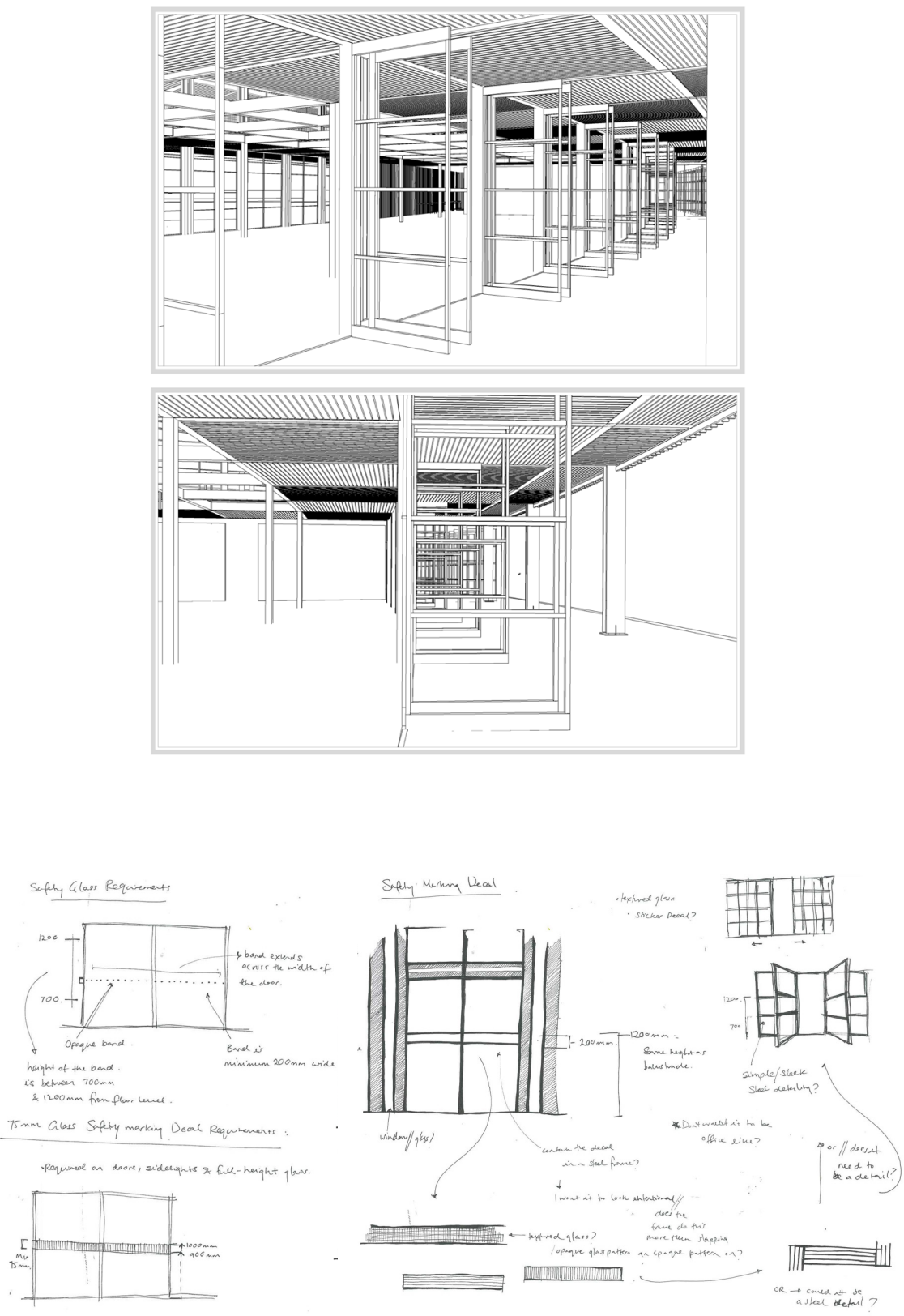

Fig.112. Marketplace door sketch development. 


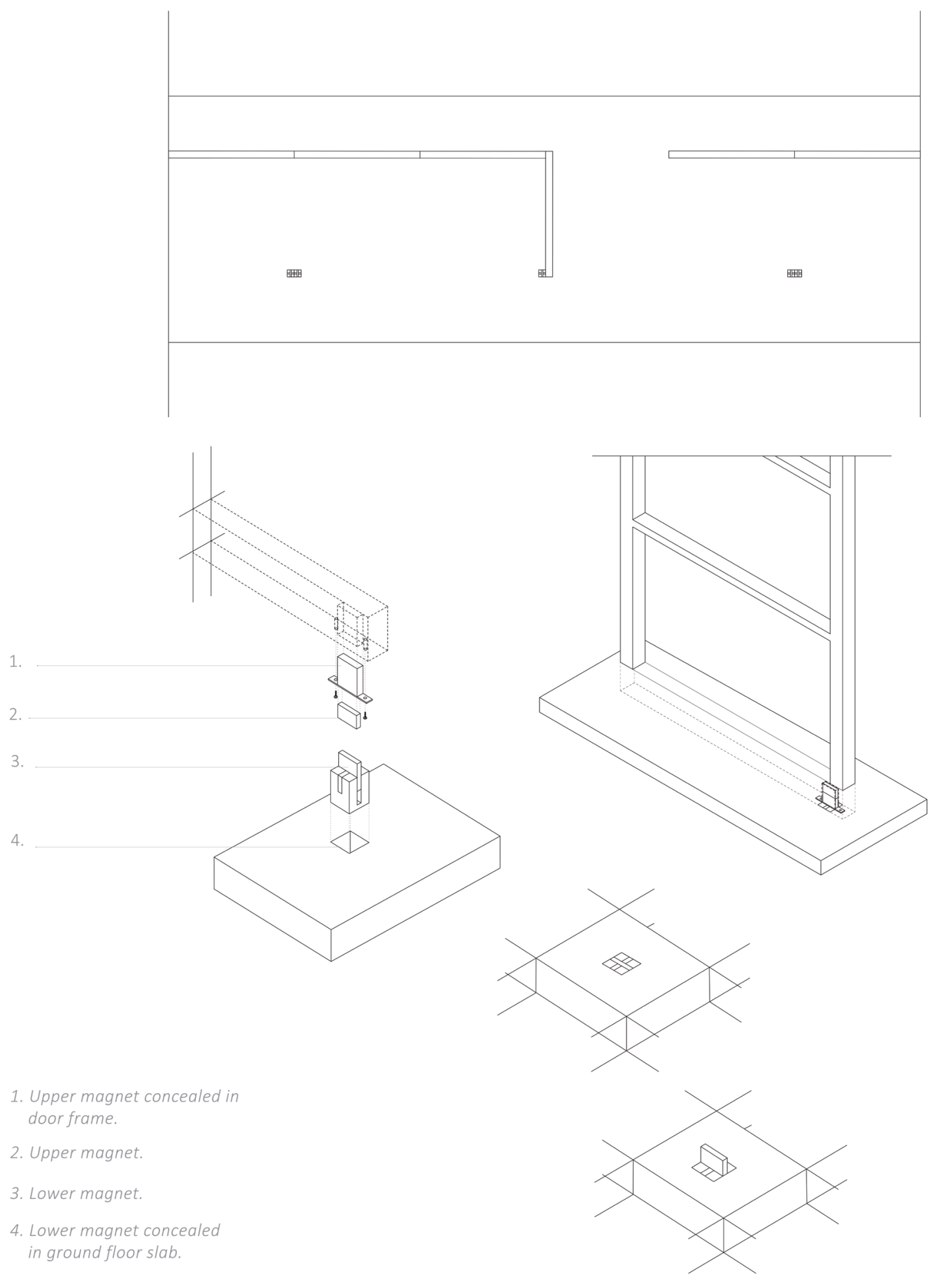

MARKETPLACE DOOR LATCH

STRUCTURAL DETAIL DEVELOPMENT

Fig.113. Door latch detail. 


\section{DETAIL DEVELOPMENT}

\section{EXHIBITION SPACE DOOR DEVELOPMENT}

This is a revolving pivot door system. There are no visible frame or hinges, but instead an invisible vertical axis allows the door open both inwardly and outwardly. The system that has been adapted to this design is the Fritsjurgens pivot hinge system 3 (FritsJurgens, n.d.). This system is a 360 rotating door with pivot points at $0 \circ, 45$ 90 o and 135 ‥

This pivot door system is located on the North - East corner of the proposed building, the most climatically vulnerable and exposed area of the site at ground level. The adaptive nature of this system makes for a responsive component, with the ability to come to rest in the desired hold position in response to the ever-changing climate.

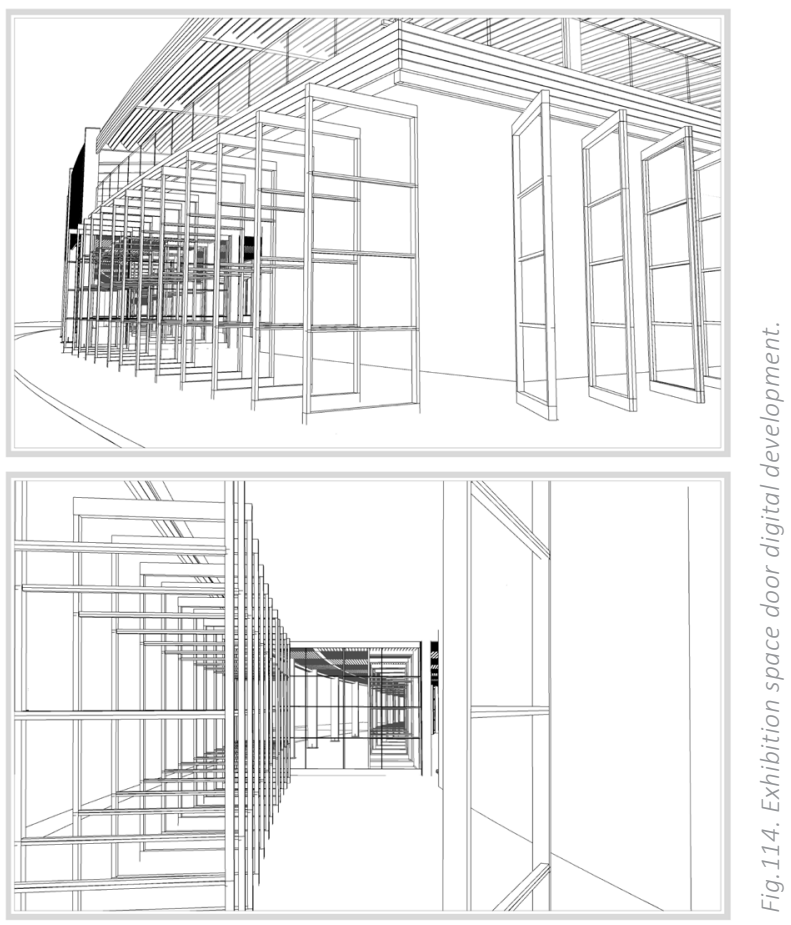




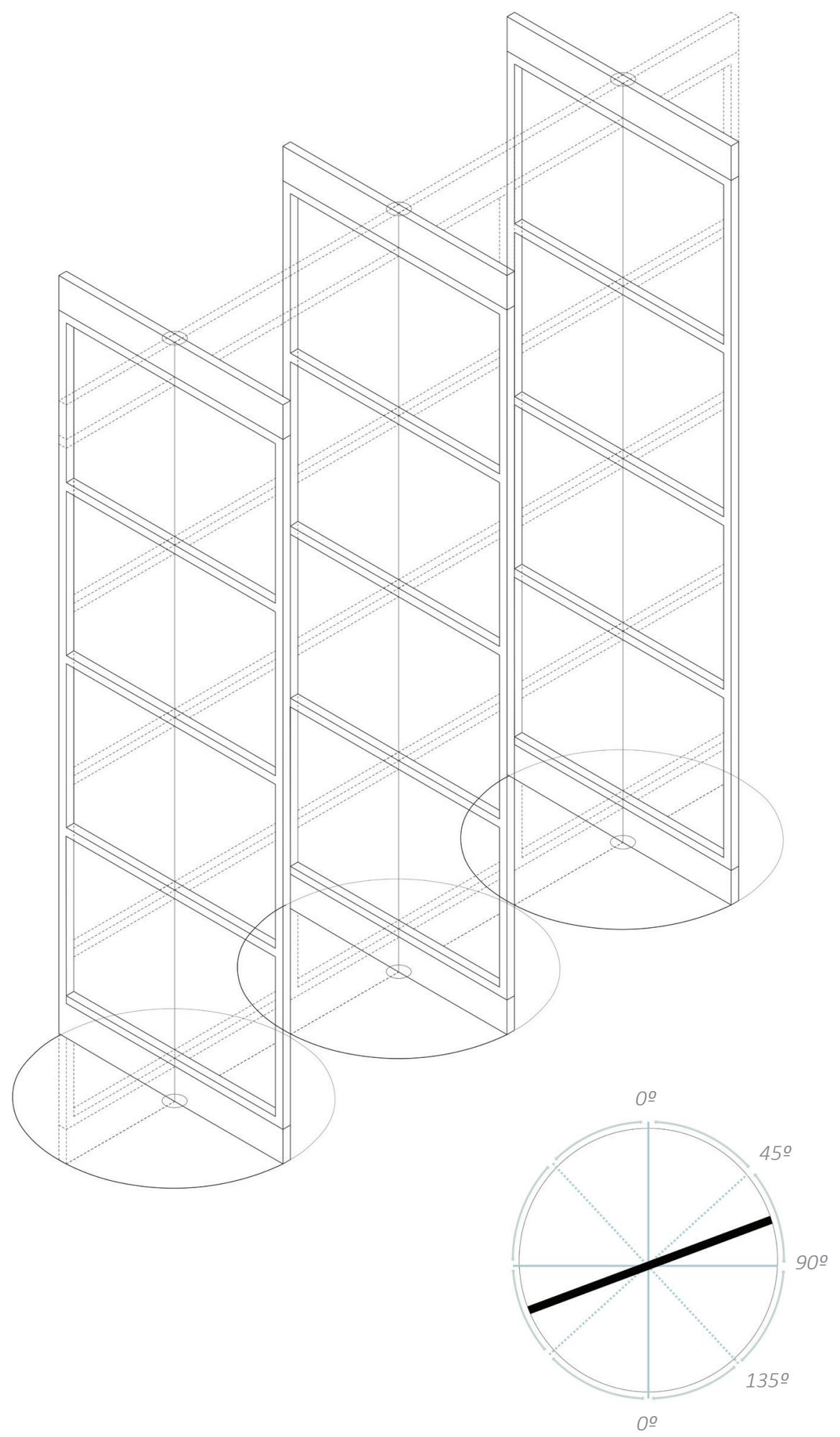

EXHIBITION SPACE

REVOLVING DOOR DETAIL DEVELOPMENT

Fig.115. Revolving door diagram. 

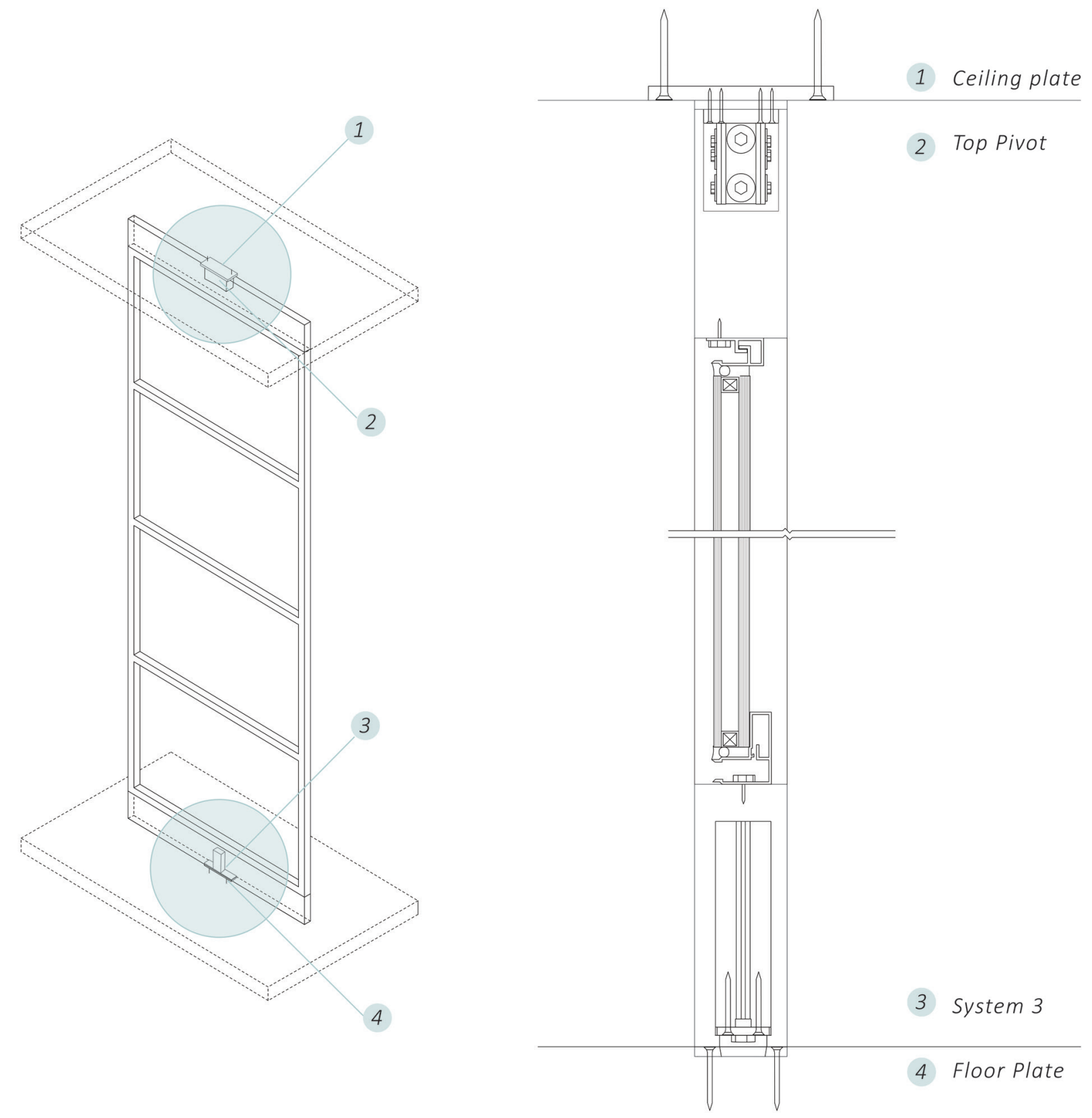

EXHIBITION SPACE

REVOLVING DOOR DEVELOPMENT

Fig.116. Revolving door detail. 


\section{DETAIL DEVELOPMENT}

\section{SERVICES}

Adding another layer of tectonic depth to the design using the same tectonic dimensions. Alternating the axis of the tectonics on each suspended ceiling tile, emulating the pattern of weaving through tessellation.
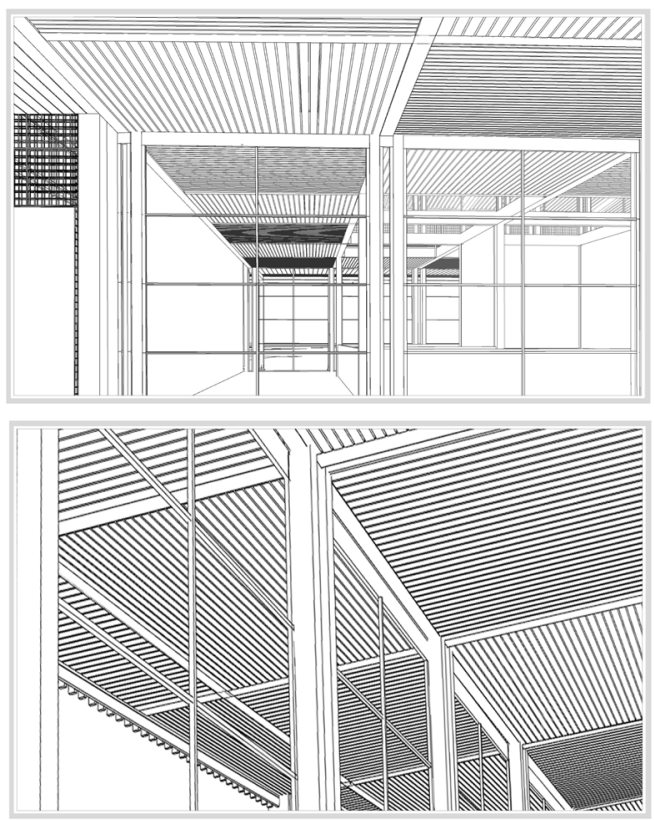

Fig.117. Services digital \& sketch development.

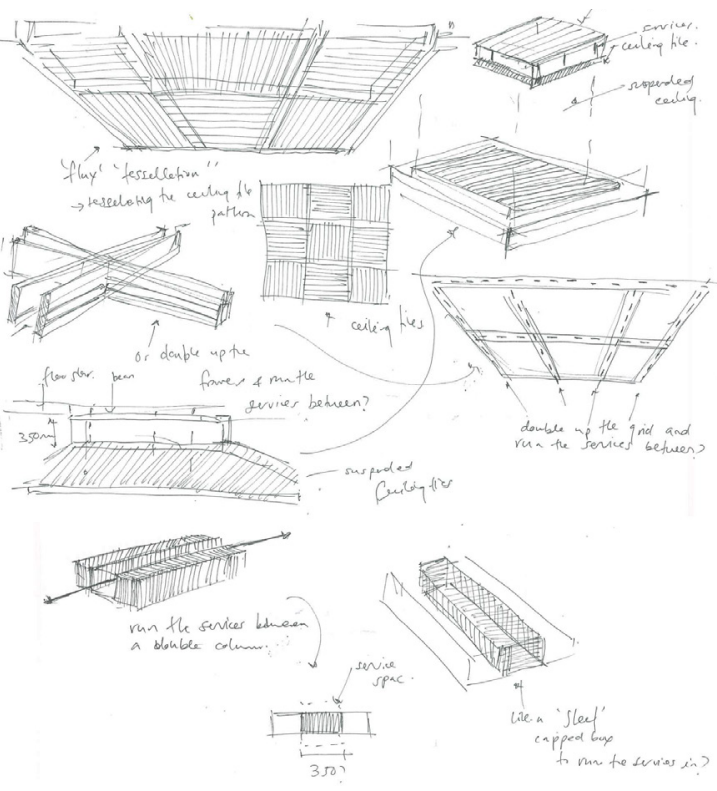




\section{DETAIL DEVELOPMENT}

\section{COMMUNITY GARDEN}

This modular living wall system is integrated into this space as a 'vertical community garden'. Encouraging community gardening in this design responds to the civic design component, 'improve nature' regarding the established framework. Thus, incorporating a vertical community garden creates an opportunity for intercultural and intergenerational interaction, supporting civic trust and participation in civic life.

The placement of these modular gardens is as indicated in figure 120. The community garden is placed along the walkway at maximum sun exposure points to optimise growth. The remainder of the walkway that is less sustainable to growth (south end) will instead remain empty as a tectonic screen and contribute to adding depth to the design through light and shadow interplay (figure 158).
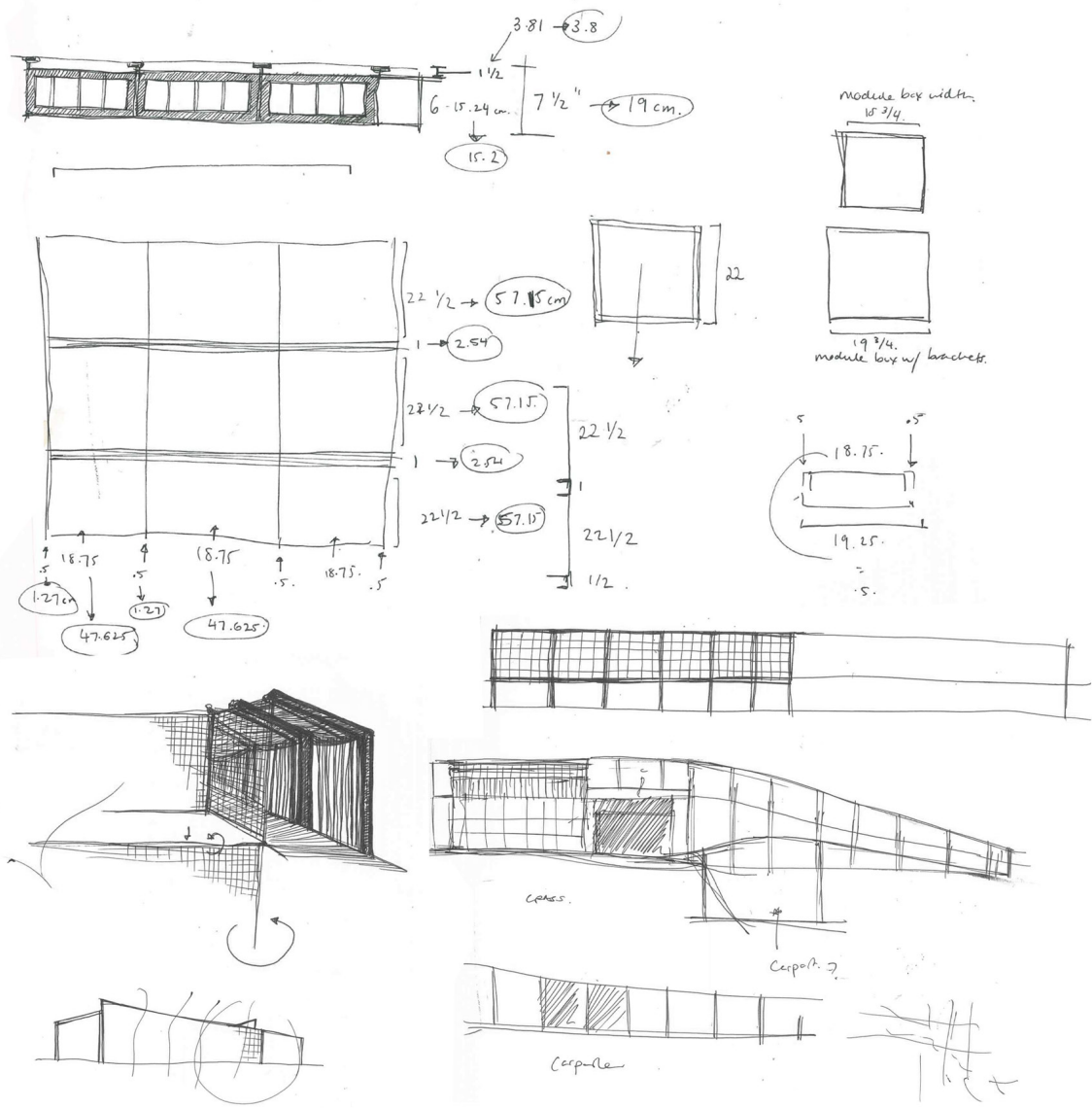

Fig.118. Green wall sketch development. 


\section{VERTICAL LIVING WALL SYSTEM}

The proposed vertical community garden references the Tournesol VGM Modular Living Wall System. This system consists of a 100\% recycled plastic planting module attached to stainless steel hanging rails. The VGM3 is a simple and robust design that enables complex planting designs and complete coverage of any surface (Tournesol, 2021).

\section{MODULES}

Modules are shipped in pieces and are assembled, filled, and planted by local contractors on site. They mount on structurally sound walls and in this case are mounded to concrete walls (figure 121). The mounting brackets are easily assembled to the box with an anti - lift arm to prevent removal by vandals or unexpected weather or seismic activity (Tournesol, 2021). 

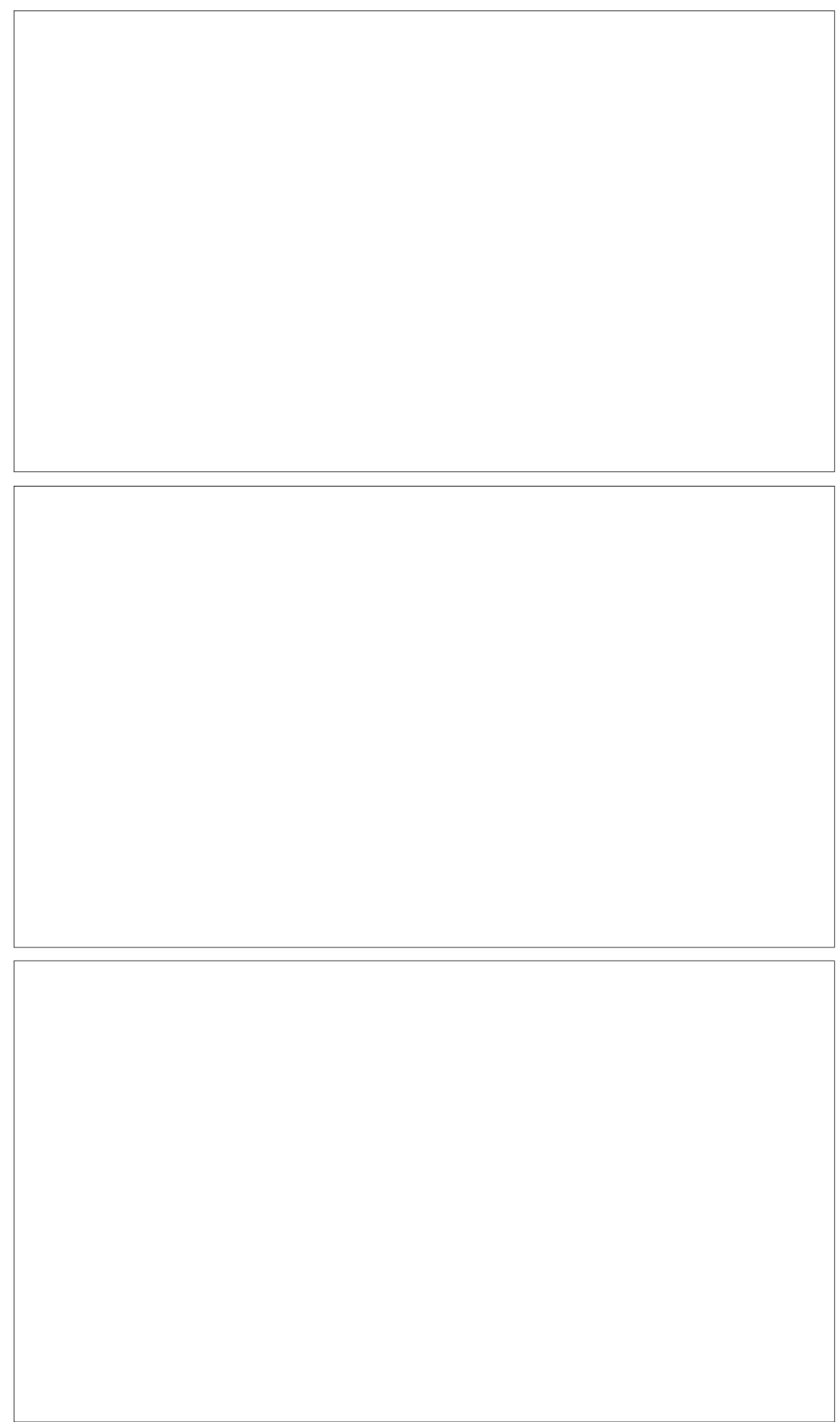

Fig.119. Tournesol VGM Modular system. 

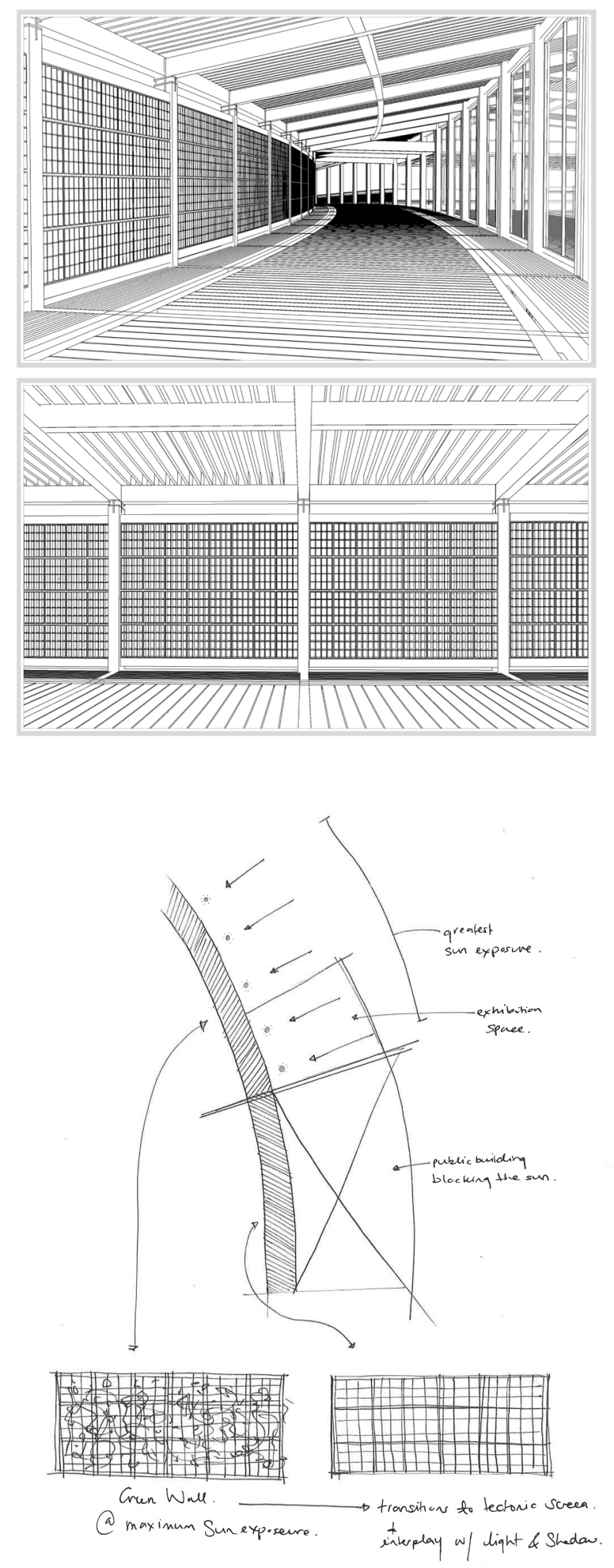

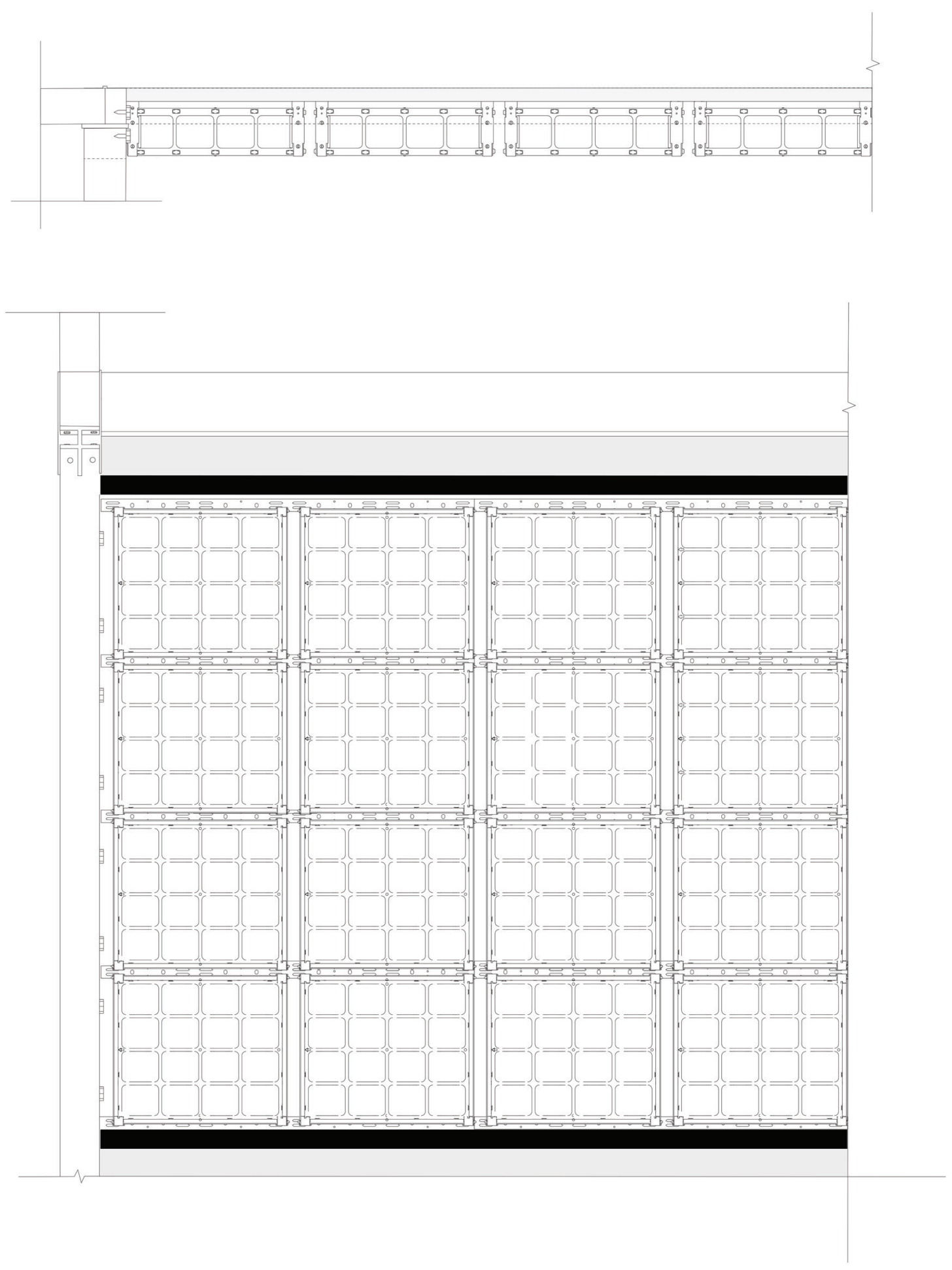

Fig.121. Community garden detail.

VERTICAL COMMUNITY GARDEN 


\section{DETAIL DEVELOPMENT}

\section{$O L D \& N E W$}

Resolving the connection between the old and new.

Following the identified scope of this thesis, this proposal seeks to respectfully contribute to the existing site. Thus, in physically connecting the proposed architecture to the existing, a subtle transition has been developed, looking to seamlessly integrate the two.
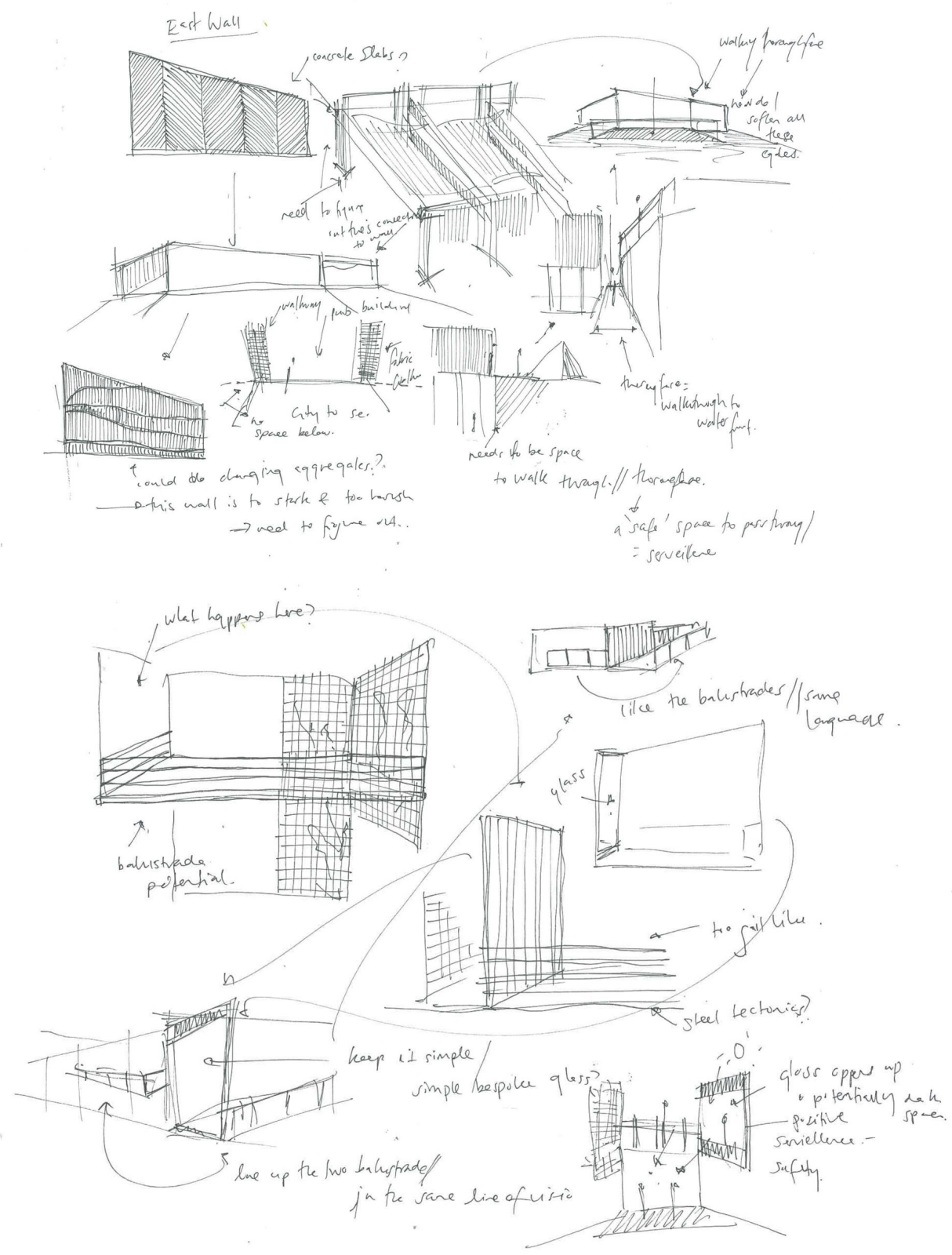
DETAIL DEVELOPMENT
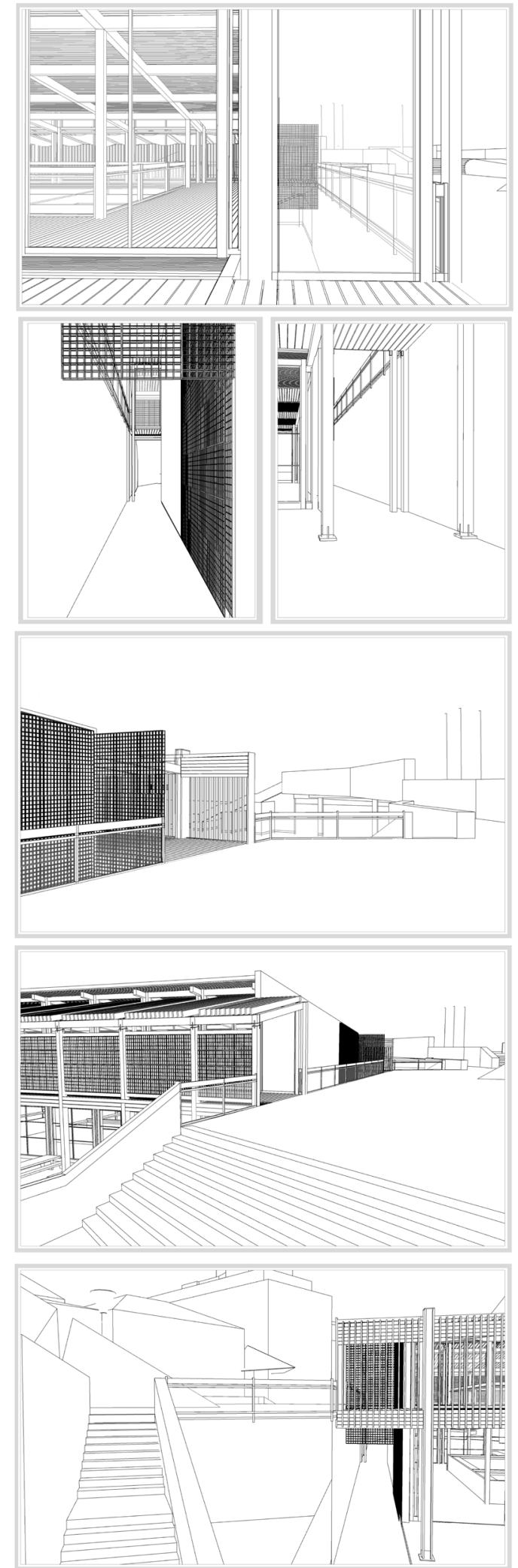
DETAIL DEVELOPMENT
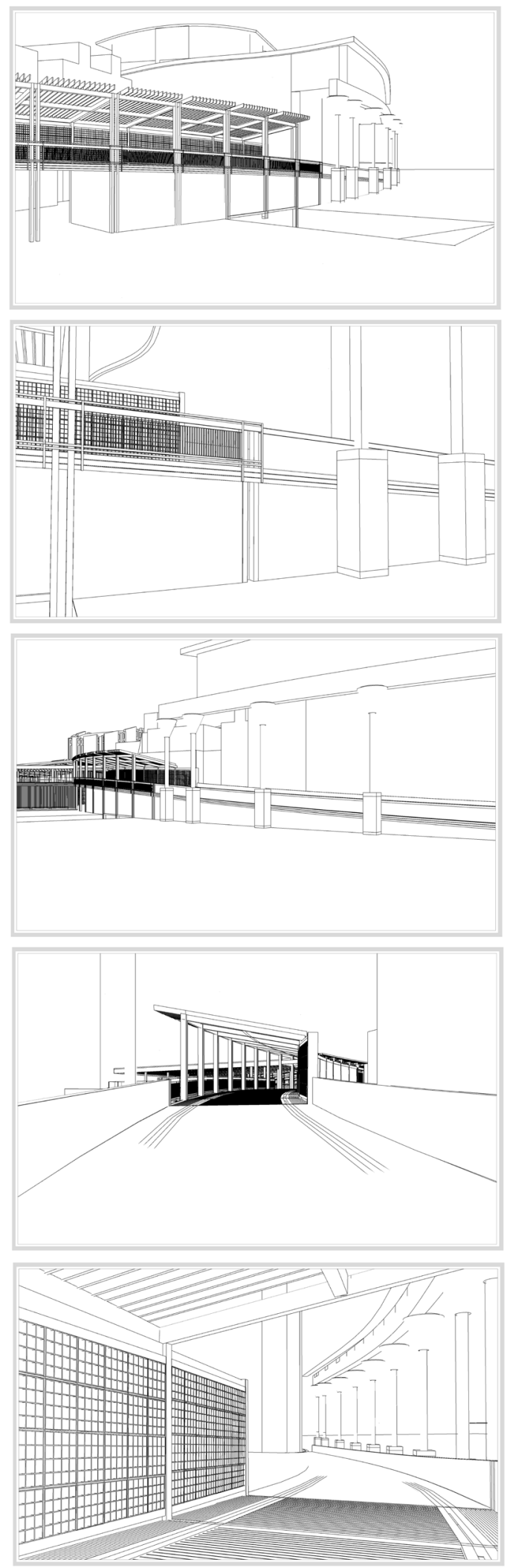


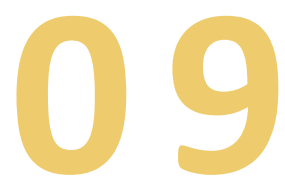

PUBLIC SCALE DESIGN OUTCOME 


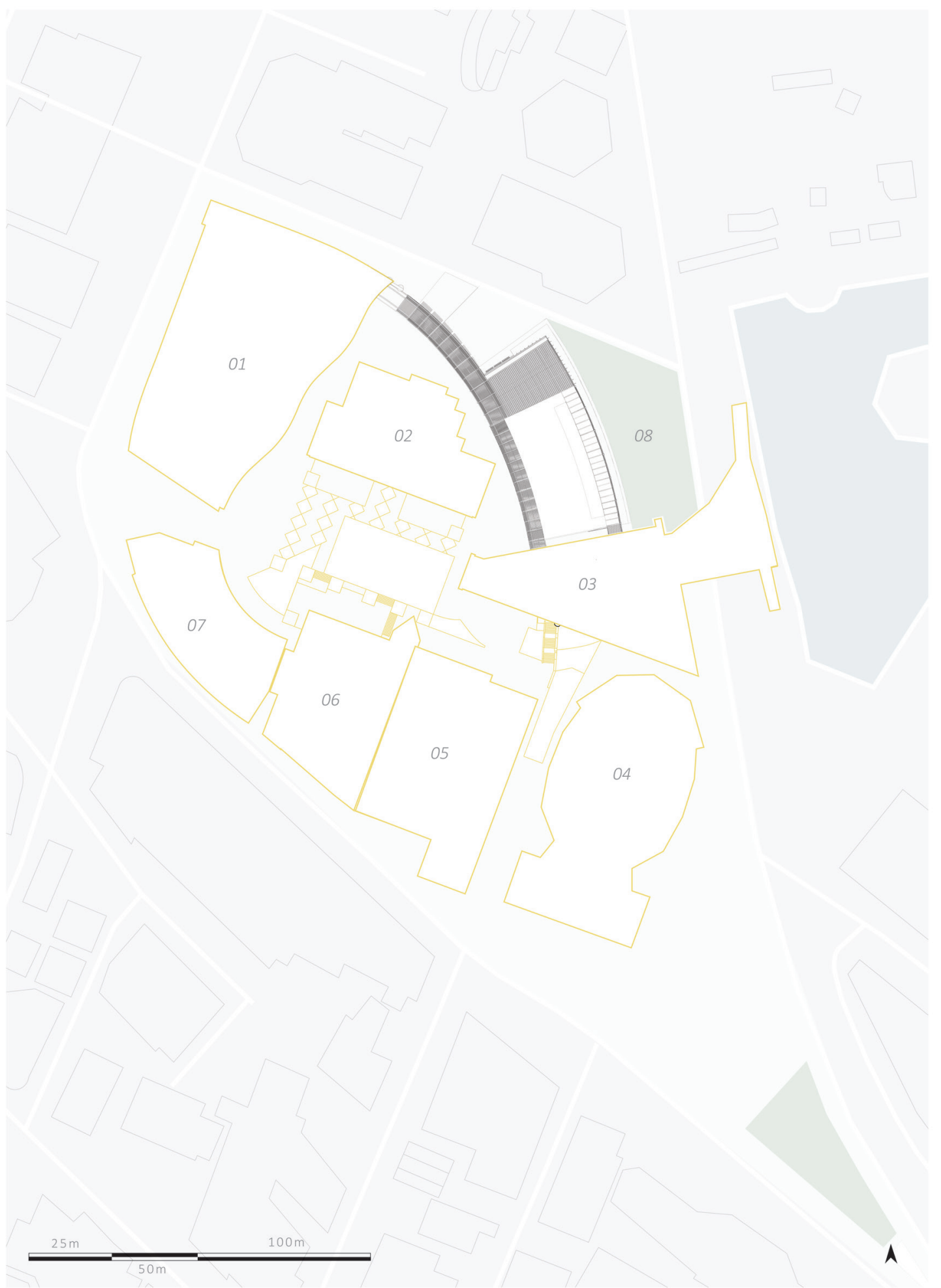

SITE PLAN

Fig.125.

1. WELLINGTON PUBLIC LIBRARY

2. CITY GALLERY WELLINGTON

3. CITY TO SEA BRIDGE

4. MICHAEL FOWLER CENTRE
5. WELLINGTON TOWN HALL

6. MUNICIPAL OFFICE BUILDING

7. CIVIC ADMINISTRATION BUILDING

8. ILOTT GREEN 


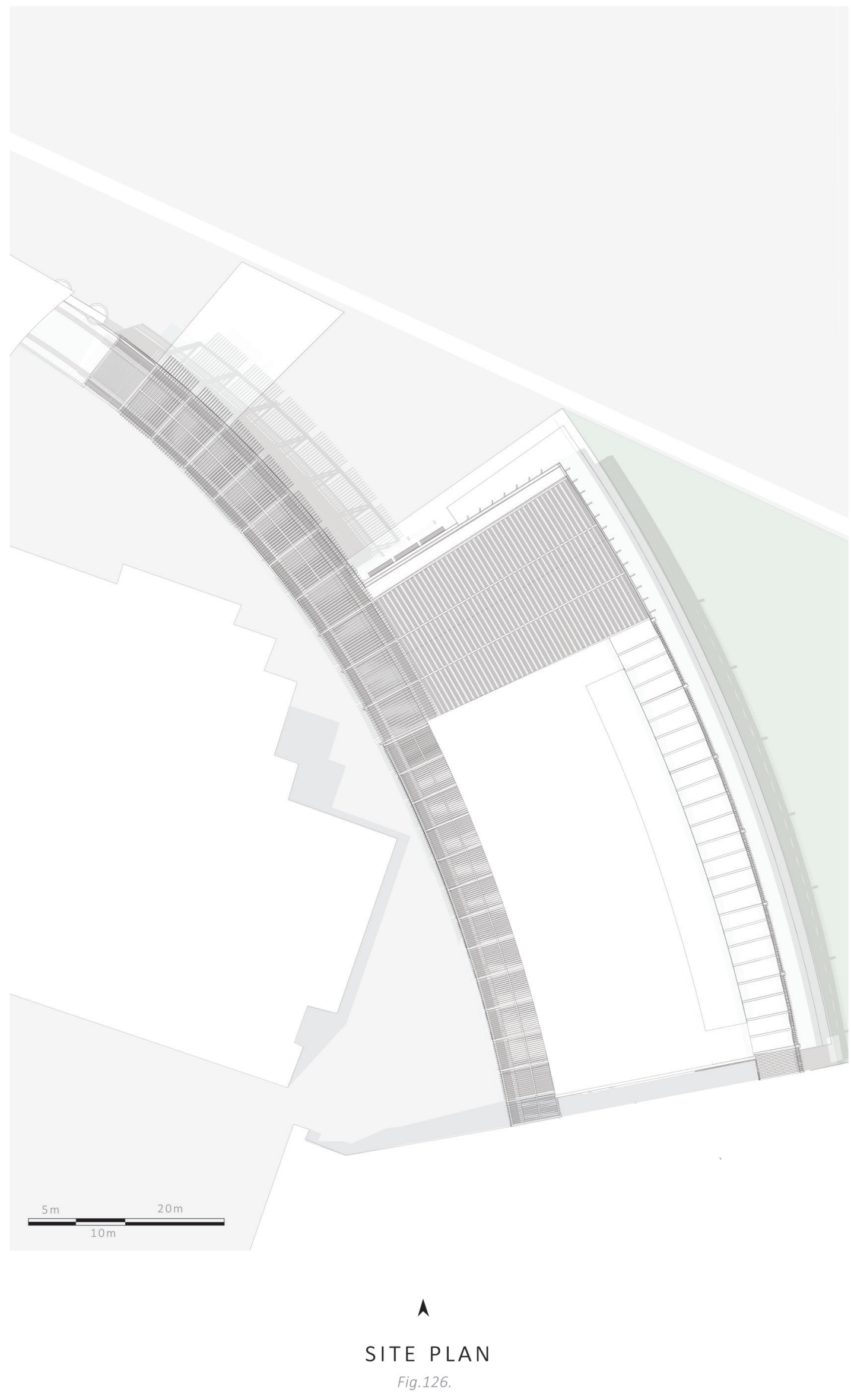




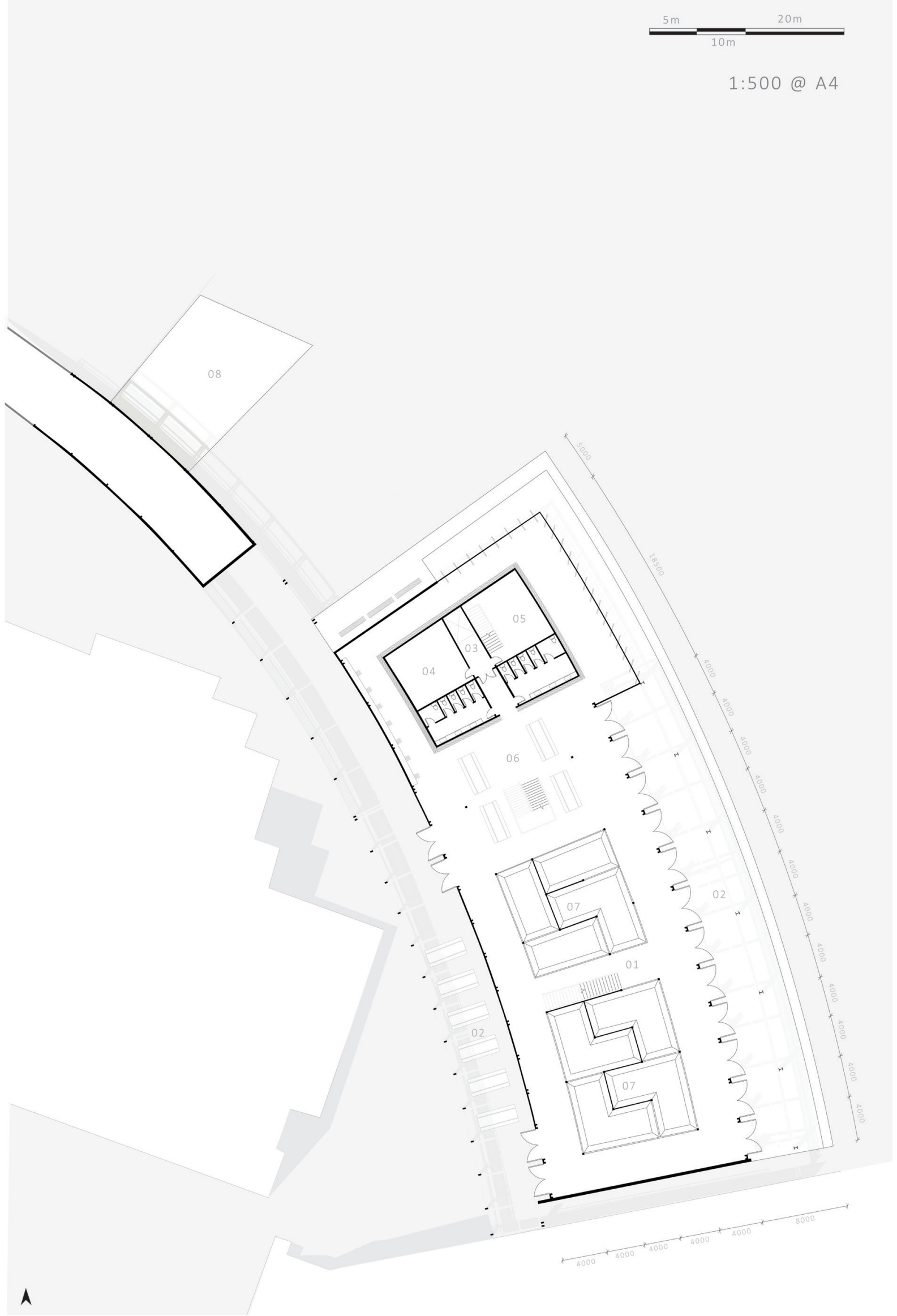

Fig.127 


\section{GROUND LEVEL FLOOR PLAN}

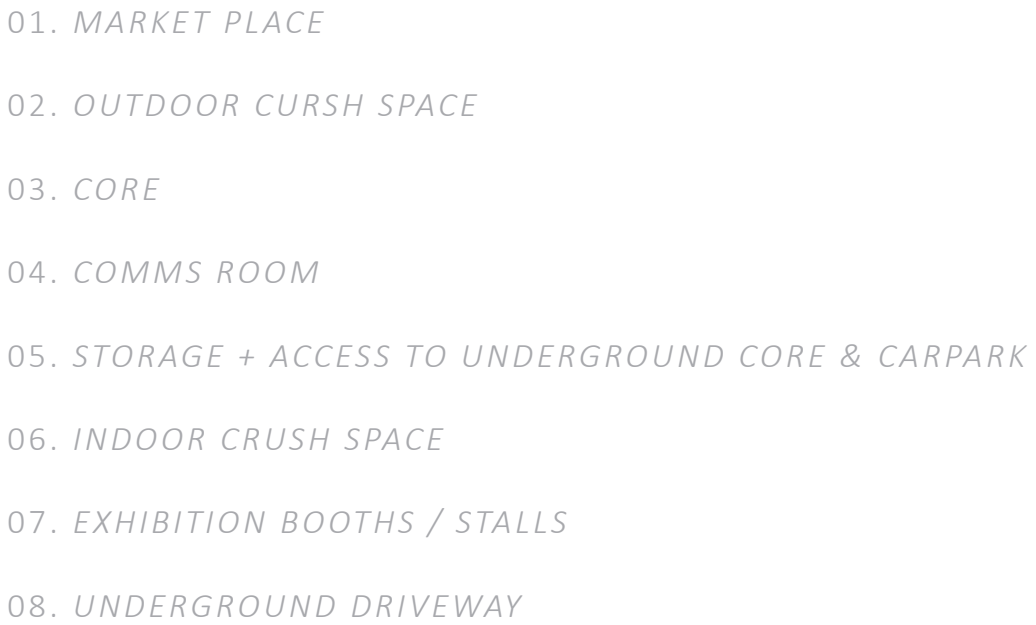




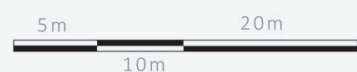

1:500@A4

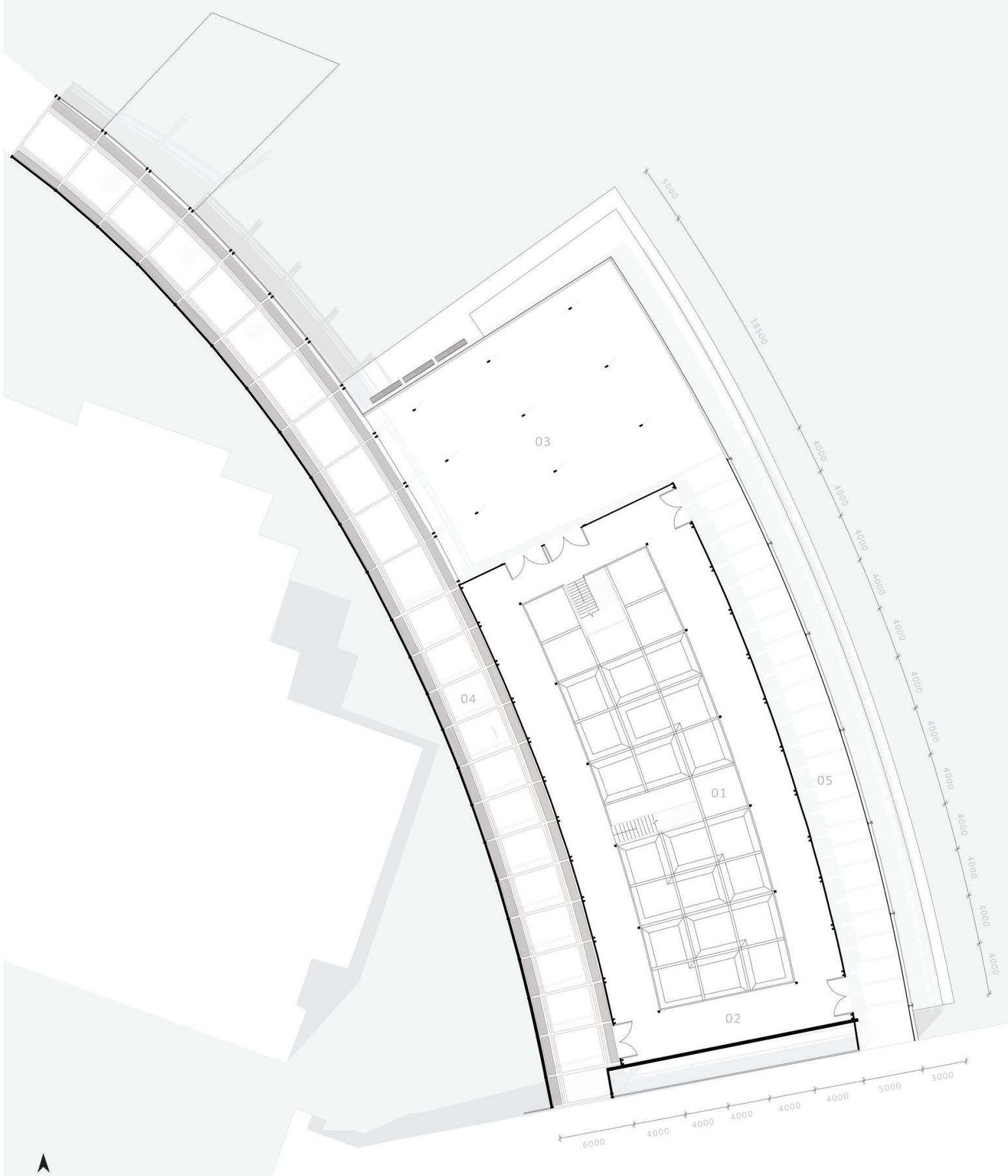

Fig.128. 
FIRST LEVEL FLOOR PLAN

01. MARKET PLACE

02. TEMPORARY MEZZANINE SPACE

03. EXHIBITION SPACE

04 NORTH TO EAST CONNETING WALKWAY (TECONIC)

O 5. FABRIC WALKWAY 

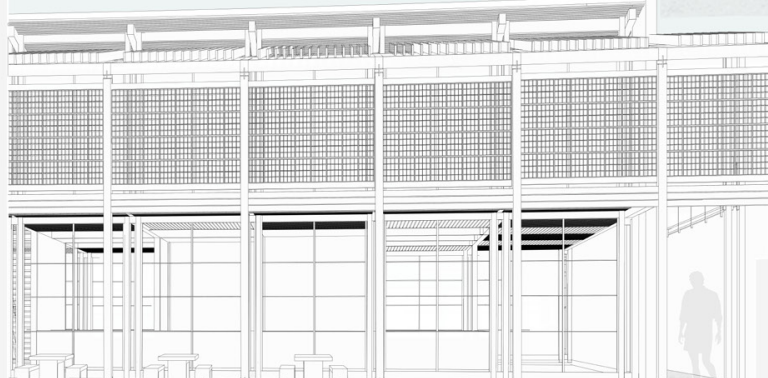

WEST ELEVATION

Fig.129. 
SOUTH ELEVATION

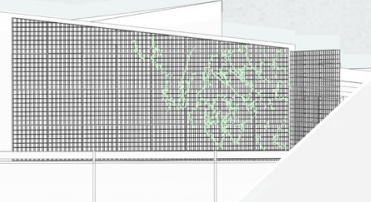

Fig.130. 


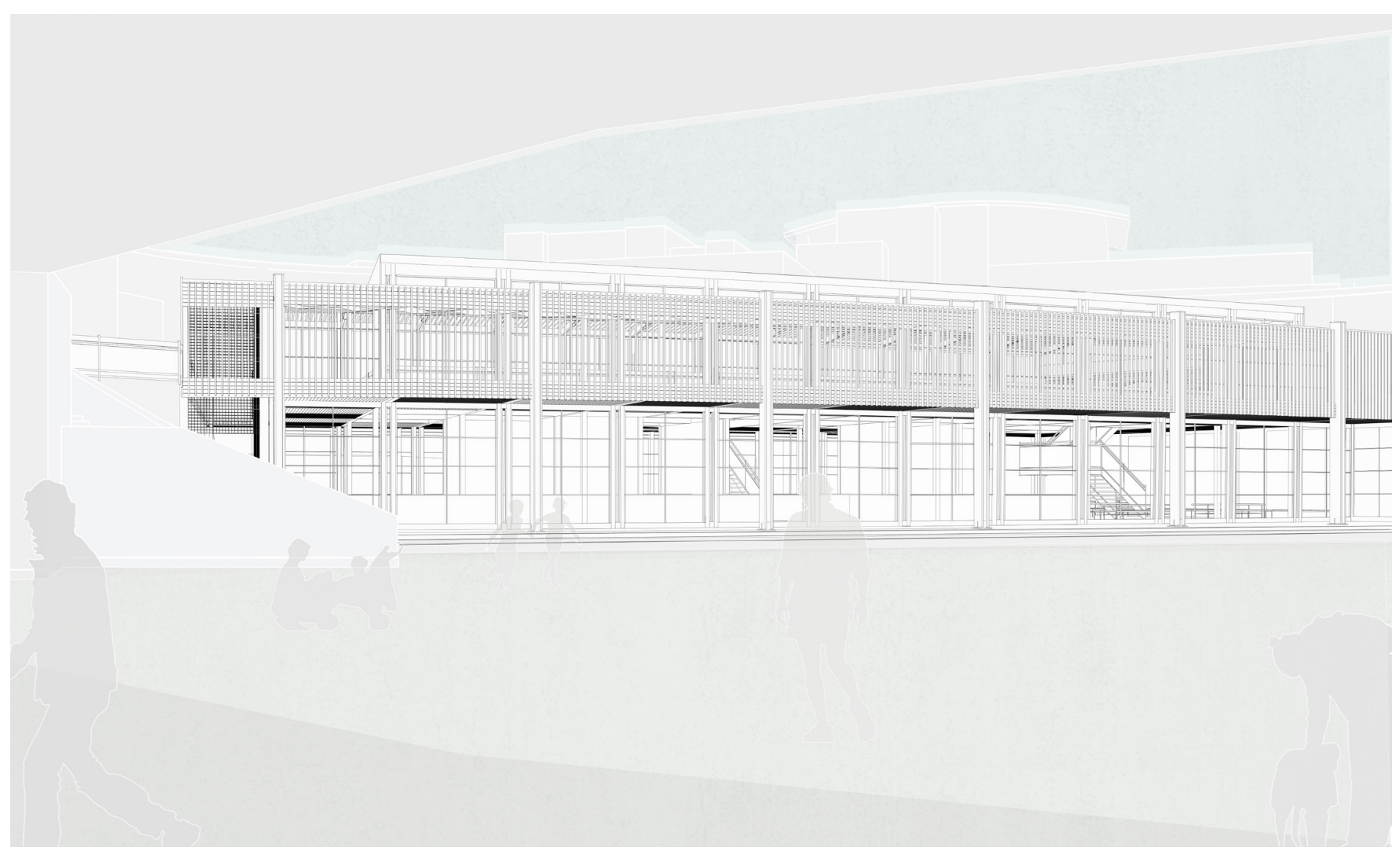

WEST ELEVATION

Fig.131. 


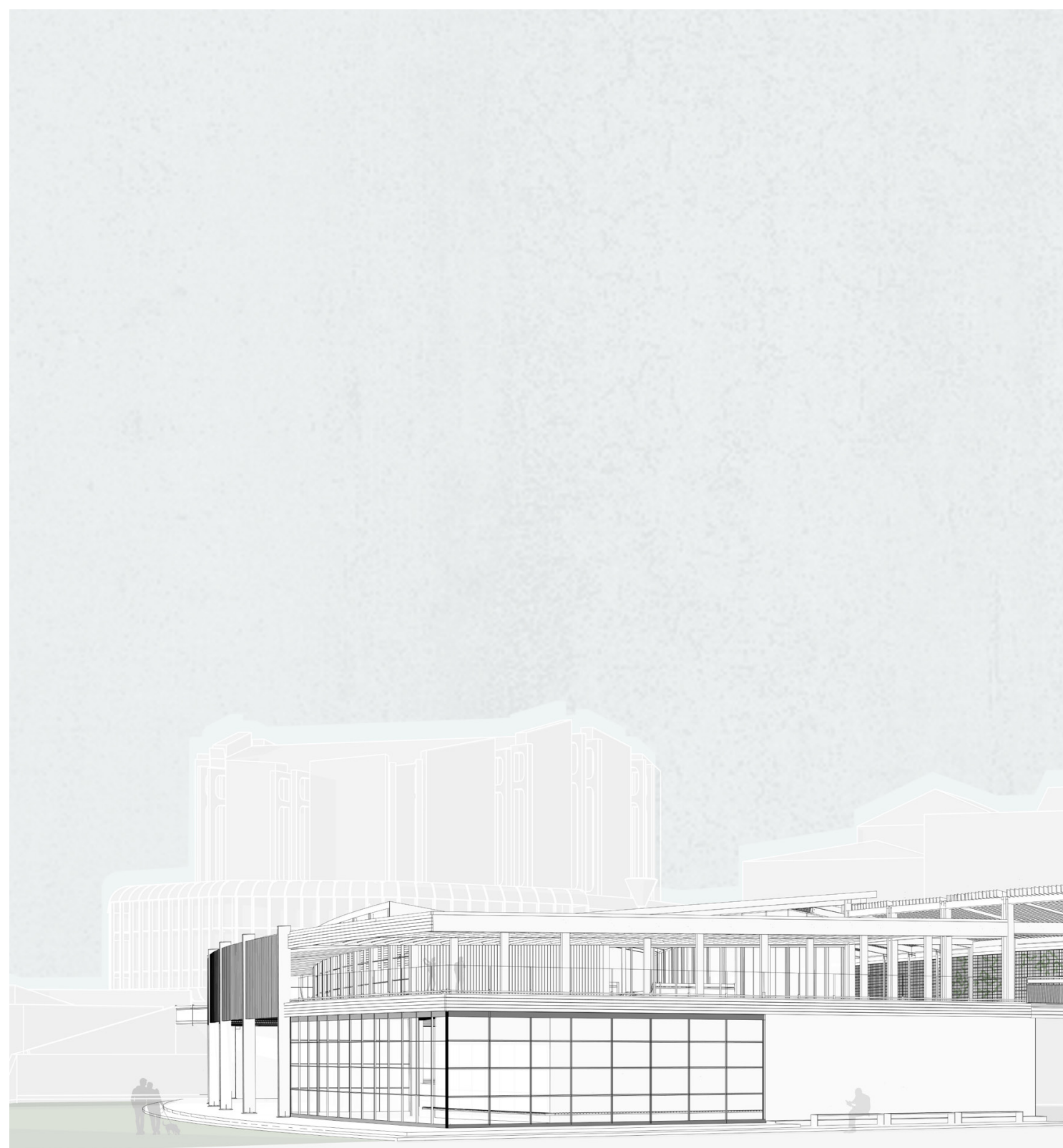

WEST ELEVATION

Fig.132. 


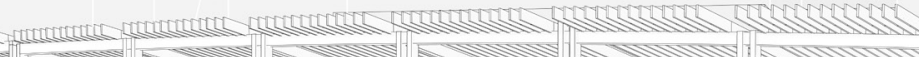

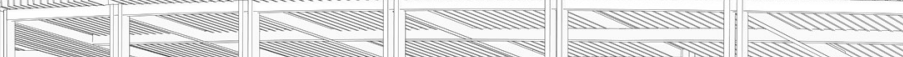

貝

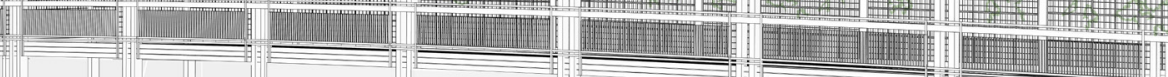



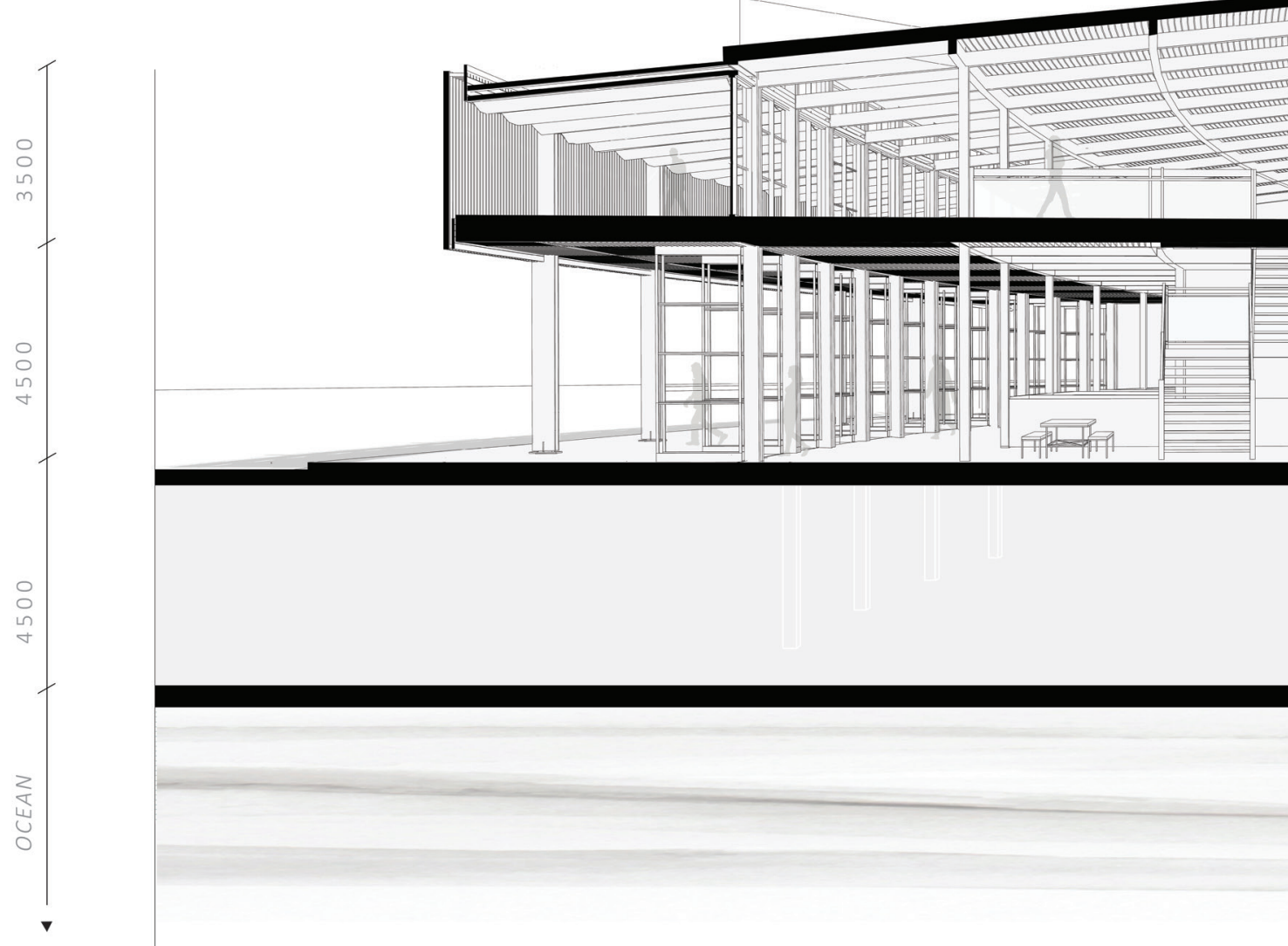

SECTION AA Fig.133.

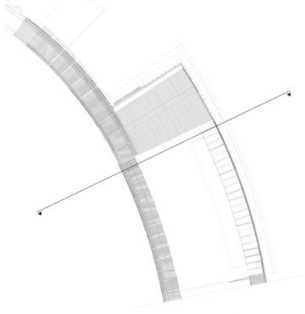




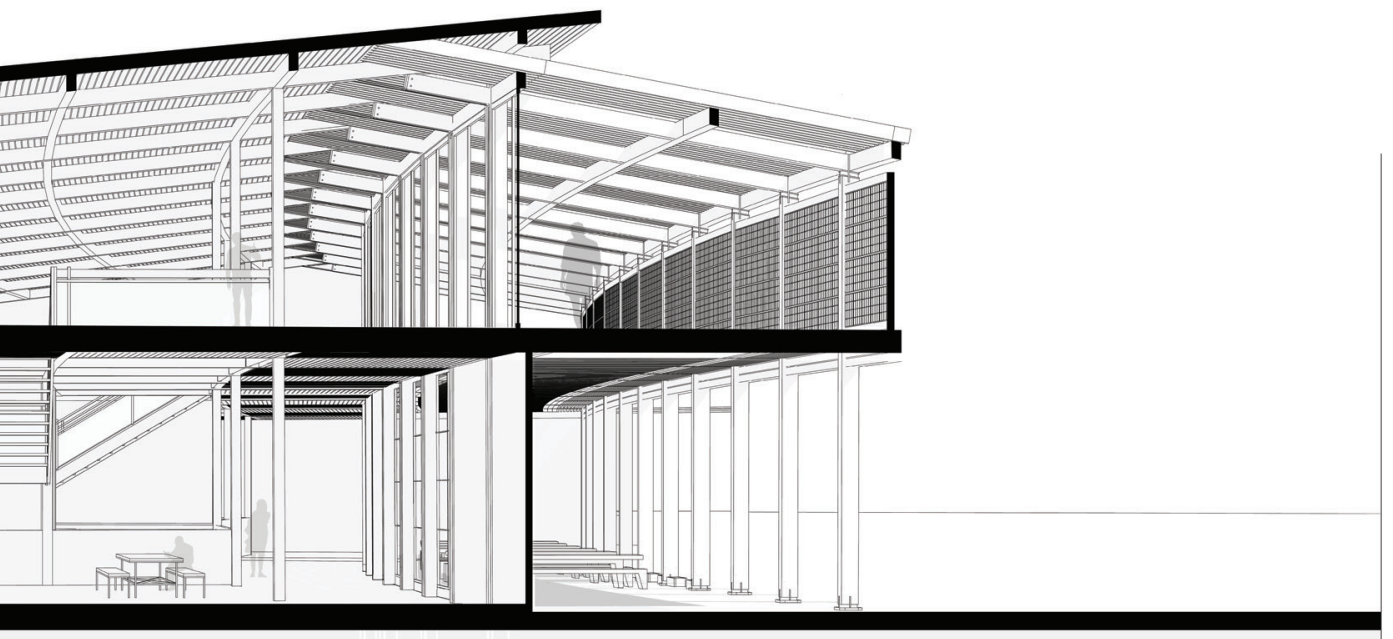




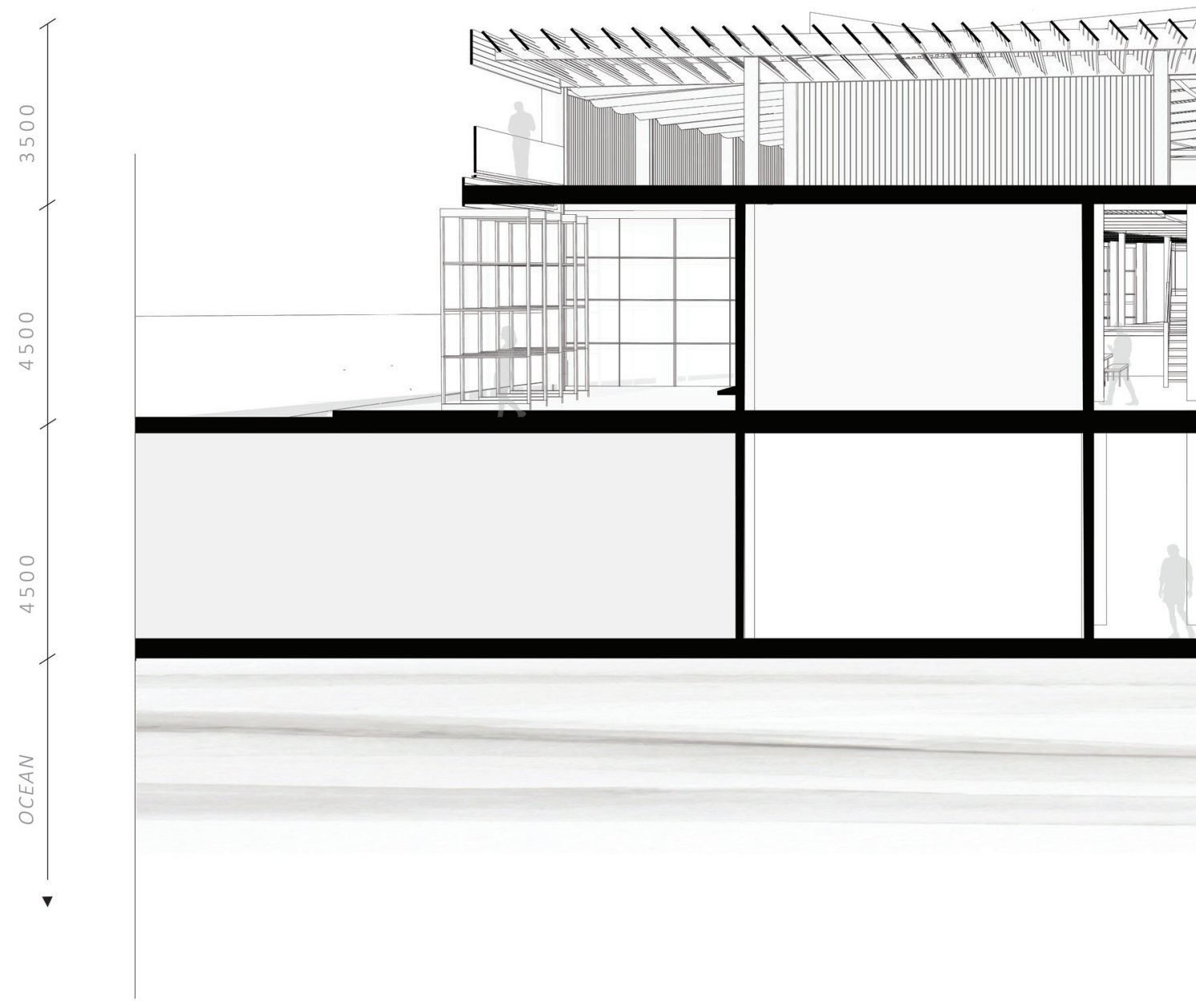

SECTION BB Fig.134. 

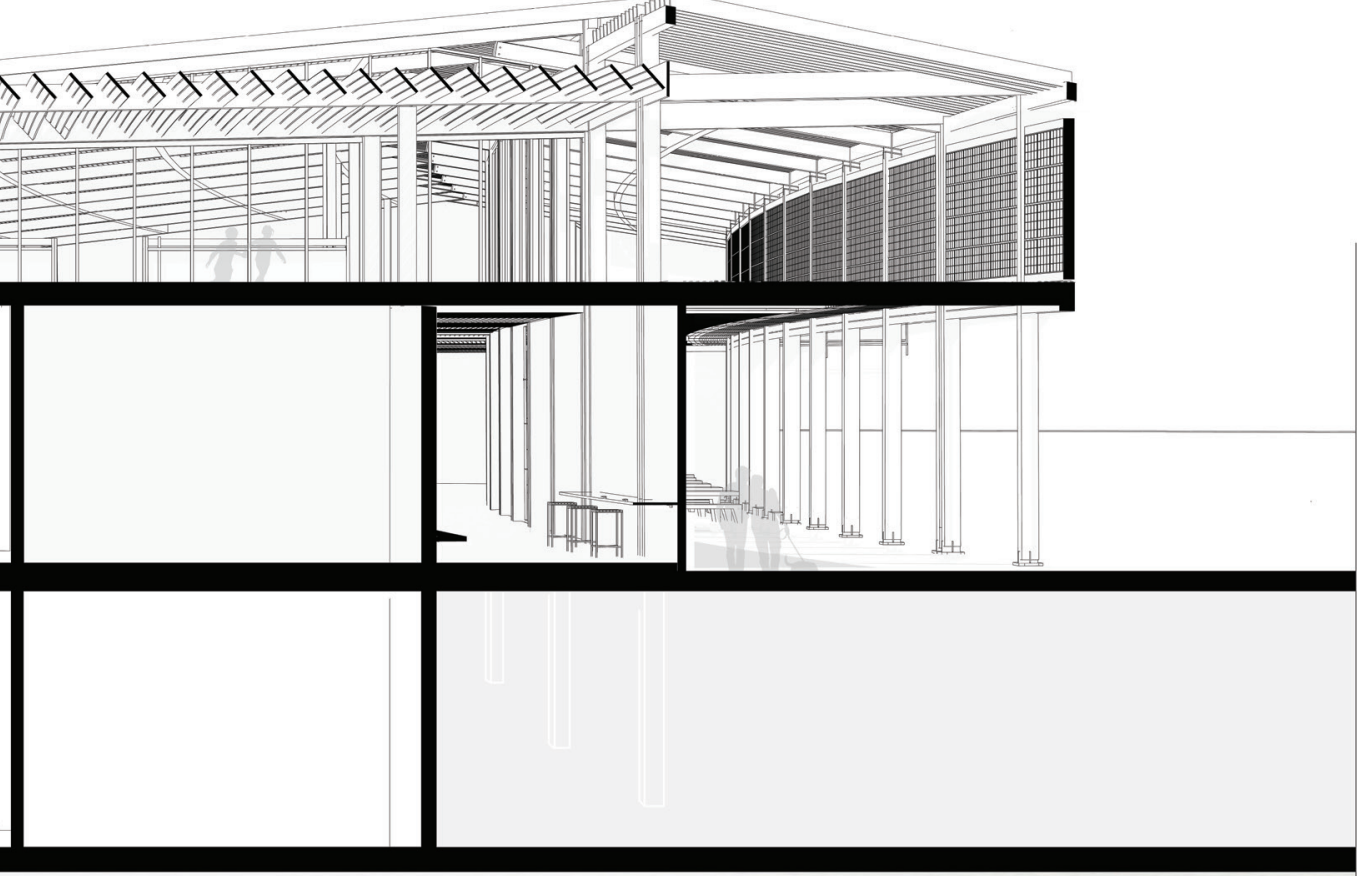


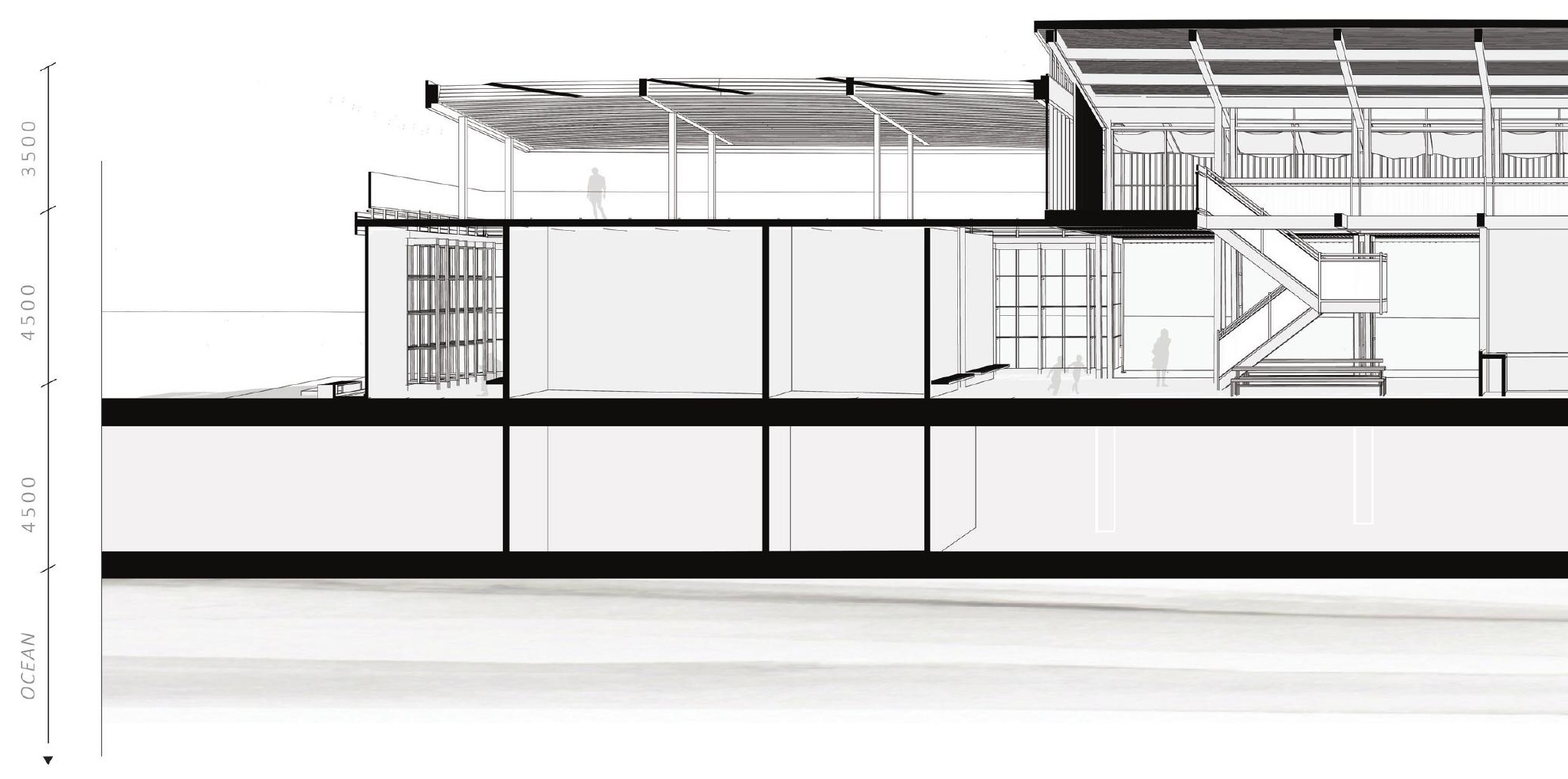




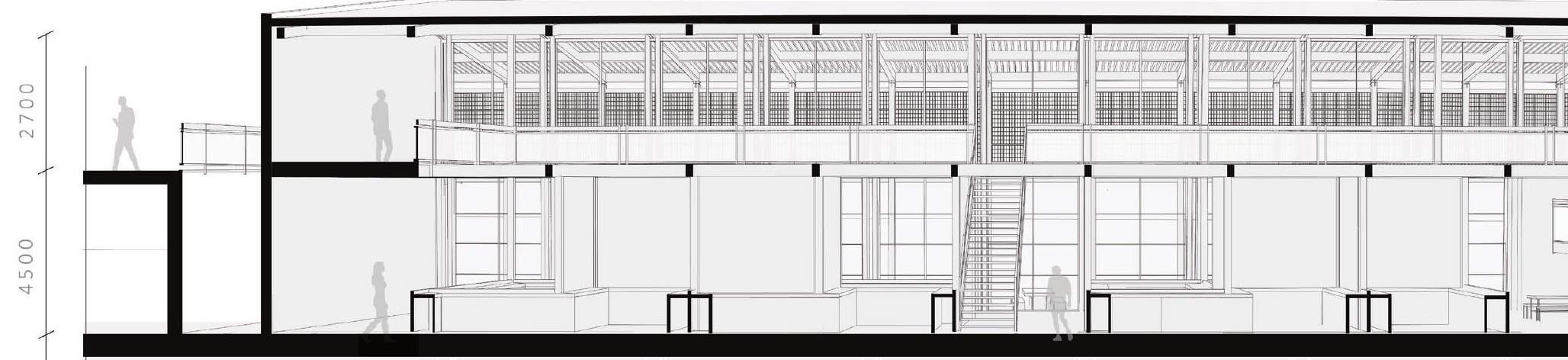




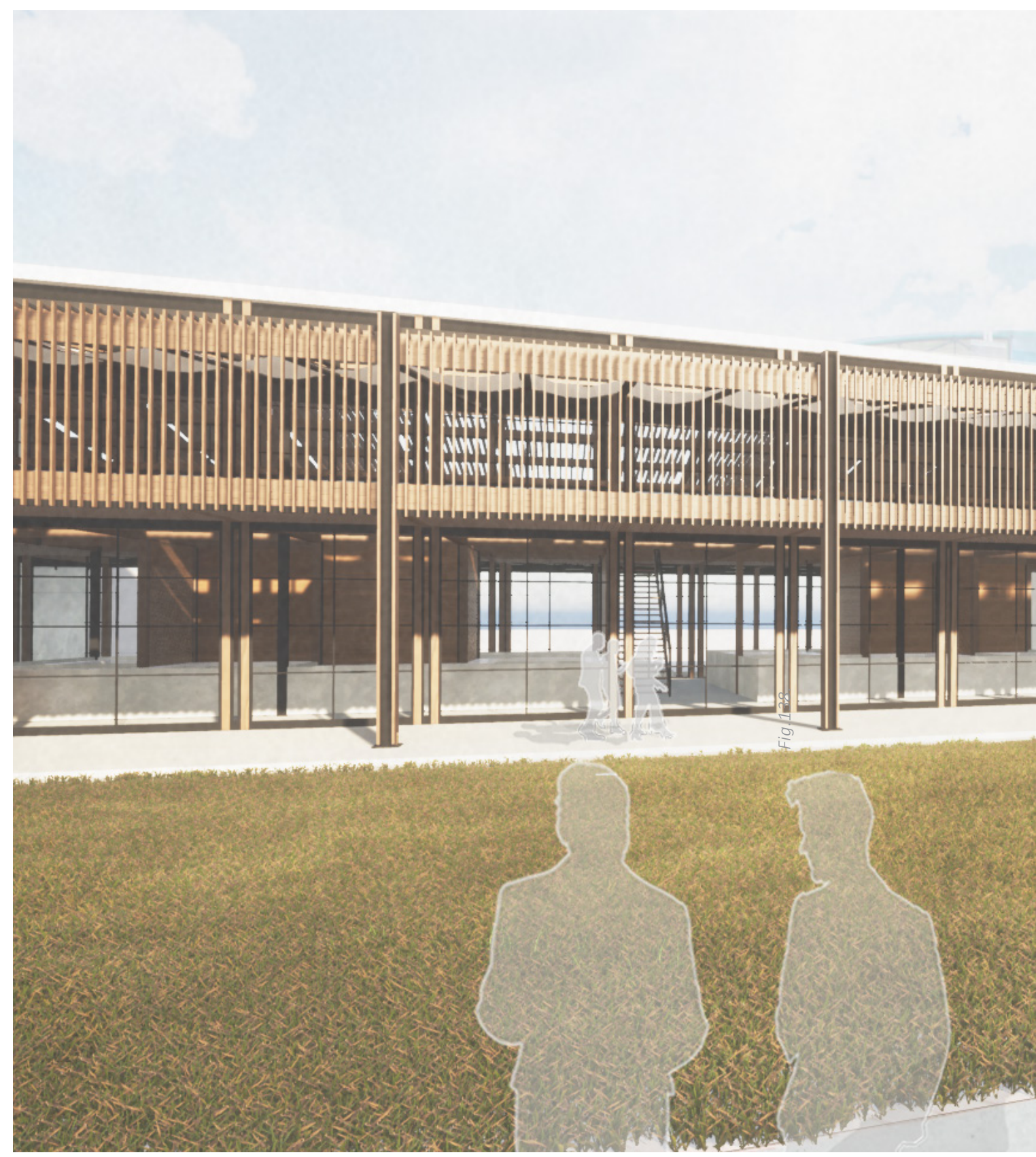




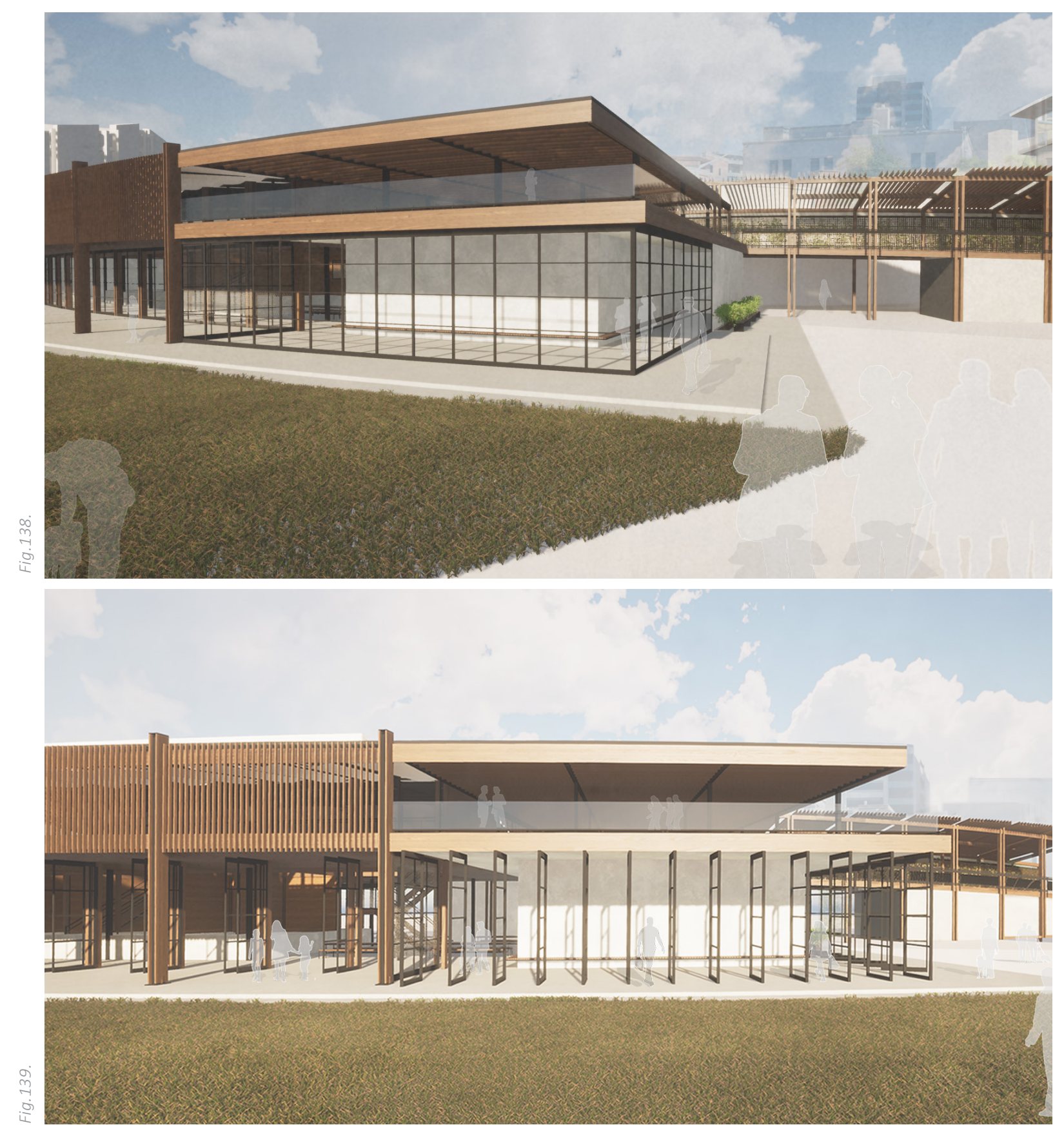




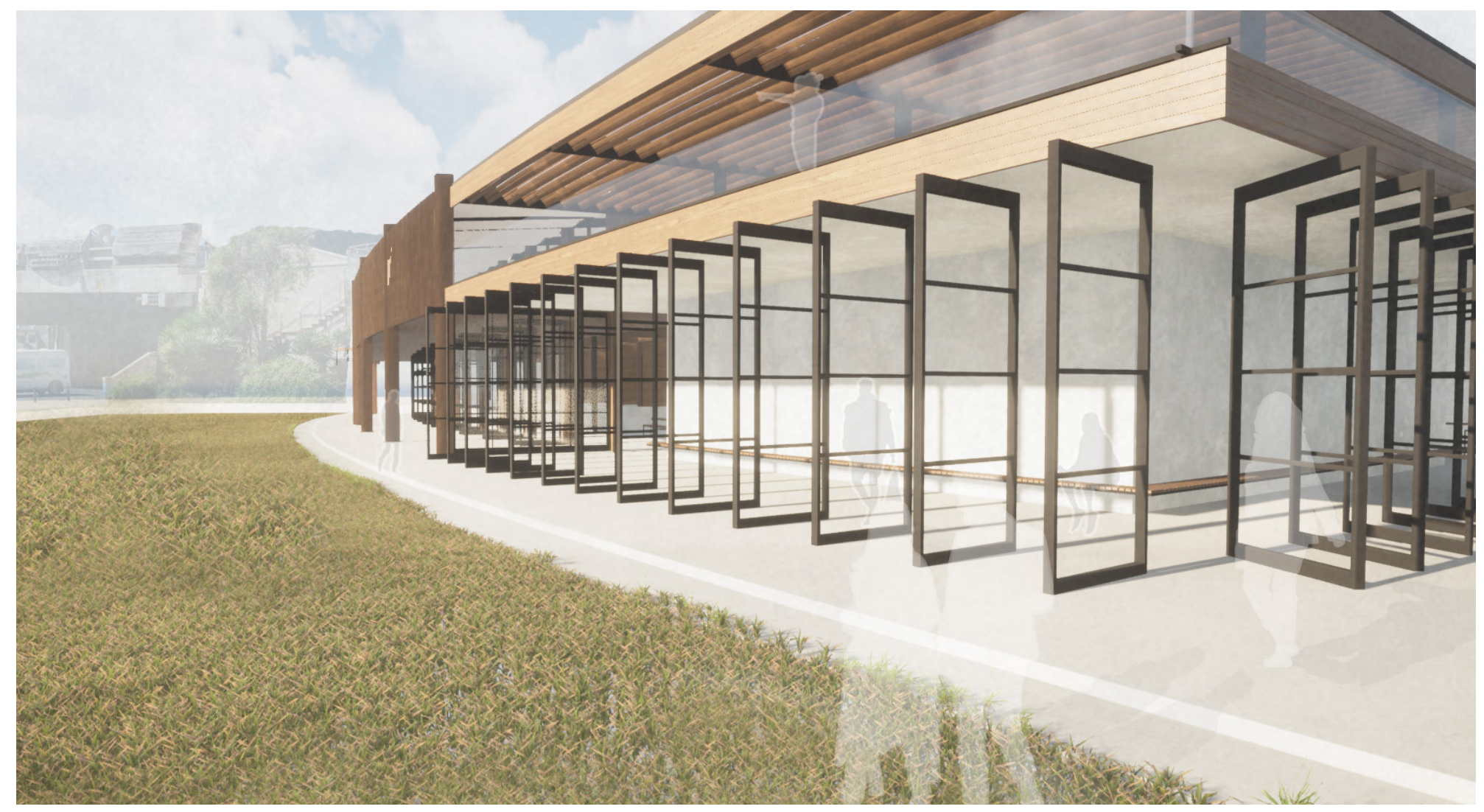

Fig.140.

REVOLVING DOORS - AREA OF FLUX 


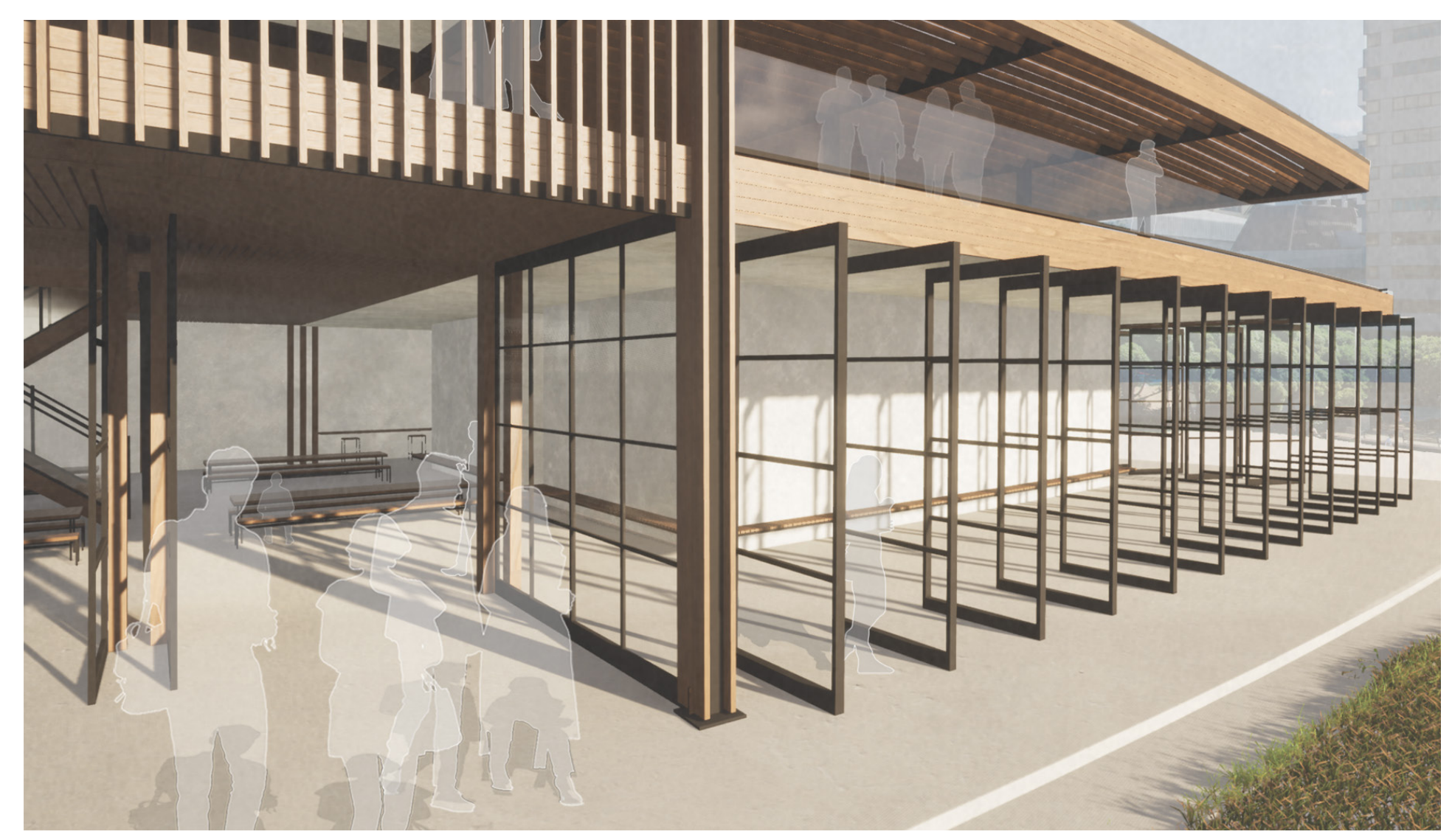

Fig. 141 .

REVOLVING DOORS - LIGHT \& SHADOW INTERPLAY 


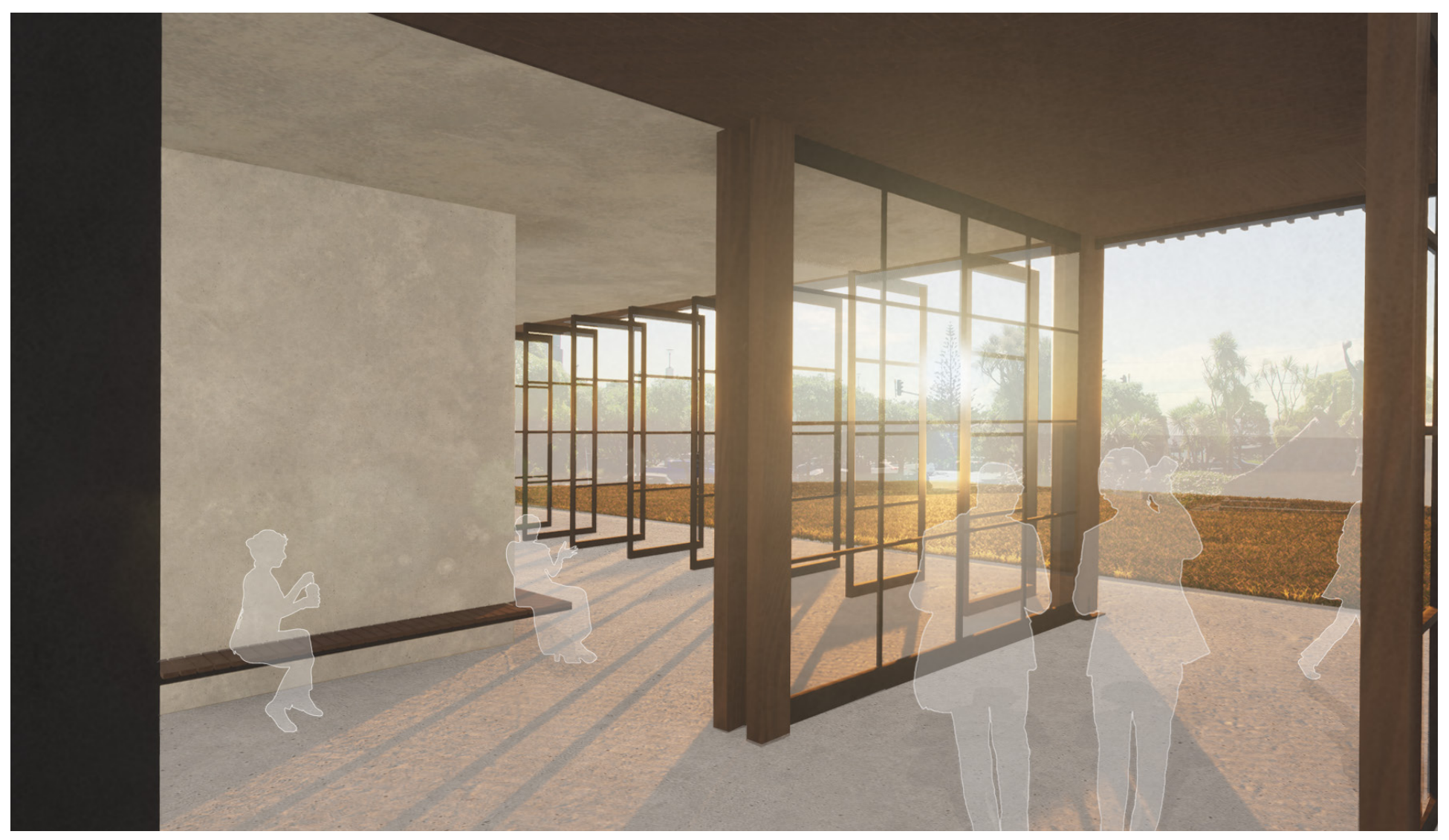

Fig. 142.

INSIDE / OUTSIDE INTERACTION 


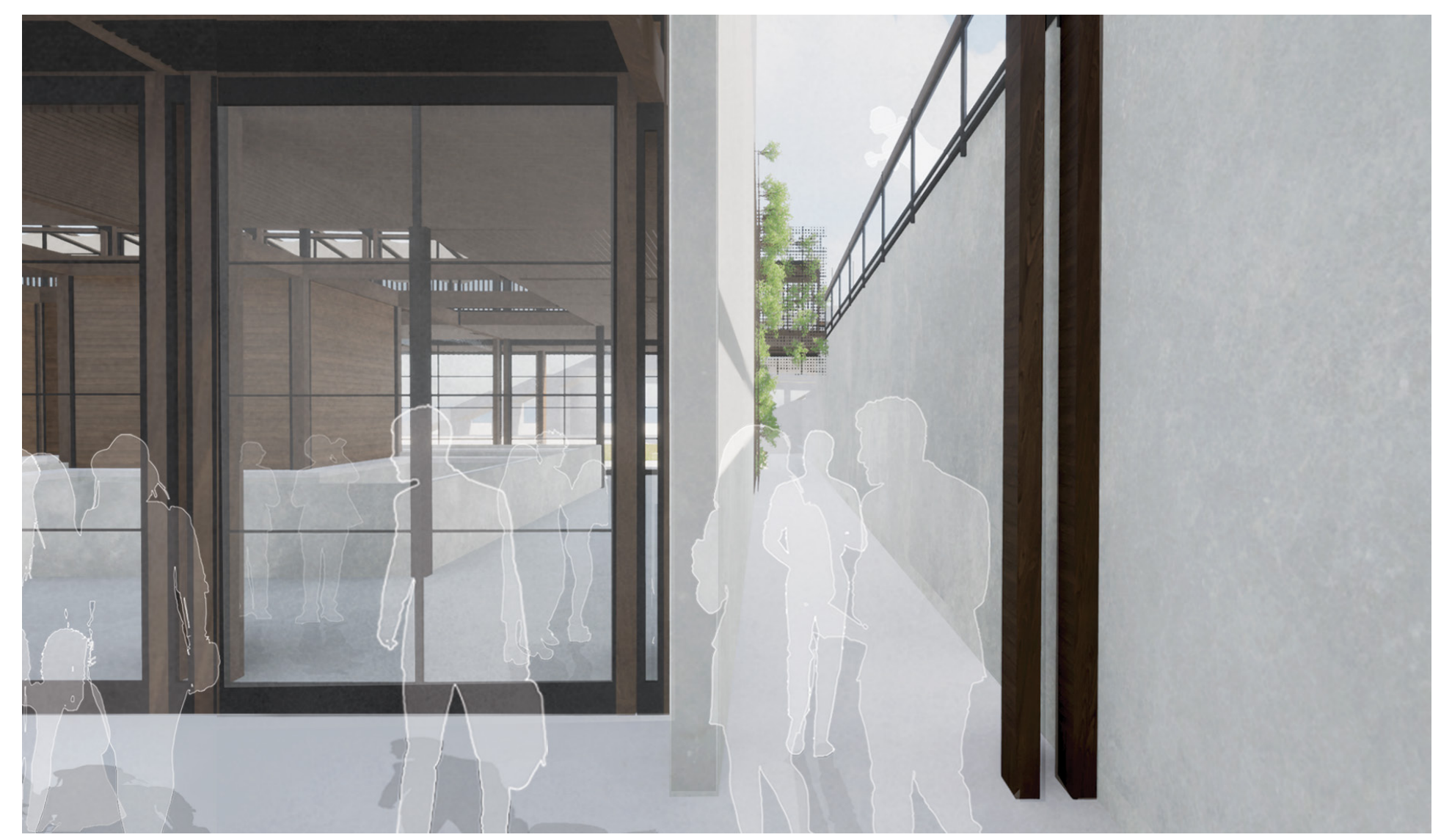

Fig.143.

EXTERNAL ACCESSIBILITY 


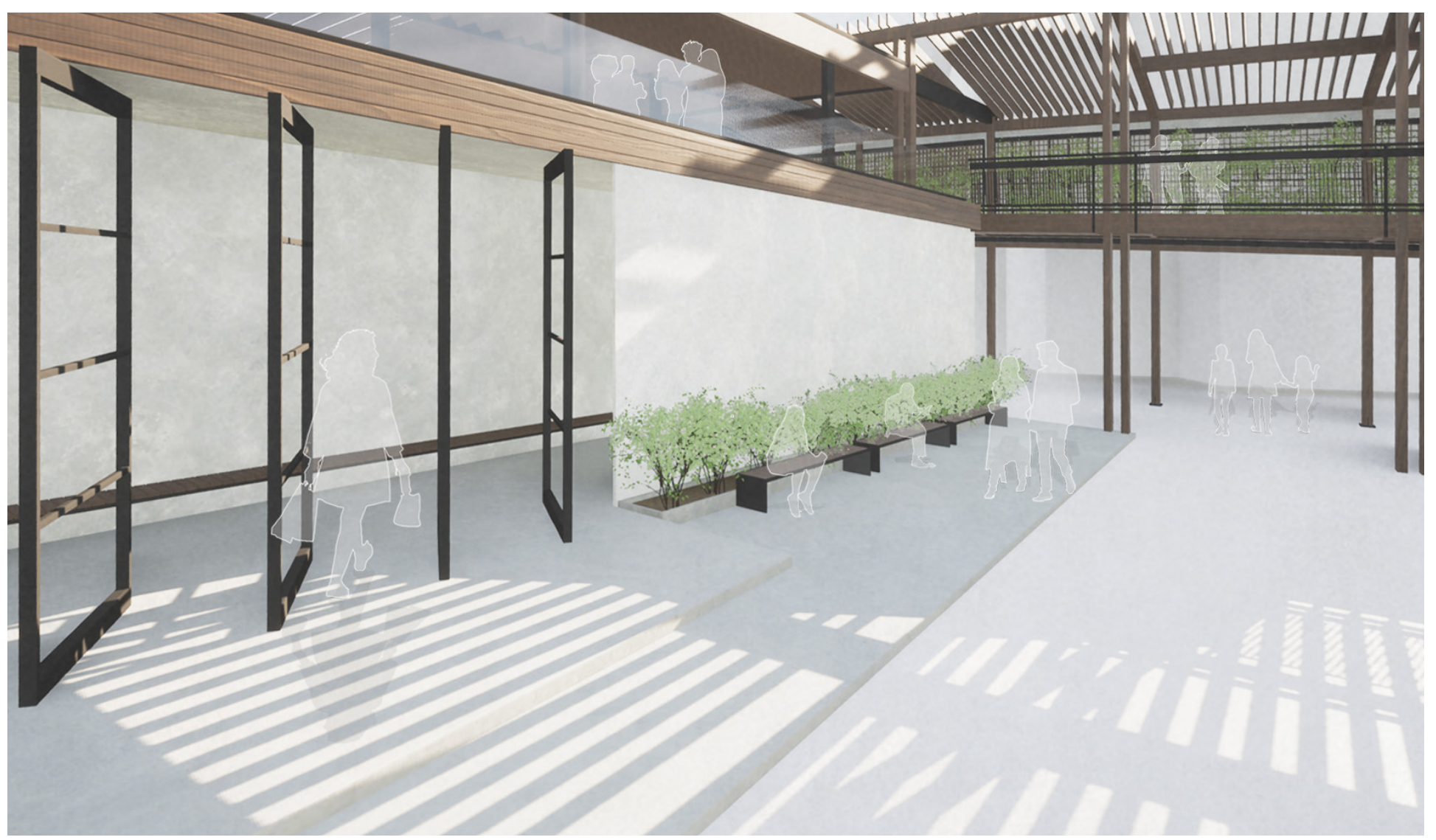

Fig. 144.

LIGHT\& SHADOW INTERPLAY 


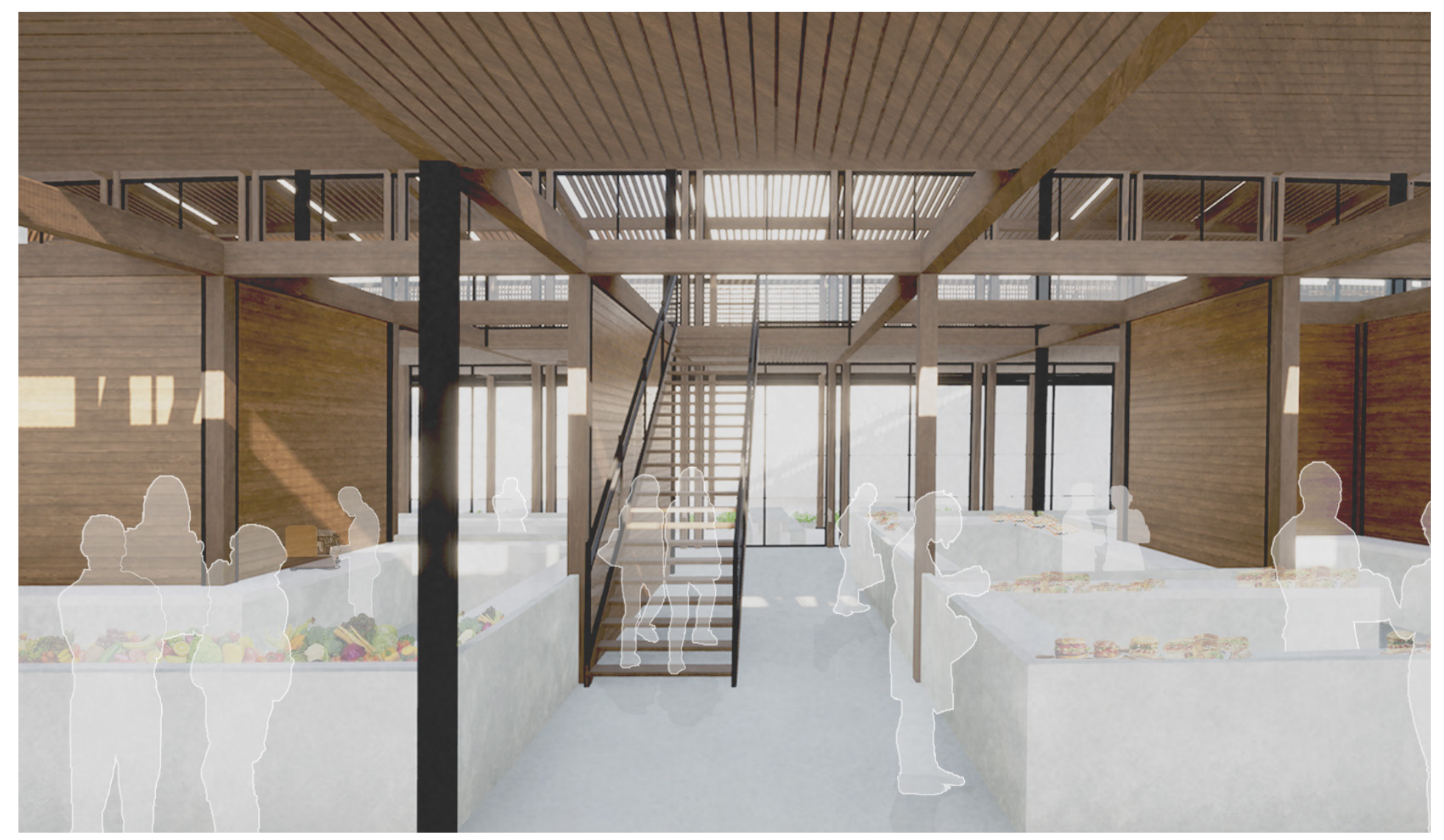

Fig. 145.

SUSPENDING CEILING ASSEMBLING LAYERS 


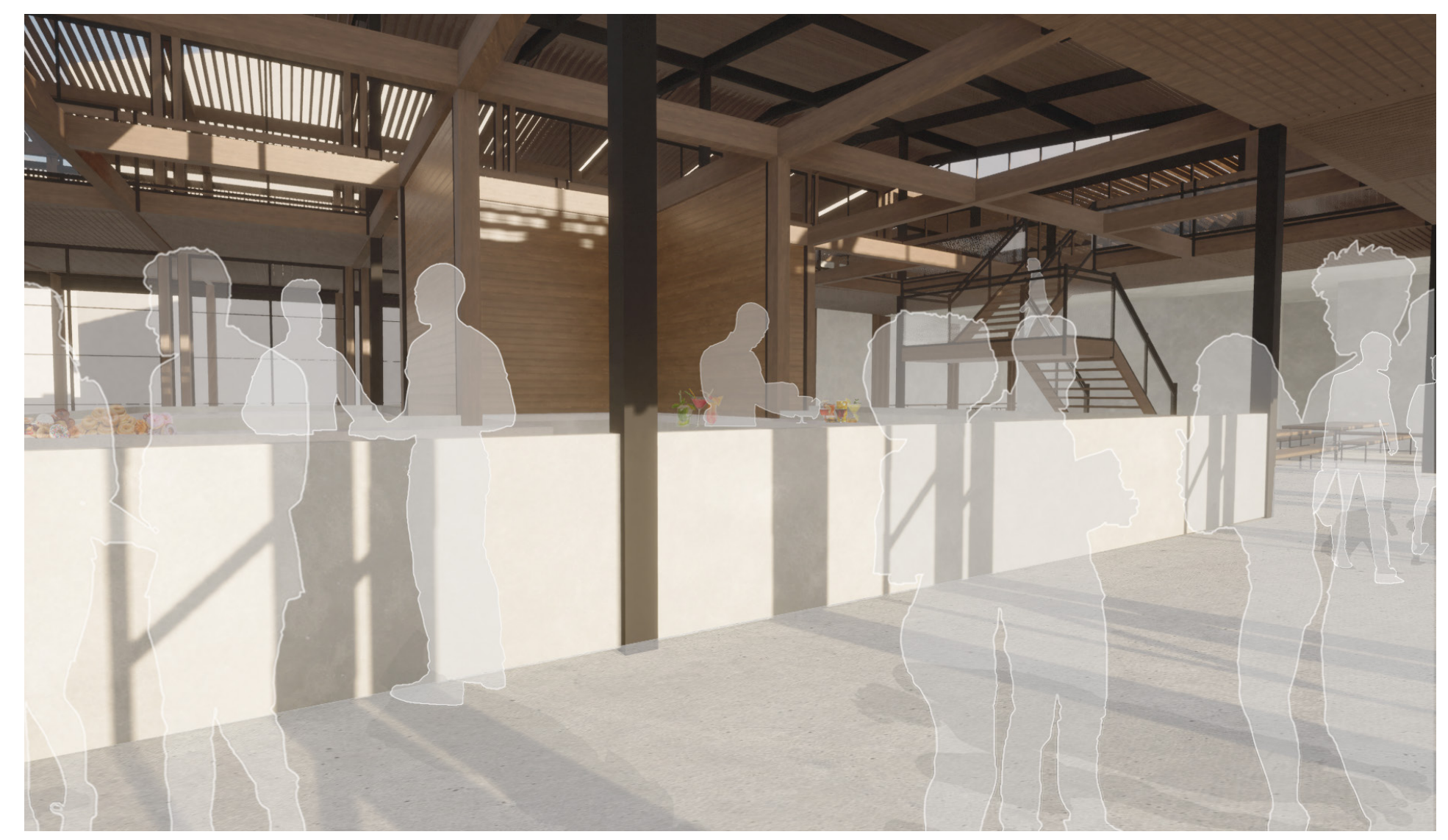

Fig. 146.

ENCOURAGING COMMUNITY INTERACTIONS 


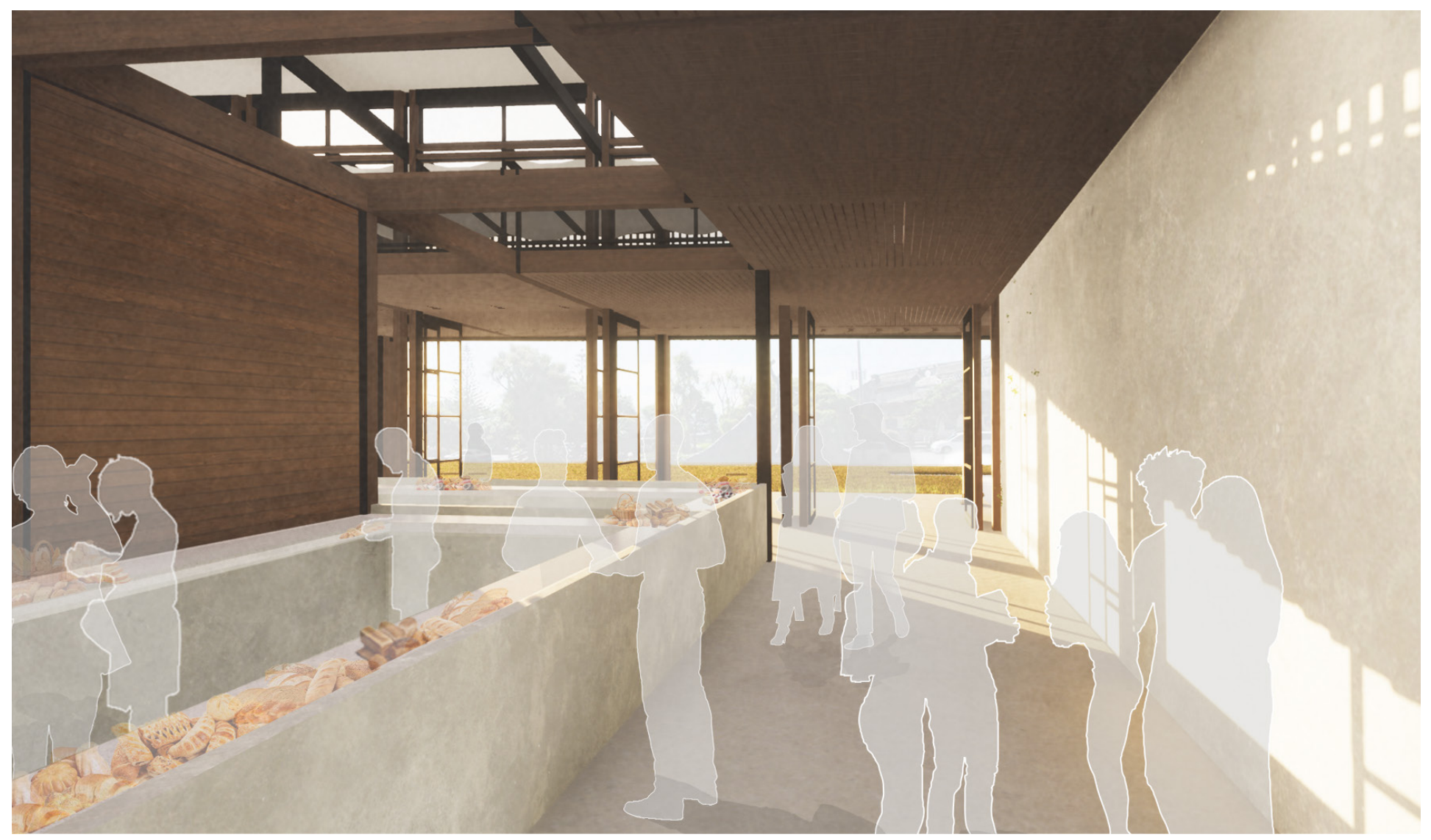

Fig.147.

MATERIALS SHOWCASING LIGHT\& SHADOW INTERPLAY 


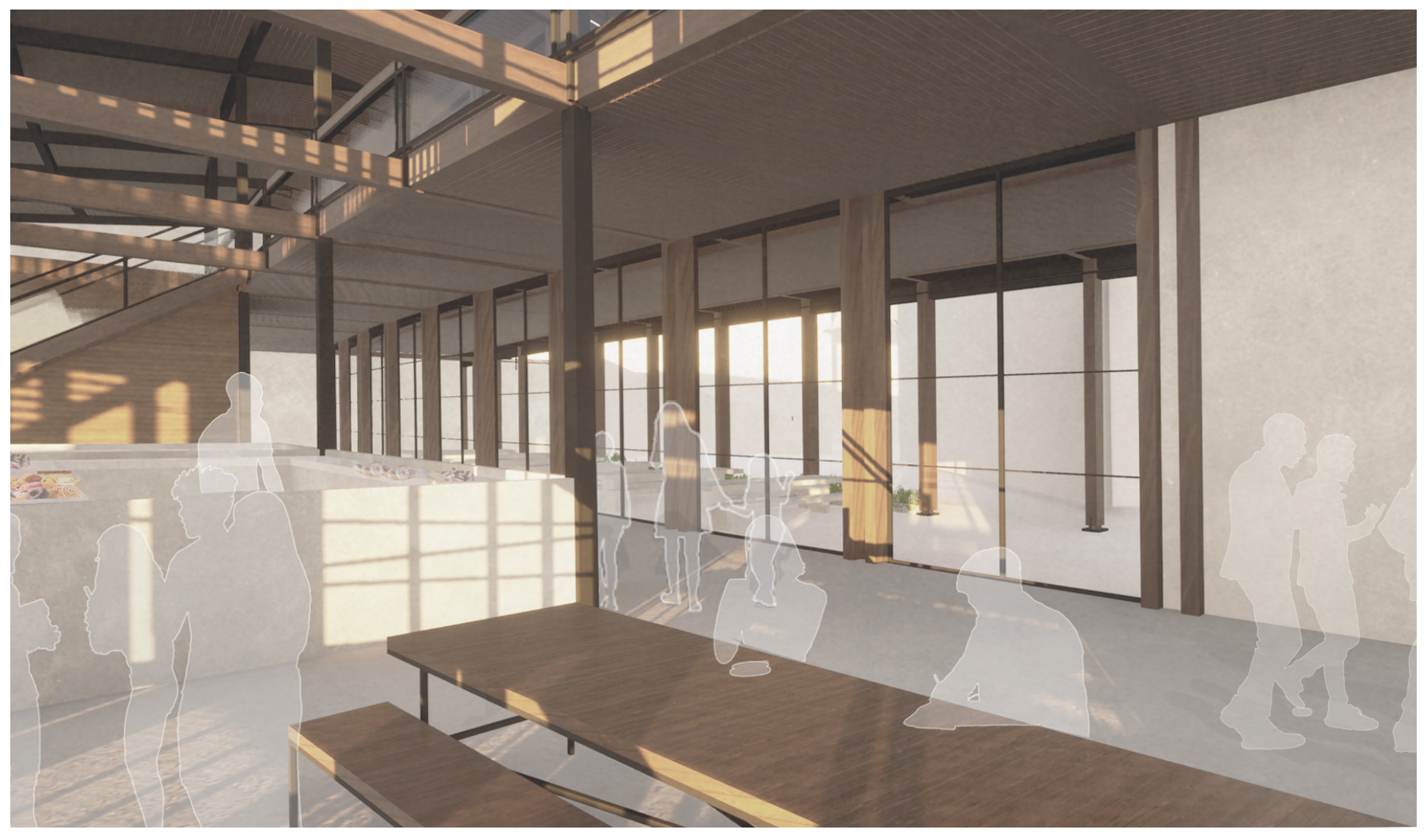

Fig.148.

ENCOURAGING COMMUNITY INTERACTIONS 


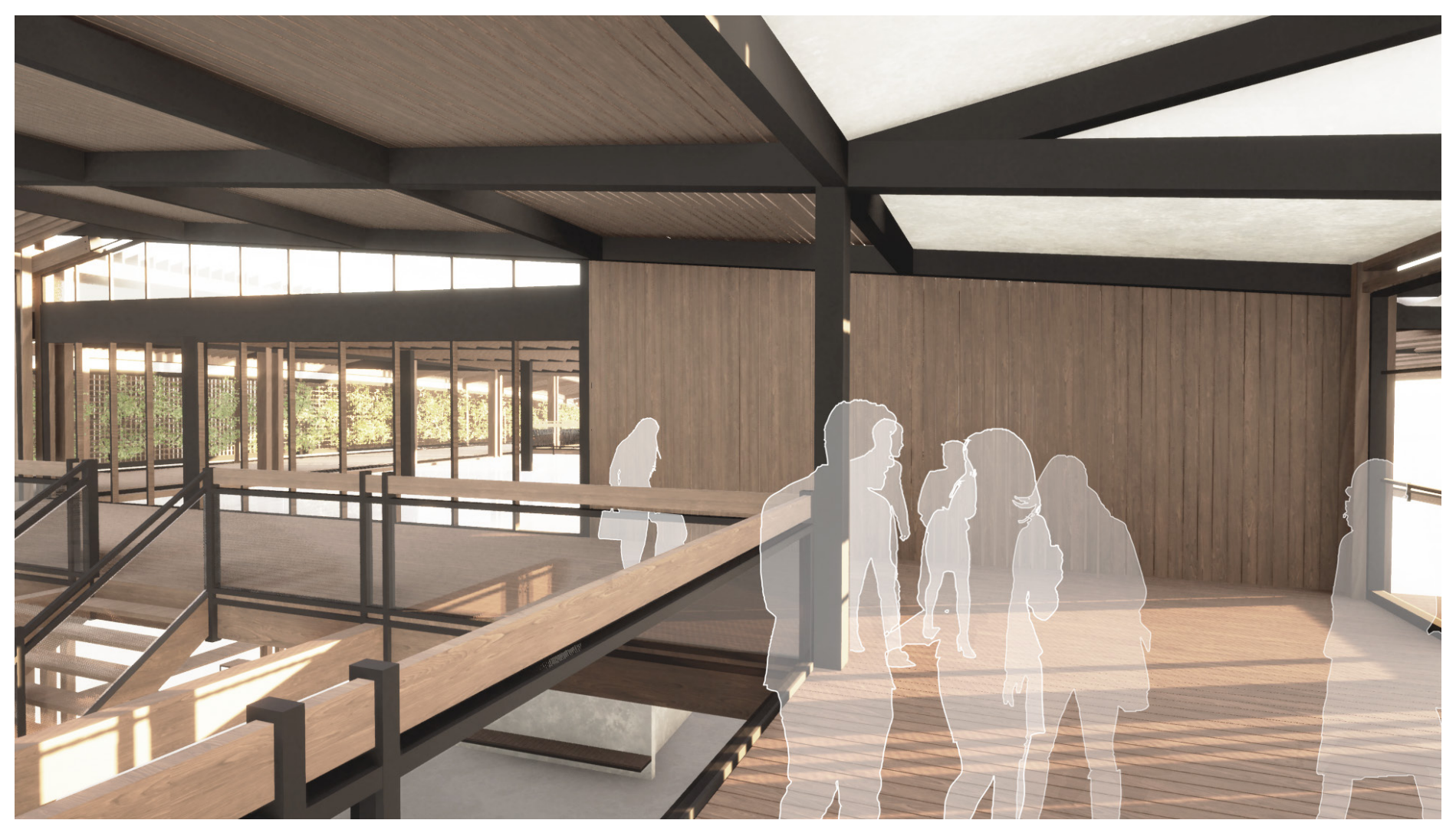

Fig.149.

VERTICAL LOUVRE SYSTEM (DETAIL FIGURE 111). 


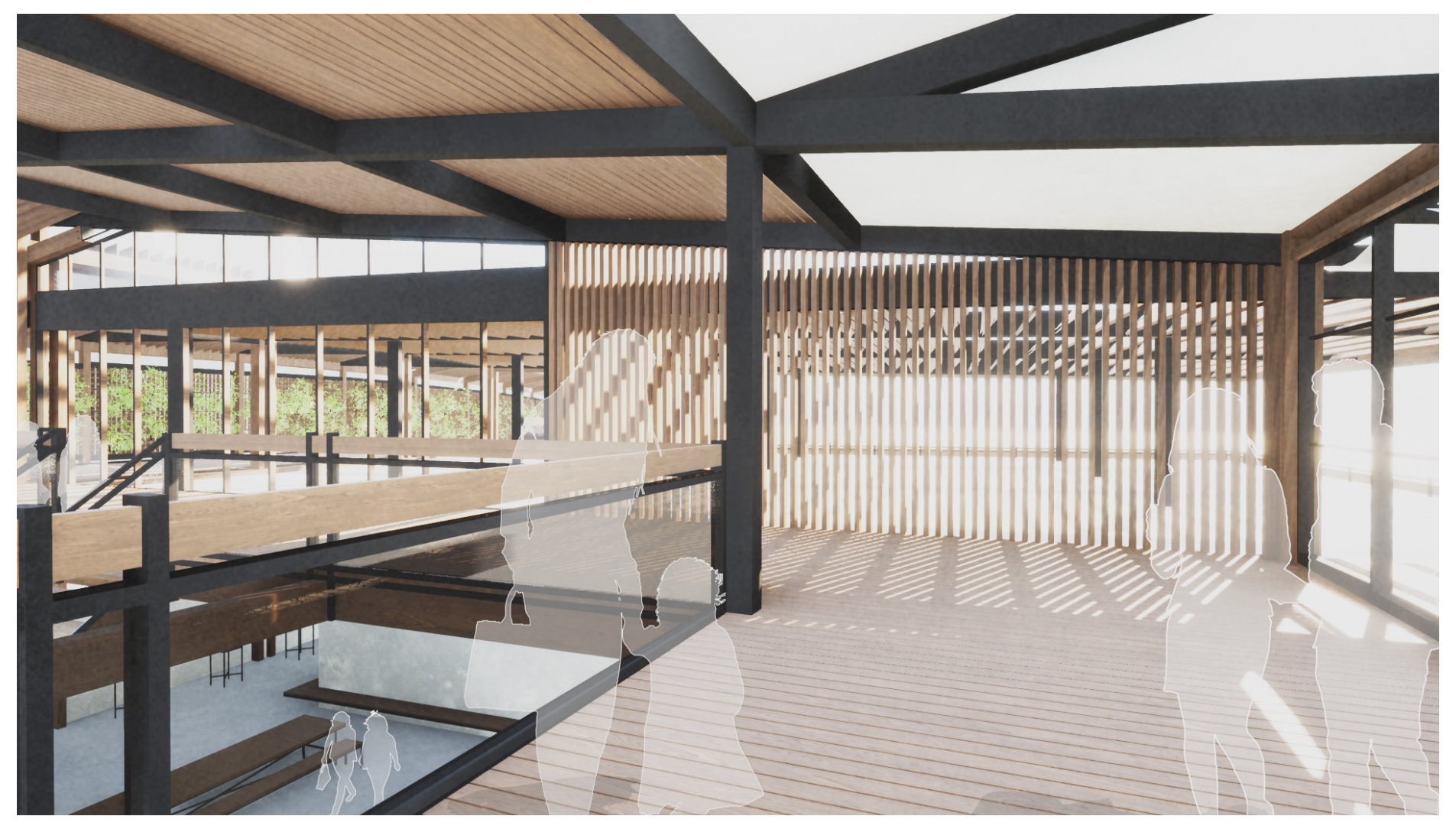

Fig.150.

AREA OF FLUX 


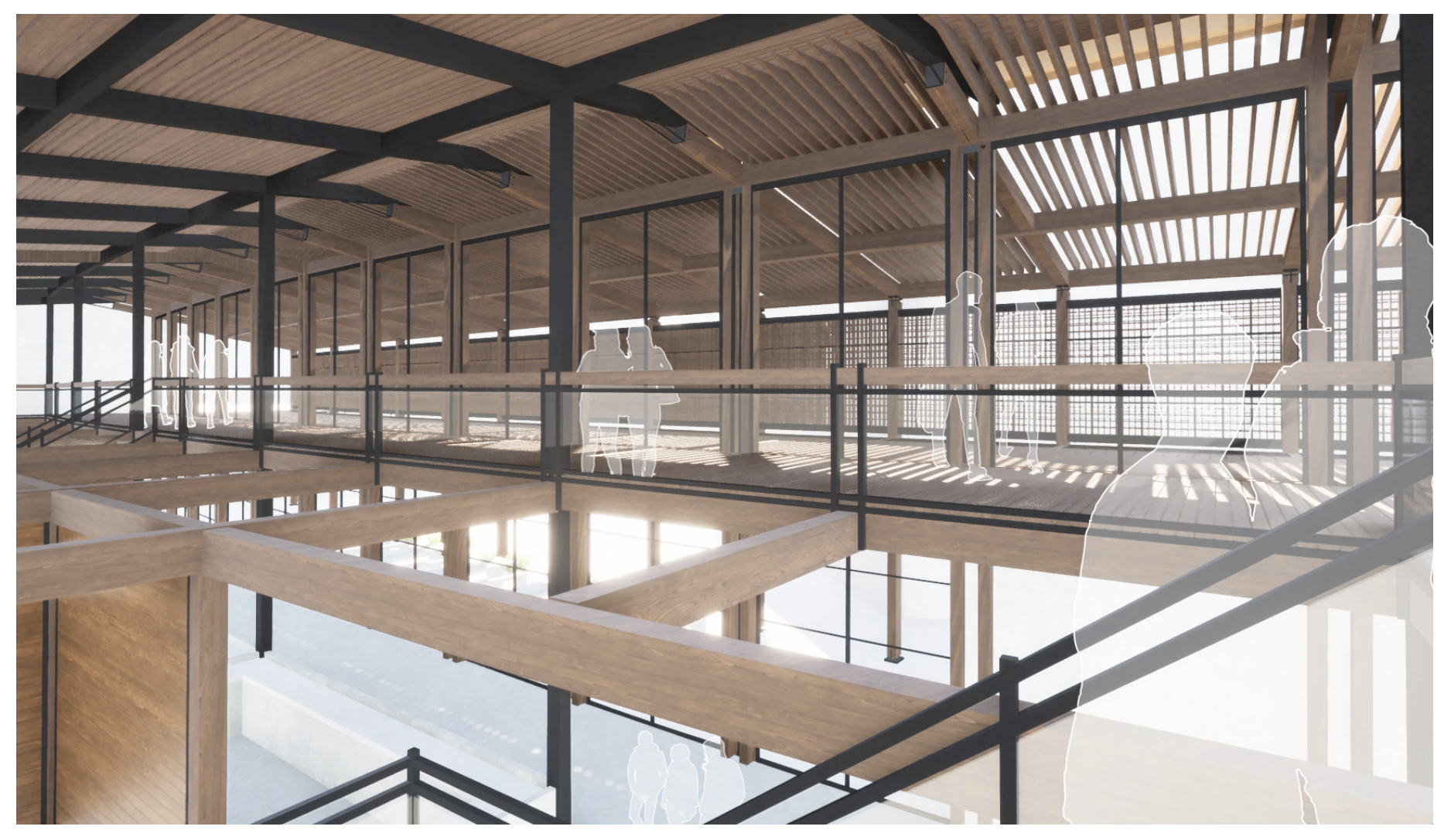

Fig.151.

SPACES VISUALLY 'WOVEN' TOGETHER 


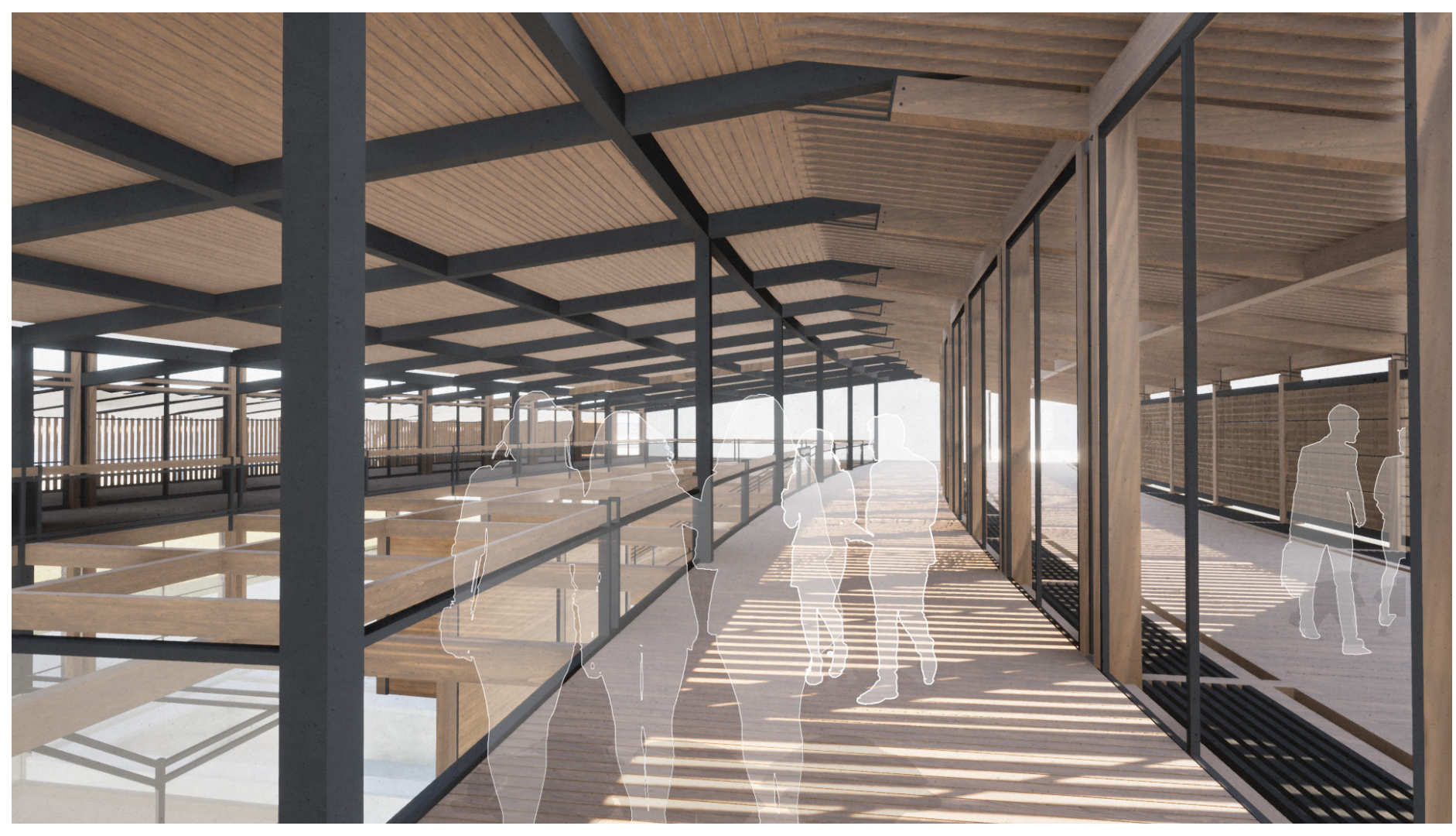

Fig.152.

STEEL CONNECTIONS (DETAIL FIGURE 107). 


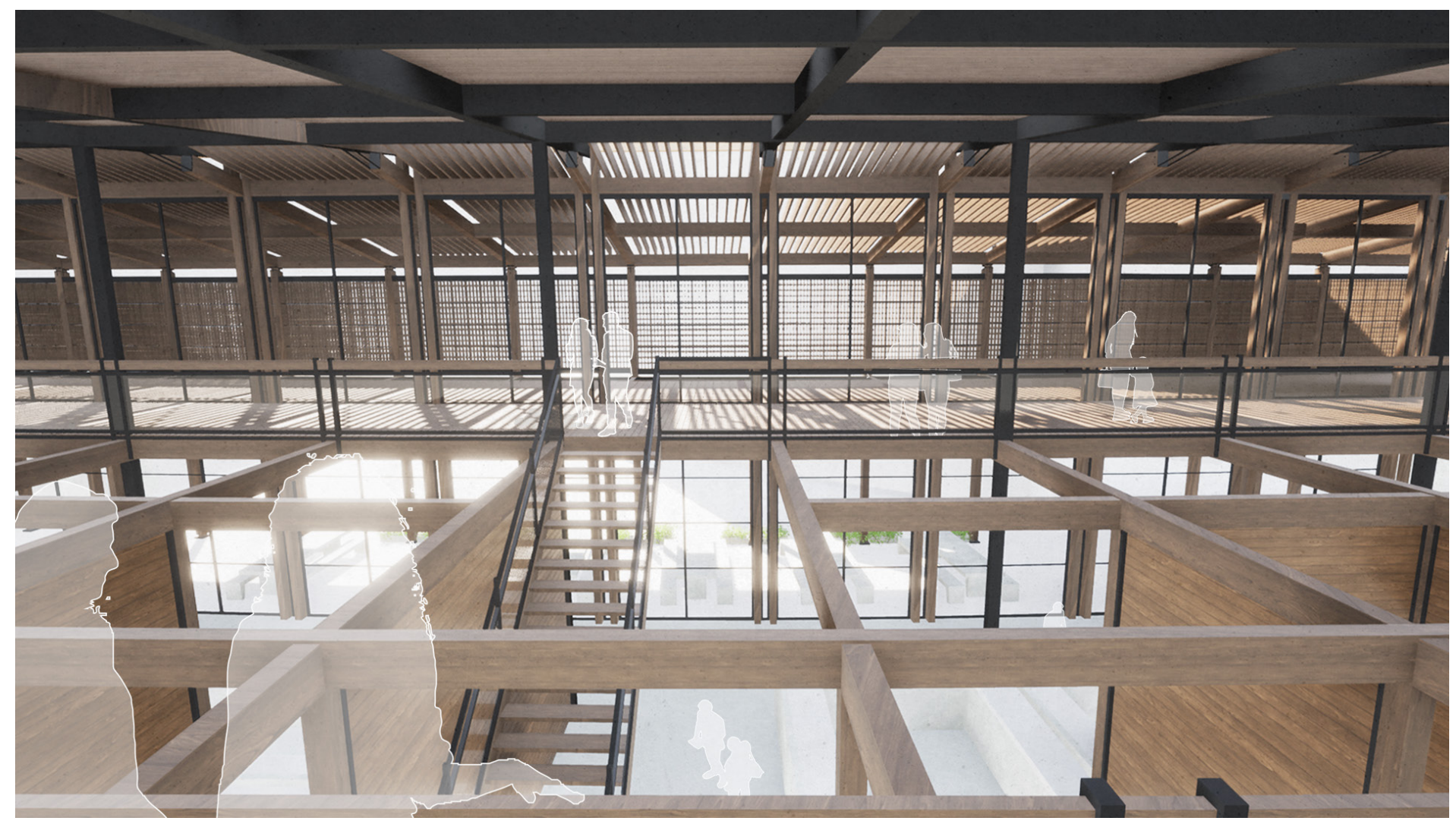

Fig.153.

ENCOURAGING COMMUNITY CONNECTION - VIEW OVER THE GROUND FLOOR 


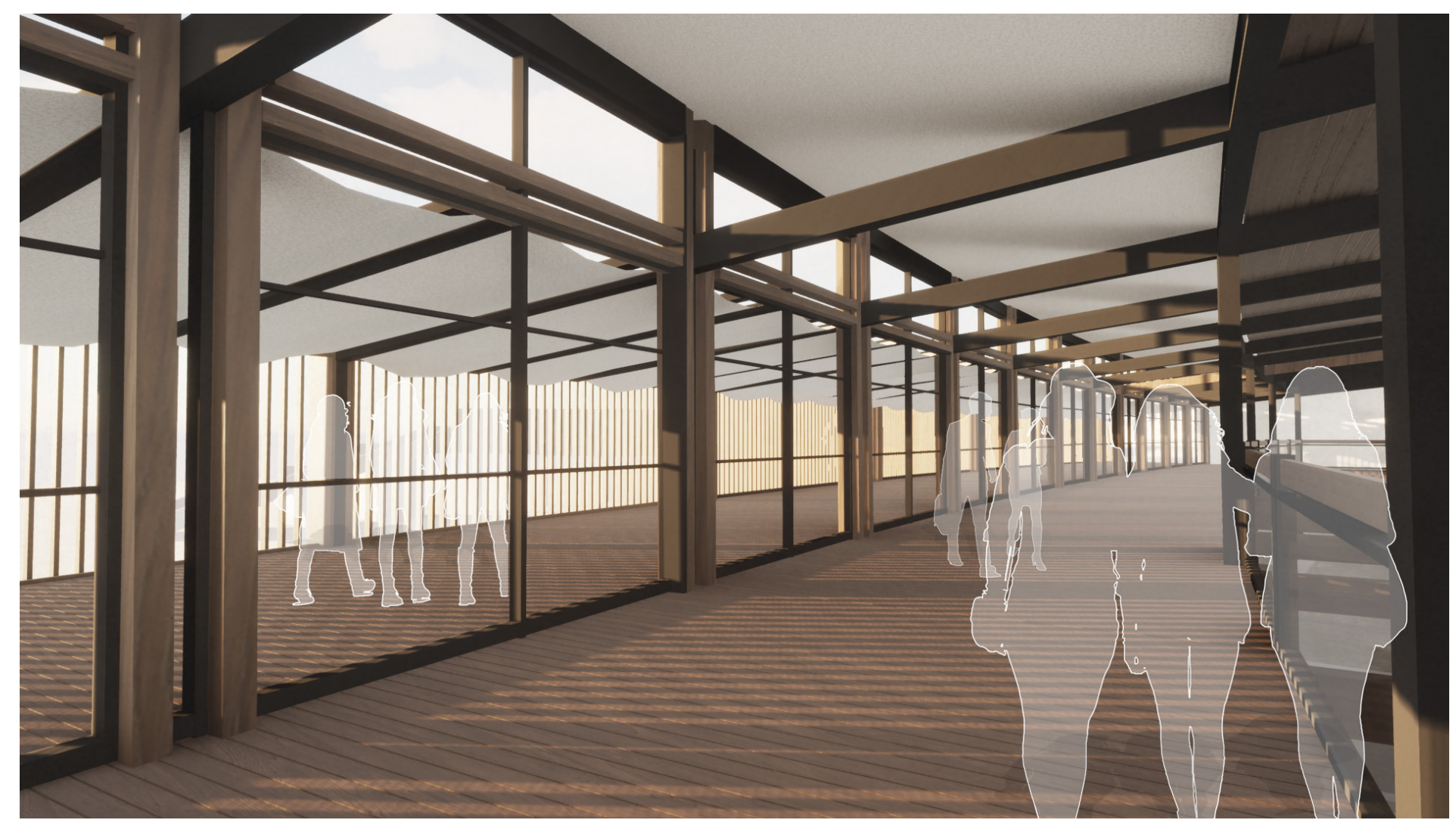

Fig.154.

UPPER LEVEL DAYLIGHTING 


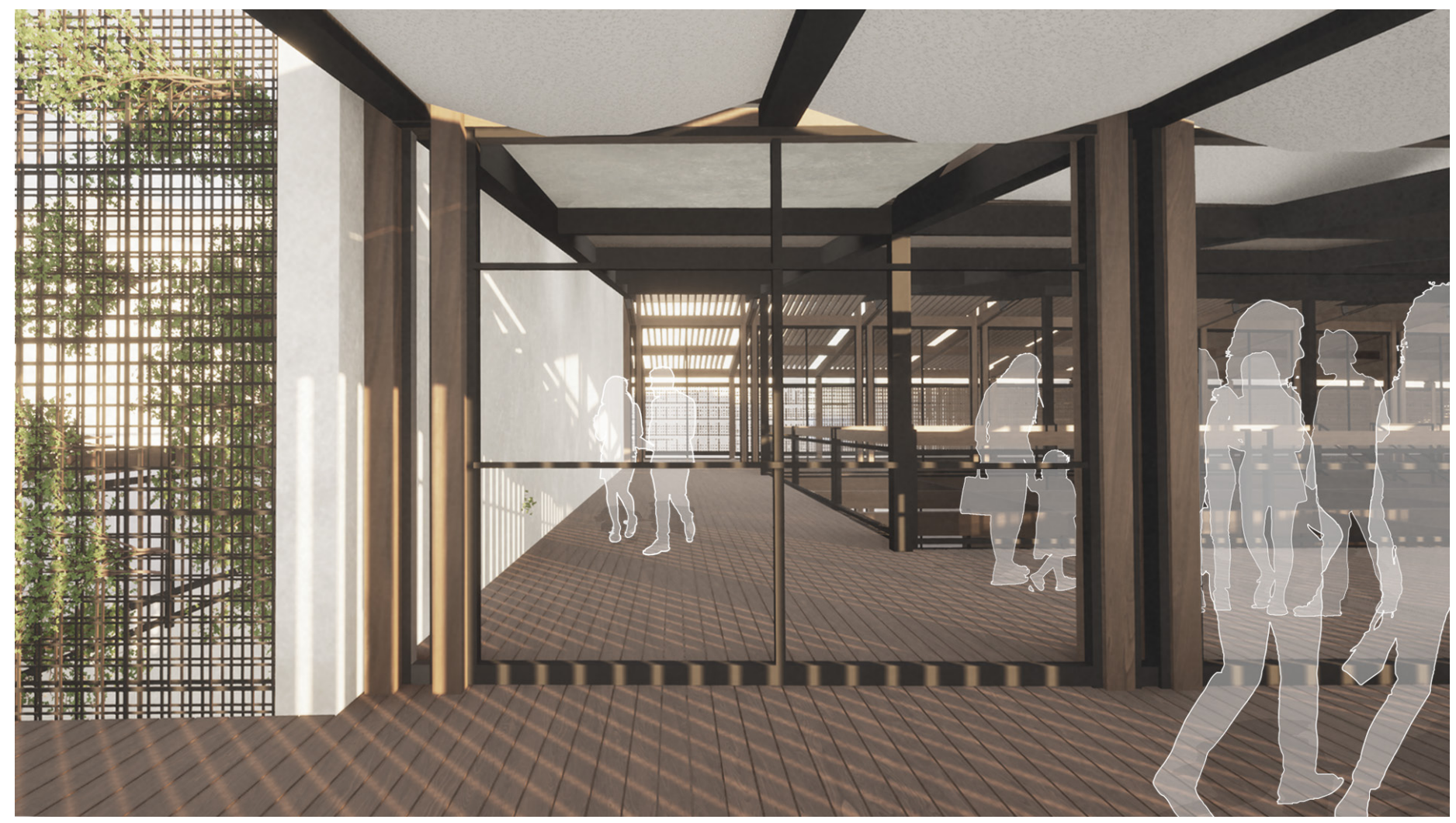

Fig. 155.

SOUTH END FABRIC WALKWAY ENTRANCE 


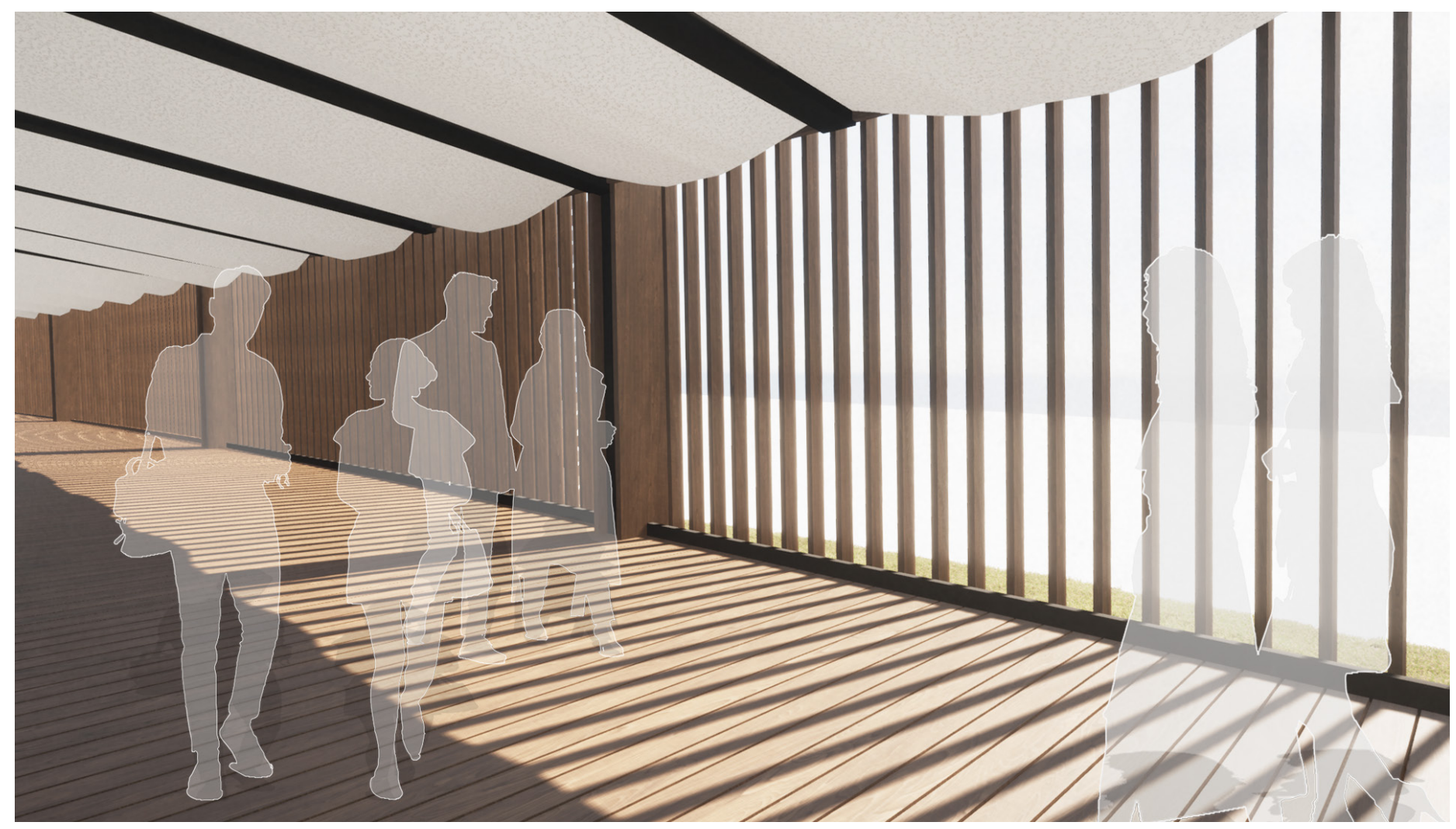

Fig.156.

FABRIC WIND INTERACTION + LIGHT \& SHADOW INTERPLAY 


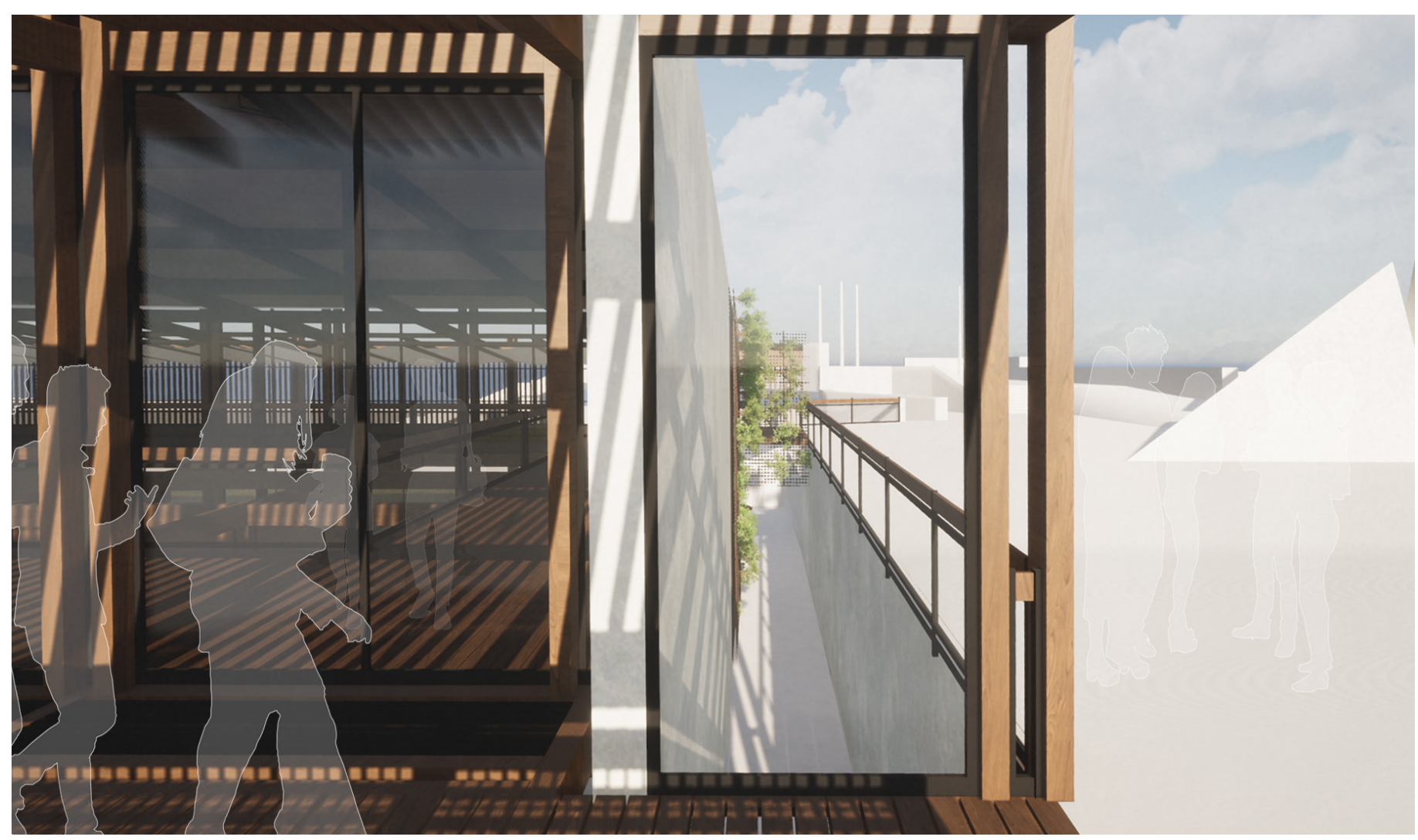

Fig.157.

SOUTH END TECTONIC WALKWAY ENTRANCE 


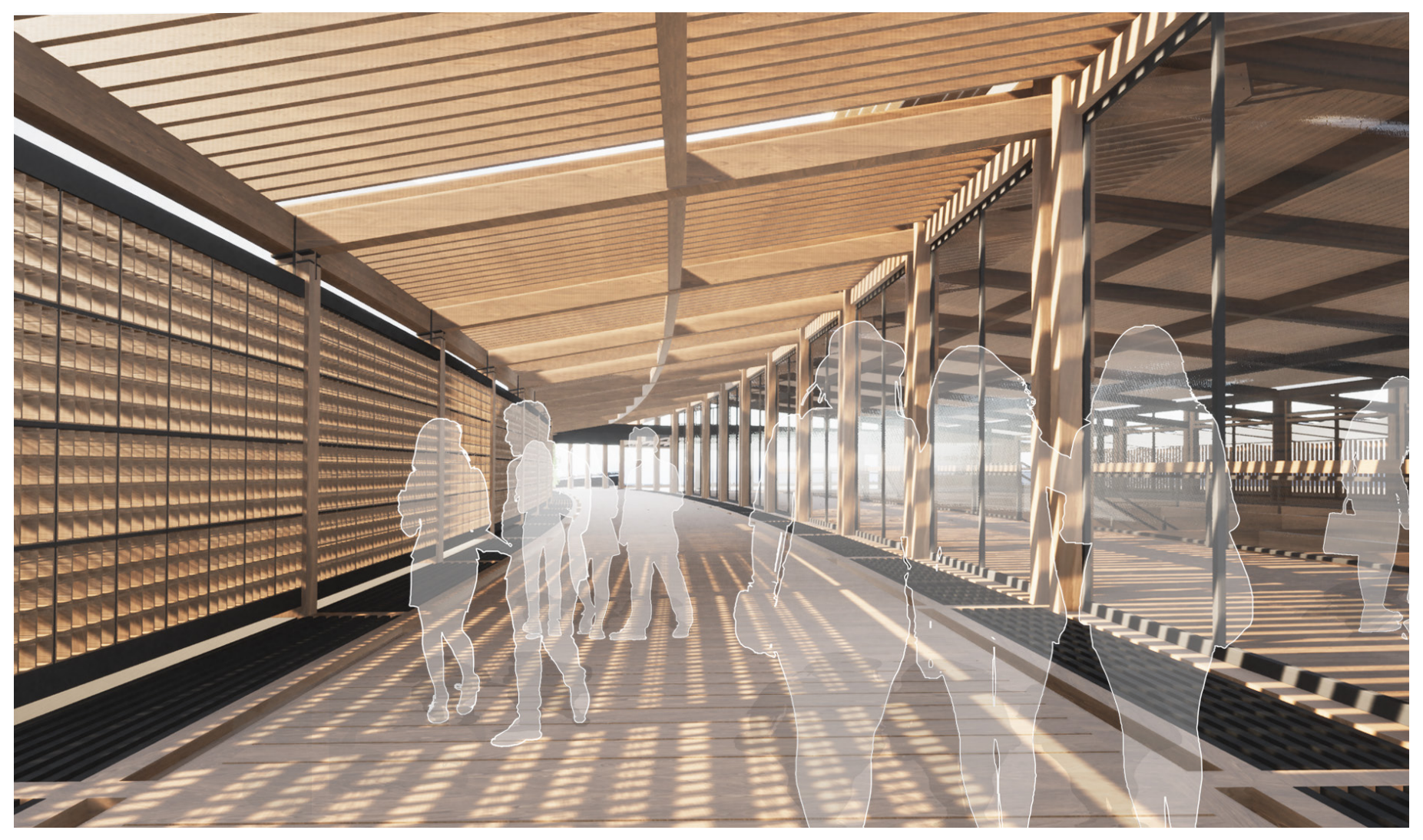

Fig.158.

TECTONIC WALKWAY LIGHT \& SHADOW INTERPLAY 


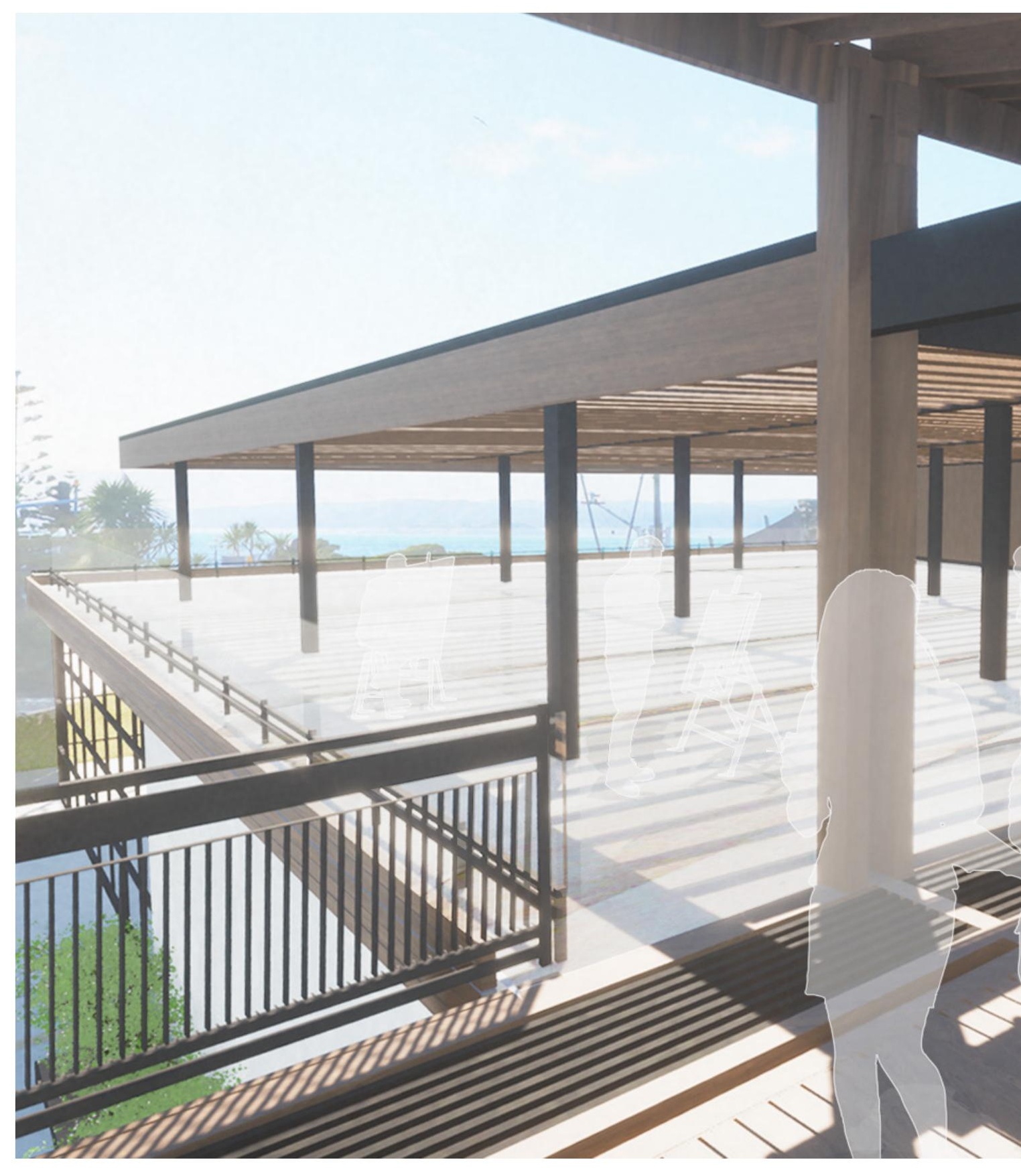

Fig.159.

QUALITIES OF EXHIBITION GROUND SURFACE - A CONSTANT STATE OF FLUX 


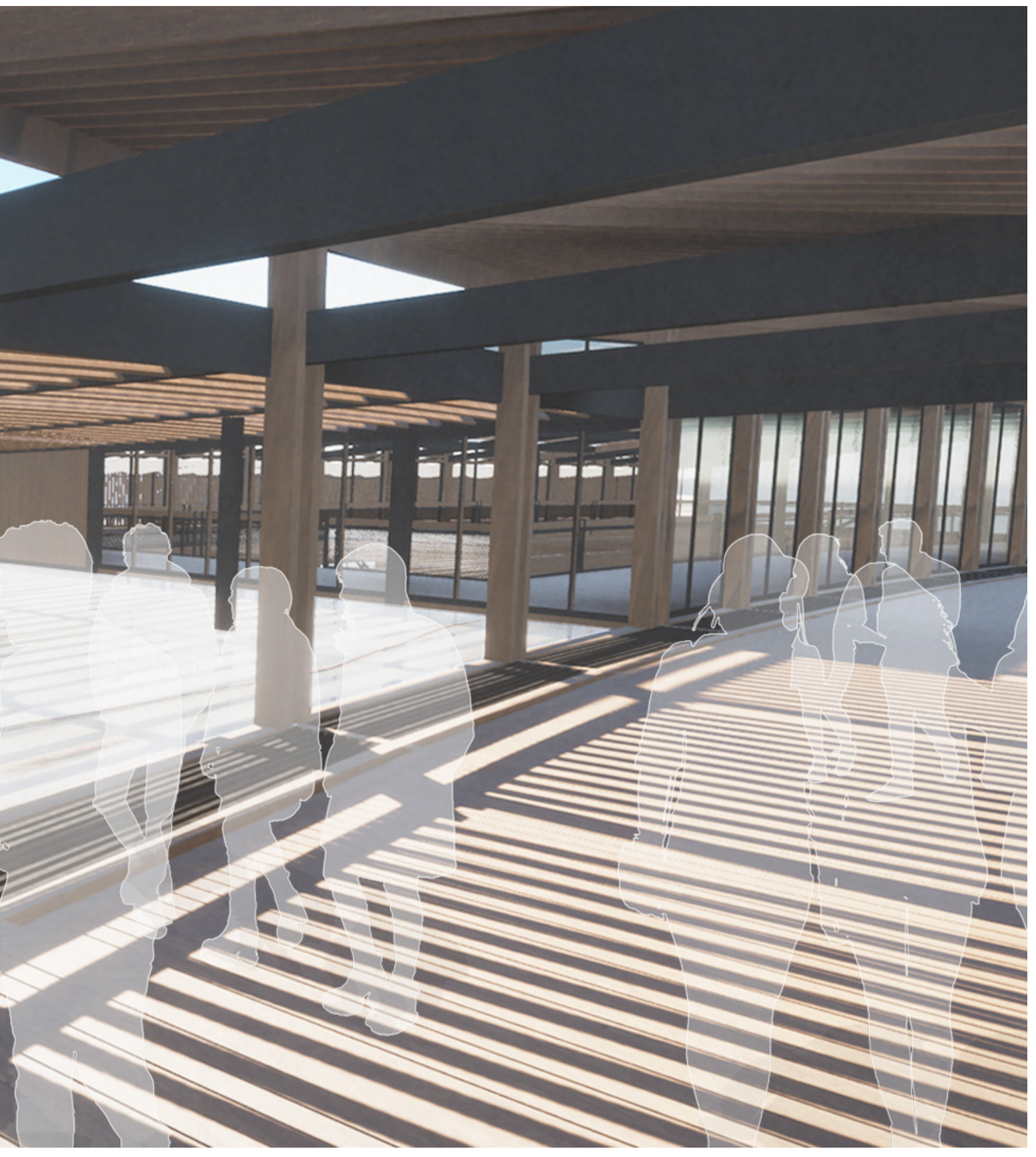




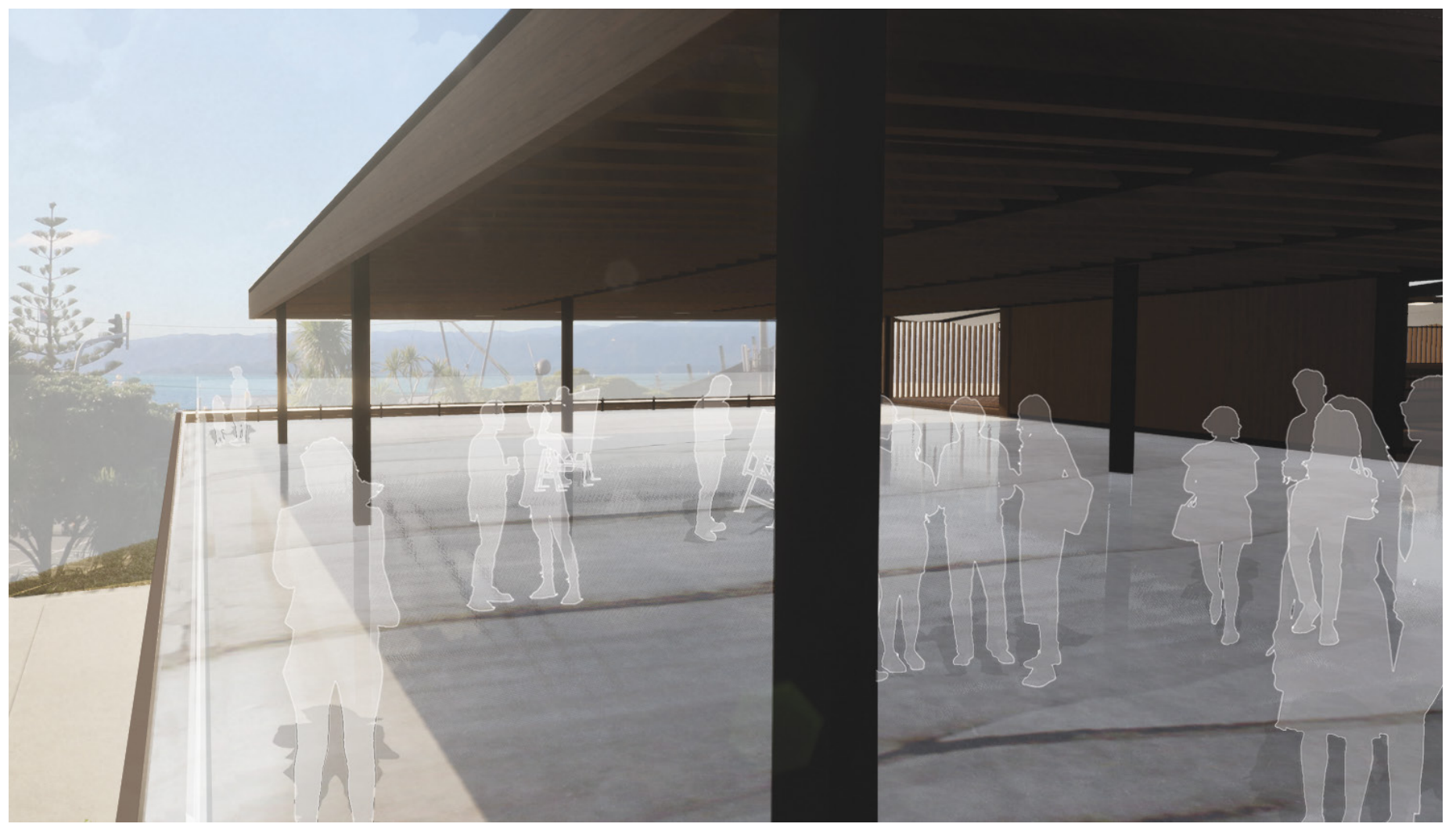

Fig.160.

VIEW SHAFT OUT TO THE WELLINGTON HARBOUR 


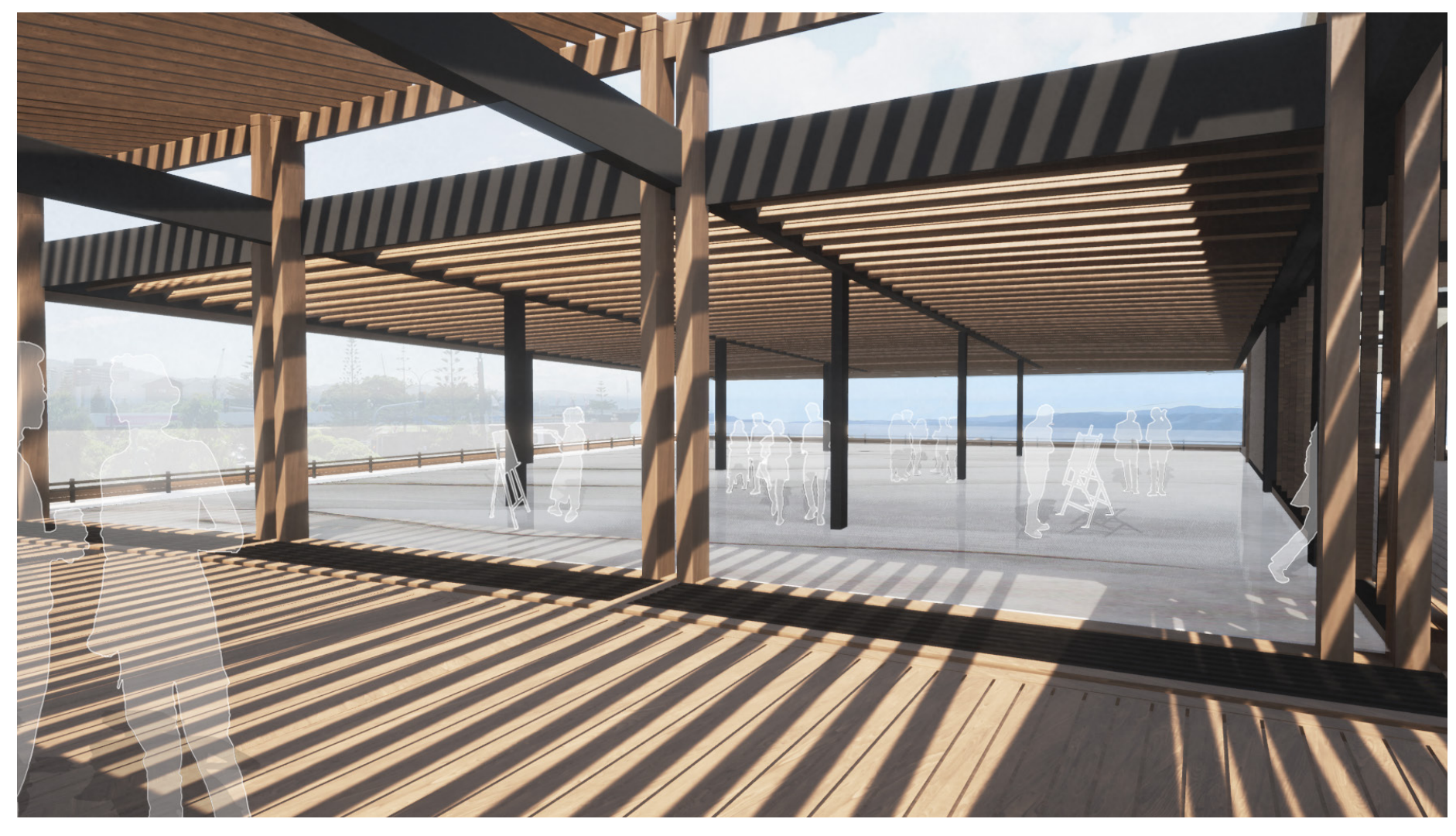

Fig.161.

AGGREGATE SYMBOLISING THE PAST SHORELINE VISUALLY CONNECTS TO THE PRESENT SHORELINE 


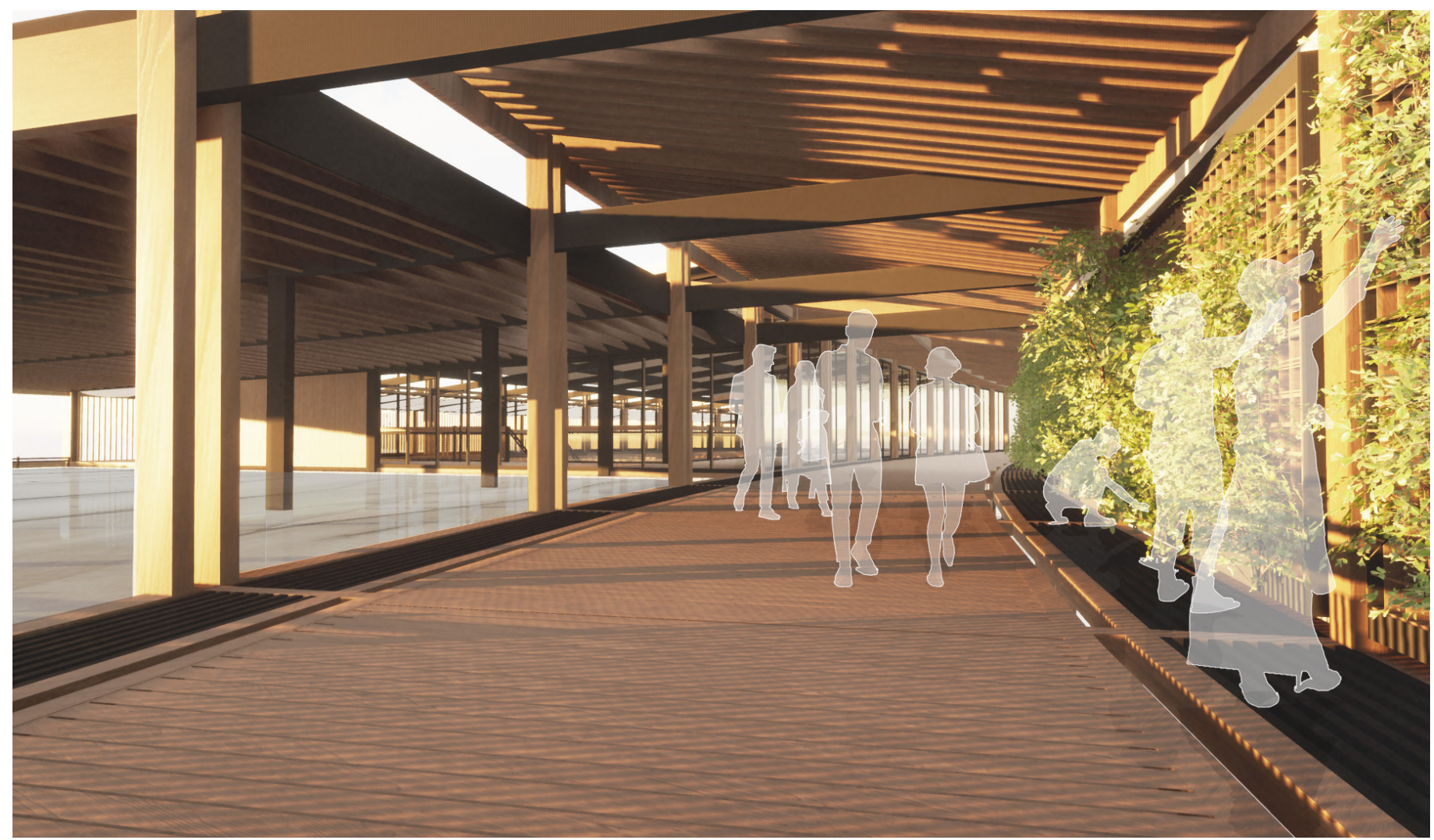

Fig.162.

SPACES VISUALLY 'WOVEN' TOGETHER 


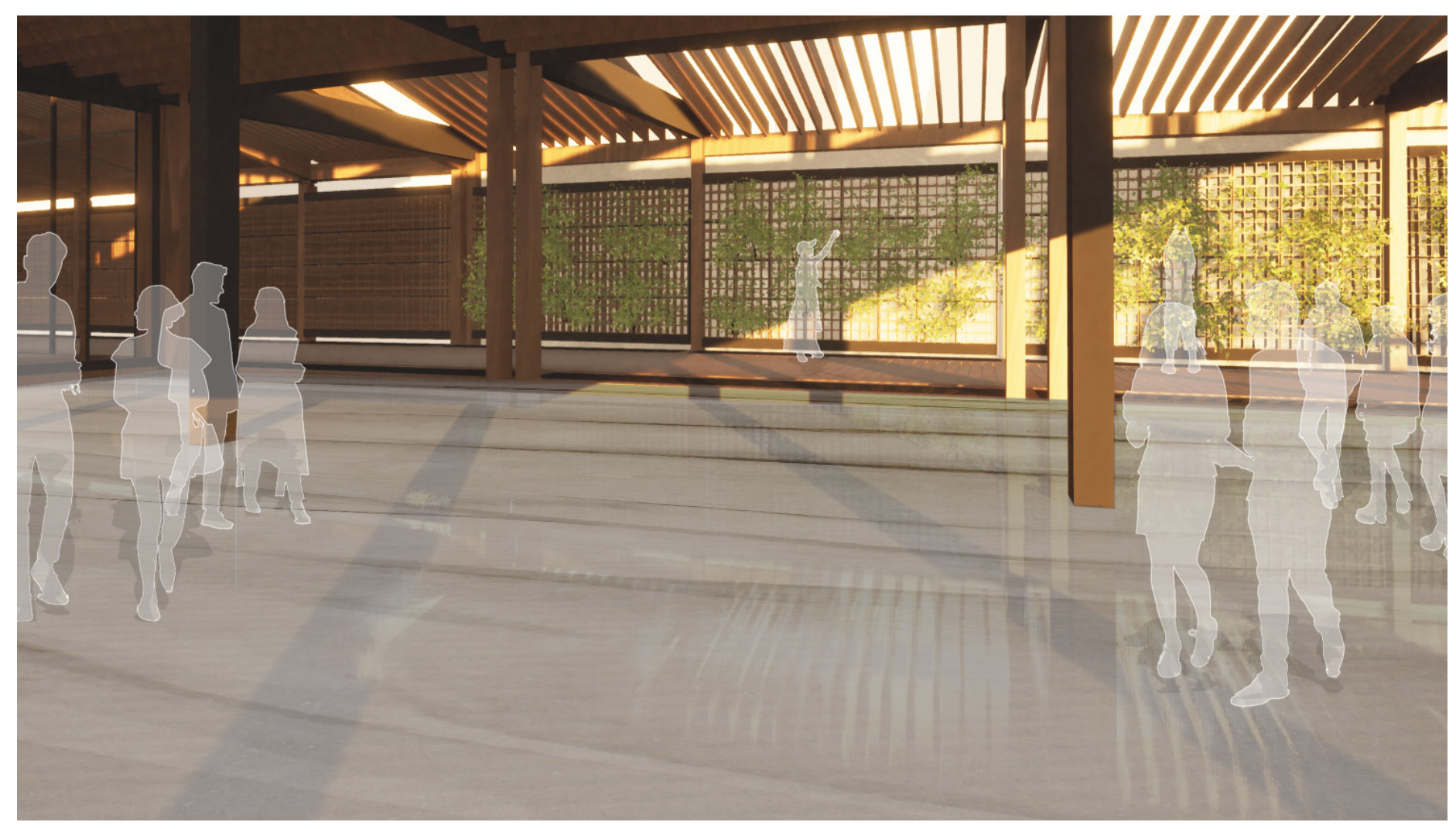

Fig. 163.

COMMUNITY GARDEN TRANSITIONS TO TECTONIC SCREEN 


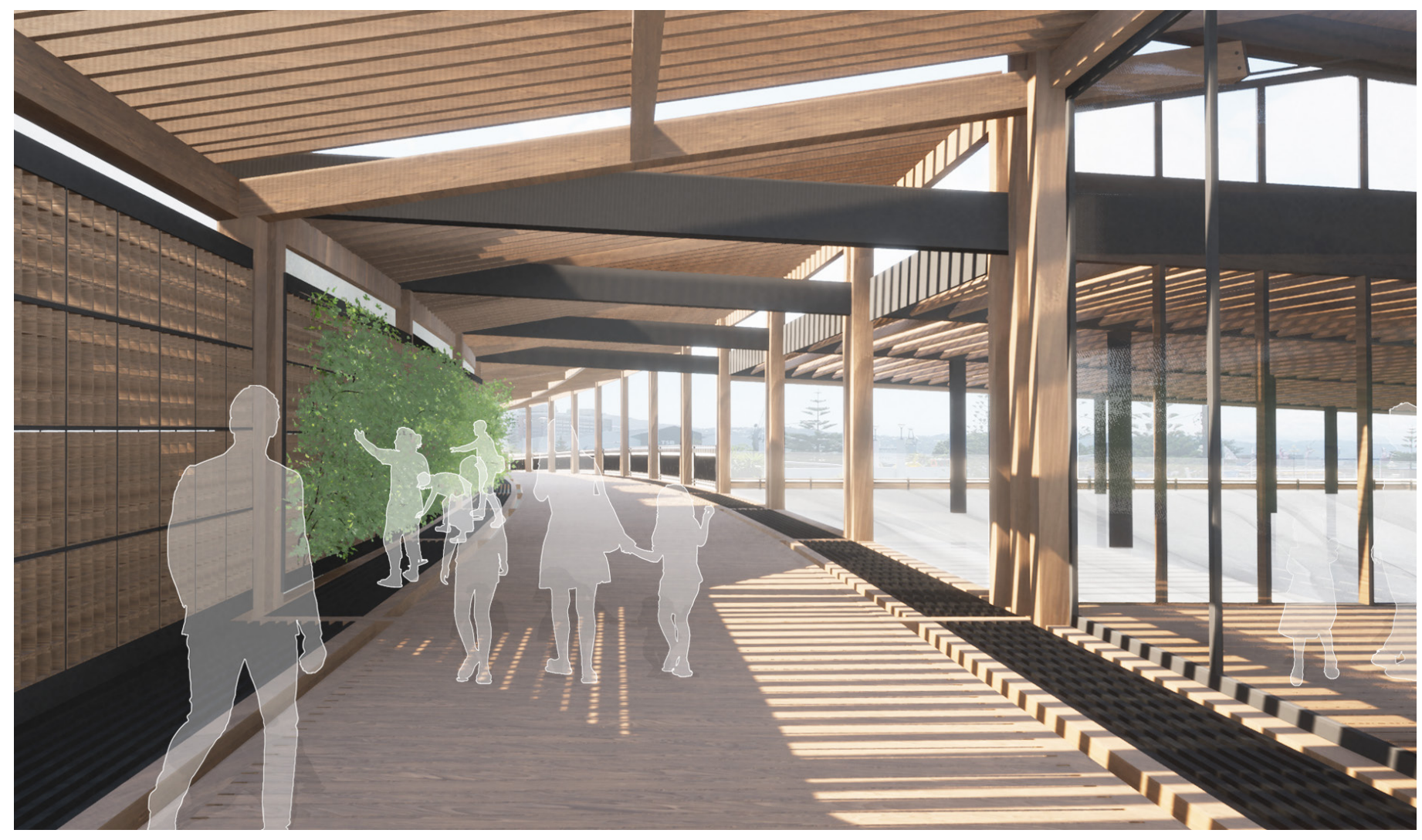

Fig.164.

SPACES VISUALLY'WOVEN' TOGETHER 


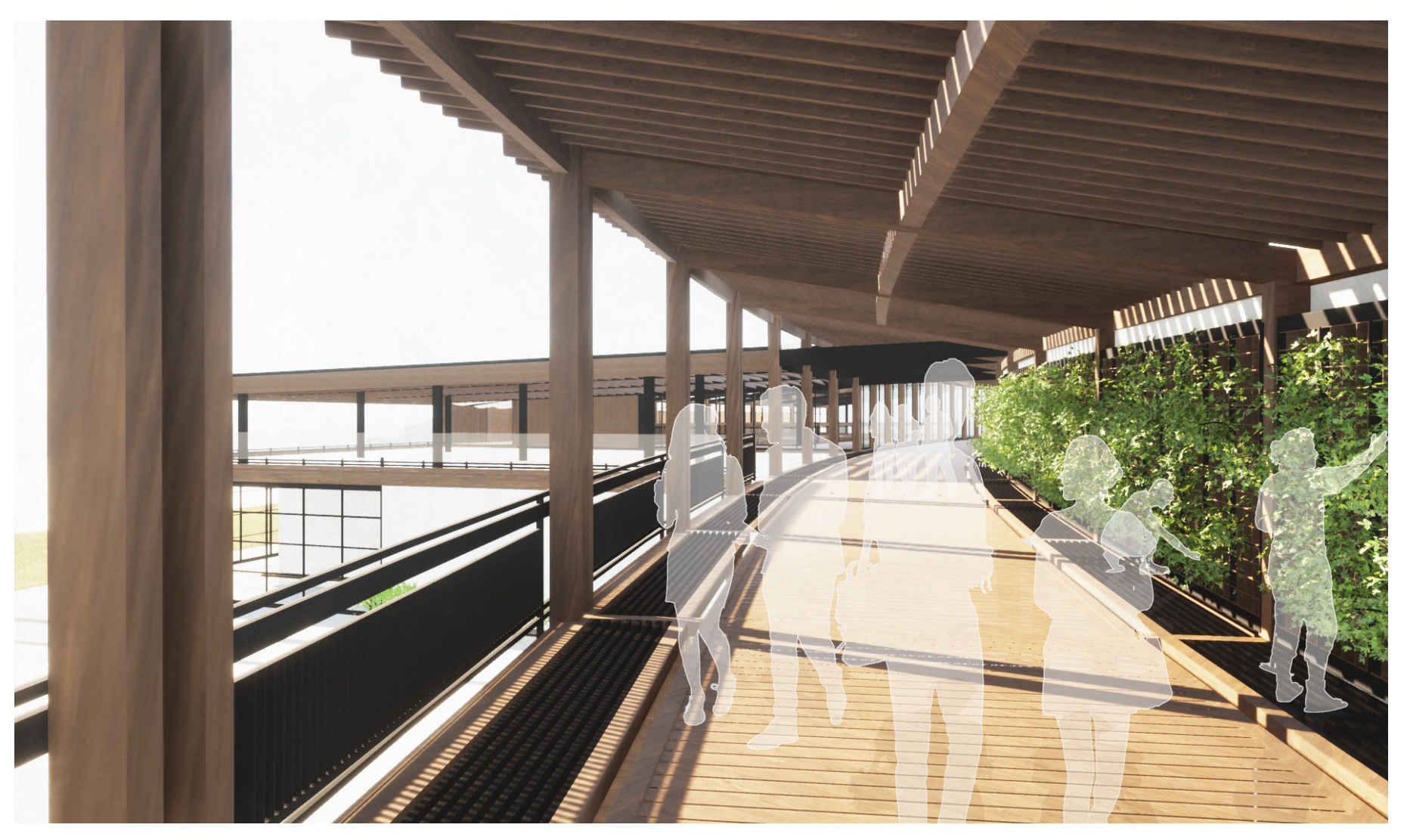

Fig. 163.

INTENTIONALITY OF THE VERTICAL COMMUNITY GARDEN 


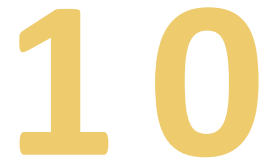

CONCLUSION 


\section{SUMMARY}

This thesis investigates opportunities within Wellington's Civic square, exploring a series of design techniques which seek to encourage and foster a rich sense of place. Architectural qualities are used as tools to research how we can design to maintain cultural and spatial differentiation within New Zealand's architectural landscape. The final public scale design outcome aims to facilitate discussion of those qualities of public space that encourage and sustain concern for a sense of place within the public realm.

The design process was explored during two progressive phases, testing theoretical research primarily through human scale design iterations, and carrying successful conceptual explorations through to the final public scale proposal.

The final proposal defines an approach towards reconstructing space that is negatively affected by the static nature of architecture, investigating how architecture can be designed to activate commonplace. The final design outcome practices researched formal and spatial qualities through the experimentation of drawing and digital modeling, responding to the notions of place attachment, place identity, place familiarity and belongingness, ultimately inviting people to linger and gather in new and existing public space. 


\section{CRITICAL REFLECTION}

\section{SENSE OF PLACE}

The human scale development (chapter six) explored an initial language regarding notions of the past and present, critical regionalism and embodiment with the intent of being carried through to the development of the final public scale outcome. However, this process uncovered methodological issues, conceived through a lack of understanding of the pragmatic needs of the site.

The human scale design development sparked research into exploring the opportunity to engage with the dialectic between pragmatic and the conceptual narrative of an architectural space. This led to re- establishing a design process that was instead constructed through both the pragmatic needs of space and conceptual meaning.

Designing public space involves a network of decisions, however in many cases appears to be driven solely by the pragmatic needs of the space, resulting in placelessness, sameness and architectural standardisation. This research was therefore driven by two often competing, objectives: the pragmatic and conceptual. Often in the practicing world, one approach is given more or complete priority over the other. This can happen due to an architectural practices primary service or aesthetic being their 'brand', thus making sense to favour one over the other. However, to prioritise one over the other in the design phase can cause the built product to be at risk of either underperforming or lacking a sense of place. This finding was emulated in the human scale design process.
Moving forward, through generating the formal design using the established Civic Design framework and further shaping the detail through the proposed architectural identity framework, the final design outcome is arguably more successful in developing a stronger sense of place. This research worked towards identifying a design process that considered an approach to civic design that looks to primarily improve the quality of public space, with the critical exploration being how that is achieved. The developed design used the dialectic between pragmatic and conceptual design approaches to reconsider the function and design of public space within the realm of Wellington's Civic Square. 


\section{CRITICAL REFLECTION}

\section{PAST \& PRESENT}

The narrative of identity in architecture acknowledges the importance of past events and their impact on the present and the future. This research has taken this notion and used the past as a leading conceptual driver in the construction of space, exploring the past through integrating it into the workflow of the design. Notions of the past have been abstractly translated into architectural form following the methods of Francis Pound.

The final design outcome responds to the site's contextual past through a tectonic and spatial exploration of both the cultural motif of weaving and water. Though the notion of the past has been used to inform the design, the perceived meaning and memories associated to place are subjective. Thus, the perceived nature of this space and the integrated translation of the past may be understood differently in response to the varying views and understandings of the individual user.

Designing through the notion of the past contributes to grounding the building in space through an acknowledged contextual consciousness. The past has been used as a method to develop a design unique to context. The contemporary nature of the design touches on the past through composition, whilst also offering opportunities for users to attach their own individual meanings and identities to the space, as space is evident but the way we perceive it is not. Thus, conceptually acknowledging the past in design constructs a collective identity, referencing the past but at the same time giving freedom to the present in creating new identities of place. 


\section{CRITICAL REFLECTION}

\section{CRITICAL REGIONALISM}

When acknowledging the success of the final design outcome in response to the earlier theory on critical regionalism, it is important to reflect on how this notion was carried through. The final design outcome successfully responds to Frampton's theory and is influenced by the topography, climate, light, and tectonic form. However, upon researching the construction of civic space in chapter seven, it became evident that in order to develop a strong sense of place that responds to both the pragmatic and conceptual narrative of the site, elements of the design can be influenced but not solely derived from critical regionalism theory.

In reality, when constructing practical, functioning public space, it is difficult to allow the climatic elements of the site to define the entirety of the design. As for example, to have wind flowing through a building continuously would not be appropriate, causing uncomfortable conditions for the inhabitants. However, this design demonstrates a calculated manner of responding to the contextual conditions of the site that aligns with the functional use of public space. In turn, critical regionalism theory has successfully enabled the proposed concept to be unextractable from its context. The final designs responsive architectural elements such as the integration of louvres and tectonic placement, strengthens the experiential nature of the design and ultimately works towards constructing a stronger architectural identity within Wellington's Civic Square. 


\section{CRITICAL REFLECTION}

\section{EMBODIMENT}

When reflecting on the final design outcome, there is scope for the refining and articulation of the architectural conditions of embodiment. The relationship between materiality and embodiment, though explored in the development of the exhibition space could have further addressed a critical role within the marketplace programme. Embodied occupation was understood and revealed within the human scale installation process, though this was somewhat digressed in the public scale process upon introducing material and programme. Thus, a comprehensive consideration of the relationship between materiality and embodiment and programme and embodiment may have worked towards further integrating the identity construction framework and civic design framework. 


\section{CRITICAL REFLECTION}

\section{CONCLUSION}

The final design outcome aims to generate a sense of place through the construction of an architectural identity. People respond to architectural space in unique ways, and as such, the architectural intervention is essentially a framework to attach meaning to. The only way to conclusively answer the question 'to what extent can the construction of an architectural identity strengthen the relationship between people and place, when articulating notions of meaning and memory?' would be through observation of the architectural intervention over time. In the event that this project were to be built, it would be essential to monitor and observe how people interact with this space over time. Upon reflection, it is completely unknown how this building would be received, as with architectural space you do not ever truly know how each individual person will experience it. The success of this space in regard to building a stronger relationship between people and space is ultimately a matter of perception and could only be understood through observing users over a period of time.
Essentially, this building is an insertion in time and how people respond to it, and the meanings they attach to the space will only unravel moving through to the future. Therefore, this building is constantly engaging with time, a space that will develop meaning with time. This building constructs a framework that responds to both time and place. The construction of an architectural identity has been used to inform and construct space with the vision of building upon a stronger relationship between people and place. The hope is this building would facilitate a sense of attachment to place through its unique design qualities derived from the construction of an architectural identity. 
This thesis is contributing to design and research within the realm of architectural place - making, positioned between previous arguments and discussion within the area of sense of place. The approaches toward architectural design within this inquiry could be modified and applied to future developments within civic architecture discourse.

The methodology could be explored in a different context, producing various outcomes of architectural space using the established frameworks toward architectural identity construction and civic design, expanding on further design research, toward place - making and civic architecture. This research set out to identify a potential work-flow where the conceptual and pragmatic objectives are achieved to foster a greater sense of place within Wellington's Civic Square.

This research has not considered participatory or co-design. It has not sought to engage people in the design process, nor investigated how people might be best engaged. Many would argue that to design a space, or sequence of spaces, which encourage a sense of place, it is necessary to engage with the present and future users of a space and place. This research could be built upon through designing and constructing small installations for Wellington's Civic Square to monitor the interactions between humans and the installations. There is a huge amount of work which could be undertaken, but this was clearly outside of the scope of this thesis.
I would enjoy undertaking further research in this area, through examining the social responsibility of architecture, looking at the 'bigger picture' through listening and gathering data from community members. Through listening to local community members and working closely with them, there would be the potential to create more socially responsible architecture, further responding in an evidence-based manner to the ethical, cultural, and humanitarian values of the site. I consider this type and depth of research to be outside the scope of a Masters thesis, but it would be something that I would be interested in being involved with in my future practice. 


\section{BIBLIOGRAPHY}

Aasarchitecture. (2014). Te Kaitaka - The Cloak by Fearon Hay Architects. https:// aasarchitecture.com/2014/09/te-kaitaka-cloak-fearon-hay-architects.html/

Adams, J. D. (2013). Theorizing a sense of place in a transnational community. Children Youth and Envi-ronments, 23(3), 43-65.

Altman, I. \& Low, S. M. (Eds.). (1992). Place Attachment. Plenum Press, New York

Athfield Architects Ltd. (n.d.) Wellington Civic Square. https://athfieldarchitects.co.nz/projects/ civic-community/wellington-civic-square

Beesley, P. \& Khan, O. (2009). Responsive architecture/performing instruments. Architectural League of New York.

Brand, S. (1994). How Buildings Learn: What Happens after They're Built (London. Orion)

Campbell,G. (2020). City Councillors signal a return to Wellington's Civic Square. New Zealand Herald. https://www.nzherald.co.nz/nz/city-councillors-signal-a-return-towellingtons-civic-square/SSN5DACHHAIDZTL2S7A6Q005NE/

Center for Active Design. (2018). Assembly: Civic Design Guidelines. New York, NY.

Cresswell, T. (2014). Place: an introduction. John Wiley \& Sons.

Derby, M. (2013). 'Daily life in Māori communities - te noho a te hapori - Changes in daily life after Eu-ropean arrival', Te Ara - the Encyclopedia of New Zealand, http:// www.TeAra.govt.nz/en/daily-life-in-Māori-communities-te-noho-a-te-hapori/ page-2

Durmus, S. (2012). Change and Transformation in Architecture: On the Concept of Zeitgeist. Global Built Environment Review, 8(1).

Fearon Hay Architects. (2014). Te Kaitaka - The Cloak / Fearon Hay Architects. ArchDaily. <https://www.archdaily.com/523468/te-kaitaka-the-cloak-fearon-hayarchitects> ISSN 0719-8884

Foster, H. (Ed.). (1985). Postmodern culture. Pluto Press.

Frampton, K. (1983). Prospects for a critical regionalism. Perspecta: The Yale Architectural Journal, 20(20), 147-162.

Gehl, J. (2011). Life between buildings: using public space. Island press. 


\section{BIBLIOGRAPHY}

Harvey, J. (2015). Architecture New Zealand (Issue 1). Christchurch Botanic Gardens Visitor Centre. https://architecturenow.co.nz/articles/christchurch-botanic-gardensvisitor-centre-1/

Haywood, B. K. (2014). A "sense of place" in public participation in scientific research. Science educa-tion, 98(1), 64-83.

Hinkel. R. et al (Ed. Hinkel. R) (2011). Private encounters and public occupations: a methodology for the exploration of public space. Urban interior - Informal explorations, interventions and occupations. The Deutsche Bibliothek. Pp $79-96$

Hough, M. (1990). Out of Place, Restoring Identity to the Regional Landscape. Yale University London. Pp, 179-193.

Isthmus. (2016). Gather and weave, Kopupaka Reserve. Isthmus Group. https://isthmus.co.nz/ project/kopupaka-park/

Maclean, C. (2015). 'Wellington region - Arts and Culture', Te Ara - the Encyclopedia of New Zealand. https://teara.govt.nz/en/photograph/13394/civic-square

Manzo, L. C. (2003). Beyond house and haven: toward revisioning of emotional relationships with places. Journal of Environmental Psychology. Vol. 23, pp47-61. 14(1-2), 1-12.

McKay, B. (2004). Māori architecture: transforming western notions of architecture. Frontiers of architectural Research, 4(2), 159-165

Miller, V. (2011). Architecture informed by social identity, meaning and memory: a provincial legislature for Pietermaritzburg, KwaZulu-Natal (Doctoral dissertation).

Modu Architecture (2020). The Second Life. https://moduarchitecture.com/Second-Life

Najafi, M. \& Shariff, M. K. B. M. (2011). The concept of place and sense of place in architectural studies. International Journal of Human and Social Sciences, 6(3), 187-193.

Norberg-Schulz, C. 1975. Meaning in Western Architecture. Studio Vista: USA. pp 426-435.

NZ Ministry for Culture and Heritage (2020a). A history of New Zealand 1769 - 1914. Steve Watters. NZHistory.net.nz team.

NZ Ministry for Culture and Heritage (2020b). The Treaty in brief. https://nzhistory.govt.nz/ politics/treaty/the-treaty-in-brief 


\section{BIBLIOGRAPHY}

Orange, C. (2012). 'Treaty of Waitangi', Te Ara - the Encyclopedia of New Zealand, http:// www.TeAra.govt.nz/en/treaty-of-waitangi

Page, S. J. (1996). Wellington. Cities, 13(2), 125-136 . Doi: 10.1016/0264-2751(95)00124

Phillips, W. J. (1952). Māori Houses and Food Stores. Dominion Museum Monograph No. 8. R.E. Owen Government Printer, Wellington

Pound, F. (1994). The space between: Pakeha use of Māori motifs in modernist New Zealand art. Work-shop Press.

PPS. (n.d.). What Makes a Successful Place? Project for Public Spaces. https://www.pps.org/ article/grplacefeat

Relph, E. (1986). Place and Placelessness. Pion Limited, London.

Rongowhakaata (2017). Ko Rongowhakaata: Ruku I te Po, Ruku i te Ao. The Story of Light and Shadow. Museum of New Zealand, Te Papa, Tongarewa.

Russ, A. Peters, S.J. Krasny, M.E. and Stedman, R.C. (2015). Development of ecological place meaning in New York City. Journal of environmental education, 46(2), 73-93.

Schielke. T. (2019). When Sunlight Meets Tadao Ando's Concrete. ArchDaily. <https://www. archdaily.com/915270/when-sunlight-meets-tadao-andos-concrete> ISSN 0719-8884

Sveiven, M. (2011). AD Classics: AD Classics: Casa Barragan / Luis Barragan. ArchDaily. https://www.archdaily.com/102599/ad-classics-casa-barragan-luis-barragan> ISSN 0719-8884

Te Ahukaramu Charles Royal (2007). 'Kaitiakitanga - guardianship and conservation connected to na-ture', Te Ara - the Encyclopaedia of New Zealand. https:// teara.govt.nz/en/kaitiakitanga-guardianship-and-conservation/page-2

The Creative group (2019). Riverside Collective. https://thecreativegroupnz.co.nz/commercialprojects/riverside-collective

Tilley, C. (2006). Introduction: Identity, place, landscape and heritage.

Tohi, F. (2016). Enriching Aotearoa with the Tongan Spirit. Reading Warrior. https:// readingwarrior.com/enriching-aotearoa-with-the-tongan-spirit/ 


\section{B IB LIOGRAPHY}

Torabi, Z. \& Brahman, S. (2013). Effective factors in shaping the identity of architecture. Middle-East Journal of Scientific Research, 15(1), 106-113.

Tuan, Y. F. (1979). Space and place: humanistic perspective. In Philosophy in geography (pp. 387-427). Springer, Dordrecht.

Vanclay, F. (2008). Place matters. Making sense of place, Chapter 1 pp 3-11.

Vieira, A.S. (2011). Flashback: Tolo House / Álvaro Siza Vieira. ArchDaily. <https://www. archdaily.com/893/tolo-house-alvaro-leite-siza> ISSN 0719-8884

Wellington City Council (2015a). Civic Centre. Wellington Heritage. https://www. wellingtoncityheritage.org.nz/areas/29-civic-centre

Wellington City Council (2015b). Te Ngakau - Civic Precinct Programme. New Zealand Government. https://wellington.govt.nz/your-council/projects/te-ngakau-civicprecinct-programme

Wellington City Council (2013). Thematic Heritage Study of Wellington. Wellington City Council. Wel-lington.govt.nz ISBN 978-1-877232-72-5

White, D. \& Johnson. K. (2004). Hautaha by Filipe Tohi. Whitespace Contemporary Art. https:// www.thebigidea.nz/node/168677 


\section{FIGURES LIST}

All unattributed images are author's own.

\section{Figure 4.}

Gollings, J. \& Chung, A. (2010). 'Surry Hills Library and Community Centre.' Photographs. Retrieved from https://www.archdaily.com/57339/surry-hills-library- and-

Figure 5. community-centre-fimt

Devitt, S. \& Toth, J. (2017). 'Christchurch Botanic Gardens/ Pattersons.' Photographs. Retrieved from https://www.archdaily.com/875161/christchurch-botanic-gardens-

Figure 8. pattersons

Archiweb (n.d.) 'Azuma house, Tadao Ando.' Photographs. Retrieved from https://www.archiweb.cz/en/b/dum-azuma

\section{Figure 9.}

Burr, R. \& Silverman, S. (2011) 'Tacubayas, Casa Luis Barragan.' Photographs. Retrieved from https://www.archdaily.com/102599/ad-classics-casa-barragan-luis-

Figure 10. barragan

Guerra, F. (2011). 'Tolo House, Alvaro Siza Vieira.' Photographs. Retrieved from https://www.archdaily.com/893/tolo-house-alvaro-leite-siza

\section{Figure 11.}

Wellington City Council (n.d.). View from Miramar Peninsula. Photograph. Retrieved from WCC Archives 00161-0-20-2. https://wellington.govt.nz/arts-and-culture/

\section{Figure 12.}

Norman, E. (circa 1842). 'Sketch of Te Aro Pa, looking towards the Hutt River.' Drawing. Retrieved from WCC Archives ATL A-049-001. https://wellington.govt.nz/-/

\section{Figure 13.} media/arts-and-culture/heritage/files/thematic-heritage-study.pdf

Alexander Turnbull Library, Wellington, New Zealand. (1865 - 2002). 'Land reclamation, Thorndon, Wellington.' Photographic negatives and prints of the Evening post newspaper. Ref: EP-0114-1/2-F. Retrieved from https://natlib.govt.nz/ records/22523626

Figure 14.

Alexander Turnbull Library, Wellington, New Zealand. (1888-1972). 'View from Mount Victoria, looking across Oriental Bay toward Wellington City, Smith, Sydney Charles.' Photograph. Ref: 1/1-022718-G. Retrieved from https://natlib.govt.nz/

Figure 15. records/22800693

Esteves, M. (2007). 'View from Mount Victoria.' Photograph. Retrieved from

Figure 17. https://www.flickr.com/photos/jackol/516092798/in/photostream/

Alexander Turnbull Library, Wellington, New Zealand. (1840). 'Plan of the town of Wellington, Port Nicholson: the first and principal settlement of the New Zealand Company. London: Smith, Elder \& Co. for the New Zealand Company.'. Retrieved from Ref: MapColl 832.4799gbbd 1840 316-8, Alexander Turnbull Library. 


\section{FIGURES LIST}

\section{Figure 23.}

Google maps. (2020). 'Map of Civic Square. 'Retrieved from https://www.google.co.nz/maps

Figure 24.-38.

Unknown Author. Wellington City Council. (1966-1980). 'Civic Square.' Photographs. Retrieved from WCC Archives. https://wellington.govt.nz/arts-and-culture/archives

\section{Figure 33.}

Niwa. (2011). 'Wind rose for Wellington Aero.' Image. Retrieved from

\section{Figure 34.}

https://niwa.co.nz/file/12211

Wellington City Council (n.d.)' Wellington City Wind Zones.' Data Retrieved from https:/l wellington.govt.nz/environment-and-sustainability/sustainability/buildsustainably-in-wellington/wellington-conditions

\section{Figure 43.}

Unknown Author (n.d.) 'Traditional Maori lashing.' Photograph. Retrieved from NZ Maritime

\section{Figure 43.}

https://www.maritimemuseum.co.nz/exhibitions/landfalls

Unknown Author (n.d.) 'Traditional Maori lashing.' Photograph. Retrieved from NZ Maritime

Figure 44.

https://www.maritimemuseum.co.nz/exhibitions/landfalls

Unknown Author (n.d.) 'Toi Maori - Traditional Maori art.' Photograph. Retrieved from Christchurch City Libraries website https://my.christchurchcitylibraries.com/toi-

\section{Figure 45.}

maori-traditional-maori-art/

LewAllen, R. (2016). 'Kiko's wa'akaulua (double hulled sailing canoe lashing).' Photograph Retrieved from http://waakaulua.com/hanne.htm

\section{Figure 46.}

Wilson, S. (2014). 'Te Kaitaka - The Cloak / Fearon Hay Architects'. Photographs. Retrieved from https://www.archdaily.com/523468/te-kaitaka-the-cloak-fearon-hay-

\section{Figure 47.} architects

Isthmus (2017). 'Kopupaka Reserve.' Photographs. Received from

Figure 48.

$$
\text { https://isthmus.co.nz/project/kopupaka-park/ }
$$

Tohi, S.F. (2012) 'Aotea (White Cloud).' Sculpture. Retrieved from https://www. aucklandartgallery.com/whats-on/exhibition/sopolemalama-filipe-tohi-aoteawhite-cloud?q=\%2Fwhats-on\%2Fexhibition\%2Fsopolemalama-filipe-tohi-

Figure 49.

Tohi, S.F. (2009). 'Matanima.'Sculpture. Retrieved from

Figure $\mathbf{5 0 .}$

https://www.bartleyandcompanyart.co.nz/exhibition,Hard_Tactics,209

Tohi. S.F. (2015). 'Manulele (Running Bird).' Sculpture. Retrieved from https://www.sculptureinthegardens.nz/welcome/034-filipe-tohi-manulele-

Figure 66. running-bird-2/

P.P.S. (n.d.). 'What makes a great place?' Diagram. Retrieved from https://www.pps.org/article/grplacefeat 


\section{FIGURES LIST}

\section{Figure 67.}

Brand. S. (1995). 'Shearing layers.' Diagram. Retrieved from: How buildings learn: What Figure 69.

happens after they're built. Penguin.

Unknown Author. (n.d.). 'Riverside market, Christchurch.' Photographs. Retrieved from

Figure 70.

https://riverside.nz/

UXUS. (2016). Street food market, Amsterdam.' Photographs. Retrieved from

\section{Figure 82.}

Unknown Author. (n.d.) 'Traditional Maori lashing.' Drawing. Retrieved from Victoria University of Wellington (2016). http://nzetc.victoria.ac.nz/tm/scholarly/teiBucMani-t1-body-d1-d4-d7-d4.html

\section{Figure 94.}

HUT Architecture. (n.d.). 'Kings Road, Chelsea.' Photographs. Retrieved from

Figure 119.

Tournesol. (n.d.). 'Tournesol VGM Modular system.' Photographs. Retrieved from https:/l www.tournesol.com/products/product/tournesol-vgm-modular-living-wallsystem 
